H. E. McCoy

J. R. DiStefano

OAK RIDGE

NATIONAL

LABORATORY

$\operatorname{coc} x \sin \operatorname{cosin} /$

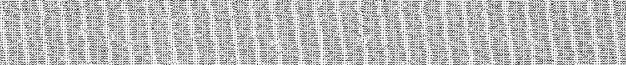

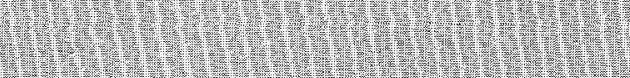

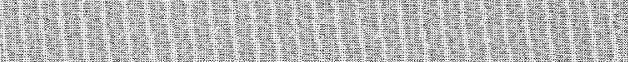

Wats

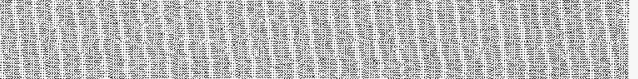

1.1.
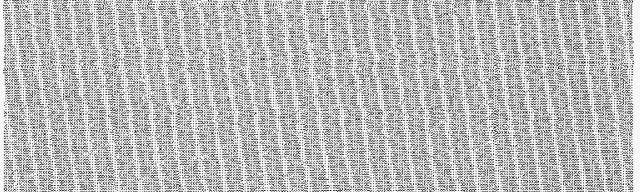

7)
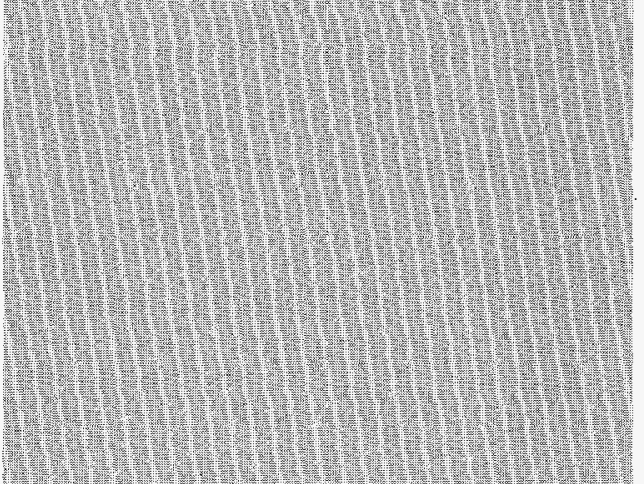

1.
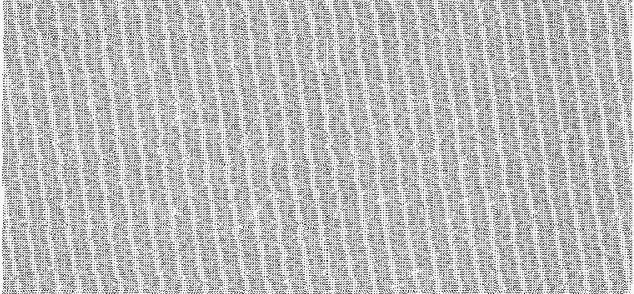
This report has been reproduced directly from the best available copy.

Available to DOE and DOE contractors from the Office of Scientific and Technical information, P.O. Box 62, Oak Ridge, TN 37831; prices available from (423) 576-8401, FTS 626-8401.

Available to the public from the National Technical Information Service, U.S. Department of Commerce, 5285 Port Royal Rd., Springfield, VA 22161.

This report was prepared as an account of work sponsored by an agency of the United States Government. Neither the United States Government nor any agency thereof, nor any of their employees, makes any warranty, express or implied, or assumes any legal liability or responsibility for the accuracy, completeness, or usefulness of any information, apparatus, product, or process disclosed, or represents that its use would not infringe privately owned rights. Reference herein to any specific commercial product, process, or service by trade name, trademark, manufacturer, or otherwise, does not necessarily constitute or imply its endorsement, recommendation, or favoring by the United States Government or any agency thereof. The views and opinions of authors expressed herein do not necessarily state or reflect those of the United States Government or any agency thereof. 


\section{DISCLAIMER}

Portions of this document may be illegible in electronic image products. Images are produced from the best available original document. 
Metals and Ceramics Division

THE MECHANICAL PROPERTIES OF T-111 AT LOW

TO INTERMEDIATE TEMPERATURES

H. E. McCoy and J. R. DiStefano

Date Published: January 1997

Notice: This document contains information of a preliminary nature. It is subject to revision or correction and therefore does not represent a final report.

Prepared by the

OAK RIDGE NATIONAL LABORATORY

Oak Ridge, Tennessee 37831-6285

managed by

LOCKHEED MARTIN ENERGY RESEARCH CORPORATION

for the

U.S. DEPARTMENT OF ENERGY

under contract DE-AC05-96OR22464 

LIST OF FIGURES $\ldots \ldots \ldots \ldots \ldots \ldots \ldots \ldots \ldots \ldots \ldots \ldots \ldots \ldots \ldots$ iv

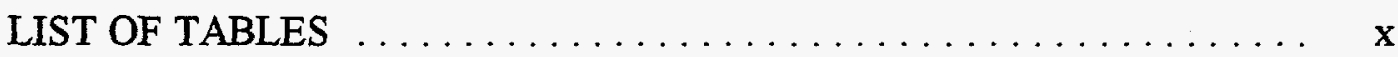

EXECUTIVE SUMMARY $\ldots \ldots \ldots \ldots \ldots \ldots \ldots \ldots \ldots \ldots \ldots \ldots$

INTRODUCTION $\ldots \ldots \ldots \ldots \ldots \ldots \ldots \ldots \ldots \ldots \ldots \ldots \ldots \ldots$

TENSILE AND CREEP TESTS $\ldots \ldots \ldots \ldots \ldots \ldots \ldots \ldots \ldots \ldots \ldots \ldots$

Material ............................. 3

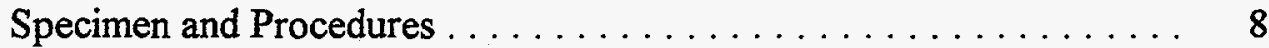

Tensile Test Results . . . . . . . . . . . . . . . . . . . . . . . 13

Creep Test Procedures . . . . . . . . . . . . . . . . . . . . 19

Creep Test Results . . . . . . . . . . . . . . . . . . . . 19

Data Analysis . . . . . . . . . . . . . . . . . . . . 27

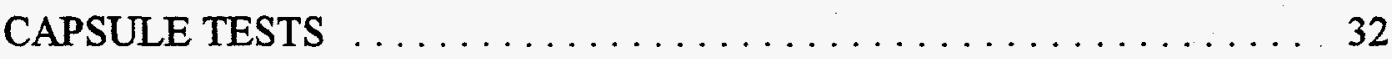

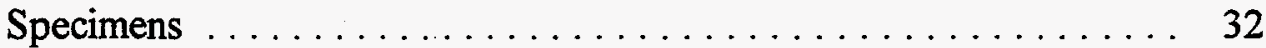

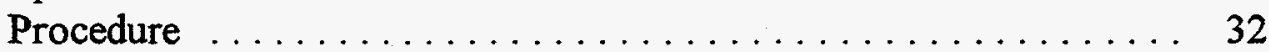

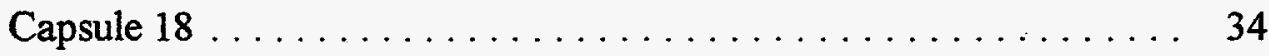

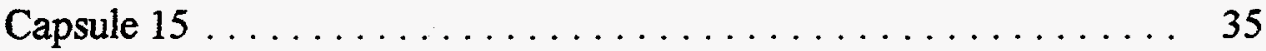

Helium Leak Rate of Failed Capsules . . . . . . . . . . . . . . . 39

Size of Failure ........................ 42

Comparison with Other Rupture Data $\ldots \ldots \ldots \ldots \ldots \ldots 44$

Destructive Examination of Capsules ................ 43

Tensile Properties of Samples from Capsules 18 and $15 \ldots \ldots \ldots .44$

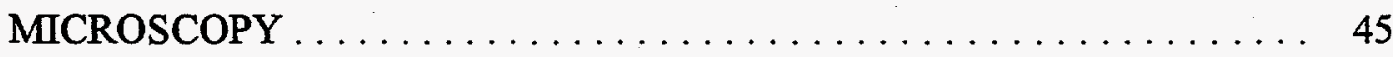

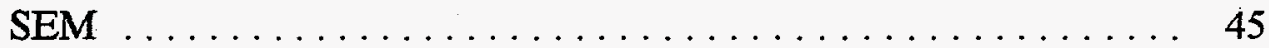

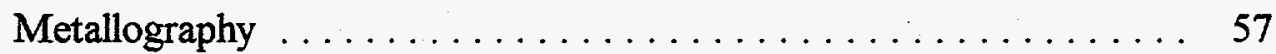

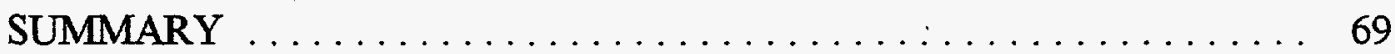

ACKNOWLEDGMENTS $\ldots \ldots \ldots \ldots \ldots \ldots \ldots \ldots \ldots \ldots \ldots \ldots$

REFERENCES $\ldots \ldots \ldots \ldots \ldots \ldots \ldots \ldots \ldots \ldots \ldots \ldots \ldots \ldots \ldots \ldots$

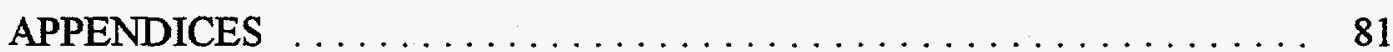

A. Strain data for $T-111$ samples $\ldots \ldots \ldots \ldots \ldots \ldots \ldots \ldots .83$

B. Measurements of the creep rate in T-111 at low stresses from 580 to $800^{\circ} \mathrm{C}$ 


\section{LIST OF FIGURES}

Figure

Page

S.1 Larson-Miller plot of selected rupture data for T-111-type alloys $\ldots \ldots \ldots \ldots \ldots \ldots \ldots \ldots \ldots \ldots \ldots \ldots \ldots \ldots \ldots \ldots$ xii

S.2 Monkman-Grant plot for several T-111-type alloys $\ldots \ldots \ldots \ldots$ xiii

S.3 Larson-Miller plot based on strain rate including all points . . . . . . xiv

1 Sixty-watt isotopic heat source $\ldots \ldots \ldots \ldots \ldots \ldots \ldots \ldots \ldots \ldots \ldots$

2 Refractory alloy welding record $\ldots \ldots \ldots \ldots \ldots \ldots$

3 Photomicrographs of section of weld: (a) view of entire weld, $12.8 \mathrm{x}$; (b) base metal, $100 \mathrm{x}$; and (c) weld metal, $100 \mathrm{x} \ldots \ldots \ldots 6$

4 Photomicrographs at half-thickness made across the weld shown in the previous figure; $100 \mathrm{x} \ldots \ldots \ldots \ldots \ldots$

5 Microhardness transverse across a section of as-welded $\mathrm{T}-111 \ldots \ldots \ldots \ldots \ldots \ldots \ldots \ldots$

6 Sketches of base metal tensile and creep samples:

(a) Sample A which has a gage width of $3.18 \mathrm{~mm}$ or $0.125 \mathrm{in}$. and (b) sample B with a gage width of $6.35 \mathrm{~mm}$ or $0.250 \mathrm{in}$.

7 Sketches of transverse weld tensile and creep samples:

(a) sample $C$ which has a gage width of $3.18 \mathrm{~mm}$ or $0.125 \mathrm{in}$. and (b) sample D with a gage width of $6.35 \mathrm{~mm}$ or $0.250 \mathrm{in}$.

8 Sketches of longitudinal weld tensile and creep sample. Designated sample $E$ with a gage width of $3.18 \mathrm{~mm}$ or 0.125 in.

9 Photograph of the five types of specimens used in the mechanical testing

10 Comparison of tensile properties for base metal samples:

A, $31.8 \mathrm{~mm}$ wide and $\mathrm{B}, 6.35 \mathrm{~mm}$ wide 
11 Comparison of tensile properties for transverse weld samples:

$\mathrm{C}, 3.18 \mathrm{~mm}$ wide and $\mathrm{D}, 6.35 \mathrm{~mm}$ wide $\ldots \ldots \ldots \ldots \ldots \ldots$

12 Comparison of the tensile properties of T-111 base metal, transverse and longitudinal weld samples.

13 Comparison of fracture strains of five specimen types as a function of temperature

14 Photograph of sample 1 from test 28525

15 After-test photographs of the base-metal samples from tests 28544 and 28584 that failed at fiduciary marks, and the sample from test 28602 that did not have fiduciary marks and failed in the gage section

16 After-test photographs of transverse weld samples from tests 28623 and 28627 that failed in the heat-affected zone

17 After-test photographs of transverse weld samples from several tests that failed in the weld or heat-affected zone

18 Larson-Miller plot of selected rupture data for T-111-type alloys

19 Monkman-Grant plot for several T-111-type alloys

20 Larson-Miller plot based on strain rate including all points 28

21 Monkman-Grant plot for several T-111-type alloys . . . . . . . . 29

22 (a) Larson-Miller plot based on strain rate including all points . . . . 29 (b) Plot of $\mathrm{S}_{\mathrm{m}}$ and $\mathrm{S}_{\mathrm{t}}$ for T-111 based on the American Society of Mechanical Engineers boiler and pressure vessel approach used for Code Case N-47

23 Photograph of the two capsules received from EG\&G

Mound Applied Technologies for testing 33

$24 \quad$ Sketch of test set-up 
25 Section of recorder chart showing failure of capsule $18 \ldots \ldots \ldots 37$

26 The pressure history of capsule 15 while in test at Mound $\ldots \ldots \ldots 38$

27 Pressure reduction in failed capsule $18 \ldots \ldots \ldots \ldots \ldots \ldots \ldots 4$

28 Pressure reduction in failed capsule $15 \ldots \ldots \ldots \ldots \ldots \ldots \ldots 41$

29 Larson-Miller plot of selected rupture data for T-111-type alloys with points superimposed for capsules $\ldots \ldots \ldots \ldots \ldots \ldots 43$

30 Scanning electron micrographs of the failure from the outside surface of capsule 18: (a) 50× (ET05405), Outside of weld showing weld arc oscillations and cracks located along the grain boundaries. The dark regions are largely contamination around the cracks. (b) $100 \times$ (ET05407), View of one of the cracks showing its intergranular path

31 Scanning electron micrographs of the failure from the inside surface of capsule 18 and opposite the failure shown in Fig. 30: (a) 20× (ET05408), Root of weld showing weld arc oscillations and cracks. (b) $100 \times$ (ET05409), View of the cracks. (c) $500 \times($ ET05410), View of cracks and surface

32 Scanning electron micrographs of a cracked region on the inside surface of capsule 18 near the failure location: (a) $20 \times$ (ET05411), Root of weld showing weld arc oscillations, perturbation in weld arc travel, and cracks. (b) 100x (ET05412), View of the intergranular cracks

33 Scanning electron micrographs of a sound region on the outside surface of capsule 18: (a) 20× (ET05414), Top of weld showing arc oscillations. (b) $100 \times($ ET05415), View of top of weld showing large grains and some fine surface debris 
34 Scanning electron micrographs of a sound region on the inside (root) surface of capsule 18: (a) 20× (ET05417), Bottom of weld showing arc oscillations. (b) $100 \times$ (ET05419), View of bottom of weld showing some fine surface debris. (c) $500 \times$ (ET05417), View of bottom of weld showing grain boundary grooving and debris

35 Scanning electron micrographs of the top (outside) of capsule 15 showing extensive branching and intergranular nature of cracks. $20 \times($ ET05426,7)

36 Scanning electron micrographs of the root (inside) of capsule 15 under the failure shown in Fig. 35: (a) $20 \times$ (ET05430) and (b) $500 \times($ ET05432) show surface debris

37 Scanning electron micrographs of the top (outside) of capsule 15 approximately $180^{\circ}$ from the failure shown in Fig. 35:

(a) $40 \times($ ET05435) and (b) $40 \times($ ET05436) show arc oscillation patterns and intergranular cracks

38 Scanning electron micrographs of the root (inside) of capsule 15 under the cracks shown in Fig. 37: (a) 20× (ET05433) Shows cracks and a portion of back-up ring. (b) $200 \times$ (ET05434) Shows intergranular cracks

39 Scanning electron micrographs of the fiduciary mark lasermachined into some of the base metal creep samples: (a) $40 \times$ (ET05421) and (b) $100 \times($ ET05423)

40 Photomicrograph of the T-111 sheet used in this study.

Etched. 100×. (a) Transverse and (b) longitudinal

41 Photomicrographs of the T-111 weld made by Mound and designated CB-2. Etched. (a) $12.8 \times$, Transverse section of weld and (b) $100 \mathrm{x}$, defect present at the root of the weld

42 Photomicrographs of the T-111 weld made by Mound and designated CB-2. Etched. 100×. (a) Base metal, (b) fusion line, and (c) weld metal 
43 Photomicrographs of the T-111 weld made by Mound and designated $\mathrm{CB}-2$, oriented approximately $180^{\circ}$ from section shown in Fig. 41. Etched. (a) 12.8×, Transverse section of weld; (b) $100 \times$, fusion line; and (c) $100 \times$, base metal

44 Photomicrographs of the T-111 weld made by Mound and designated CB-1. Etched. (a) 12.8×, Transverse section of weld; (b) $100 \times$, fusion line; and (c) 100×, base metal

45 Photomicrographs of the T-111 weld made by Mound and designated CB-1. Approximately $180^{\circ}$ from section in Fig. 44 . Etched. 100×. (a) Base metal, (b) fusion line, (c) weld metal, and $(d)$ large grains in heat-affected zone

46 Photomicrographs of the T-111 weld made by Mound and designated CB-3. Etched. 100×. (a) Base metal, (b) fusion line, and (c) weld metal

47 Photomicrographs of a transverse section through the failure of capsule 18. Etched. 20x

48 Photomicrographs of a transverse section through the failure of capsule 18. Etched. (a) 12.8×, Transverse section; (b) $100 \times$, base metal; (c) 100x, fusion line; and (d) 100x, weld metal

49 Photomicrograph of a longitudinal section through the failure of capsule 18. As-polished 100x.

50 Photomicrographs of a longitudinal section through the failure of capsule 18. Etched. $20 \times$ 68

51 Photomicrographs of a transverse section through the failure of capsule 15. As-polished. 50×. Taken near the outside surface

52 Photomicrograph of a transverse section through the failure of capsule 15. (a) 12.8×, Transverse section; (b) 100×, large grains in the heat-affected zone; and (c) 100×, base metal 
53 Photomicrograph of a transverse section through the failure of capsule 15 showing cracks. Etched. $100 \times \ldots \ldots \ldots 73$

54 Photomicrograph of the inside surface of a transverse section through the failure of capsule 15 showing surface reaction.

Etched. 500x

55 Photomicrographs of a transverse section through the failure of capsule 15. Additional material was removed after the photomicrographs shown in Fig. 51 were taken. As-polished. $50 \times$. Taken near the outside surface 74

56 Photomicrographs of a longitudinal section through the failure of capsule 15. As-polished. 20x

57. Photomicrographs of a longitudinal section through the failure of capsule 15. Etched. 20x

58 Photomicrographs of a longitudinal section through the failure of capsule 15. Etched. 100×. (a) Outside edge and (b) inside edge (root)

59 Microhardness profile across transverse section of weld in capsule 18 


\section{LIST OF TABLES}

Table

Page

1. Analysis of T-111 specimens for oxygen, nitrogen, and carbon ..... 9

2. Summary of tensile test results $\ldots \ldots \ldots \ldots \ldots \ldots \ldots \ldots \ldots$

3. Summary of strain measurements made on tensile specimens $\ldots \ldots \quad 18$

4. Summary of creep/creep-rupture results - updated $7-1-96 \ldots \ldots 20$

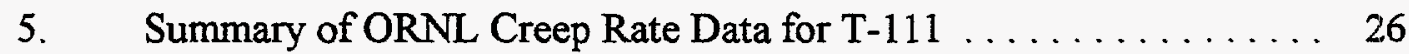

6. Vacuum and pressure data for capsule $18 \ldots \ldots \ldots \ldots$

7. Vacuum and pressure data for capsule $15 \ldots \ldots \ldots \ldots \ldots$

8. Summary of tensile test results from samples made from capsule scraps and starting base and transverse weld materials . . . . 45

B-1. Results from "high accuracy" creep rate measurements and from previous longer term data $\ldots \ldots \ldots \ldots \ldots \ldots$

B-2. Results of optical strain measurements on samples with transverse welds 


\section{EXECUTIVE SUMMARY}

In the design of the 60-W Isotopic Heat Source (IHS), a tantalum alloy (T-111*) strength member serves as the primary containment shell for the IHS during operation (He-gas internal environment and inert gas or vacuum external environment). An outer Hastelloy S clad is used to protect the T-111 from oxidation, and both the Hastelloy $S$ clad and the T-111 strength member are sealed by automatic gas tungsten arc (GTA) welding. The expected life of the IHS is 5 years at about $650^{\circ} \mathrm{C}$ preceded by up to 5 years of storage at approximately $300^{\circ} \mathrm{C}$. For this application, one important concern is failure of the T-111 strength member due to capsule pressurization arising from helium generation as a fuel decay product. To provide specific data on the mechanical behavior of base and weld metal T-111 under conditions appropriate to the IHS use conditions, a testing program was formulated and carried out.

Three types of mechanical tests were conducted. Tensile properties were measured over the temperature range of 25 to $1100^{\circ} \mathrm{C}$ on T-111 base metal and samples with either longitudinal or transverse autogenous welds. Creep tests on base metal and samples with transverse welds were run to failure over the temperature range of 1100 to $850^{\circ} \mathrm{C}$. Creep tests were also run on several transverse weld samples over the temperature range of 500 to $900^{\circ} \mathrm{C}$ at stresses where failure did not occur, and the creep rates were measured.

Two prototypical capsules of the T-111 strength member were fabricated by EG\&G Mound Applied Technologies (Mound Laboratories). To verify the mechanical properties design data developed above, these were tested to failure (leak) in a vacuum chamber with the inside of the capsule pressurized by either argon or helium.

In an initial evaluation of the IHS system, life predictions based on failure by a stress-rupture mechanism indicated some probability of failure of the T-111 strength member during various stages of its life cycle. This analysis was based upon rupture life of T-111 capsules from high-temperature/short-time tests and a Larson-Miller extrapolation to the IHS conditions. Monte Carlo techniques were used to obtain failure probabilities. After a literature search, additional data on T-111 were obtained, but data under specific IHS conditions were still lacking, especially at the low temperatures. The tensile and creep/creep-rupture tests performed in this study have provided significant additional data.

${ }^{*} \mathrm{Ta}-8 \% \mathrm{~W}-2 \% \mathrm{Hf}$. 
To analyze the data obtained, three other data sets, from two sources, were used in three types of correlations. In Fig. S.1, results are plotted in the form of a Larson-Miller relation where:

$$
\begin{aligned}
& \mathrm{P}=\mathrm{T} / 1000(15+\log \text { time-to-rupture), } \\
& \mathrm{T}=\text { temperature in Kelvin, } \\
& \mathrm{tr}=\text { time to rupture }(\mathrm{h}), \text { and } \\
& 15=\text { the Larson-Miller constant. }
\end{aligned}
$$

The four rupture points from the present study are identified in the figure. Based on the data in Fig. S.1, the results of the present study appear consistent with those from other studies. Figure S.2 is a plot of the time-to-rupture as a function of minimum creep rate (Monkman-Grant correlation) for the same tests shown in Fig. S.1, and once again the present data are consistent with the larger data population, albeit on the lower side.

Another type of correlation is shown in Fig. S.3. The ordinate is the stress and the abscissa is a Larson-Miller parameter that is based upon strain rate (CR in Fig. S.3) instead of time-to-rupture shown previously in Fig. S.1. All of the Oak Ridge National Laboratory data generated in this study together with the previous data are shown in Fig. S.3, and the temperatures shown were calculated based upon the low creep rates and long times of interest to the IHS. This plot suggests a relatively constant stress to cause rupture of T-111 from approximately 300 to $700^{\circ} \mathrm{C}$ that closely corresponds to the ultimate tensile strength of $\mathrm{T}-111$ at these temperatures.

Alternately, the methodology of the American Society of Mechanical Engineers (ASME) Boiler and Pressure Vessel Code from Case N-47 can be applied to the existing data to estimate the allowable stress for a 50,000-h life. This analysis also shows that the allowable design stress is controlled by tensile properties from 25 to $900^{\circ} \mathrm{C}$. Based upon application of the rules in N-47, the stress allowable for T-111 in this temperature range is about $180 \mathrm{MPa}$ (26 ksi).

Tensile and creep tests were conducted with and without a weld. The weld process resulted in a deposit of melted weld metal surrounded by a region of grains that were enlarged from those of the base material by the heat input to the weld. This heat-affected zone (HAZ) was slightly softer than the base metal and the weld metal. Most specimens having a transverse weld failed in the HAZ, but the strength was not reduced appreciably. The fracture strain was lower for samples with a transverse weld than for base metal, largely because deformation in the weld samples was mostly restricted to a narrow band of large grains in the HAZ. Scanning electron microscopy (SEM) and metallographic observations revealed that the failure of $T-111$ samples with a transverse GTA weld occurred in the HAZ or weld. Features associated with the failure were intergranular cracks, surface debris in the welds, and interruptions in the weld process that caused discontinuities. 


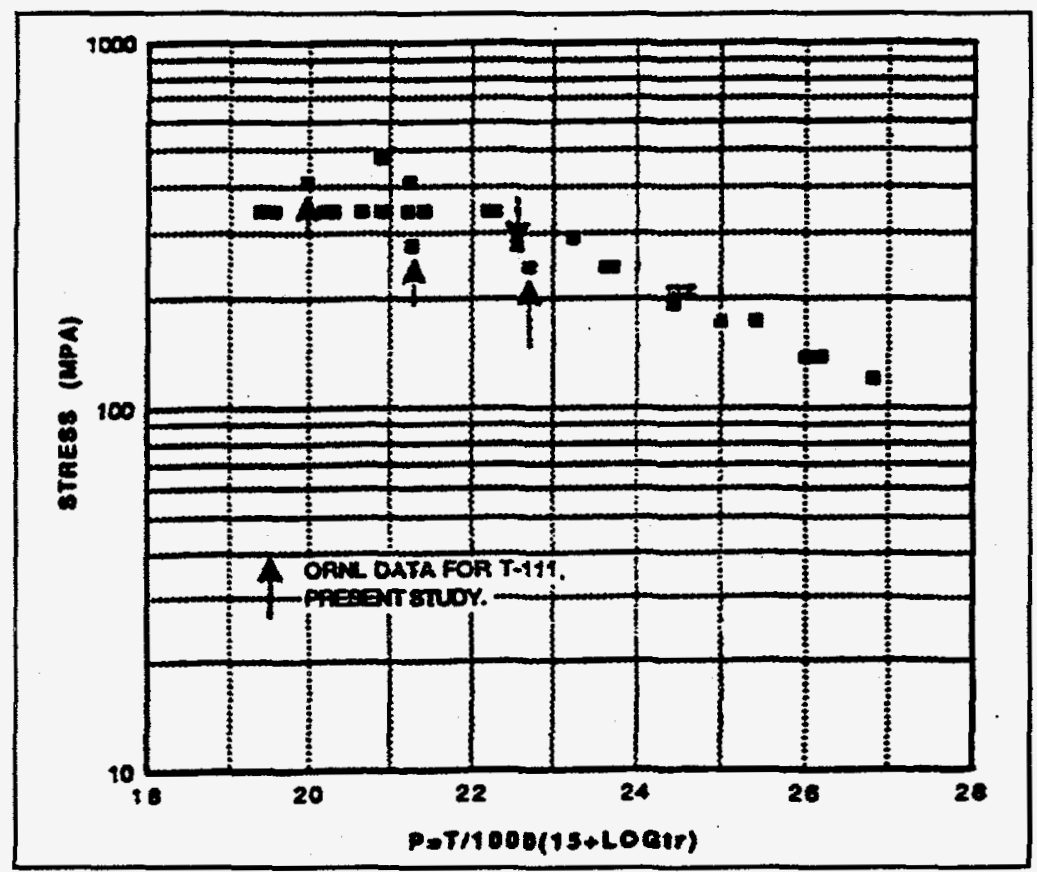

Fig. S.1. Larson-Miller plot of selected rupture data for T-111-type alloys.

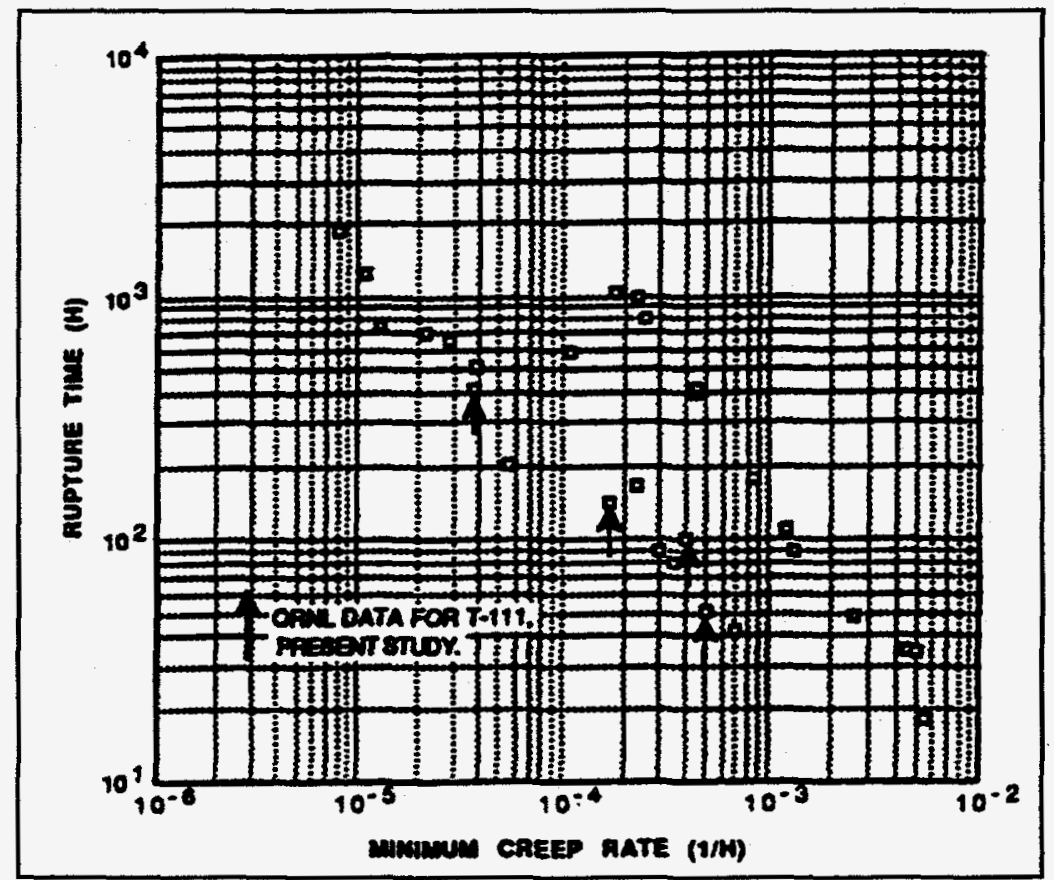
alloys.

Fig. S.2. Monkman-Grant plot for several T-111-type 


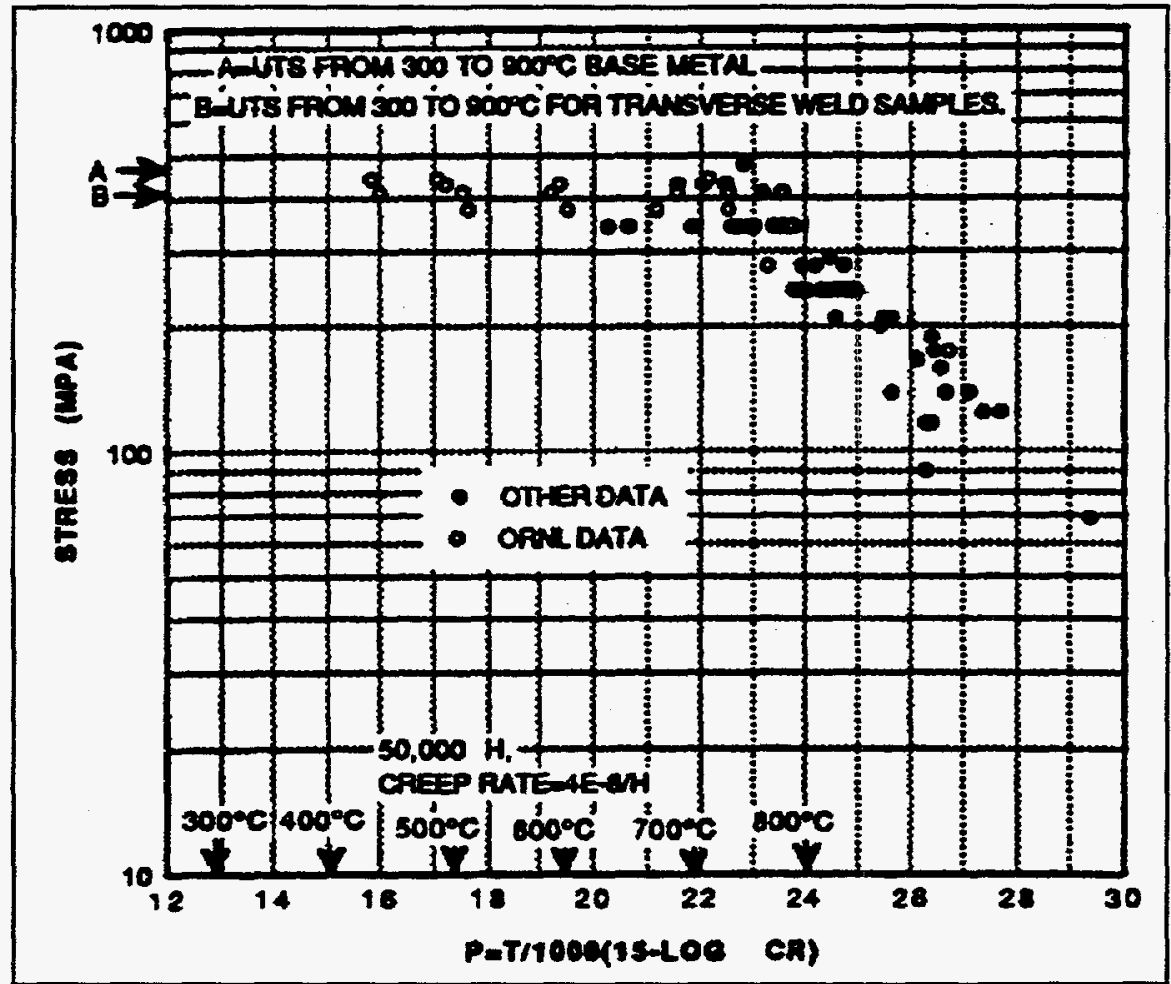
points.

Fig. S.3. Larson-Miller plot based on strain rate including all

Two capsules made by Mound using standard production procedures were tested to failure. The capsules were internally pressurized with inert gas while being heated in a vacuum system to protect the T-111 from reaction with air. Both of these capsules failed in the girth weld and had diametral strains of about $1.5 \%$. The times to failure were reasonable but were on the weak side of the larger population of strength data for T-111 base metal. After failure, leak rates of the capsules were measured at $25^{\circ} \mathrm{C}$, and the diameter of the leaking defect was calculated. The leak rates were reasonable in light of the fine cracks that were noted during post-test destructive examination of the capsules.

The failure regions of the capsules were examined by SEM. Intergranular cracks were noted on the inner and outer surfaces. These cracks were located predominately in the weld but often penetrated into the HAZ. Cracks were noted in some regions where leaking could not be detected by a helium leak detector.

Samples of the tested capsules were examined metallographically, and cracks were noted throughout the welds in the failed regions of the capsules. These cracks were often associated with interruptions in the welding process that resulted in craters or other steps in weld thickness. Examination of these weld cross sections showed that the weld metal was sound and free of strength-reducing defects. 


\title{
THE MECHANICAL PROPERTIES OF T-111 AT LOW TO INTERMEDIATE TEMPERATURES
}

\author{
H. E. McCoy, Jr., and J. R. DiStefano
}

\section{INTRODUCTION}

In the design of the 60-W Isotopic Heat Source (IHS), a T-111 strength member (see Fig. 1) serves as the primary containment shell for the IHS (He-gas internal environment and inert gas or vacuum external environment). An outer Hastelloy $\mathrm{S}$ clad is used to protect the T-111 from oxidation, and both the Hastelloy S clad and the T-111 strength member are sealed by automatic gas tungsten arc (GTA) welding. The expected life of the IHS is 5 years at about $650^{\circ} \mathrm{C}$ preceded by up to 5 years of storage at approximately $300^{\circ} \mathrm{C}$. For this application, one important concern is failure of the T-111 strength member due to pressure buildup from the fuel helium decay product. To provide specific data on the mechanical behavior of base and weld metal T-111 under conditions appropriate to the IHS use conditions, a testing program was formulated and carried out.

Three types of mechanical tests were conducted. Tensile properties were measured over the temperature range of 25 to $1100^{\circ} \mathrm{C}$ on $\mathrm{T}-111$ base metal and samples with either longitudinal or transverse autogenous welds. Creep tests on base metal and samples with transverse welds were run to failure over the temperature range of 850 to $1100^{\circ} \mathrm{C}$. Creep tests were also run on several transverse weld samples over the temperature range of 500 to $900^{\circ} \mathrm{C}$ at stresses where failure did not occur, and the creep rates were measured.

Finally, two prototypical capsules of the outer T-111 member shown in Fig. 1 were fabricated by EG\&G Mound Applied Technologies (Mound Laboratories), and these were tested to failure (leak) in a vacuum chamber with the inside of the capsule pressurized by either argon or helium.

\footnotetext{
*Research was sponsored by the U.S. Department of Energy, Office of Fossil Energy, Advanced Research and Technology Development Materials Program, [DOE/FE AA 1510 10 0, Work Breakdown Structure Element ORNL-2(H)], under contract DE-AC05-96OR22464 with Lockheed Martin Energy Research Corporation.
} 


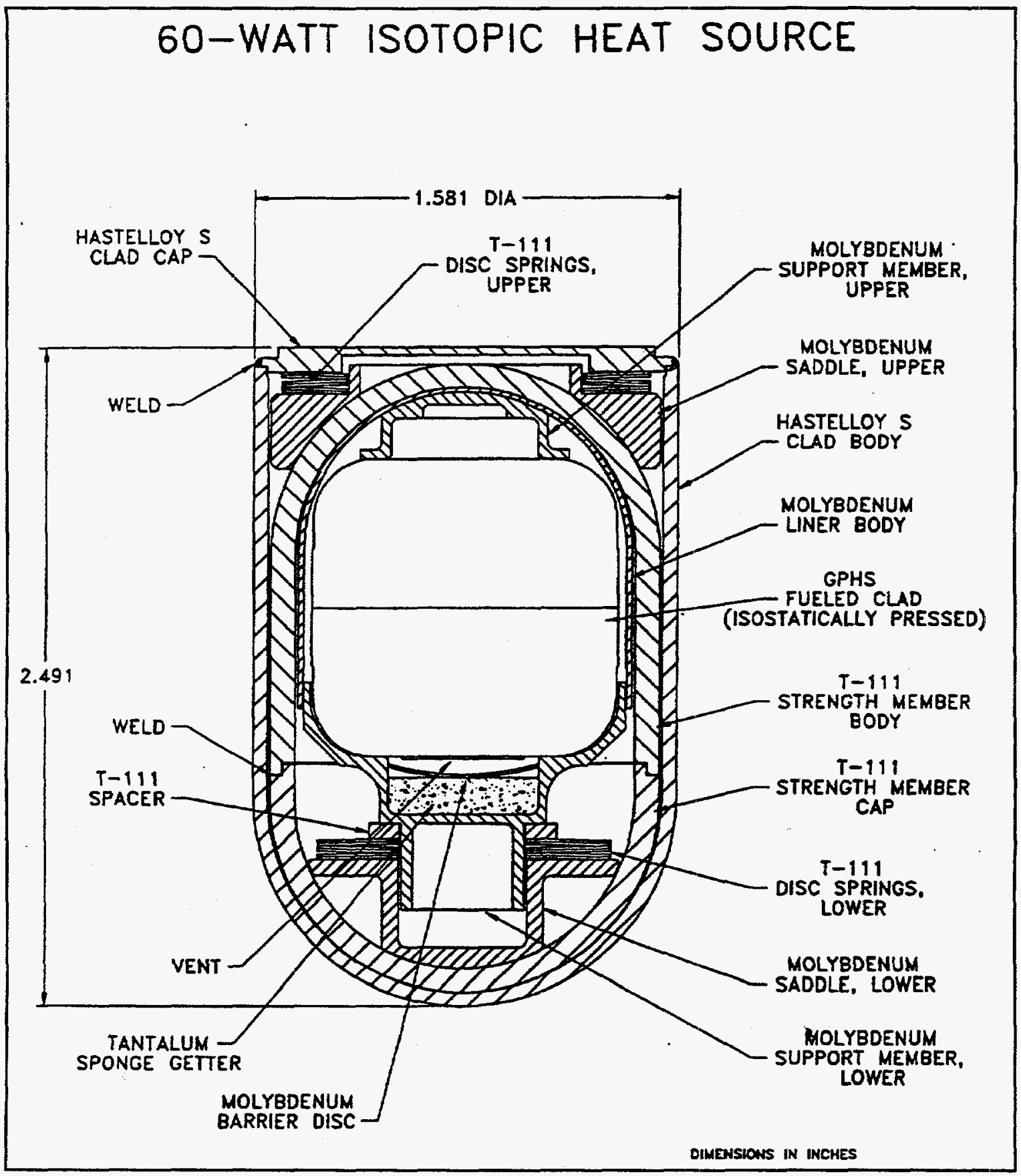

Fig. 1. Sixty-watt isotopic heat source. 
Before the mechanical testing program began, metallography was performed on several capsule girth welds made by Mound and on Oak Ridge National Laboratory (ORNL) welded (autogenous, bead-on-plate) sheet samples for mechanical property studies. The microstructure of the ORNL bead-on-plate and Mound capsule girth welds was very similar. Following the test program, additional metallography was performed and the fracture surfaces of selected samples were examined by scanning electron microscopy (SEM).

The order of this report will be:

1. Description of the starting material and the procedures used to obtain the specimens for tensile and creep testing.

2. Description of the tensile tests including the overall test matrix, the test procedure, and the test results.

3. Description of the creep results. Some of the creep tests are still in progress, and the report will deal with the results to date.

4. Results of the two pressurized capsule tests.

5. Presentation of the metallographic and SEM results.

6. Discussion of the predictions of the mechanical behavior of T-111 over the range of 300 to $650^{\circ} \mathrm{C}$ based on the new mechanical results.

\section{TENSILE AND CREEP TESTS}

Material. Two plates of T-111, $248 \mathrm{~mm}$ wide $\times 311 \mathrm{~mm}$ long $\times 2.92 \mathrm{~mm}$ thick $(9.75 \times$ $12.25 \times 0.115 \mathrm{in}$.), were supplied for this work by Mound Laboratories. This material was from the same lot used by Mound to manufacture pressure burst test capsules and heat source hardware. The plates were (1) acid cleaned, (2) cold-rolled to $2.29 \mathrm{~mm}$ (0.090 in.) thick, (3) re-cleaned, (4) annealed in vacuum for $1 \mathrm{~h}$ at $1427^{\circ} \mathrm{C}$, and (5) fluorescent dye penetrant inspected. Several surface indications were noted and these were marked with a permanent marker, so that these regions were not included in the gage sections of any of the test specimens.

Since the IHS contains a circumferential closure weld made by the GTA process, test specimens for mechanical testing were made with a similar configuration. After IHS 
welding parameters were received from Mound, welding procedures were developed at ORNL for making similar welds in 2.29-mm (0.090-in.)-thick sheet. A copy of the welding record is shown in Fig. 2. The most problematic variable in the starting sheet material was a variation of about $0.13 \mathrm{~mm}(0.005 \mathrm{in}$.) in thickness. Each piece was measured before welding and the current adjusted to compensate for thickness variations. The welds were made by the bead-on-plate technique and did not involve the use of filler metal. The negative weld reinforcement on the arc side was 0.13 to $0.25 \mathrm{~mm}(0.005$ to 0.010 in.), and the root reinforcement was 0.25 to $0.38 \mathrm{~mm}(0.010$ to $0.015 \mathrm{in}$.).

These variations led to the thickness of the weld being about $0.25 \mathrm{~mm}(0.010 \mathrm{in}$.) thicker than that of the base metal. No machining or burnishing operations were carried out to remove this small amount of weld reinforcement. The area of the base metal portion of the samples was used to compute stresses.

A section of the weld was viewed metallographically, and typical photomicrographs are shown in Figs. 3 and 4. A section of the weld is shown in Fig. 3(a) magnified 12.8 times. The initial base metal had the microstructure shown in Fig. 3(b), which has a grain size of American Society for Testing and Materials (ASTM) number 8. The microstructure of the weld metal is dendritic as shown in Fig. 3(c). A portion of the region of large grains adjacent to the weld metal [see Fig. 3(a)] is shown at higher magnification in Fig. 4. Most of the tensile and creep fractures in welded samples occurred in these large grains. Microhardness measurements across the weld and base metal (see Fig. 5) show that the hardness does not vary much across the weldment, but the base metal adjacent to the fusion line is slightly softer than the remainder.

Chemical analyses for oxygen, nitrogen, and carbon were made on a very limited number of samples, and the results are presented in Table 1. The first two groups of analyses in Table 1 are for the as-received material and for the weld metal. Welding was performed by the GTA process in a glove box, and the analyses indicate no evidence of contamination of the T-111 during this step. Oxygen, nitrogen, and carbon concentrations are very low in both the as-received and the welded material. (The remainder of the analyses in Table 1 will be discussed later in the report). 
5

REFRACTORY ALLOY WELDING RECORD

DATa SHEet No. JFK $-R-75$

DATE: $5 / 31 / 95$

material: T- TII THICKNESS: $\approx 0,090 \mathrm{im}$ HEAT NUMBER:

JOINT GEOMETRY: BeAD ON PLATE

FILLER METAL: $N / A$

HEAT NUMBER:

$N / A$

SHIELDING GAS: ARgON

WELDING CURRENT: $265-290$ AMPERES; POLARITY: $D C E N$ PULSE: $X$ ON, OFF

$\because$ OF WELD CURRENT: $77.7 \%$

LOW PULSE TIME: 0.05 SeC.

HIGH PULSE TIME: $0.05 \mathrm{sec}$.

WELDING VOLTAGE:

or ARC GAP: $0.05 \mathrm{in}$.

TRAVEL SPEED: 5 ip m

ELECTRODE TYPE: EWTH-2 DIAMETER:

ELECTRODE GEOMETRY: ₹ $60^{\circ}$ included angle

WELDING ATMOSPHERE ANALYSIS AT END OF WELD $\mathrm{O}_{\mathrm{H}_{2} \mathrm{O}: \leq 10 \mathrm{pPm}}$

REMARKS:

Sigmajig fixture used to clamp specimens. welding curRent was increased on thicker specimens to achieve uniform pereteatiow

welding operator: D. Q. Anedicuk

WeLding ENGINEER: 7.7 . King

Fig. 2. Refractory alloy welding record. 

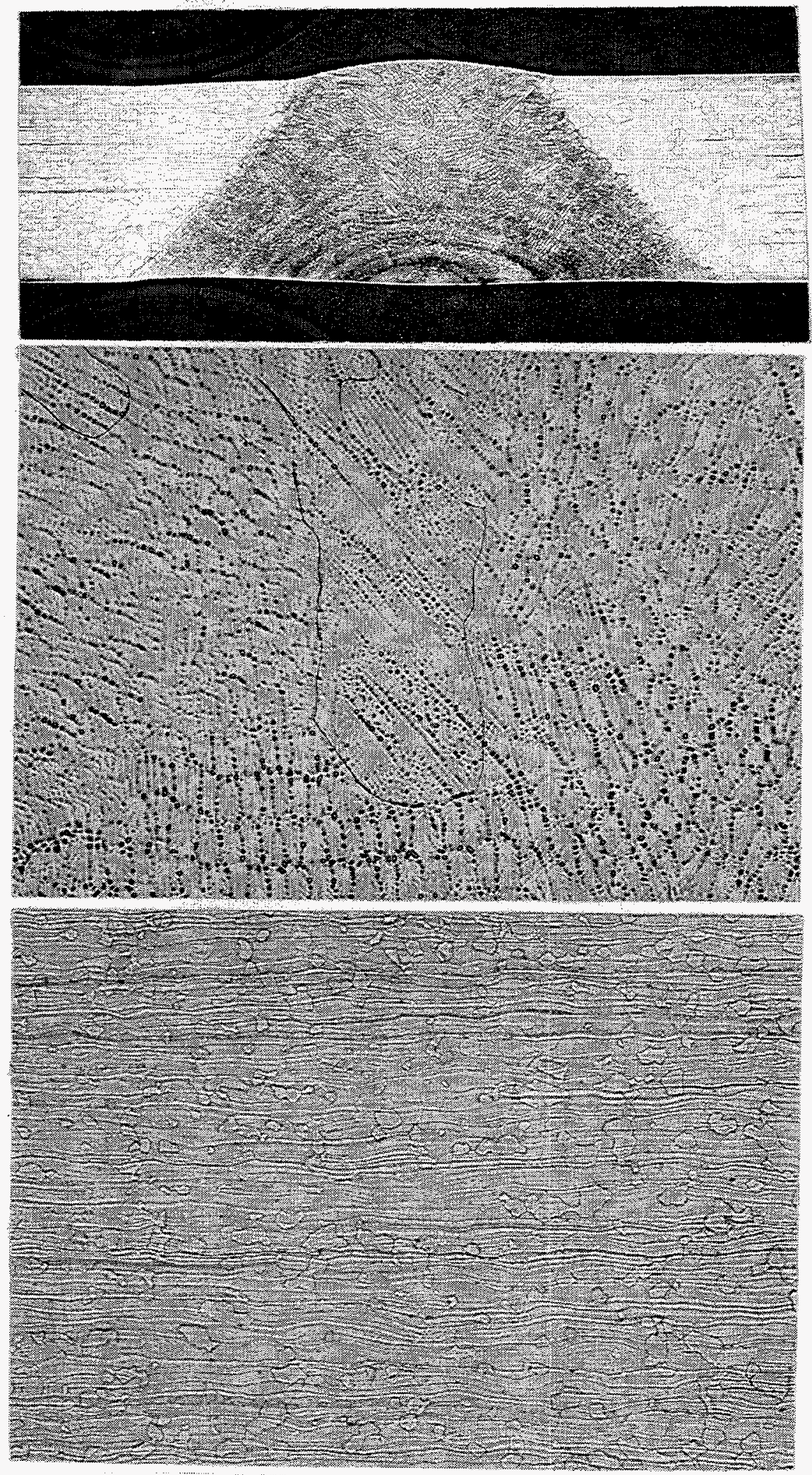

Fig. 3. Photomicrographs of section of weld: (a) view of entire weld, $12.8 \times ;$ (b) base metal, 100×; and (c) weld metal, 100×. 


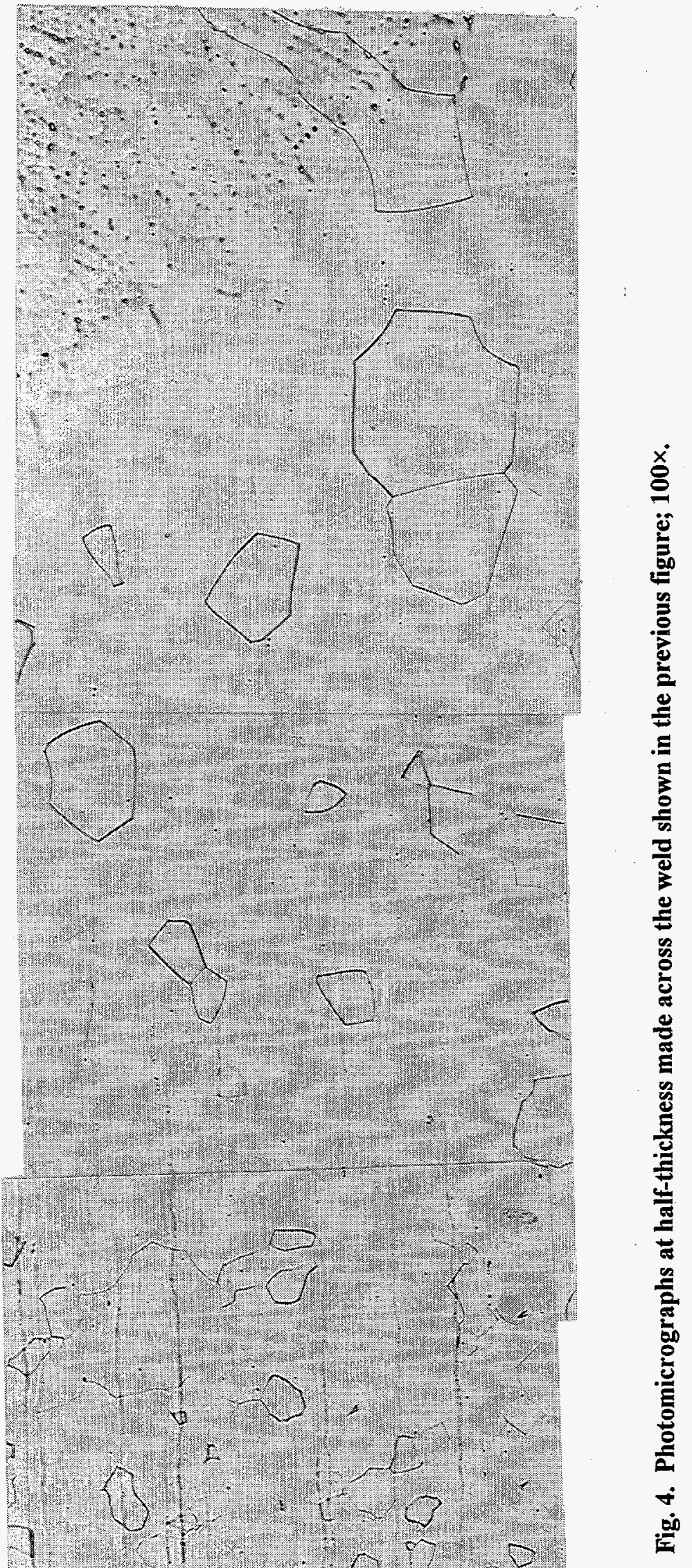




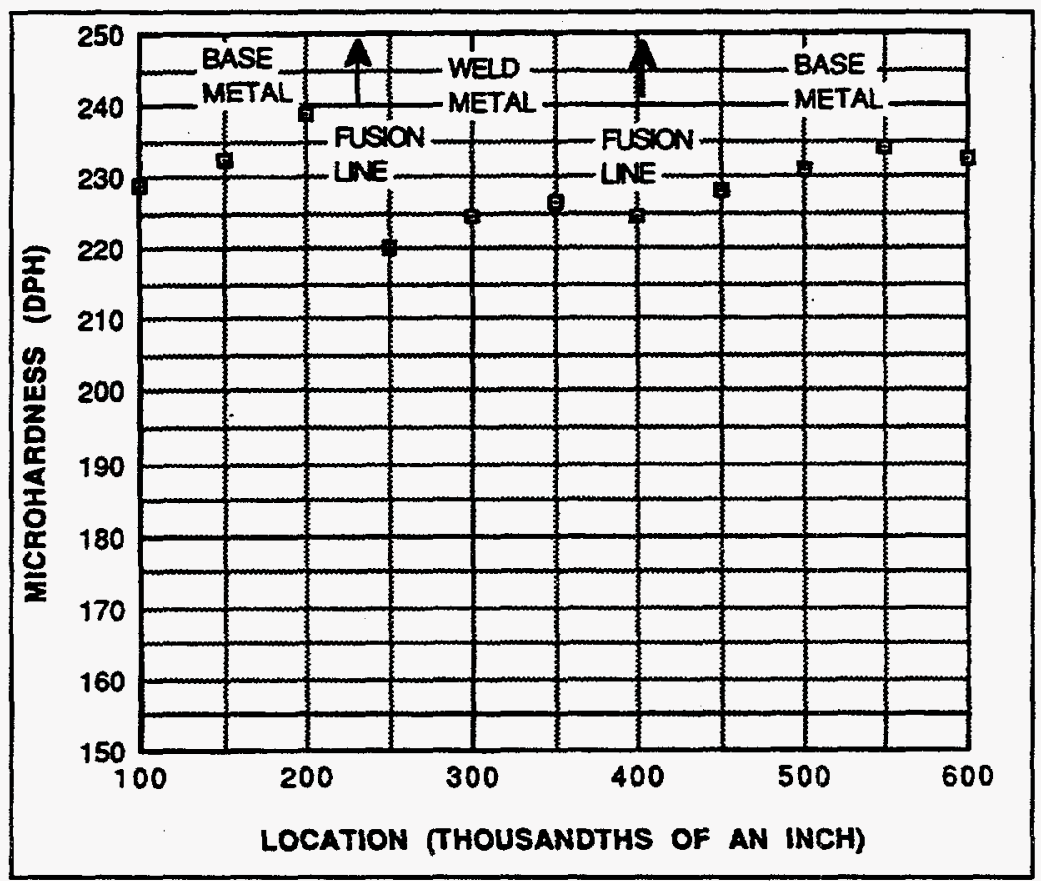

Fig. 5. Microhardness traverse across a section of as-welded T-111.

Specimen and Procedures. The specimen geometry that has been used at ORNL for creep and tensile tests has a gage length of $25 \mathrm{~mm}(1 \mathrm{in}$.) and a gage width of $6.35 \mathrm{~mm}(0.250$ in.). Since the creep machines are dead-loaded, the high strength of T-111 at the low test temperatures of interest made it questionable whether specimens with a cross section of $14.5 \mathrm{~mm}^{2}\left(0.0225\right.$ in. $\left.^{2}\right)$ could be tested without extensive equipment modifications. A specimen with one-half the width ( $3.18 \mathrm{~mm}$ or $0.125 \mathrm{in}$.) was fabricated, and the two specimen types were tested in duplicate at some of the tensile test conditions to determine if the two specimens gave equivalent results. Sketches of the two base metal sample geometries are shown in Fig. 6. By similar reasoning, welded samples having two gage widths were tested, and the sketches of these are shown in Fig. 7. A few specimens were also tested in which the weld was parallel to the specimen axis, and a sketch of this specimen is shown in Fig. 8. One further structural geometry detail was that the ends were reinforced to prevent failure from occurring at the holes used to attach the specimen to the load train (see Figs. 7 and 8). The reinforcement pads were made of T-111 or $\mathrm{Nb}-1 \mathrm{Zr}$ and were welded to the samples along the longitudinal edges of the test sample. $\mathrm{A}$ photograph showing each type of finished specimen is shown in Fig. 9. 
Table 1. Analysis of T-111 specimens for oxygen, nitrogen, and carbon

\begin{tabular}{|c|c|c|c|}
\hline Spec No. & Oxygen concentration & Nitrogen concentration & Carbon concentration \\
\hline & wt $\%$ & wt $\%$ & wt $\%$ \\
\hline ARW & & & $.0016, .0015$ \\
\hline ARW & $.0035, .0033$ & $.0017, .0021$ & \\
\hline ARB & & & $.0016, .0018$ \\
\hline $\mathrm{ARB}$ & $.0030, .0023$ & $.0012, .0020$ & \\
\hline $5 \mathrm{~B}$ & & & $.0017, .0019$ \\
\hline 5B & $.0026, .0022$ & $.0015, .0019$ & \\
\hline $6 \mathrm{~B}$ & & & 0.0016 \\
\hline $6 \mathrm{~B}$ & $.0021, .0024$ & $.0017, .0017$ & \\
\hline $6 \mathrm{~W}$ & $.0022, .0025$ & $.0022, .0015$ & \\
\hline $13 \mathrm{~B}$ & $.0030, .0028$ & $.0017, .0017$ & \\
\hline $13 \mathrm{~B}$ & & & $.0021, .0022$ \\
\hline $13 \mathrm{~W}$ & $.0024, .0029$ & $.0013, .0021$ & \\
\hline $15 B$ & $\begin{array}{l}.0156, .0113, .0250 \\
.0191\end{array}$ & $\begin{array}{l}.0026, .0032, .0035 \\
.0033\end{array}$ & \\
\hline $15 \mathrm{~B}$ & & & $.0017, .0019$ \\
\hline $15 \mathrm{~W}$ & $.0120, \quad .0124$ & $.0045, .0047$ & \\
\hline $15 \mathrm{~W}$ & & & $.0028, .0024$ \\
\hline $18 \mathrm{~B}$ & $.0016, .0018$ & $.0018, .0019$ & \\
\hline $18 \mathrm{~B}$ & & & $.0031, .0022, .0026$ \\
\hline $18 \mathrm{~W}$ & $.0034, .0035, .0062$ & $.0022, .0019, .0019$ & \\
\hline $18 \mathrm{~W}$ & & & $.0018, .0018$ \\
\hline
\end{tabular}




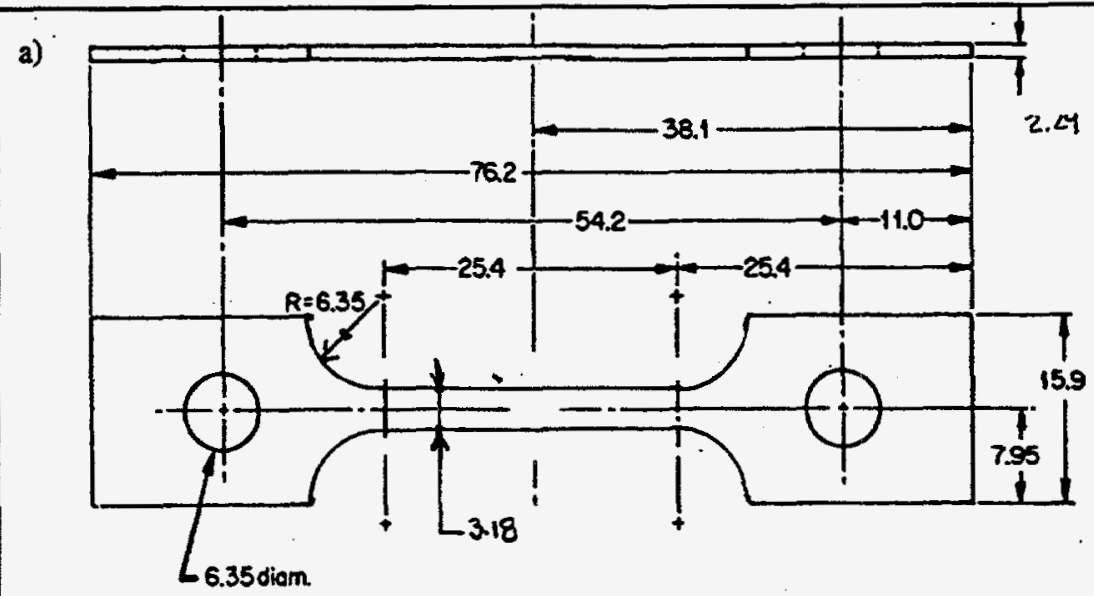

NOTE: ALL DIMENSIONS IN MILLIMETERS

(a)

b)

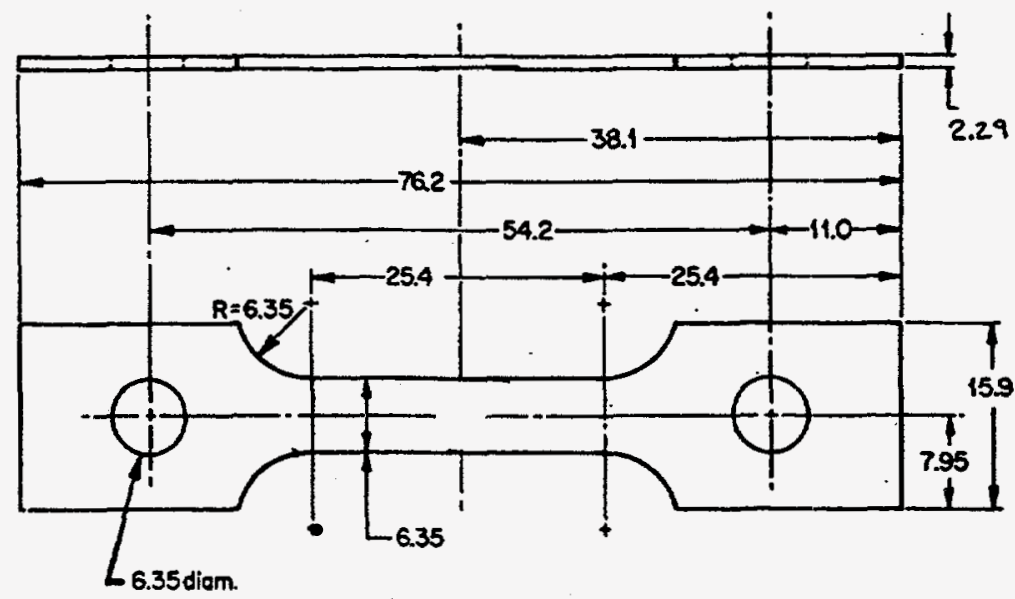

NOTE: ALL DIMENSIONS IN MILLIMETERS

(b)

Fig. 6. Sketches of base metal tensile and creep samples:

(a) sample A which has a gage width of $3.18 \mathrm{~mm}$ or $0.125 \mathrm{in}$. and

(b) sample $B$ with a gage width of $6.35 \mathrm{~mm}$ or $0.250 \mathrm{in}$. 


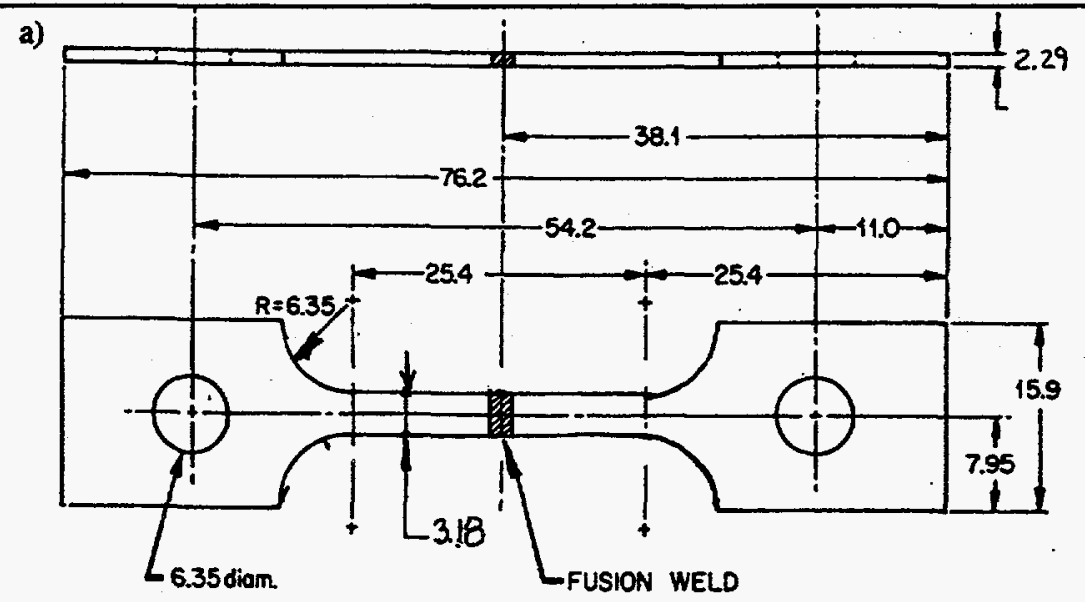

NOTE: ALL DIMENSIONS IN MILLIMETERS

b)

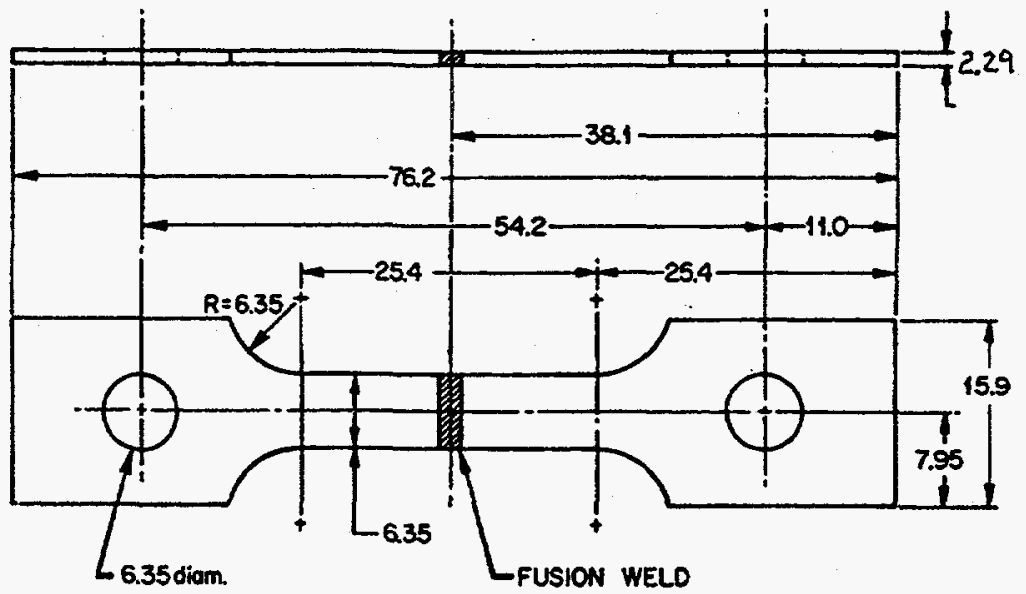

NOTE: ALL DIMENSIONS IN MILLIMETERS

Fig. 7. Sketches of transverse weld tensile and creep samples:

(a) Sample $C$ which has a gage width of $3.18 \mathrm{~mm}$ or $0.125 \mathrm{in}$. and

(b) sample $D$ which has a gage width of $6.35 \mathrm{~mm}$ or $0.250 \mathrm{in}$. 


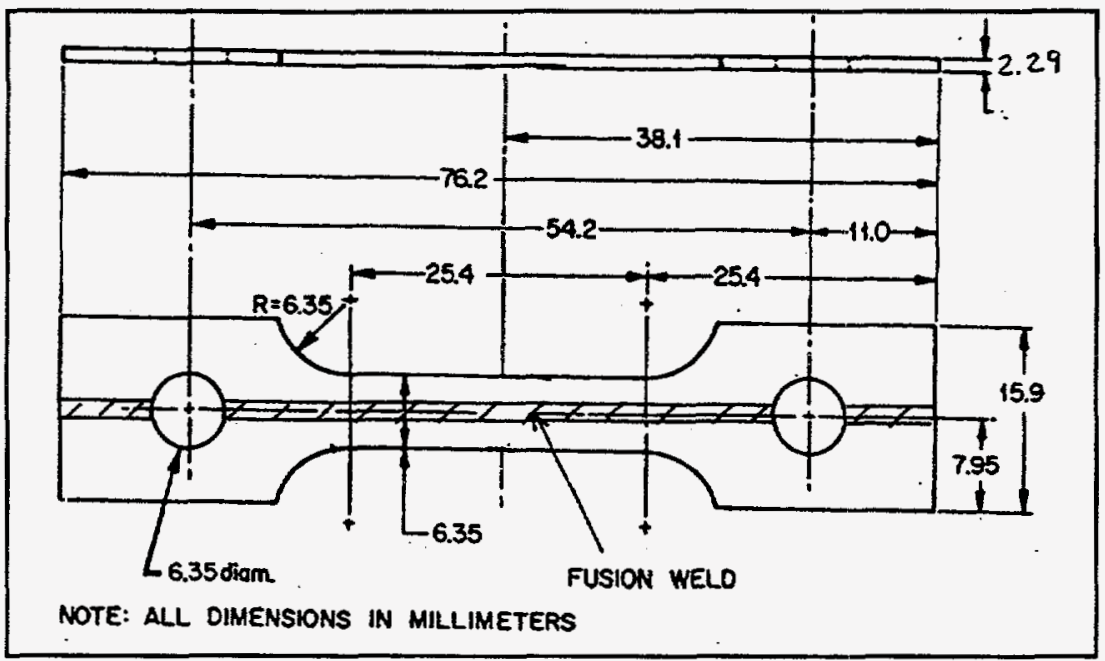

Fig. 8. Sketches of longitudinal weld tensile and creep sample. Designated sample $E$ with a gage width of $3.18 \mathrm{~mm}$ or $0.125 \mathrm{in}$.

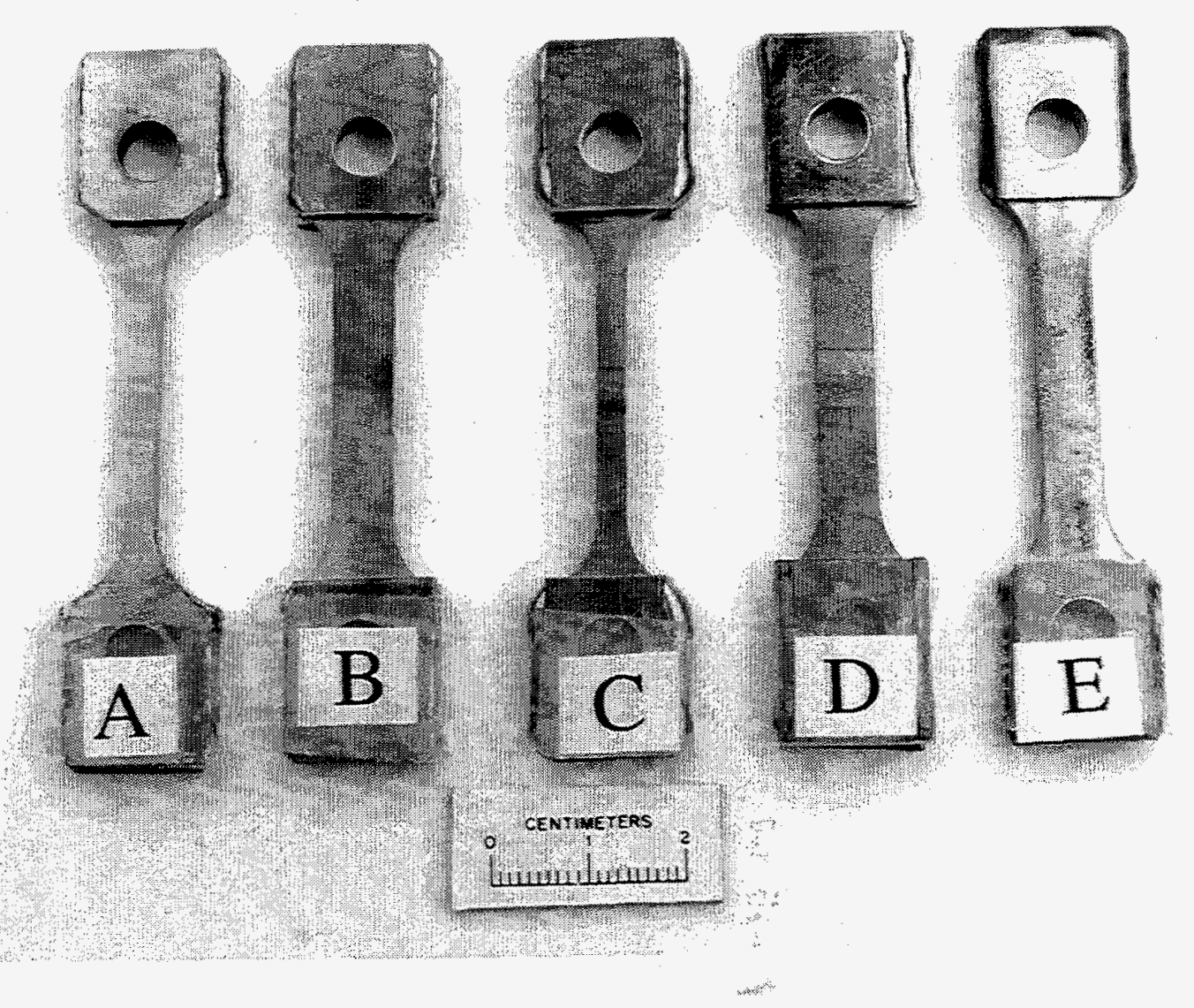

Fig. 9. Photograph of the five types of specimens used in the mechanical testing. 
Small fiduciary marks were generally made on each specimen for use in making strain measurements. In the tensile tests, strain was measured from the movement of the load train, and small hardness impressions on the surface of the specimen were examined after the test to determine the relative amounts of strain in the weld and base metal. For strain measurements in creep tests, small holes about $0.13 \mathrm{~mm}(0.005 \mathrm{in}$.) in diameter are normally machined by electrodischarge machine (EDM) using an optical system.

However, in this study these holes were machined by laser, and failure occurred at these locations. (This will be discussed further in the presentation of the metallographic results.) Only a few specimens were laser machined, and the procedure for making strain measurements was modified to use hardness impressions made with a Braille indentor and a 60-kg load. These impressions did not appear to influence fracture location.

All test samples were cleaned by the procedure described in ref. 1 . The procedure involved degreasing; acid etching in a solution of $\mathrm{HF}, \mathrm{HNO}_{3}, \mathrm{H}_{2} \mathrm{SO}_{4}$, and $\mathrm{H}_{2} \mathrm{O}$; rinsing in water and ethanol; and air drying.

The tensile tests were carried out using the five types of specimens shown in Figs. 6 through 9. The test equipment consisted of an Instron Universal Testing Machine with an attached cryo-pumped test chamber. Good vacuum practices for cleanliness were exercised in all testing, and the vacuum in the tests conducted above room temperature was kept in the vicinity of $1 \mathrm{E}-7$ torr. Tests were run at the rate of approximately one per $24 \mathrm{~h}$. The moderately good vacuum and the short time at temperature were sufficient to prevent significant contamination of the test samples. The crosshead movement rate was $0.021 \mathrm{~mm} / \mathrm{s}(0.05 \mathrm{in} . \mathrm{min})$.

Tensile Test Results. A summary of the tensile test results is shown in Table 2. Some tests of each of the five types of specimens were run over the temperature range of 25 to $1100^{\circ} \mathrm{C}$. At $25^{\circ} \mathrm{C}$ the T- 111 exhibited lower and upper yield points, and in several tests at temperatures of 300 to $700^{\circ} \mathrm{C}$ exhibited serrated yielding. All samples containing transverse welds failed in the heat-affected-zone (HAZ) adjacent to the weld.

Figures 10 and 11 compare results from samples with either 3.18 or $6.35 \mathrm{~mm}$ ( 0.125 and $0.25 \mathrm{in}$.) gage widths to determine if they give similar test results. The yield and ultimate tensile strengths are shown in Fig. 10 for types A and B base metal samples. 
Similar results are shown in Fig. 11 for transverse weld samples designated as types $\mathrm{C}$ and D. In general, the results from the two types of samples do agree very well, and it was concluded that the narrow specimens $(3.18 \mathrm{~mm}$ or $0.125 \mathrm{in}$.) give the same test results as the wider specimens ( $6.35 \mathrm{~mm}$ or $0.25 \mathrm{in}$.). Hence, we used the narrower samples in the creep tests with confidence that they would give representative results.

The observation that the test results were not detectably influenced by specimen geometry also allowed the tensile test results for the two widths of specimens to be combined. In Fig. 12, the yield and ultimate tensile strengths for base metal (sample types A and B), transverse weld (sample types C and D), and longitudinal weld (sample type E) are compared. Samples with transverse or longitudinal welds have yield and ultimate tensile strengths 10 to $20 \%$ lower than base metal. Samples with longitudinal welds are also slightly weaker than those with transverse welds.

The fracture strains of the five types of specimens are shown in Fig. 13. Transverse weld samples (types $C$ and $D$ ) consistently have lower fracture strains than do base metal samples (types A and B). The type $E$ samples generally have fracture strains nearer those of the base metal than the transverse weld metal samples.

The detailed strain measurements in Table 3 give some further insight into the variations in the fracture strain for the different types of specimens. Small hardness impressions were made in the transverse weld samples as markers to help determine the location of the strain. As shown by the two right-hand columns in Table 3, strain in the weld and the HAZ was much higher than in the base metal. Since the weld and the HAZ were weaker than the base metal, they flowed in preference to the base metal. Strain, and ultimately fracture, occurred primarily in the weld and HAZ.

The creep machines were of the dead-load type and loads up to about $750 \mathrm{lbs}$ were required to achieve the desired stress levels. Because of the high loads required, the extension members whereby the load was applied had to be redesigned. Strain was determined from dial indicators that measured the motion of the loading system, and by an optical measuring microscope that sighted on shallow hardness impressions on the specimen surface. The optical system has a small measuring range, so it could only be used during the first few percent strain. 
Table 2. Summary of tensile test results

\begin{tabular}{|c|c|c|c|c|c|c|c|}
\hline Test No & Sample type & Temperahur & YS $02 \%$ & YS & ITS & Elongatio & Fract lo \\
\hline & & ${ }^{\circ} \mathrm{C}$ & $\mathrm{MPa}$ & $\mathrm{MPa}$ & $\mathrm{MPa}$ & $\%$ & \\
\hline$D 1$ & $D^{*}$ & 25 & 586 & 586 & 687 & 240 & HAZ \\
\hline DI & $D^{*}$ & 25 & 592 & 592 & 693 & 232 & HAZ \\
\hline 1 & $A$ & 25 & 619 & 663 & 684 & 314 & $\mathrm{~B}$ \\
\hline 2 & $\mathrm{~B}$ & 25 & 607 & 665 & 673 & 325 & $\mathrm{~B}$ \\
\hline 3 & $c$ & 25 & 561 & 561 & 678 & 215 & HAZ \\
\hline 5 & $D$ & 25 & 563 & 563 & 645 & 226 & HAZ \\
\hline 4 & $E$ & 25 & 566 & 566 & 654 & 305 & W/BM/HA \\
\hline 28 & $\mathrm{~B}$ & 300 & 407 & & 489 & 330 & $\mathrm{~B}$ \\
\hline 27 & $D$ & 300 & 332 & & 439 & 216 & HAZ \\
\hline 19 & A & 640 & 330 & & 496 & 173 & $\mathrm{~B}$ \\
\hline 23 & $\mathrm{~B}$ & 640 & 328 & & 489 & 213 & $\mathrm{~B}$ \\
\hline 18 & c. & 640 & 270 & & 424 & 119 & HAZ \\
\hline 24 & $D$ & 640 & 276 & & 443 & 156 & HAZ. \\
\hline 25 & $\mathrm{E}$ & 640 & 248 & & 446 & 280 & W/BM/HA \\
\hline 21 & $\mathrm{~B}$ & 700 & 321 & & 530 & 251 & $\mathrm{~B}$ \\
\hline 20 & D & 700 & 277 & & 453 & 158 & HAZ \\
\hline 22 & $E$ & 700 & 264. & & 488. & 259 & W/BM/HA \\
\hline 7 & A & 900 & 299 & & 501 & 224 & $\mathrm{~B}$ \\
\hline 16 & $\mathrm{~B}$ & 900 & 284 & & 496 & 270 & $B$ \\
\hline 8 & c & 900 & 270 & & 441 & 14.8 & HAZ \\
\hline 17 & $D$ & 900 & 260 & & 431 & 170 & HAZ \\
\hline 15 & $E$ & 900 & 249 & & 446 & 286 & W/BM/HA \\
\hline 14 & $\mathrm{~B}$ & 1000 & 267 & & 474 & 275 & $\mathrm{~B}$ \\
\hline 11 & $D$ & 1000 & 260 & & 417 & 157 & HAZ \\
\hline 6 & $A$ & 1100 & 289 & & 451 & 180 & $\mathrm{~B}$ \\
\hline 13 & $B$ & 1100 & 244 & & 407 & 304 & $\mathrm{~B}$ \\
\hline 9 & C & 1100 & 266 & & 366 & 71 & HAZ \\
\hline 10 & D & 1100 & 259 & & 378 & 111 & HAZ \\
\hline 12 & $\mathrm{E}$ & 1100 & 233 & & 382 & 118 & W/BM/HA \\
\hline \multicolumn{8}{|c|}{$\begin{array}{l}{ }^{a} \text { A, current material, base metal, } 0.125 \text { in. wide; } B \text {, current material, base metal, } 0.250 \text { in. wide; } C \text {, } \\
\text { current material, transverse weld, } 0.125 \text { in. wide; } D \text {, current material, transverse weld, } 0.250 \text { in. } \\
\text { wide; } D^{*} \text {, previous material, transverse weld, } 0.250 \text { in. wide by } 0.040 \text { in. thick; and } E \text {, current } \\
\text { material, longitudinal weld, } 0.250 \text { in. wide. }\end{array}$} \\
\hline${ }^{b} \mathrm{~B}=$ bas & tal, I & etal. & $Z=h e$ & & & & \\
\hline
\end{tabular}




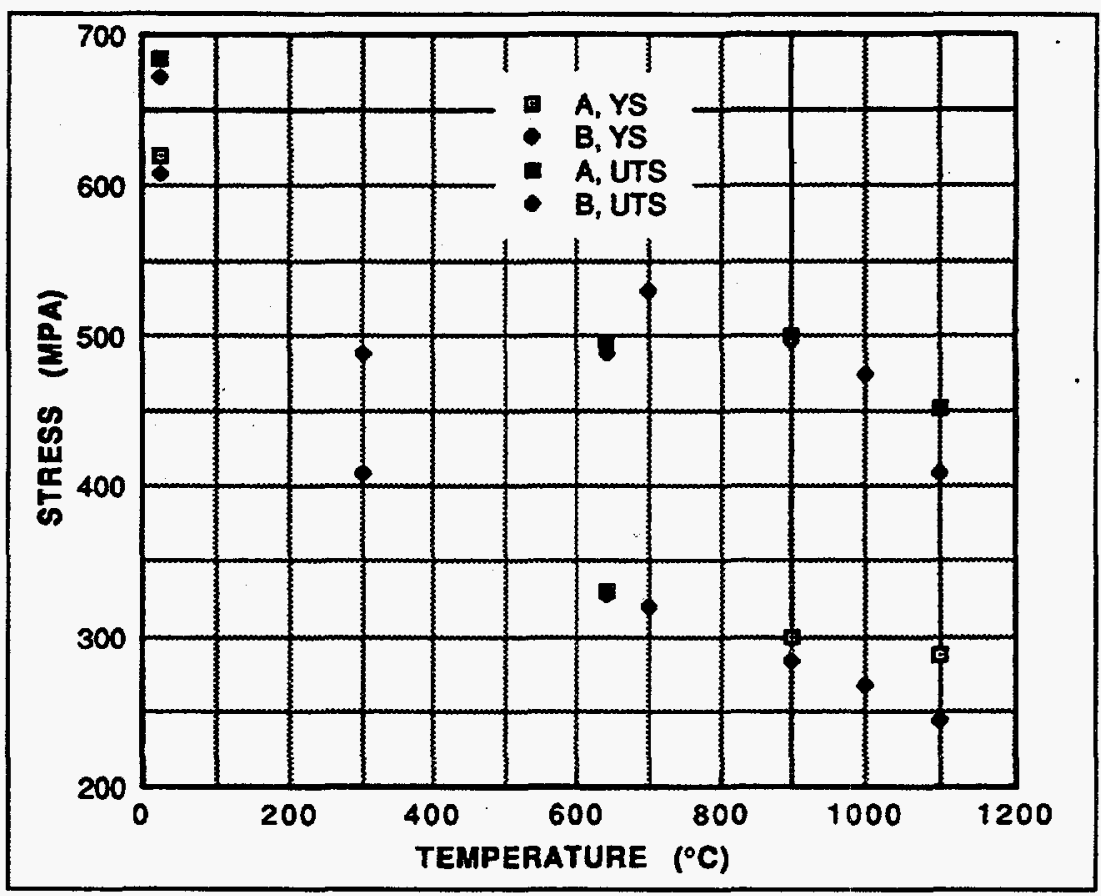

Fig. 10. Comparison of tensile properties for base metal samples: $A, 3.18 \mathrm{~mm}$ wide and $B, 6.35 \mathrm{~mm}$ wide.

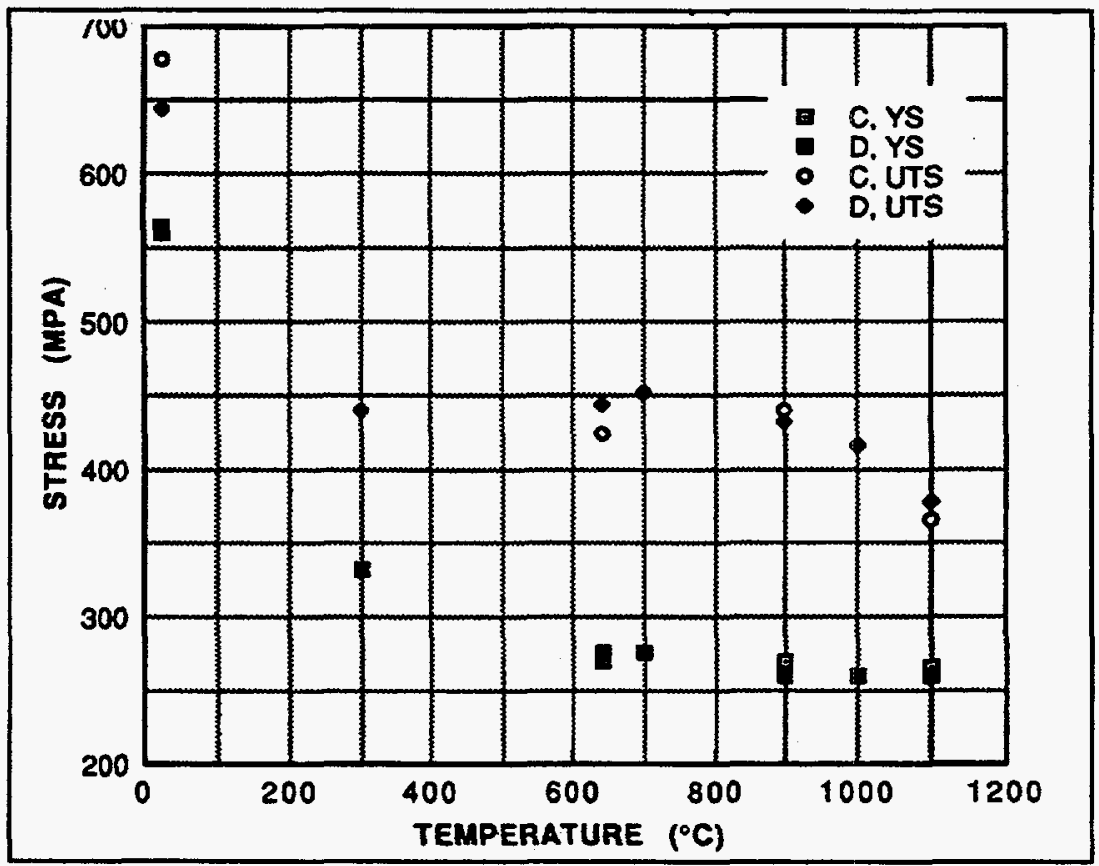

Fig. 11. Comparison of tensile properties for transverse weld samples: $C, 3.18 \mathrm{~mm}$ and $D, 6.35 \mathrm{~mm}$ wide. 


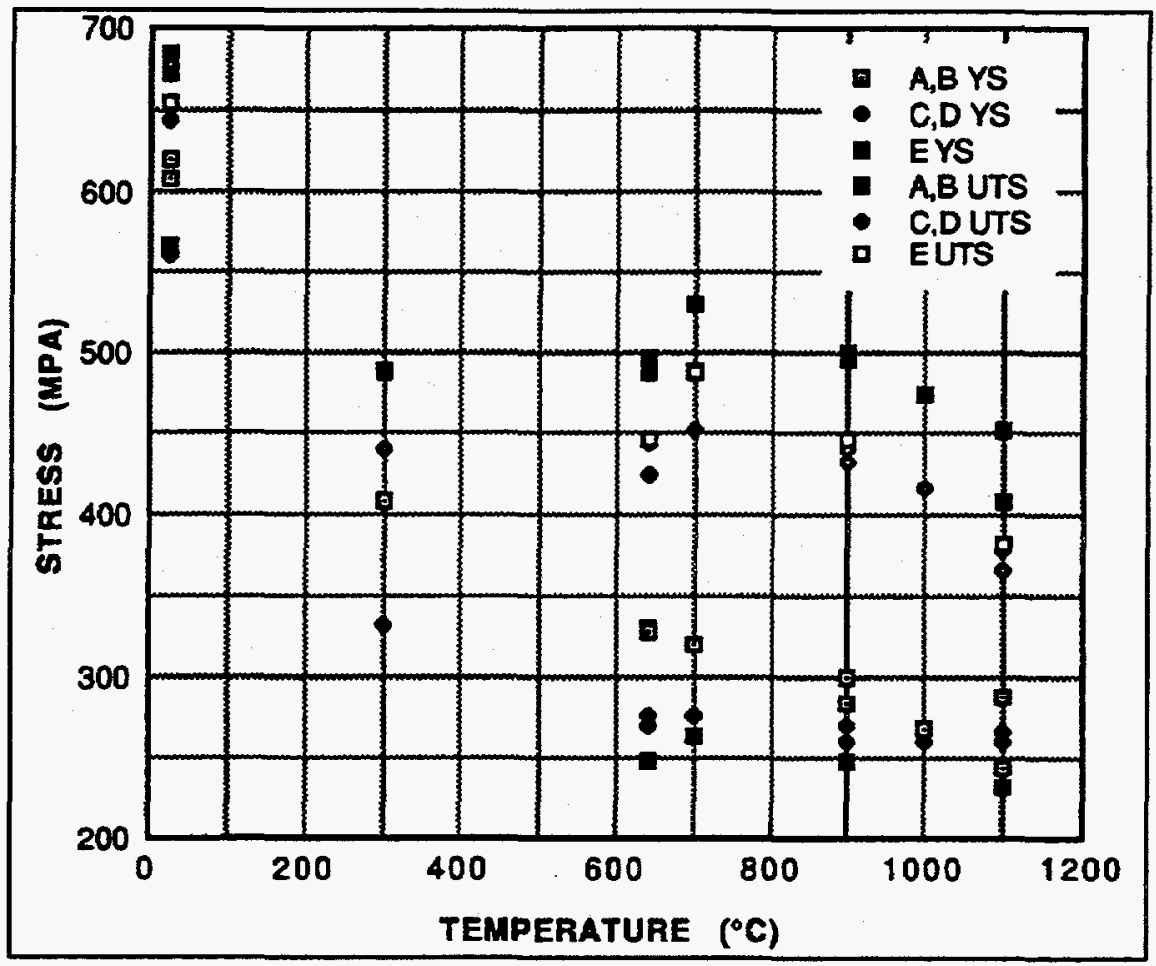

Fig. 12. Comparison of the tensile properties of $T-111$ base metal, transverse and longitudinal weld samples.

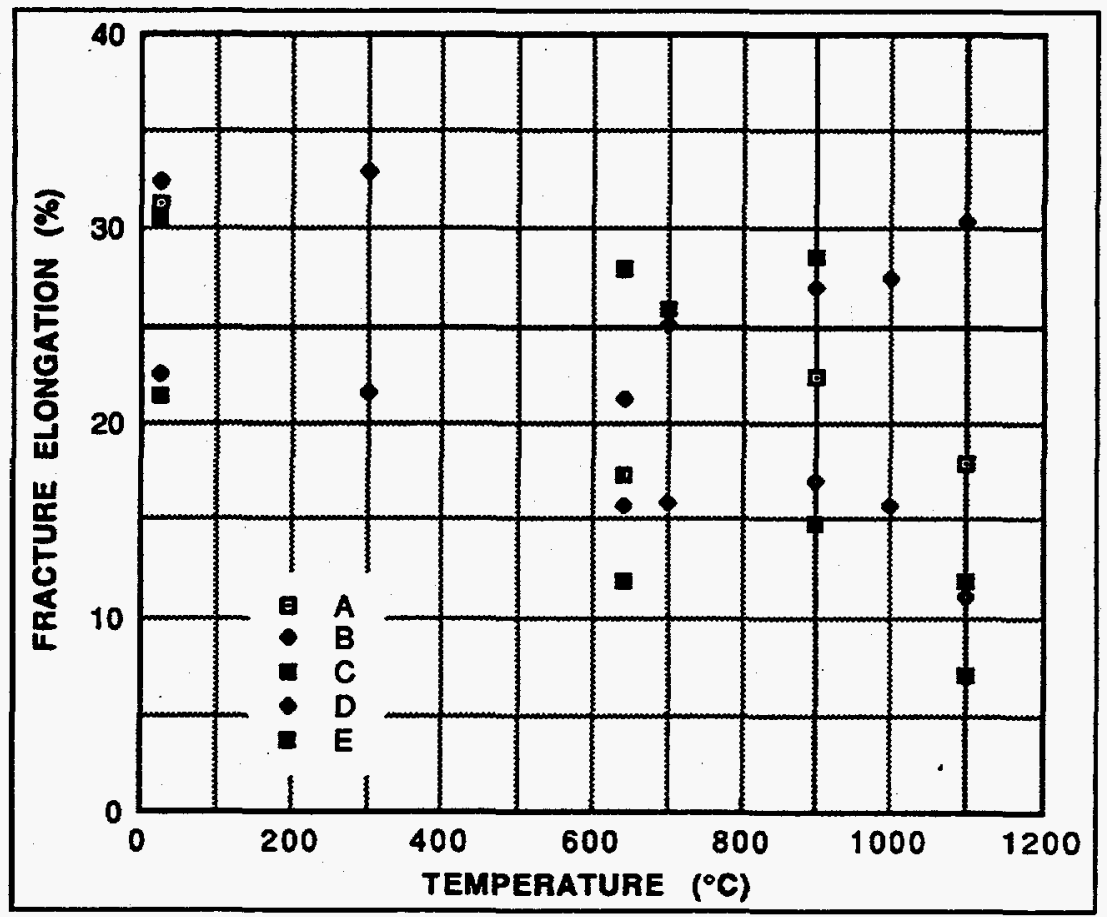

Fig. 13. Comparison of fracture strains of five specimen types as a function of temperature. 
Table 3. Summary of strain measurements made on tensile specimens

\begin{tabular}{|c|c|c|c|c|c|c|c|}
\hline Test No & Sample & Temperatur & Elongatio & Eract loc & \multirow{2}{*}{$\begin{array}{l}\text { Strain, } \\
\text { overall }\end{array}$} & \multirow{2}{*}{$\begin{array}{l}\text { Strain, } \\
\text { center }\end{array}$} & \multirow{2}{*}{$\begin{array}{l}\text { Strain, } \\
\text { end-to- }\end{array}$} \\
\hline & & & & & & & \\
\hline & a & ${ }^{\circ} \mathrm{C}$ & $\%$ & $\bar{b}$ & $0 \%$ & $\%^{d}$ & weld/ge \\
\hline$D 1$ & $D^{*}$ & 25 & 240 & HAZ & & & \\
\hline $\mathrm{D2}$ & $D^{*}$ & 25 & 232 & $\mathrm{HAZ}$ & & & \\
\hline 1 & A & 25 & 314 & $\mathrm{~B}$ & & & \\
\hline 2 & $B$ & 25 & 325 & $\mathrm{~B}$ & & & \\
\hline 3 & $\mathrm{C}$ & 25 & 215 & $\mathrm{HAZ}$ & 209 & 328 & $124 / 103$ \\
\hline 5 & n & 25 & 226 & $\mathrm{HAZ}$ & 209 & 417 & $86 / 107$ \\
\hline 4 & $E$ & 25 & 305 & W/BM/HA & & & \\
\hline 28 & $\mathrm{~B}$ & 300 & 330 & $B$ & & & \\
\hline 27 & $D$ & 300 & 216 & HAZ & 193 & 418 & $23 / 54$ \\
\hline 19 & $A$ & 640 & 173 & $\mathrm{~B}$ & & & \\
\hline 23 & $B$ & 640 & 213 & $\mathrm{~B}$ & & & \\
\hline 18 & $c$ & 640 & 119 & HAZ & 121 & 247 & $19 / 31$ \\
\hline 24 & $D$ & 640 & 156 & $\mathrm{HAZ}$ & 153 & 332 & $48 / 49$ \\
\hline 25 & $E$ & 640 & 280 & WRMM/HA & & & \\
\hline 21 & $B$ & 700 & 251 & $\mathrm{~B}$ & & & \\
\hline 20 & $D$ & 700 & 158 & HAZ & 150 & 351 & 44 \\
\hline 22 & $\mathrm{E}$ & 700 & 259 & W/BM/HA & & & \\
\hline 7 & A & 900 & 224 & $\mathrm{~B}$ & & & \\
\hline 16 & $\mathrm{~B}$ & 900 & 270 & $\mathrm{~B}$ & & & \\
\hline 8 & $\mathrm{C}$ & 900 & 148 & $\mathrm{HAZ}$ & 141 & 321 & $39 / 42$ \\
\hline 17 & $D$ & 900 & 170 & HAZ & 161 & 379 & $56 / 35$ \\
\hline 15 & E & 900 & 286 & W/BM/HA & & & \\
\hline 14 & $\mathrm{~B}$ & 1000 & 275 & $\mathrm{~B}$ & & & \\
\hline 11 & $D$ & 1000 & 157 & $\mathrm{HAZ}$ & 155 & 324 & $61 / 43$ \\
\hline 6 & $A$ & 1100 & 180 & R & & & \\
\hline 13 & $\mathrm{~B}$ & 1100 & 304 & B & & & \\
\hline 9 & $c$ & 1100 & 71 & HAZ & 97 & 202 & $29 / 23$ \\
\hline 10 & $D$ & 1100 & 111 & $\mathrm{HAZ}$ & 100 & 176 & $55 / 48$ \\
\hline 12 & $\mathrm{E}$ & 1100 & 118 & W/BM/HA & & & \\
\hline $\begin{array}{l}a_{\text {A curr }} \\
\text { transverse } \\
\text { weld, } 0.250 \\
\mathrm{~B}=\mathrm{bas} \\
c \text { Strain } \\
{ }^{d} \text { Strain } \\
e_{\text {Strain }}\end{array}$ & $\begin{array}{l}\text { material, b } \\
\text { d, } 0.125 \text { in. } \\
\text { wide by } 0 \\
\text { metal, W = } \\
\text { ween the out } \\
\text { ween center } \\
\text { ween pairs of }\end{array}$ & $\begin{array}{l}\text { at, } 0.125 \text { in. wide } \\
\text { D, current mate } \\
\text { thick; and } \mathrm{E} \text {, } \\
\text { etal, and } \mathrm{HAZ}= \\
\text { iduciary marks. } \\
\text { tciary marks, prin } \\
\text { lost and center fid }\end{array}$ & $\begin{array}{l}\text { B, current m } \\
\text { al, transverse } \\
\text { urrent materia } \\
\text { eeat-affected zo } \\
\text { urily weld. } \\
\text { ciary marks. }\end{array}$ & $\begin{array}{l}\text { terial, base meta } \\
\text { veld, } 0.250 \text { in. } \\
\text { longitudinal we } \\
\text { e. }\end{array}$ & $\begin{array}{l}.250 \text { in } \mathrm{x} \\
0.250 \text { in. } \\
\mathrm{D}^{\circ} \text { pre }\end{array}$ & $\begin{array}{l}\text { C, curren } \\
\text { s material } \\
\text { e. }\end{array}$ & $\begin{array}{l}\text { raterial, } \\
\text { ansverse }\end{array}$ \\
\hline
\end{tabular}


Creep Test Procedures. All tests were run in ion-pumped vacuum systems, normally at a pressure $1 \mathrm{E}-7$ torr when first loaded and at approximately $1 \mathrm{E}-8$ torr after $100 \mathrm{~h}$. Three typical samples $(5,6$, and 13$)$ were analyzed for oxygen, nitrogen, and carbon after testing, and the results in Table 1 show that the tested samples had essentially the same concentrations of these elements as did the starting material.

Creep Test Results. The creep test matrix consisted of several tests of T-111 base metal (sample type A) and T-111 transverse welds (sample type B). Some samples were tested to rupture over the temperature range of 900 to $1100^{\circ} \mathrm{C}$, and others were run at 500 to $900^{\circ} \mathrm{C}$ long enough to determine the creep rate. The reasoning behind this approach was that the failed tests would provide the information to construct a plot of log-creep rate versus log-rupture time (known as the Monkman-Grant Correlation). This master plot would then be used to estimate the rupture life of $\mathrm{T}-111$ at a certain temperature and stress based on its creep rate.

Results of the creep tests are summarized in Table 4. Individual creep curves for each test are given in Appendix $A$ in the order of the test numbers in the first column of Table 4. There were some anomalous or difficult-to-explain test results. Test 28525 was a transverse weld specimen that failed in the base metal after $590 \mathrm{~h}$ (see Fig. 14). However, an associated base metal sample (test 28543) was discontinued after $1589 \mathrm{~h}$ without failure. In fact, all other transverse weld samples failed in the weld or HAZ. Since these two tests appear to be in conflict, results from both tests were not included.

The samples in tests 28584 and 28544 were base metal, and both failed at the laser-formed fiduciary marks machined in each end of the gage length for references in making optical strain measurements. The sample in test 28602 did not have fiduciary marks and lasted much longer than the sample in test 28584 that had fiduciary marks. Thus, the results from tests 28584 and 28544 were not used. Photographs of the samples with and without fiduciary marks are shown in Fig. 15.

The sample in test 28578 did not give useful data because the extension member failed and the sample was bent. The samples in tests 28627 and 28623 were run at 414 $\mathrm{MPa}$ and failed almost instantly. They did not give useful creep information, but the facts that the fractures occurred very quickly at this stress and that the fractures occurred in the 
Table 4. Summary of creep/creep-rupture results - updated 7-1-96

\begin{tabular}{|c|c|c|c|c|c|c|c|c|c|c|}
\hline \multirow[t]{2}{*}{ Tess No. } & \multirow[t]{2}{*}{ Sample No. } & \multirow{2}{*}{$\begin{array}{c}\text { Sample } \\
\text { type }\end{array}$} & \multirow{2}{*}{$\frac{\text { Siress }}{\mathrm{MPa}}$} & \multirow{2}{*}{$\frac{\text { Temperature }}{{ }^{\circ} \mathrm{C}}$} & \multirow{2}{*}{ Time } & \multirow{2}{*}{$\begin{array}{c}\text { Loid slrain } \\
\%\end{array}$} & \multirow{2}{*}{$\begin{array}{c}\text { Creen strain } \\
\%\end{array}$} & \multirow{2}{*}{$\frac{\text { Crecp strain }}{\% \text { (dial gage) }}$} & \multirow[t]{2}{*}{ F:or IP' } & \multirow{2}{*}{$\frac{\text { Pract loc }}{b}$} \\
\hline & & & & & & & & & & \\
\hline 28525 & 1 & $c$ & 172 & 1100 & 590 & 0.1 & 35.0 & & $\mathbf{F}$ & B \\
\hline 28626 & 11 & $c$ & 241 & 1050 & 143 & 0.6 & 4.5 & 1.6 & $F$ & HAK. \\
\hline 28533 & 2 & $c$ & 276 & 1000 & 51 & 0.5 & 5.5 & 5.7 & $F$ & $w$ \\
\hline $28584^{\circ}$ & 8 & $\Lambda$ & 276 & 1000 & $115^{\prime \prime}$ & 2.8 & 3.0 & 4.0 & $F$ & B \\
\hline 28602 & 9 & $A^{*}$ & 276 & 1000 & 510 & 0.6 & +9.0 & & : & B \\
\hline 28535 & 3 & $c$ & +14 & 900 & 101 & 3.4 & 4.5 & 11.2 & F & IIAZ \\
\hline 28577 & 6 & $c$ & $345 / 414^{\prime} / 431^{\prime}$ & 900 & 1367 & 1.1 & 1.7 & 6.2 & $F$ & $w$ \\
\hline $28544^{*}$ & 5 & $A$ & 414 & 900 & $9.4^{d}$ & 6.0 & 1.7 & & $\mathbf{F}$ & B \\
\hline 28630 & 13 & $c$ & $379 / 414^{m} / 431^{n} / 448^{\prime \prime}$ & 850 & 930 & & 4.1 & 6.3 & $\mathrm{~F}$ & \\
\hline $28627 *$ & 12 & $\mathrm{C}$ & 414 & 850 & 0.1 & & & & $\mathrm{~F}$ & IIAZ \\
\hline 28600 & 31 & 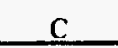 & $379 / 414^{g} / 431^{\circ}$ & 800 & $3738^{i}$ & 5.3 & 5.5 & 7.2 & D & \\
\hline $28578^{*}$ & 7 & $\mathrm{C}$ & 379 & 580 & $33.6^{c}$ & 3.8 & (Approx) 0 & & $\mathbf{F}$ & HAZ \\
\hline 28594 & 30 & $\mathrm{C}$ & $379 / 414^{h} / 431^{k} / 448^{p} / 276^{1}$ & 580 & 6625 & 7.1 & 1.9 & 4.97 & IP & \\
\hline $28623 *$ & 10 & $\mathrm{C}$ & 414 & 500 & 0.1 & & 16.0 & & F & HAZ \\
\hline 28632 & 15 & $\mathrm{C}$ & $379 / 414^{r} / 448^{s}$ & 500 & $2226^{i}$ & 2.2 & 3.8 & 5.4 & $\underline{\mathrm{D}}$ & \\
\hline 28695 & 17 & $\mathrm{C}$ & 250 & 680 & 2619 & 0.28 & 0.13 & 0.52 & & \\
\hline 28693 & 16 & $\mathrm{C}$ & 276 & 580 & 2593 & 1.5 & 0.07 & 0.56 & IP & \\
\hline 28694 & 18 & $\mathrm{C}$ & 226 & 800 & 2521 & 0.01 & 0.14 & 1.30 & IP & \\
\hline \multicolumn{11}{|c|}{$\begin{array}{l}\text { a A, current material, base metal, } 0.125 \text { in. wide; } B \text {, current material, base metal, } 0.250 \text { in. wide; } C \text {, current material, transverse weld, } 0.125 \text { in. wide; } D \text {, current material, transverse } \\
\text { weld, } 0.250 \text { in. wide; } D^{*} \text {, previous material, transverse weld, } 0.250 \text { in. wide by } 0.040 \mathrm{in} \text {. thick; and } E \text {, current material, longitudinal weld, } 0.250 \text { in. wide. }\end{array}$} \\
\hline \multicolumn{4}{|c|}{${ }^{b} \mathrm{~B}=$ base metal, $\mathrm{W}=$ weld metal, and $\mathrm{HAZ}=$ heat-affected zone. } & & \multicolumn{2}{|c|}{ Increased stress at $1316 \mathrm{~h}}$. & & \multicolumn{3}{|c|}{${ }^{r}$ Increased stress at $79 \mathrm{~h}}$. \\
\hline \multicolumn{4}{|c|}{${ }^{c}$ Pull rod system failed. Not a valid rupture time. } & & \multicolumn{2}{|c|}{${ }^{k}$ Increased stress at $702 \mathrm{~h}}$. & & \multicolumn{3}{|c|}{${ }^{s}$ Increased stress at $143 \mathrm{~h}}$. \\
\hline \multicolumn{4}{|c|}{${ }^{\mathrm{d}}$ Failed at fiduciary mark. } & & \multicolumn{6}{|c|}{ ' $F=$ fractured, $I P=$ in progress, $D=$ discontinued prior to fracture. } \\
\hline \multicolumn{4}{|c|}{${ }^{c}$ Base metal specimen 0.125 in. wide without fiduciary marks. } & & \multicolumn{2}{|c|}{${ }^{m}$ Increased stress at $192 \mathrm{~h}$. } & & \multicolumn{3}{|c|}{$'$ Increased stress at $500 \mathrm{~h}}$. \\
\hline${ }^{h}$ Increase & ress at $429 h$. & & & & pIncreased & ess at $1626 \mathrm{~h}$. & & " Decreased sir & sat $3858 \mathrm{~h}$ & \\
\hline${ }^{\prime}$ Termin & prior to fractu & & & & ${ }^{9}$ Increaseds & ess at $330 \mathrm{~h}$. & & & & \\
\hline${ }^{*}$ Creep c & s not includes & ppendix $A$ & & & & & & & & \\
\hline
\end{tabular}




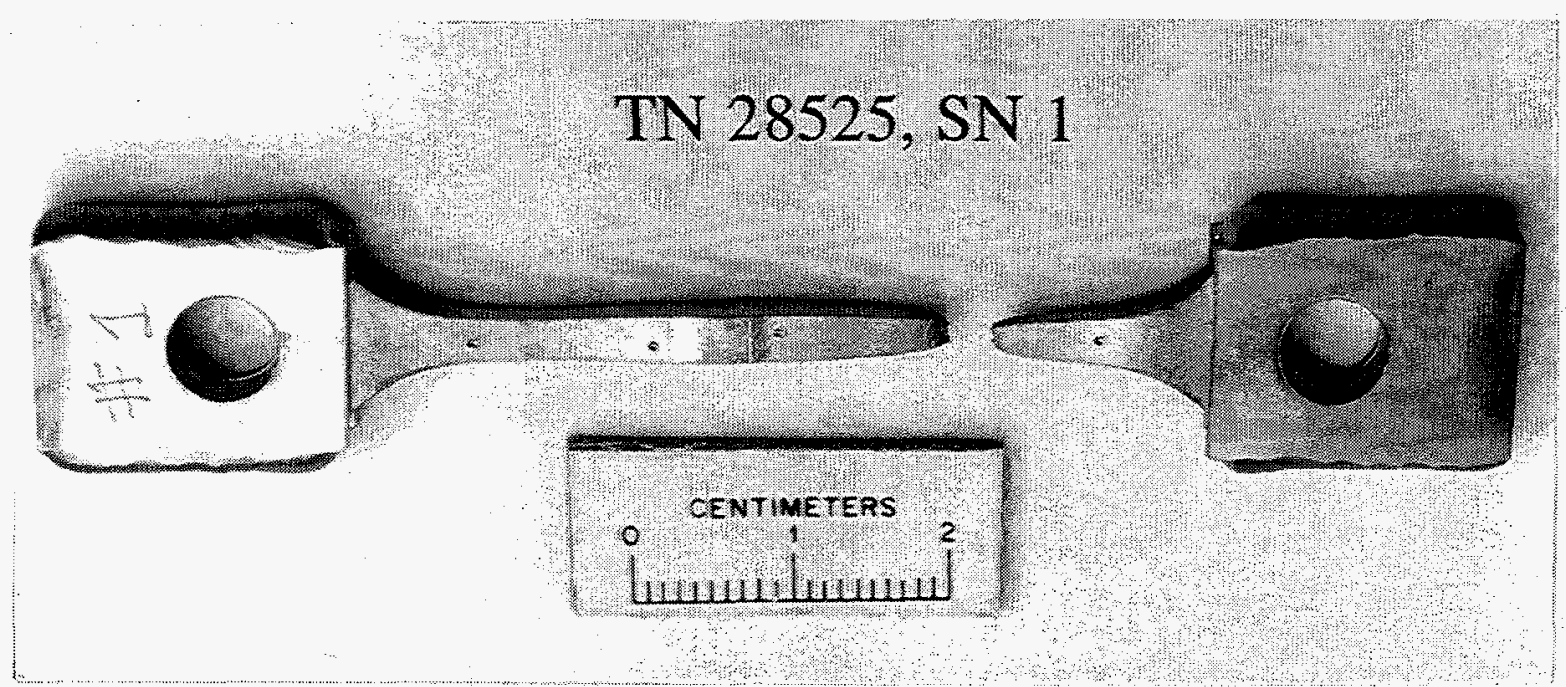

Fig. 14. Photograph of sample 1 from test 28525. The sample failed in the base metal.

The sample is necked down in the base metal on the end opposite from the fracture, and the weld metal in the center crept very little.

HAZ (see Fig. 16) are very important. This is very near the ultimate tensile strength, and a slight amount of vibration during loading may have caused failures. Added precautions were taken to avoid vibrations during loading subsequent tests. After-test photographs are shown in Fig. 17 of several specimens that failed in the weld or HAZ.

Several of the tests were run at more than one stress. In the tests in which the stress was monotonically increased, true creep rates were likely obtained at each stress level, since the time held at each stress was judged sufficient to equilibrate the creep rate at that stress level. Five tests $(28631,28594,28693,28694$, and 28695$)$ were still in progress at the time this report was prepared.

It is useful to compare the data obtained in this study with that from other sources. Three other data sets from two sources were used in the analysis of the rupture data: data at $1016^{\circ} \mathrm{C}$ for $\mathrm{T}-111$ obtained by TRW; $;^{2}$ data at 982,1093 , and $1204^{\circ} \mathrm{C}$ for T-222 obtained by $\mathrm{ORNL},{ }^{3}$ and data at $1204^{\circ} \mathrm{C}$ for $\mathrm{T}-10 \mathrm{~W}$ obtained by $\mathrm{ORNL} .^{3}$ All materials were in the recrystallized or partially recrystallized condition. These results are shown in Fig. 18 in the form of a Larson-Miller plot where:

$P=T / 1000(15+\log \mathrm{tr})$,

$\mathrm{T}$ is the temperature in $\mathrm{K}$,

15 is the Larson-Miller constant, and

tr is the time to rupture in hours. 

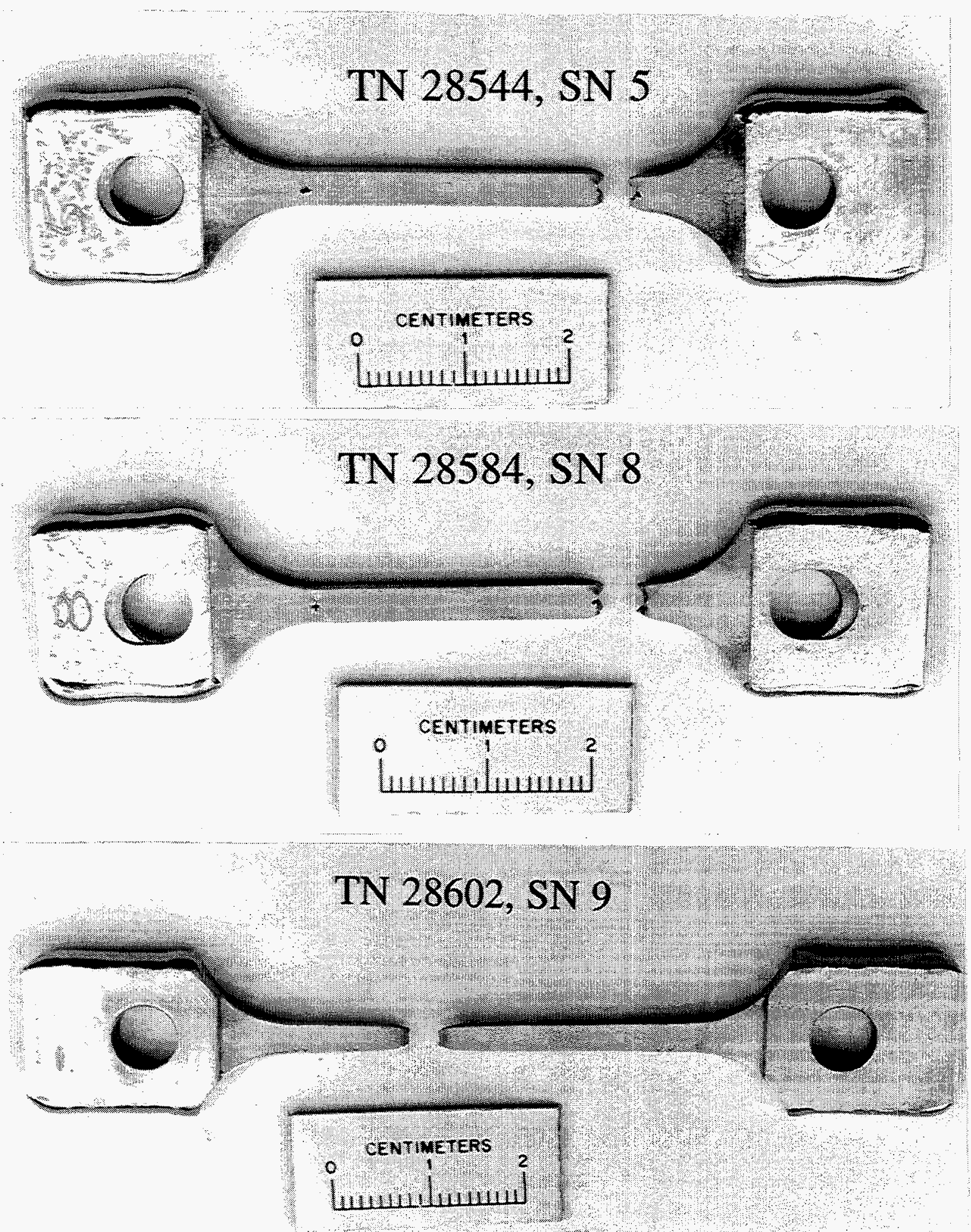

Fig. 15. After-test photographs of the base-metal samples from tests 28544 and 28584 that failed at fiduciary marks, and the sample from test $\mathbf{2 8 6 0 2}$ that did not have fiduciary marks and failed in the gage section. 

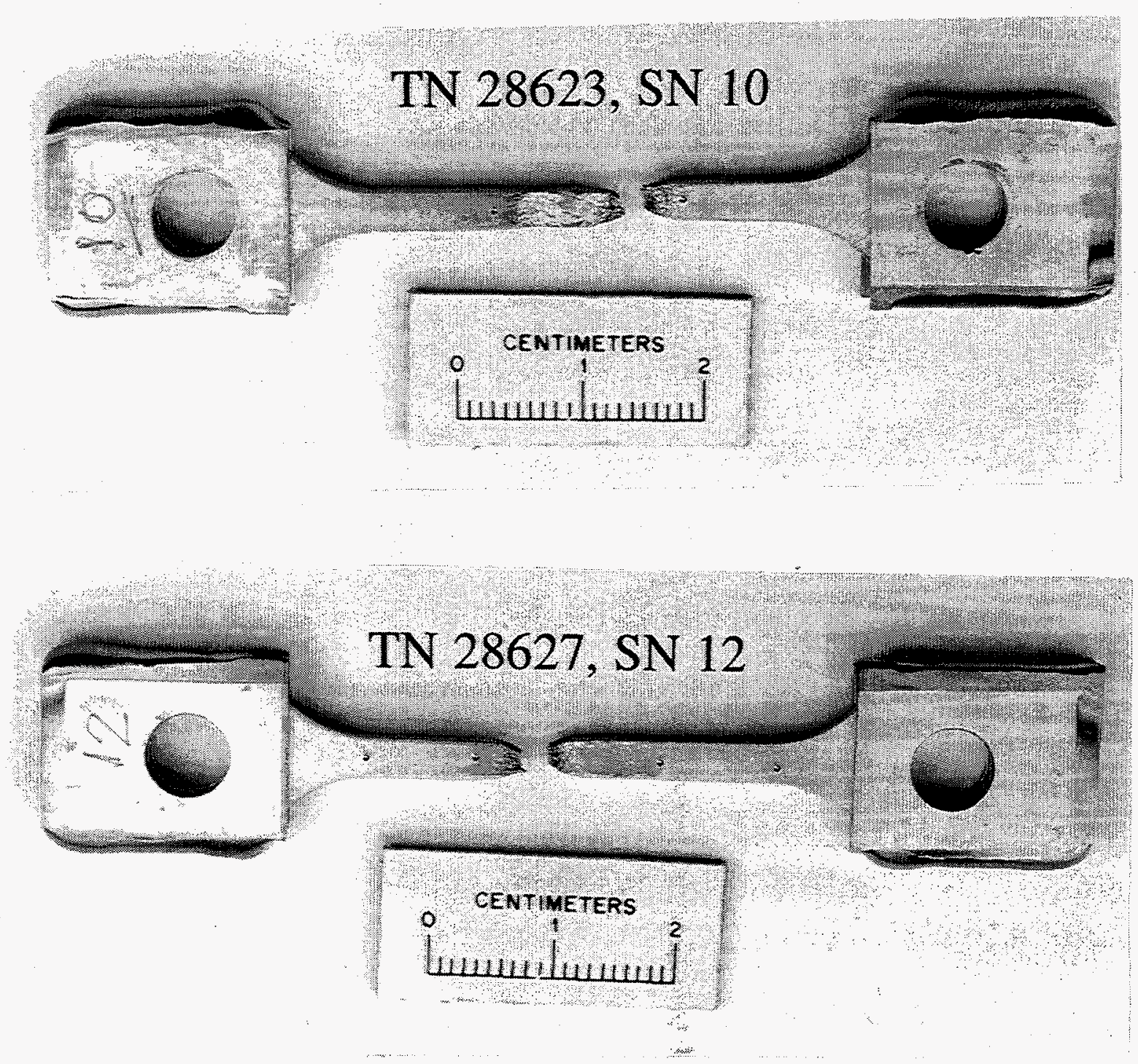

Fig. 16 After-test photographs of transverse weld samples from tests 28623 and 28627 that failed in the heat-affected zone. 

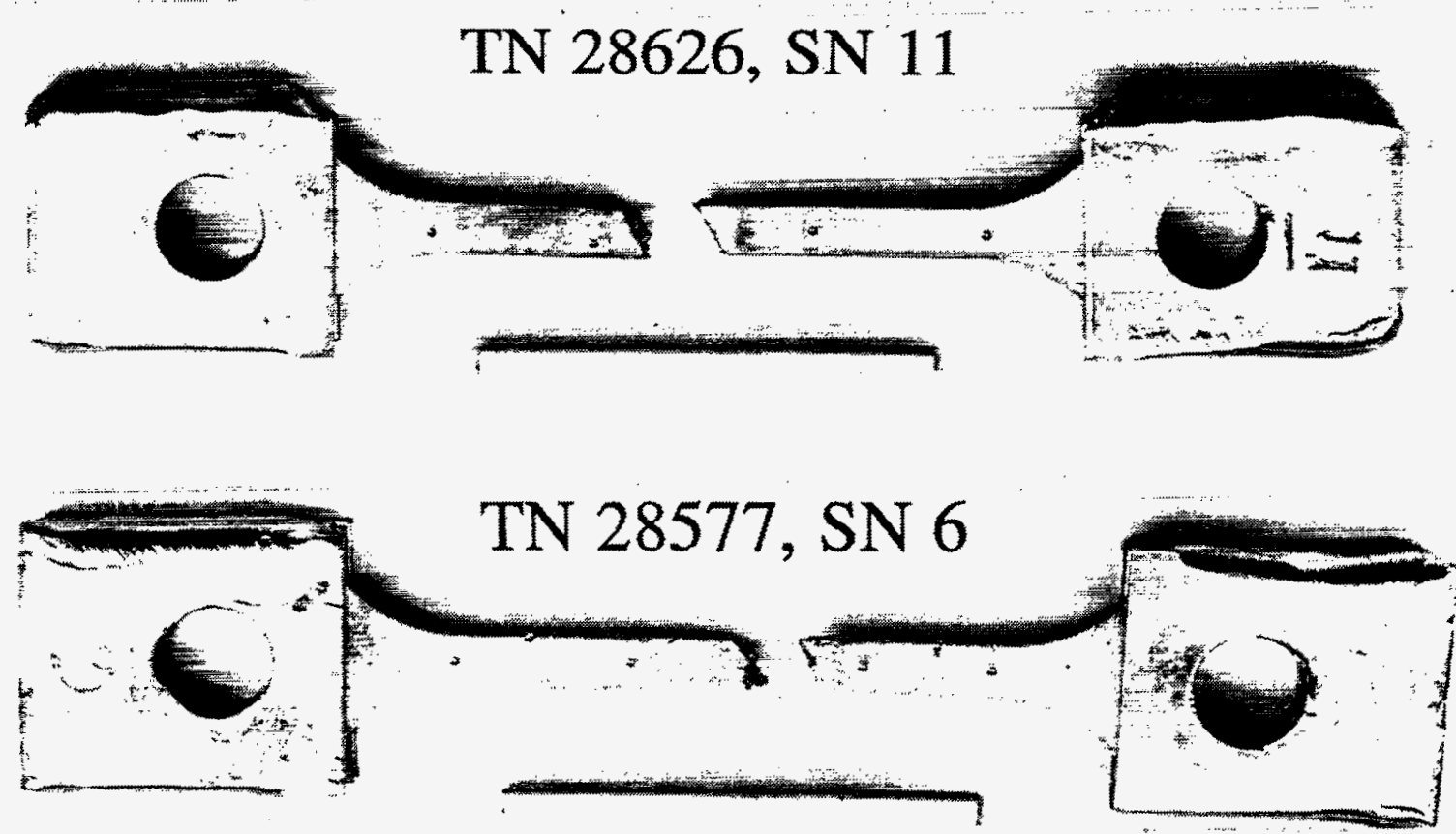

TN 28535, SN 3
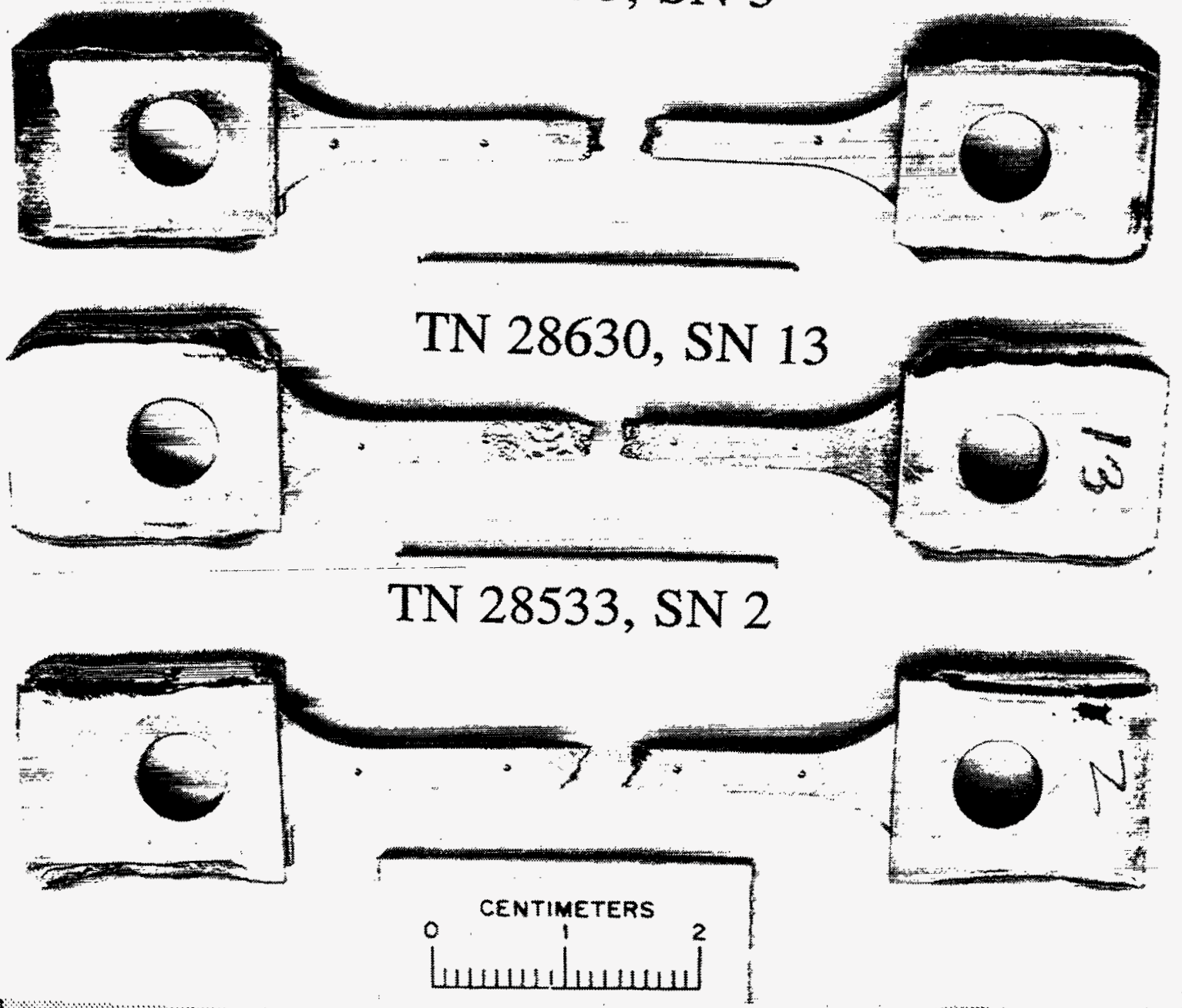

Fig. 17. After-test photographs of transverse welds from several tests that failed in the weld or heat-affected zone. 
The four rupture points from the present study are identified in Fig. 18, and the points from the other sources are randomly distributed in the figure. Based on Fig. 18, the results of the present study appear consistent with those from the other sources. The line of points (for a single heat) at a stress of $350 \mathrm{MPa}$ from the TRW study illustrates the degree of scatter common to this type of analysis.

The various minimum creep rates measured from the tests in Table 4 are summarized in Table 5. Minimum creep rates for the Ta-10\%W and T-222 data from ORNL were given but were estimated for the TRW data using the reciprocal of the time to $1 \%$ creep strain. Figure 19 shows a plot of the time to rupture as a function of the minimum creep rate (Monkman-Grant Correlation, ref. 4) for the same tests shown in Fig. 18. Although the data appear to split into two lines in Fig. 19, a detailed examination of each point revealed that the scatter is random with respect to the data set. The four points from the present work tend to fall on the lower side (shorter rupture time) of the data.

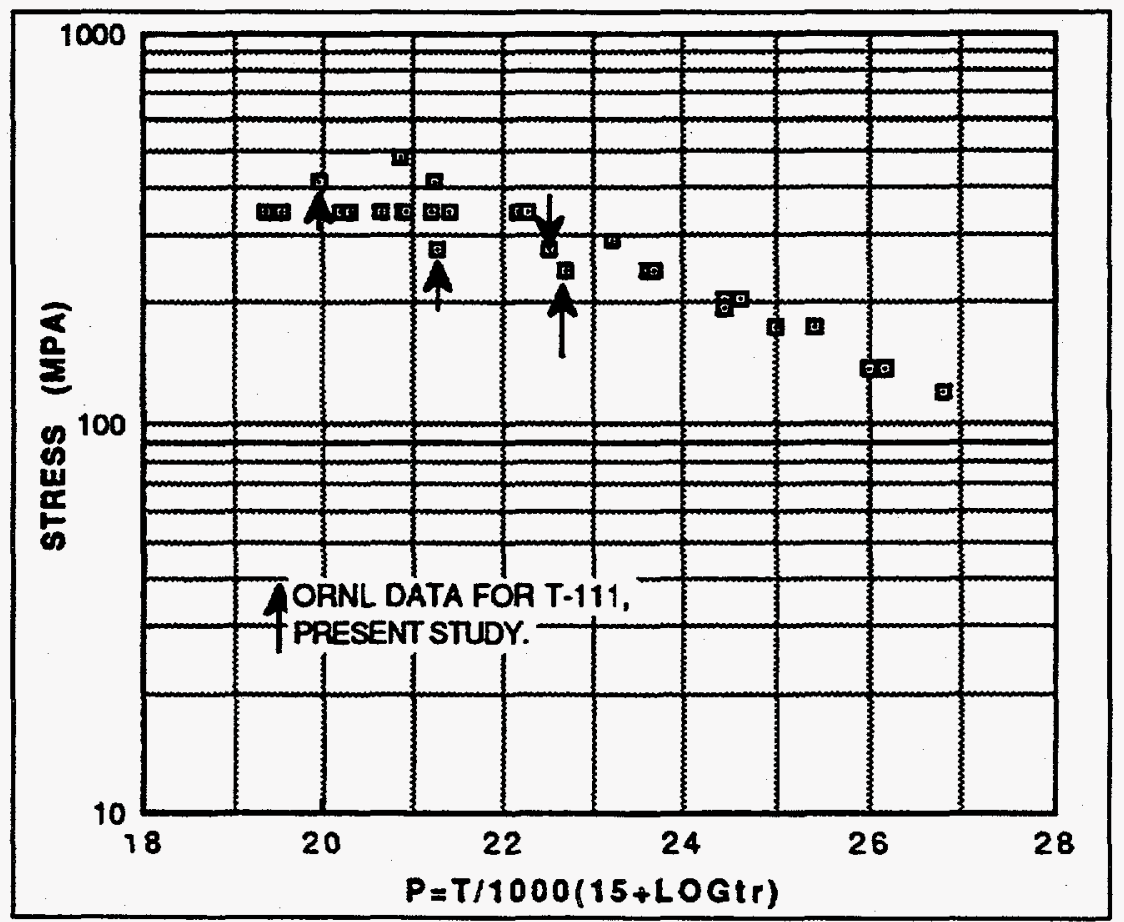

Fig. 18. Larson-Miller plot of selected rupture data for T-111-type alloys. 
Table 5. Summary of ORNL Creep Rate Data for T-111

\begin{tabular}{|c|c|c|c|c|c|c|c|}
\hline Test No & Sample No & Sample & Temperatur & Stress & Stress & Minimum creep & Buphure. \\
\hline & & $a^{2}$ & ${ }^{\circ} \mathrm{C}$ & $\mathrm{MPa}$ & $\mathrm{ksi}$ & $\% / h$ & $\mathrm{~h}$ \\
\hline & & & & & & & \\
\hline 28543 & 4 & $A^{b}$ & 1100 & 172 & 250 & $00035^{*}$ & \\
\hline 28535 & 3 & $c$ & 900 & 414 & 600 & 004 & 101 \\
\hline 28533 & 2 & $c$ & 1000 & 276 & 400 & كم05 & 51 \\
\hline \multirow[t]{3}{*}{28577} & 6 & c & 900 & 345 & 500 & م0006 & \\
\hline & & & & 414 & 600 & م0008 & \\
\hline & & & & 431 & 625 & 00163 & \\
\hline \multirow{4}{*}{28594} & 30 & $c$ & 580 & 379 & 550 & 00002 & \\
\hline & & & & 414 & 600 & 000028 & \\
\hline & & & & 431 & 625 & $000065^{* *}$ & \\
\hline & & & & 448 & 650 & n $0010^{*}$ & \\
\hline \multirow[t]{3}{*}{28600} & 31 & $c$ & 800 & 379 & 550 & 00018 & \\
\hline & & & & 414 & 600 & $000083^{* * * *}$ & \\
\hline & & & & 431 & 625 & $000080^{* * * * * *}$ & \\
\hline 28602 & 9 & $A^{b}$ & 1000 & 276 & 400 & 00039 & 510 \\
\hline 28626 & 11 & $c$ & 1050 & 241 & 350 & $0017^{*}$ & 143 \\
\hline \multirow{3}{*}{28631} & 14 & $c$ & 680 & 379 & 550 & $n 00031^{*}$ & \\
\hline & & & & 414 & 600 & $000072^{*}$ & \\
\hline & & & & 431 & 625 & $000048^{* * * * *}$ & \\
\hline \multirow[t]{4}{*}{28630} & 13 & عـ & 850 & 379 & 550 & $000085^{*}$ & \\
\hline & & & & 414 & 600 & $000090^{*}$ & \\
\hline & & & & 431 & 625 & $0.0005^{*}$ & \\
\hline & & & & 448 & 650 & $00019^{* * *}$ & $380^{* * *}$ \\
\hline \multirow[t]{3}{*}{28632} & 15 & $c$ & 500 & 379 & 550 & not measurable ${ }^{* * *}$ & \\
\hline & & & & 414 & 600 & $00002^{* * * *}$ & \\
\hline & & & & 448 & 650 & $000034^{* * *}$ & \\
\hline \multirow{2}{*}{\multicolumn{8}{|c|}{${ }_{a}^{a}$, current material, hase metal, 0125 in wide; $C$, current material transyerse weld, 0125 in wide }} \\
\hline & & & & & & & \\
\hline \multicolumn{8}{|c|}{${ }^{b}$ Base metal specimen 0125 in wide without fiduciary marks } \\
\hline & & & & & & & \\
\hline \multicolumn{8}{|c|}{ *Added since summary of $11 / 3 / 95$} \\
\hline & & & & & & & \\
\hline \multicolumn{8}{|c|}{${ }^{* *}$ Revised since summary of $11 / 3 / 95$} \\
\hline & & & & & & & \\
\hline \multicolumn{8}{|c|}{ *** Added since summary of $12 / 6 / 95$} \\
\hline & & & & & & & \\
\hline \multicolumn{8}{|c|}{${ }^{* * * *}$ Revised since summary of } \\
\hline & & & & & & & \\
\hline${ }^{* * * * * *}$ & Lsincesumr & & & & & & \\
\hline & & & & & & & \\
\hline
\end{tabular}




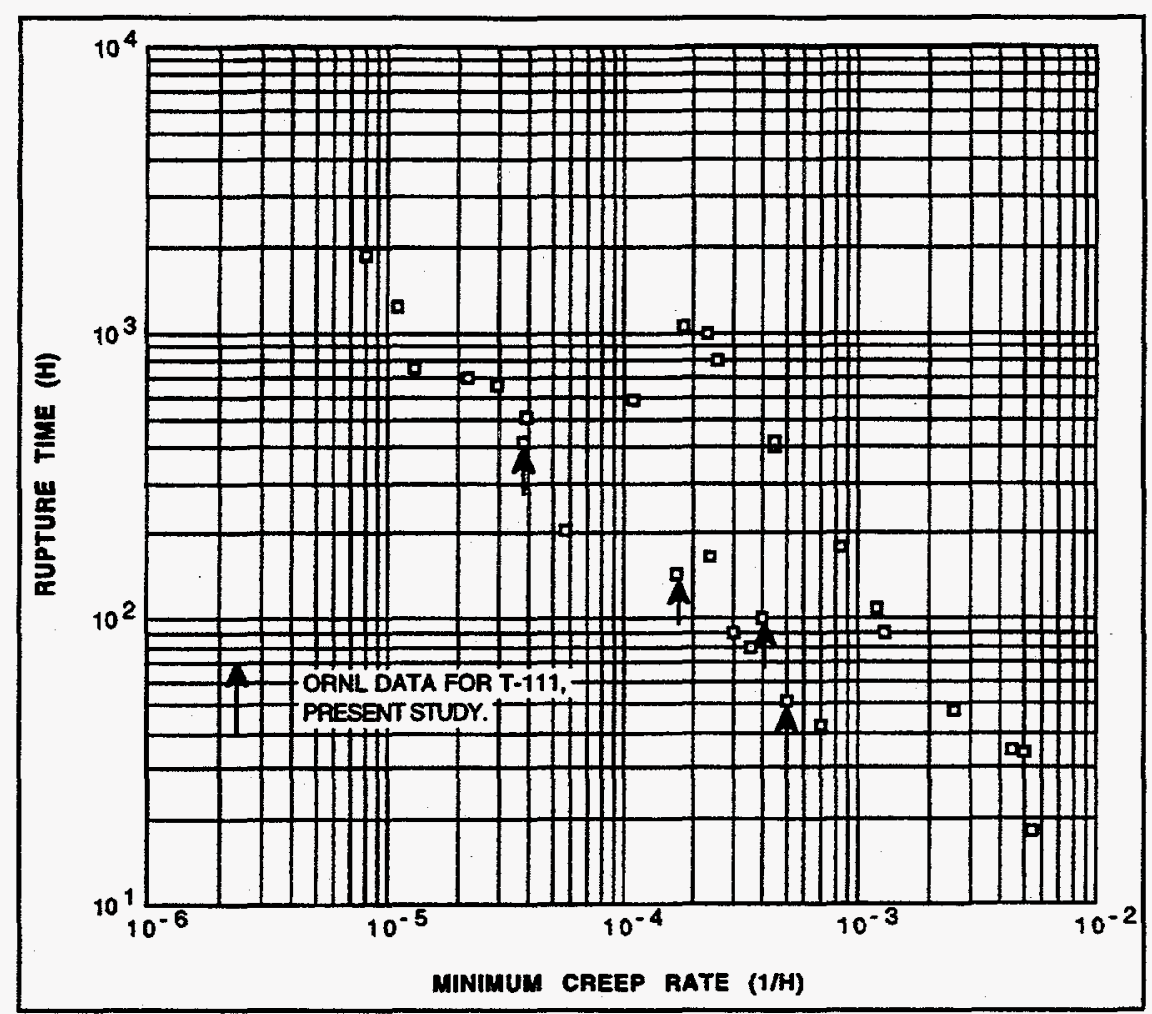

Fig. 19. Monkman-Grant plots for several T-111-type alloys.

A Larson -Miller plot based on the strain rate is shown in Fig. 20. This plot includes the data sets mentioned previously, plus all the present ORNL data given in Table 5 and all the TRW data. $^{2}$ Thus, the present ORNL data are consistent with existing data from other sources and provide a significant source of lower temperature information on T-111.

Data Analysis. In the present IHS application, the predicted stress that would result in failure of $\mathrm{T}-111$ after long times at reasonably low temperatures of 300 to $600^{\circ} \mathrm{C}$ is needed. Toward this goal, a correlation was developed by Teledyne Brown Engineering as shown by the three lines (a center average line with upper and lower bounds of uncertainty) in Fig. 21. ${ }^{5}$ The data from Fig. 19 are plotted in Fig. 21, and the plot bounds have been extended to include the low creep rates and long times of interest. The new data fit the correlation very well.

The Larson-Miller plot based on strain rate is shown again in Fig. 22(a) with some additional information. The data in Fig. 22(a) can be represented by two lines: one on the right side with a slope and a horizontal one with a scatterband on the left. The ultimate tensile strength of T-111 is independent of temperature over the range 300 to $900^{\circ} \mathrm{C}$ (see Figs. 10 and 11 ) and is 
noted along the ordinate of Fig. 22(a) for welds and base metal. The intersection of the horizontal and sloped lines occurs at a Larson-Miller parameter of about 24. At an operating life . of $50,000 \mathrm{~h}$, and a failure strain of $1 \%$, the approximate minimum creep rate would be $2.0 \mathrm{E}-7 / \mathrm{h}$ and the corresponding temperature at the intersection of the two lines in Figure 22(a) can be calculated as $833^{\circ} \mathrm{C}$. These limited data suggest that up to $\sim 850^{\circ} \mathrm{C}(03.5 \mathrm{Tm})$, the mechanical properties of $T-111$ are time-independent and constant. At higher temperatures, creep rate becomes a factor and the allowable stress decreases significantly.

This procedure has involved extrapolation of data based on times and strain rate ranges where we do have data. We do not have 50,000 h rupture life for T-111 (at any temperature) nor do we have creep rate measurements at E-7/h. At present we have five creep tests in progress at low temperature/low stress. The limit of detection of strain in these tests is $0.001 \mathrm{in}$. per sample gage length of $1 \mathrm{in}$; after $2000 \mathrm{~h}$ we have not detected any strain and this implies a creep rate of $<5 \mathrm{E}-7 / \mathrm{h}$.

After this report was completed and edited, an attempt was made to provide more accurate measurements of the creep rate from 580 to $800^{\circ} \mathrm{C}$. The results from this effort are described in Appendix B.

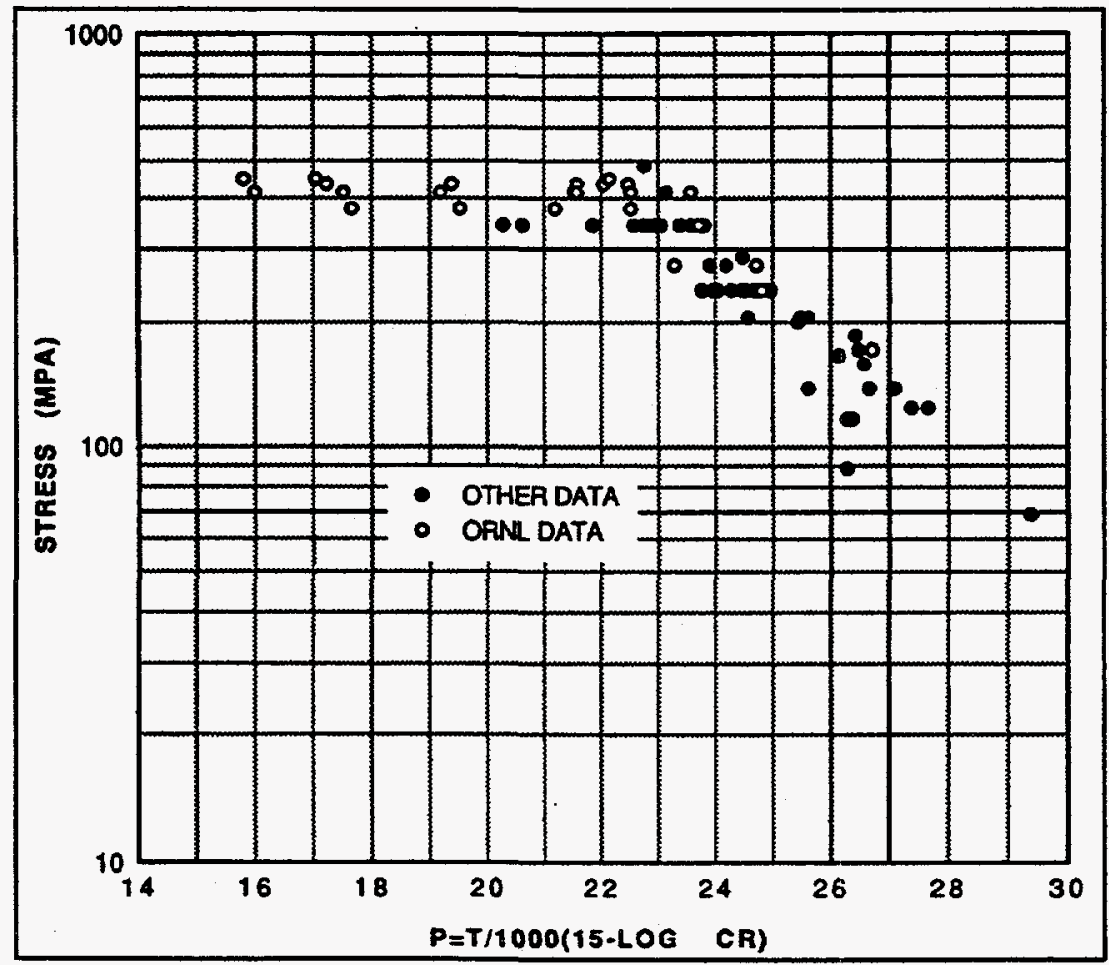
all points.

Fig. 20. Larson-Miller plot based on strain rate including 


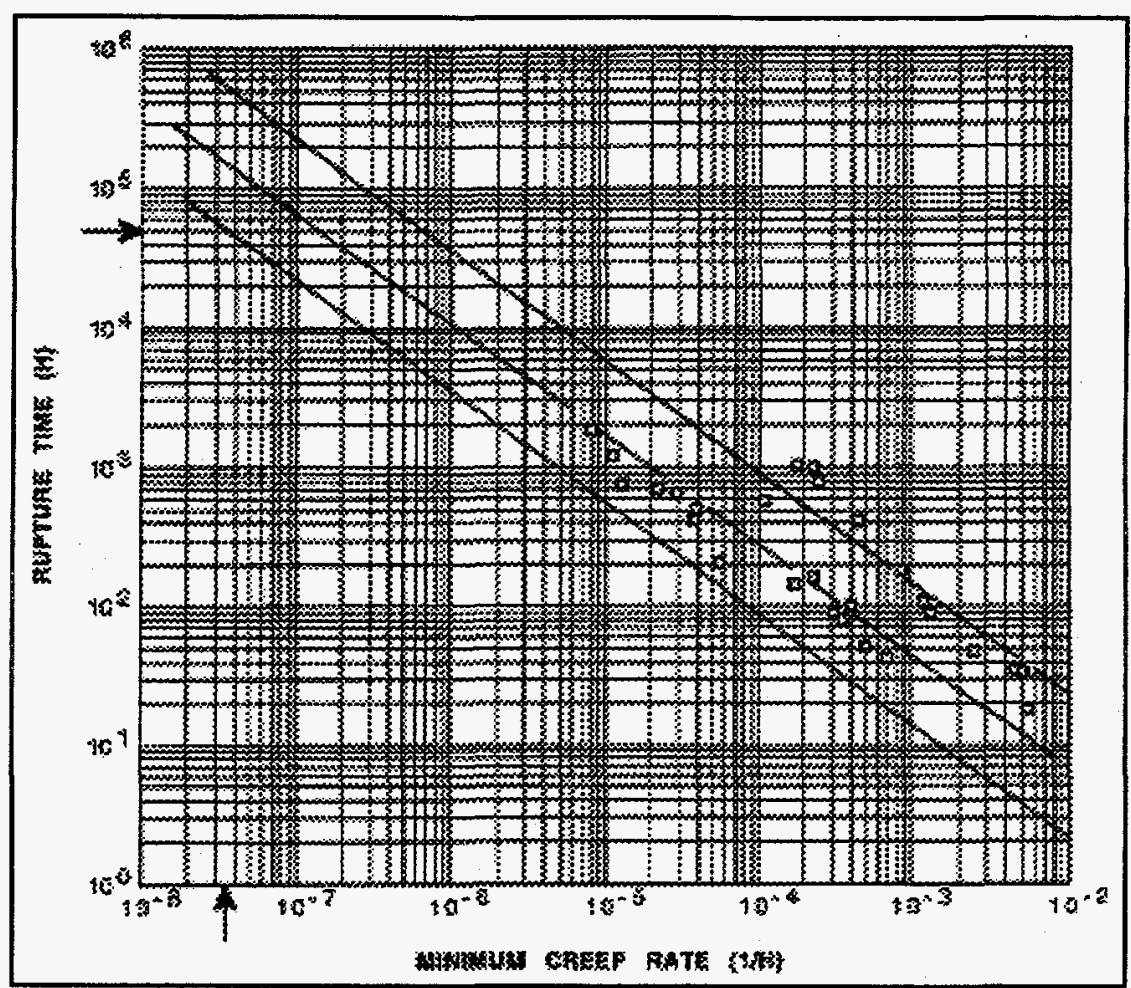

Fig. 21. Monkman-Grant plot for several T-111-type alloys.

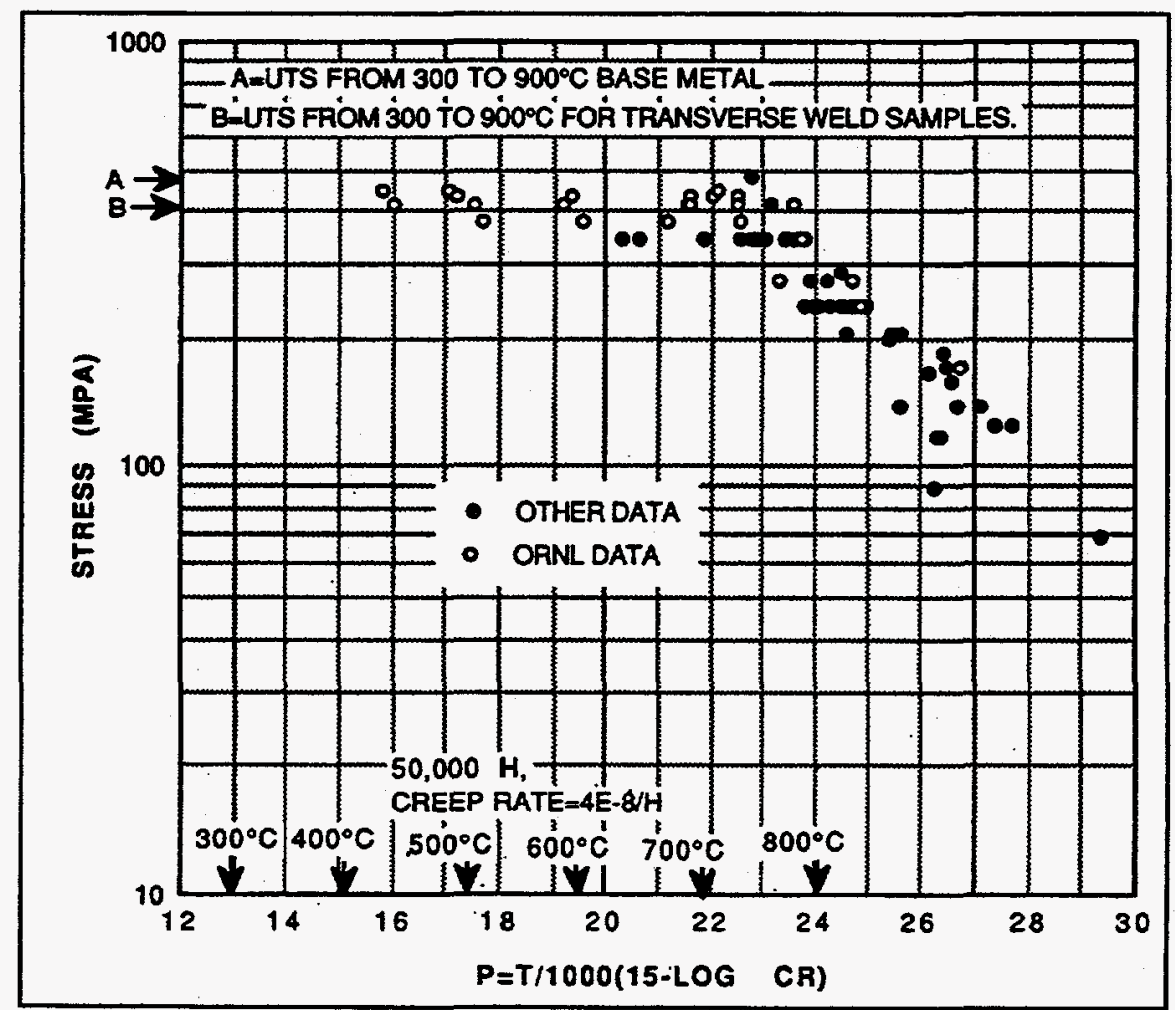
points.

Fig. 22(a). Larson-Miller plot based on strain rate including all 
An alternate method of determining a design stress was used by the ASME Boiler and Pressure Vessel Code in their Code Case N-47. The detailed rules for this method are given in Appendix A of Section III of the ASME Boiler and Pressure Vessel Code. Although we do not have sufficient data for T-111 to apply this method rigorously, there are sufficient data to illustrate the methodology. The approach defines a stress intensity, $\mathrm{S}_{\mathrm{m}}$, as a function of temperature based on time-independent tensile properties. (The Code uses a term called stress intensity or equivalent intensity of combined stresses. It is defined as twice the maximum shear stress on a component and is equal to the largest algebraic difference between any two of the principal stresses obtained by the maximum shear stress theory.) Various creep parameters are used to estimate time-dependent stress intensities, $S_{b}$ as a function of temperature for various service lives. The design stress intensity, $\mathrm{S}_{\mathrm{m} t}$ is the lower of $\mathrm{S}_{\mathrm{m}}$ and $\mathrm{S}_{\mathrm{t}}$. Some of the data for $\mathrm{T}$ 111 was used to develop the design stress intensity plot shown in Fig. 22(b) which is based largely upon the rules of Code Case N-47. The design stress intensity is controlled by the timeindependent tensile properties from 25 to $900^{\circ} \mathrm{C}$ where creep becomes a factor and begins to control the design stress. Below $900^{\circ} \mathrm{C}$, the plot in Fig. 22(b) suggests that $\mathrm{S}_{\mathrm{m}}$ values as obtained from tensile test data determine the allowable stress intensity for $\mathrm{T}-111$. The ratio of $900^{\circ} \mathrm{C}$ to the melting temperature of $2982^{\circ} \mathrm{C}$ (based on homologous temperatures) is 0.36 . This is a very common homologous temperature above which creep has been noted to be significant for numerous other alloys. However, no additional data were used in the Code approach than in the previous analysis, so the results are subject to the same uncertainties, viz., no long-term creeprupture data, particularly at the temperatures of interest for the IHS. 


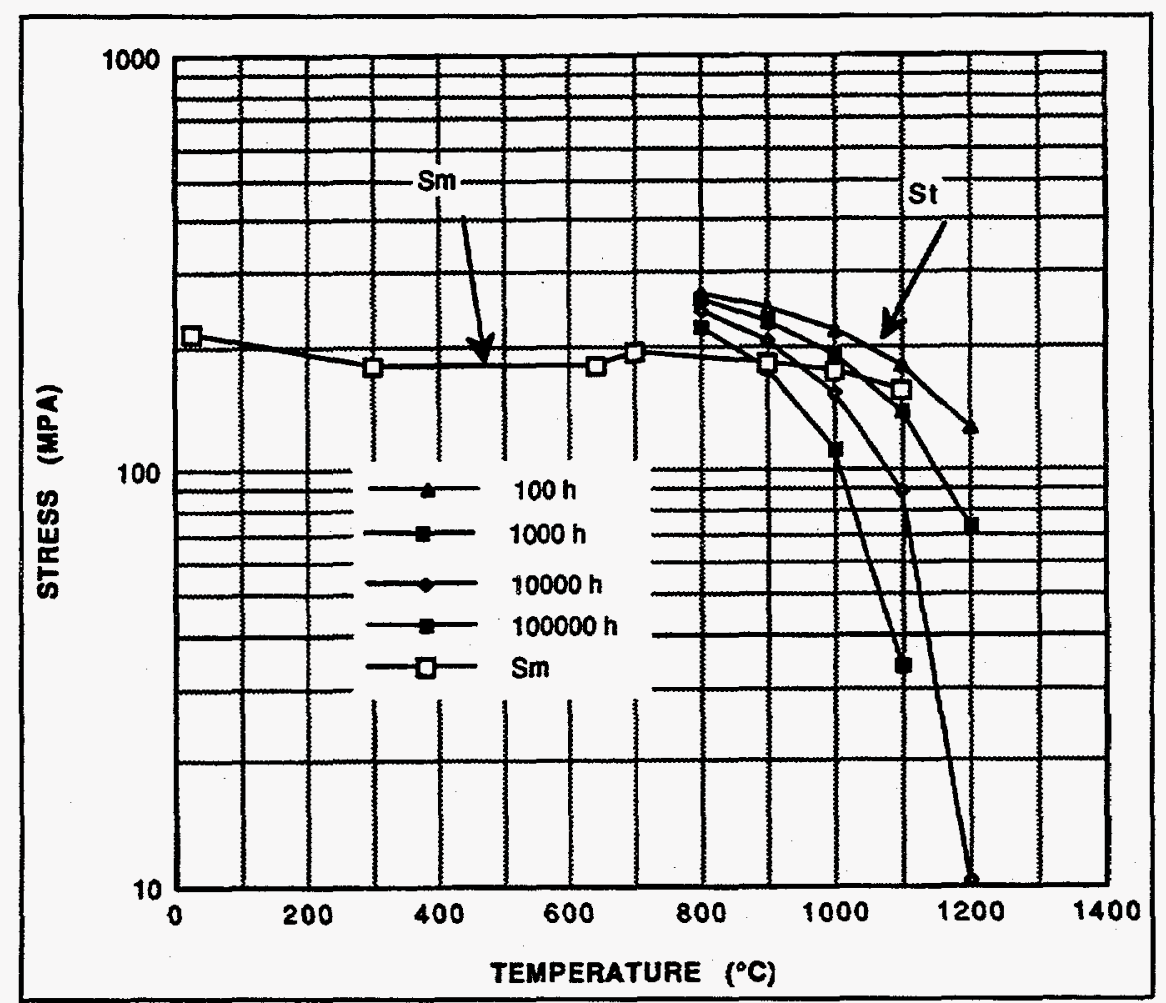

Fig. 22(b). Plot of $S_{m}$ and $S_{t}$ for $T-111$ based on American Society of Mechanical Engineers boiler and pressure vessel approach used for Code Case N-47.

Specimens. Two capsule specimens fabricated by the production process used at Mound were provided to ORNL for pressure testing. A section of the capsule is shown in Fig. 1. Its nominal dimensions are 40 $\mathrm{mm}$ (1.58 in.) diam $\times 63 \mathrm{~mm}(2.49 \mathrm{in}$.) long $\times 2.3 \mathrm{~mm}(0.090 \mathrm{in}$.) thick, with a girth weld made by the GTA welding process. A photograph of the two capsules initially received for testing is shown in Fig. 23. Capsule PB 15 was tested, but capsule PB 17 was returned to Mound for further examination and was replaced by capsule PB 18. The specified test conditions were that capsule PB 18 be pressurized to 19.72 $\mathrm{Mpa}(2860 \mathrm{psi})$ at $1171^{\circ} \mathrm{C}$ and that capsule $\mathrm{PB} 15$ be pressurized to $43.78 \mathrm{MPa}(6350 \mathrm{psi})$ at $900^{\circ} \mathrm{C}$.

Capsules PB 15, 17, and 18 were helium leak tested without the compression fitting, and each was found to have a leak rate of $<2.9 \mathrm{E}-8$ standard $\mathrm{cc}$ helium per second (lowest standard leak available). 
Procedure. The test system is shown schematically in Fig. 24. The pressure source was a Heiskel air-driven pump, and the pressurized gas used to pressure the capsule was either helium or argon. Prior to pressurization, the capsule was placed inside an ion-pumped creep machine that had a tungsten mesh heating element with an inside diameter of $63.5 \mathrm{~mm}$ (2.5 in.). The gas line to the inside of the capsule was equipped with a pressure transducer and valves as shown in Fig. 24. This orientation allowed the pressure to the specimen to be continually monitored by the pressure transducer. After the desired test pressure was established in the capsule, the pressure source was isolated from the line to the capsule by two valves. These valves were opened again only to repressurize the capsule. The normal operating mode of the capsule was for it to be isolated from the pressure source by two valves and for the pressure in the capsule to be continually monitored by the pressure transducer. The vacuum system had a residual gas analyzer (RGA), which served as one means of detecting failure of the capsule by a rise in the concentration of gas (helium or argon) used to pressure the capsule. Besides the RGA, failure could also be detected by a decrease in the pressure in the capsule or by an increase in the vacuum pressure inside the test chamber.

One change was made in the as-received condition of the capsules shown in Fig. 23. Originally, the capsules had a short segment of Ta-10\%W tubing leading to a stainless steel compression fitting. In similar tests at Mound, stainless steel line was run from the compression fitting to the pressure source. Since the compression fitting would be heated in our system to about 300 to $500^{\circ} \mathrm{C}$, the difference in thermal expansion between stainless steel and Ta- $10 \% \mathrm{~W}$ would likely cause leakage of the high-pressure gas to the vacuum inside the chamber (giving a false indication that the capsule had failed). Therefore, the Ta- $10 \% \mathrm{~W}$ tubing was cut near the stainless steel fitting, and approximately $305 \mathrm{~mm}$ (12 in.) of T-111 tubing was welded to the Ta- $10 \% \mathrm{~W}$ tubing. The weld was made by the GTA process in a glove box, and tantalum filler 


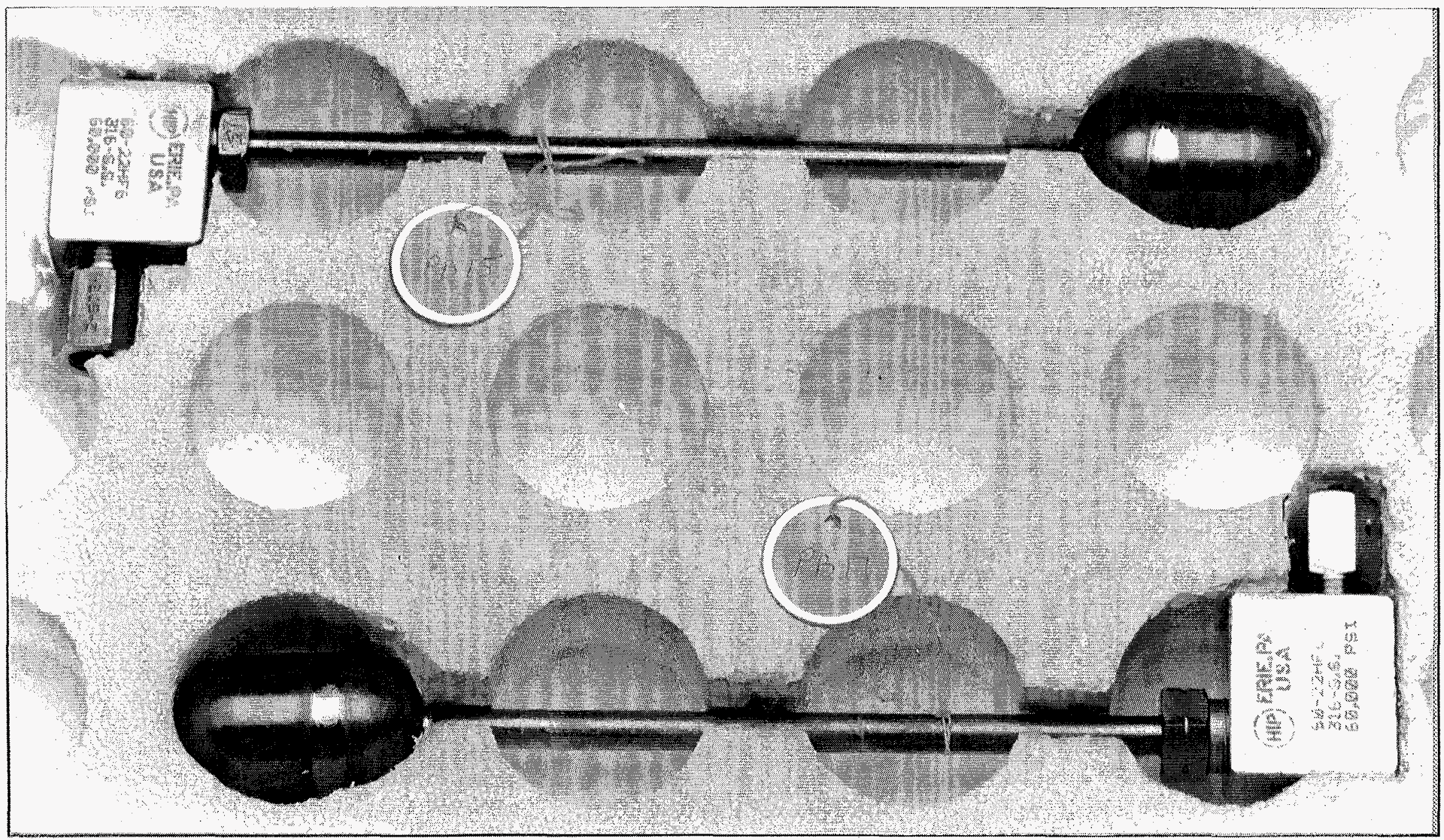

Fig. 23. Photograph of the two capsules received from EG\&G Mound Applied Technologies for testing. For scaling purposes, the capsules are approximately $400 \mathrm{~mm}(1.6 \mathrm{in}$.) in diameter $\times 64 \mathrm{~mm}(2.5 \mathrm{in}$.) long. Each capsule has an extension tube of a tantalum-based alloy and a stainless steel compression fitting to make the transition to a stainless steel pressurization tube. The background material is Styrofoam. 


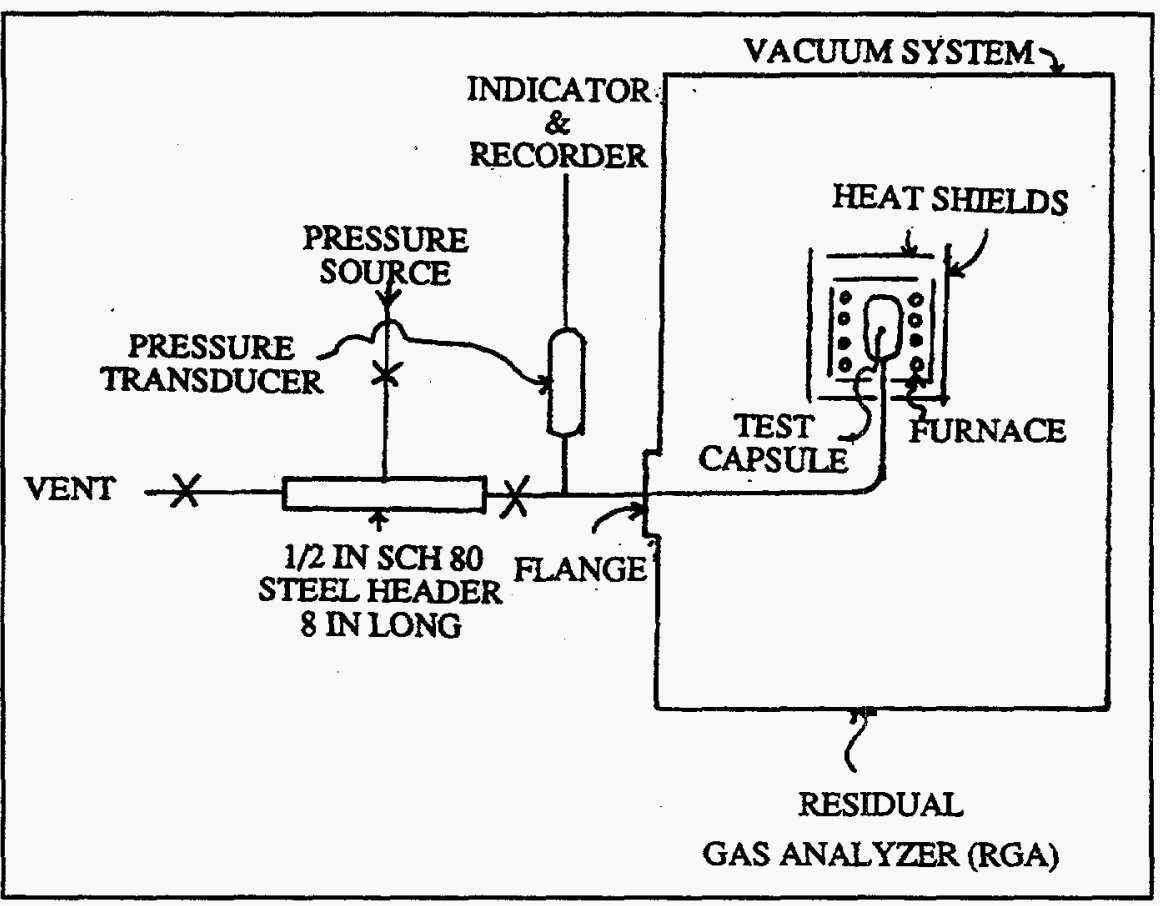

Fig. 24. Sketch of test set-up.

added manually to reinforce the weld. The total length of Ta-10\%W/T-111 tubing was then sufficient to reach the water-cooled flange where the pressure line exited the vacuum chamber. At this location the temperature was low enough to confidently use a stainless steel compression fitting to attach the capsule to the pressure source.

Capsule 18. The desired test conditions were $19.72 \mathrm{MPa}(2860 \mathrm{psi})$ at $1171^{\circ} \mathrm{C}$. Pretest examination of the capsule at a magnification of $15 \times$ revealed several suspicious features in the girth weld and in the capsule/ $/ \mathrm{Ta}-10 \% \mathrm{~W}$ tube weld. However, the capsule had a leak rate of $<2.9 \mathrm{E}-8$ standard cc helium per second, and preparations to test the capsule continued. Several dimensional measurements were made. The capsule was cleaned with ethanol, air dried, and handled thereafter with white gloves. Four thermocouples were attached, and the capsule was assembled into the furnace of the vacuum creep chamber. The capsule was pressurized to the desired test pressure while at $25^{\circ} \mathrm{C}$ and held $16 \mathrm{~h}$ without any detectable change in pressure. The capsule pressure was then reduced to $1.38 \mathrm{MPa}$ ( $200 \mathrm{psi})$, the system closed, and the chamber baked and ion-pumped to 1E-7 torr. The capsule was heated to the test temperature over a 24-h period and then pressurized to $19.72 \mathrm{MPa}(2860 \mathrm{psi})$. After pressurization of the capsule, the high-pressure pump valve to the capsule was closed, and pressure on the pump side of the valve was reduced.

The capsule was pressurized with helium. The procedure to minimize impurities in the pressurization gas was to use pure helium and to flush the system (including the capsule) to remove any 
residual air. The capsule pressure was generally kept within $0.5 \%$ of $19.71 \mathrm{MPa}(2860 \mathrm{psi})$, but the highpressure pump failed at $188 \mathrm{~h}$ and the pressure was lower than desired for about $40 \mathrm{~h}$. However, three increases in internal pressure were also required to maintain pressure within $0.5 \%$ prior to the pump failure: $+19 \mathrm{psi}$ at $46 \mathrm{~h},+10 \mathrm{psi}$ at $97 \mathrm{~h}$, and $+30 \mathrm{psi}$ at $142 \mathrm{~h}$. The system vacuum level and the capsule pressure are summarized for the history of the test of capsule 18 in Table 6 . The capsule failed at $342 \mathrm{~h}$, including the time at the lower pressure.

Test data were recorded manually about every $4 \mathrm{~h}$ by operators and continuously by a recorder. The trace from the recorder near the time of failure is shown in Fig. 25. The sequence of events at failure was: (1) the pressure in the vacuum chamber increased until (2) the furnace power was turned off, and (3) the capsule pressure began to decrease. The scale for the system vacuum runs from 0 to 10 . The vacuum in torr is obtained by: (1) reading the value indicated by the line, (2) subtracting the lowest whole number from 11 to obtain the order of magnitude, and (3) determining the anti-log of the chart value that is $<1$. This anti-log value is the first portion of the pressure.

The chart scale for the capsule pressure is approximately $0.689 \mathrm{MPa}(100 \mathrm{psig})$ per division. Hence the initial small changes in the capsule pressure were not detectable. Only after the heater power was turned off did the capsule pressure change detectably (due to cooling). After failure, the capsule was repressurized after it had cooled, and the pressure was noted to decay at the rate of $0.077 \mathrm{~Pa} / \mathrm{s}$ ( 1 psig per $1.5 \mathrm{~min}$ ).

After removal from the test chamber, examination under a microscope revealed that the failure consisted of a network of cracks at the "stop" puddle in the girth weld. The diametral strain at the failure location was $1.5 \%$. The leak behavior of the failed capsule was examined with a helium leak detector, and the leak rate was noted to be greater than the largest standard leak of $1 E-4$ standard cc helium per second. The use of very small probes made it possible to isolate the leak to the same area where cracks were noted microscopically. Further evaluations were made of capsule 18 as described later.

Capsule 15. Capsule 15 was previously pressure tested by Mound for approximately $1000 \mathrm{~h}$ at $900^{\circ} \mathrm{C}$. During the test period, the pressure varied from $43.85 \mathrm{MPa}(6360 \mathrm{psi})$ to $31.92 \mathrm{MPa}$ (4630 psi). The pressure during the first $880 \mathrm{~h}$ of testing is shown in Fig. 26, and it appears that the pressure in the capsule decreases during the entire time of exposure. ${ }^{6}$

The testing procedure for capsule 15 was generally the same as that described above for capsule 18 . The desired test conditions for capsule 18 were $43.78 \mathrm{MPa}(6350 \mathrm{psi})$ and $900^{\circ} \mathrm{C}$. The capsule was placed in the test chamber, and the sequence of rough pumping, bake-out, and ion pumping followed. The residual gas 
Table 6. Vacuum and pressure data for capsule 18

\begin{tabular}{|c|c|c|c|}
\hline Time & Capsule pressure & System pressure & Comments \\
\hline & nsi & torr & \\
\hline & & & \\
\hline 0 & 2856 & $8.00 \mathrm{E}-07$ & \\
\hline 25 & 2860 & $690 \mathrm{E}-07$ & \\
\hline 53 & 2862 & $4.20 \mathrm{E}-07$ & \\
\hline 80 & 2865 & $3.80 \mathrm{E}-07$ & \\
\hline 120 & 2867 & $370 \mathrm{E}-07$ & \\
\hline 149 & 2868 & $3.60 \mathrm{E}-07$ & \\
\hline 188 & 2857 & $3.60 \mathrm{E}-07$ & Pump failure \\
\hline 191 & 2826 & $3.70 \mathrm{E}=07$ & \\
\hline 193 & 2755 & $3.70 \mathrm{E}-07$ & \\
\hline 197 & 2644 & $370 \mathrm{E}-07$ & \\
\hline 201 & 2559 & $3.70 \mathrm{E}-07$ & . \\
\hline 204 & 2522 & $3,70 \mathrm{E}-07$ & \\
\hline 200 & 2459 & $370 \mathrm{E}-07$ & \\
\hline 213 & 2426 & $370 \mathrm{E}-07$ & \\
\hline 215 & 2414 & $370 \mathrm{E}-07$ & \\
\hline 219 & 2386 & $3.70 \mathrm{E}-07$ & \\
\hline 220 & 2800 & $3.70 E-07$ & Pump repaired \\
\hline 225 & 2800 & $3.70 E-07$ & \\
\hline 230 & 2800 & $3.70 \mathrm{E}-07$ & \\
\hline 236 & 2800 & $370 \mathrm{E}=07$ & \\
\hline 237 & 2865 & $3.70 \mathrm{E}=07$ & \\
\hline 240 & 2867 & $3,70 \mathrm{E}-07$ & \\
\hline 244 & 2867 & $3.70 \mathrm{E}-07$ & \\
\hline 265 & 2862 & $3.70 \mathrm{E}-07$ & \\
\hline 296 & 2855 & $3.70 \mathrm{E}-07$ & \\
\hline 315 & 2871 & $3.70 \mathrm{E}-07$ & \\
\hline 331 & 2865 & $3.70 \mathrm{E}-07$ & \\
\hline 337 & 2864 & $3.70 \mathrm{E}-07$ & \\
\hline 340 & 2864 & $3.70 \mathrm{E}-07$ & \\
\hline 341 & 2864 & $3.70 \mathrm{E}=07$ & \\
\hline 342 & 2860 & $5.00 \mathrm{E}-07$ & Failure \\
\hline 343 & 2860 & $140-\mathrm{E} 06$ & Heat off \\
\hline 344 & 2620 & $100 \mathrm{E}-03$ & Pumpsoff \\
\hline \multirow[t]{2}{*}{355} & 2862 & $320 \mathrm{E}-04$ & System cold leak \\
\hline & & & cate $=10$ psi/l $5 \mathrm{mi}$ \\
\hline
\end{tabular}




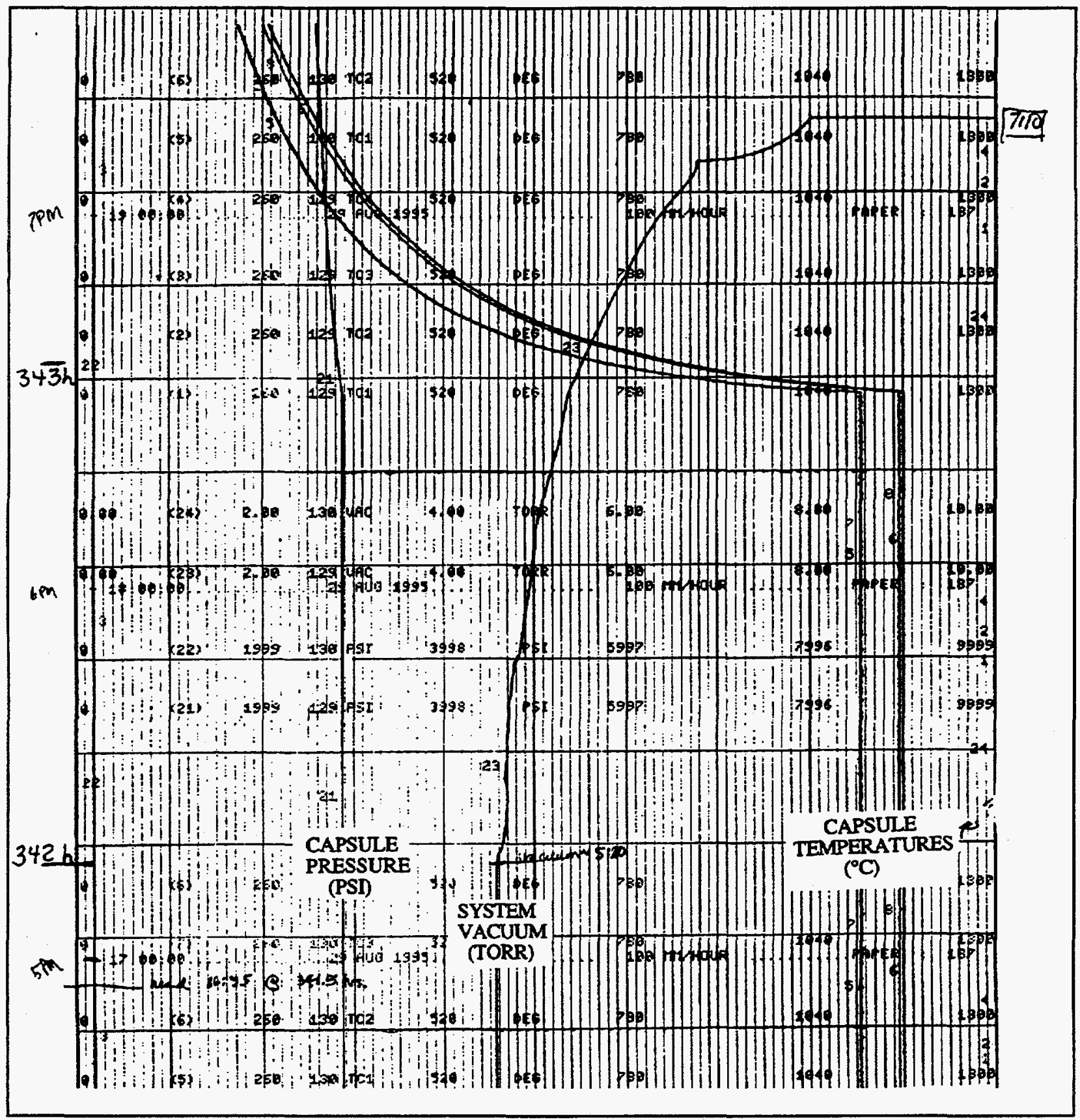

Fig. 25. Section of recorder chart showing failure of capsule 18. 


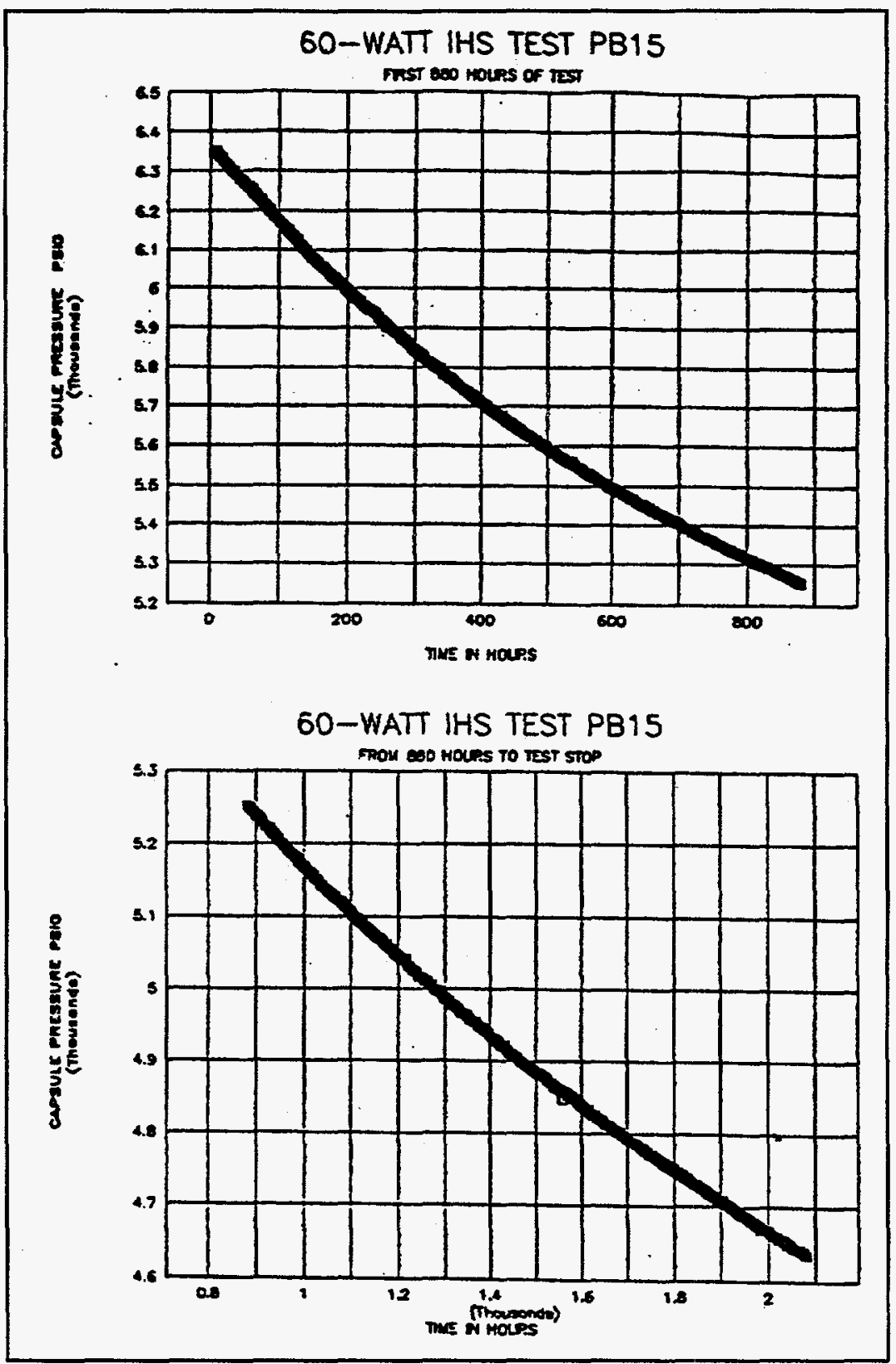

Fig. 26. The pressure history of capsule 15 while in test at Mound. These data were taken in pounds per square inch (psi) units. Multiply psi times 0.006894 to convert to $\mathrm{MPa}$.

in the chamber after failure of capsule PB-18 was largely helium; therefore, the pressurizing gas was changed to argon to obtain better sensitivity for detecting a leak. After pressurizing the capsule and closing the high-pressure valve to the pump, the pressure on the pump side was not reduced as had been done with capsule 18 previously. 
Some of the vacuum/pressure history of the ORNL test on capsule 15 is given in Table 7. The vacuum was marginal at the beginning of the test and worsened with time. The system was shut down after $191 \mathrm{~h}$ of operation, and numerous modifications were made over the next 2 months in an effort to improve the vacuum. These changes included the installation of a turbomolecular pump on a spare flange and the reworking of seals around the furnace electrodes. The vacuum improved and the test was restarted. The system ran without further problems, and the capsule failed after $1683 \mathrm{~h}$. During the test period, only two minor increases in pressure were required to maintain the capsule pressure, which indicates that the decrease in capsule pressure in the previous test probably was caused by leakage of the high-pressure valve when a large differential pressure across the valve was maintained. Numerous parameters were recorded, but the chart was too light to reproduce for this report. Failure was indicated by an increase in the vacuum system pressure and a decrease in the internal capsule pressure. However, in this test these changes were not large enough to turn off the system heaters automatically, and this was done manually.

The capsule was removed from the vacuum system and examined under a microscope. Cracks were noted at a discontinuity in the girth weld. The girth weld in this sample was not very uniform, and the finish point of the weld was not obvious. The capsule was leak tested and found to have a leak rate in excess of the largest standard leak of $1 \mathrm{E}-4$ standard $\mathrm{cc}$ helium per second. The leak was isolated to the same region where the cracks were noted.

Helium Leak Rate of Failed Capsules. To facilitate calculated predictions of the hole size in the failed capsules, each capsule was pressurized at room temperature to the test pressure and the pressure recorded as a function of time. These tests were run in the same equipment used to run the capsule tests, but the chamber was not evacuated. The volume of each system was also measured, and these varied significantly because capsule 15 had a tantalum plug inside the capsule while capsule 18 was empty. The results of these tests are given in Figs. 27 and 28 for capsules 18 and 15 , respectively. 
Table 7. Vacuum and pressure data for capsule 15

\begin{tabular}{|c|c|c|c|}
\hline Time & Capsule pressure & System pressure & Comments \\
\hline $\mathrm{h}$ & psi & torr & \\
\hline 0 & 6368 & $3.70 \mathrm{E}-06$ & \\
\hline 14 & 6363 & $2.10 \mathrm{E}-06$ & \\
\hline 74 & 6355 & $6.80 \mathrm{E}-07$ & \\
\hline 129 & 6347 & $6.30 \mathrm{E}-07$ & \\
\hline 163 & 6355 & $5.60 \mathrm{E}-07$ & \\
\hline 188 & 6363 & $3.70 \mathrm{E}-06$ & \\
\hline 191 & 6375 & $5.60 \mathrm{E}-06$ & \\
\hline $191-221$ & 6350 & $5.00 \mathrm{E}-07$ & $a$ \\
\hline 224 & 6363 & $2.90 \mathrm{E}-07$ & \\
\hline 242 & 6360 & $3.20 \mathrm{E}-08$ & \\
\hline 314 & 6364 & $2.20 \mathrm{E}-08$ & \\
\hline 353 & 6368 & $4.70 \mathrm{E}-08$ & \\
\hline 391 & 6365 & $2.40 \mathrm{E}-08$ & \\
\hline 467 & 6363 & 2.10E-08 & \\
\hline 602 & 6360 & $2.00 \mathrm{E}-08$ & \\
\hline 700 & 6357 & $2.00 \mathrm{E}-08$ & \\
\hline 842 & 6354 & $1.90 \mathrm{E}-08$ & \\
\hline 971 & 6358 & $2.70 \mathrm{E}-08$ & \\
\hline 1115 & 6364 & $2.20 \mathrm{E}-08$ & \\
\hline 1235 & 6362 & $2.00 \mathrm{E}-08$ & \\
\hline 1364 & 6350 & $2.00 \mathrm{E}-08$ & \\
\hline 1483 & 6348 & $2.00 \mathrm{E}-08$ & \\
\hline 1626 & 6347 & $2.00 \mathrm{E}-08$ & \\
\hline 1675 & 6368 & $1.90 \mathrm{E}-08$ & \\
\hline 1682 & 6311 & $1.80 \mathrm{E}-04$ & \\
\hline 1683 & 6033 & $1.60 \mathrm{E}-03$ & Furnace off \\
\hline
\end{tabular}




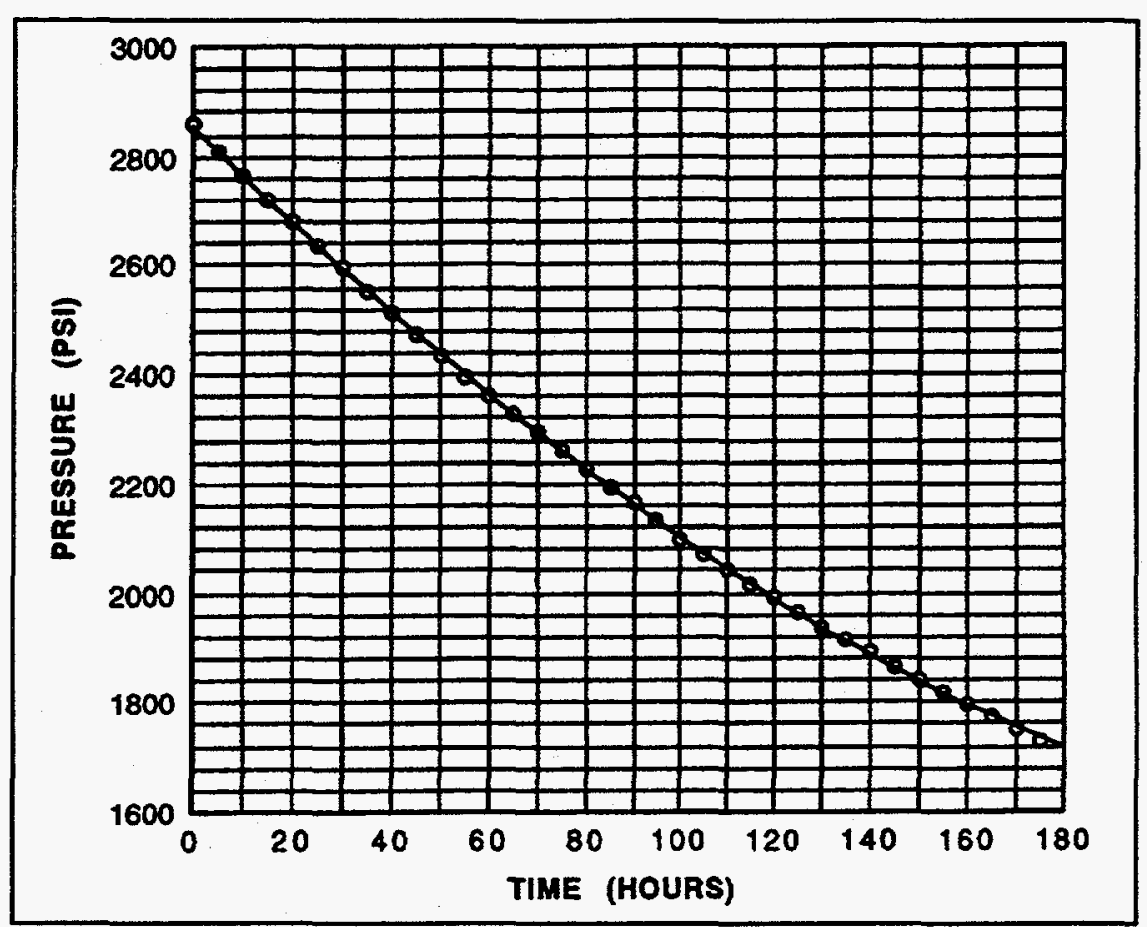

Fig. 27. Pressure reduction in failed capsule 18. Measured at $25^{\circ} \mathrm{C}$, using argon in a system with volume of $59 \mathrm{cc}$.

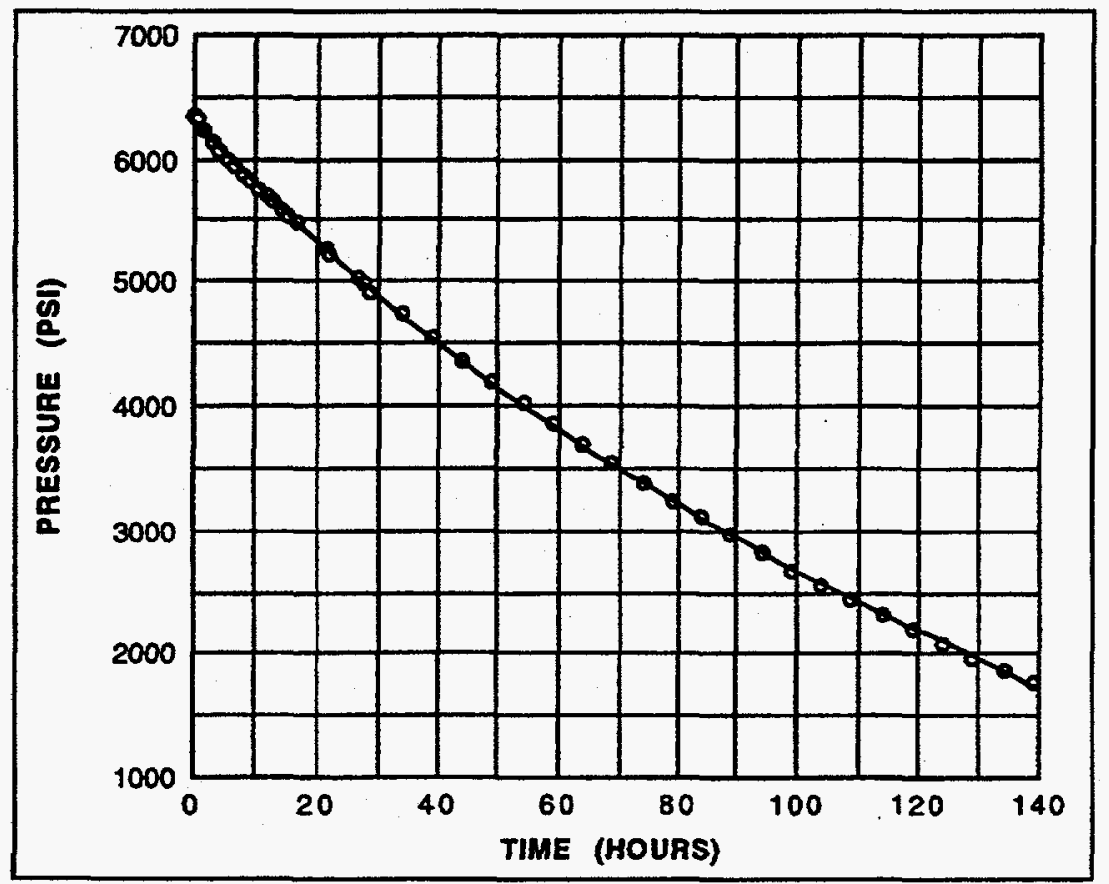

Fig. 28. Pressure reduction in failed capsule 15. Measured at $25^{\circ} \mathrm{C}$, using argon in a system with volume of $59 \mathrm{cc}$. 
Size of Failure. In order to evaluate the potential for fuel particles escaping from the T-111 capsule when failure occurs, the leak rate of each capsule was related to the size of a single through-wall crack using the equation:

$$
\frac{\Delta P}{\Delta t}=\frac{P a v}{V_{\text {system }}}\left[\frac{67 d c^{4}(P a v)}{l c}+\frac{325 d c^{3}}{l c}\right],
$$

where $P=$ system pressure in mbars,

$P_{a v}=$ average system pressure in mbars,

$t=$ time ins seconds,

$\mathrm{V}=$ volume of system in liters,

$\mathrm{dc}=$ diameter of crack in centimeters, and

$l c=$ length of crack in centimeters (taken as equal to the wall thickness of the capsule).

The room-temperature leak rates of capsules PB 18 and PB 15 are shown in Figs. 27 and 28, respectively. Experimentally, the pressure was measured in psi and the time in hours, as shown by the plots. In mbar-sec ${ }^{-1}$, the leak rate for PB 18 was 0.161 , and for PB 15 it was 0.47 . The crack diameters corresponding to these leak rates are $0.000338 \mathrm{~cm}$ ( 0.13 mils) for PB 18 and 0.000417 $\mathrm{cm}$ (0.16 mils) for PB 15 .

Comparison with Other Rupture Data. The stress, rupture time, and temperature are shown as a Larson-Miller correlation in Fig. 18 for selected T-111 alloys. The four rupture points from the present study shown in this figure agree well with the previous data. These same results are shown in Fig. 29, and the two failure points for the capsules are shown for comparison. The

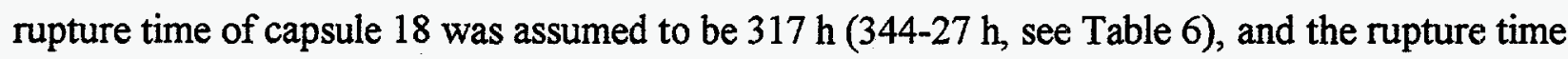
for capsule 15 was assumed to be $1683 \mathrm{~h}$ (the previous exposure at Mound was assumed to have no significant effect on the rupture life). The standard thin-wall equation was used in computing the maximum hoop stress. The outside diameter was used, and the wall thickness of each capsule was assumed to be $2.29 \mathrm{~mm}(0.090 \mathrm{in}$.). 
The two rupture points for the capsules agree well with the rest of the data, but the capsules tend to fall on the weak side of the data population. The agreement is good considering the numerous simplifying assumptions made.

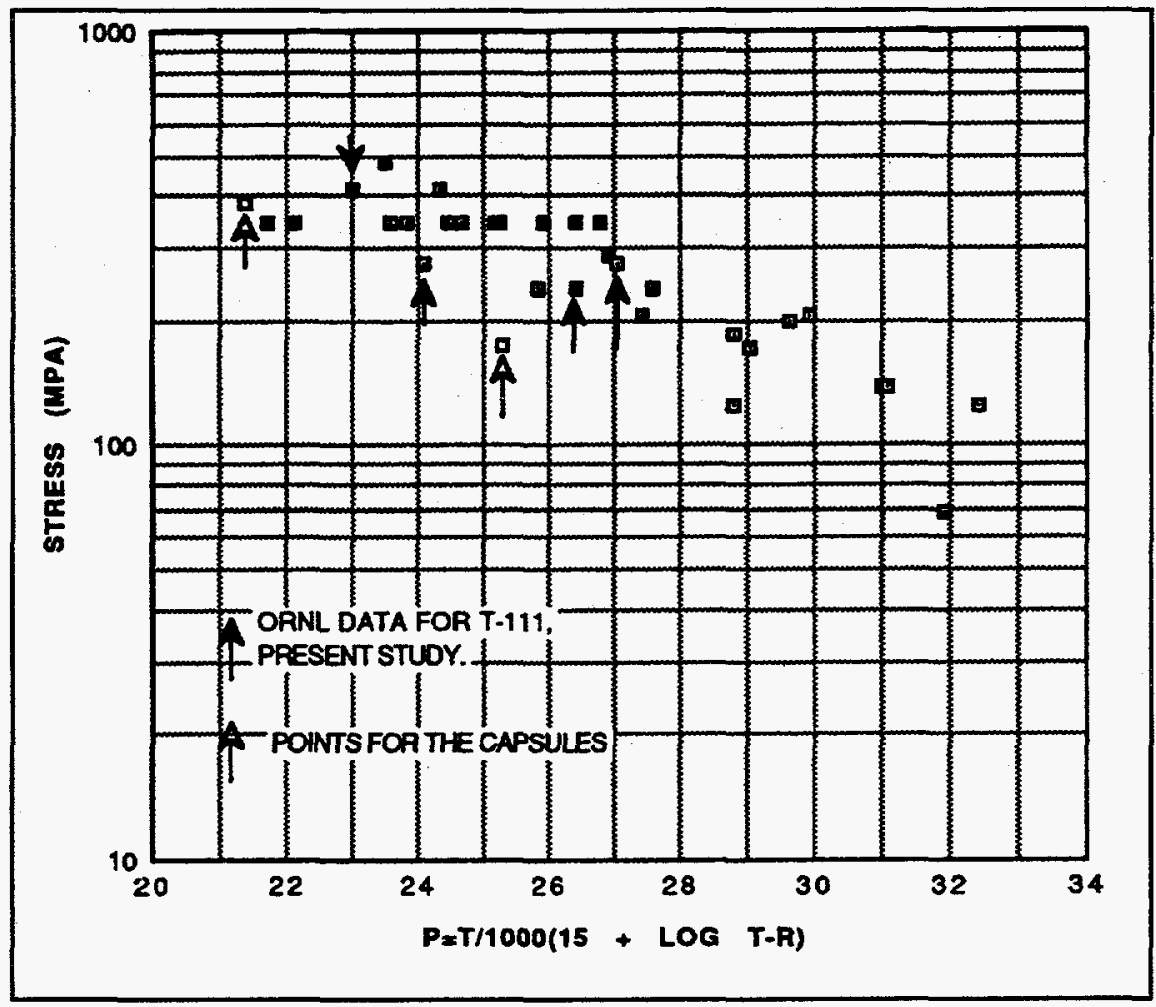

Fig. 29. Larson-Miller plot of selected rupture data for T-111type alloys with points superimposed for capsules.

Destructive Examination of Capsules. A ring was cut from each capsule that included the girth weld and about $6 \mathrm{~mm}$ ( $0.25 \mathrm{in}$.) on each side of the weld. These rings were small enough to be examined in detail by a stereo microscope. Capsule 18 had some soot on the inside that was easily removed. We believe that this contamination occurred as a result of a small amount of oil being introduced into the pressurization system when the pressure transducer was being calibrated. At the test temperature of $1171^{\circ} \mathrm{C}$, not much penetration of the carbon into the T-111 would be expected. The chemical analyses in Table 1 for weld and base metal samples of capsule 18 do not show any increase of oxygen, nitrogen, or carbon. Microscopic examination revealed one region of cracking on the outside surface. This same region was identified as the failure site optically and by the leak detector. There was a corresponding region of cracking on the inside surface directly under the cracked region on the outside surface. There was also a second crack on the inside surface a short distance from the first. 
Capsule 15 was clean on the inside, but the chemical analyses in Table 1 showed that the weld and base metal picked up approximately $100 \mathrm{ppm}(0.01 \%)$ oxygen and $20 \mathrm{ppm}(0.0020 \%)$ nitrogen. This likely occurred during the first $200 \mathrm{~h}$ of the test (see Table 7) during which the vacuum was in the E-6 to E-7 torr range. No information is available of the vacuum history during the approximately $1000 \mathrm{~h}$ of test time for this capsule at Mound. Microscopic examination of the ring revealed that the visual "failure" region had cracks on the outside and inside surfaces that were opposite one another. At another location approximately $180^{\circ}$ from the failure, there was a region of cracks on the outside surface, and there were some cracks on the inside surface nearby but not directly opposite the outside cracks. The inside weld surface exhibited numerous variations in the depth of weld penetration. A piece a foil was used as a weld shield on the inside surface in much the way a backup ring would be used in pipe welding. The shield was fused in some locations and free in other regions. This shield was too thin to have played a significant role in the weld quality of capsule 15 .

Based on the microscopic examination of both capsules, locations were selected for additional cuts to prepare samples for chemistry, SEM, and metallography. These samples were cut and evaluated.

Tensile Properties of Samples from Capsules 18 and 15. Small tensile specimens having a gage length of about $25 \mathrm{~mm}$ ( $1 \mathrm{in}$.) and section of $2.3 \mathrm{~mm}$ thick by $5.1 \mathrm{~mm}$ wide $(0.090 \mathrm{in}$. by $0.2 \mathrm{in}$.) were cut from the capsules. Samples were also made of the starting base metal and the transverse welds for comparison. These samples were tested at $25^{\circ} \mathrm{C}$ at a strain rate of $0.05 / \mathrm{min}$, and the results are given in Table 8 . Comparison of the data in Table 8 with those in Table 2 for the larger specimens shows that, except for samples from capsule 15, the tensile properties of both sets of specimens are in good agreement. The samples made from capsule 15 are about $10 \%$ stronger than the unexposed samples in Table 2 and the samples from capsule 18 given in Table 8. Note also in Table 8 the comment that the samples from capsule 15 had shallow cracks on the inside surface. The surface cracks, the $10 \%$ higher strength, and the chemical data in Table $\mathbb{1}$ are all consistent with capsule 15 having been contaminated with oxygen and nitrogen from the inside surface. 
Table 8. Summary of tensile test results from samples made from capsule scraps and starting base and transverse weld materials

\begin{tabular}{|l|c|c|c|c|}
\hline Sample source & Yield strength & Ultimate tensile strength & Elongation & Comments \\
\hline & $\mathrm{MPa}$ & $\mathrm{MPa}$ & $\%$ & \\
\hline & & & & \\
\hline Base metal & 591 & 702 & 42 & \\
\hline & 559 & 705 & 40 & \\
\hline & & & & \\
\hline Transverse weld & 550 & 666 & 25 & Fracture HAZ ${ }^{a}$ \\
\hline & 570 & 672 & 23 & Fracture HAZ ${ }^{a}$ \\
\hline & & & & \\
\hline Capsule 18 & 571 & 709 & 28 & \\
\hline & 606 & 688 & 38 & \\
\hline & & & & \\
\hline Capsule 15 & 660 & 773 & 15 & Shallow cracks-ID surface \\
\hline & 645 & 733 & & \\
\hline
\end{tabular}

\section{MICROSCOPY}

SEM. Rings from each capsule were cut in half so they could be manipulated in the scanning electronic microscope. When the samples were viewed in the optical microscope, features of interest were marked to help locate them more easily in the scanning electron microscope. A view of the outside weld surface where the fracture occurred in capsule 18 is shown in Fig. 30. The markings are due to the oscillation of the weld beam. There are numerous surface cracks that are predominantly intergranular.

The inside (root) of the girth weld where the failure in PB 18 occurred is shown in Fig. 31. The large crack in Fig. 31(a) passes through both the weld metal and the HAZ. The other electron micrographs in

Fig. 31 show considerable debris on the inside surface and some grain boundary grooving associated with the high temperature during welding. Another place on the inside surface of capsule 18 was cracked, 


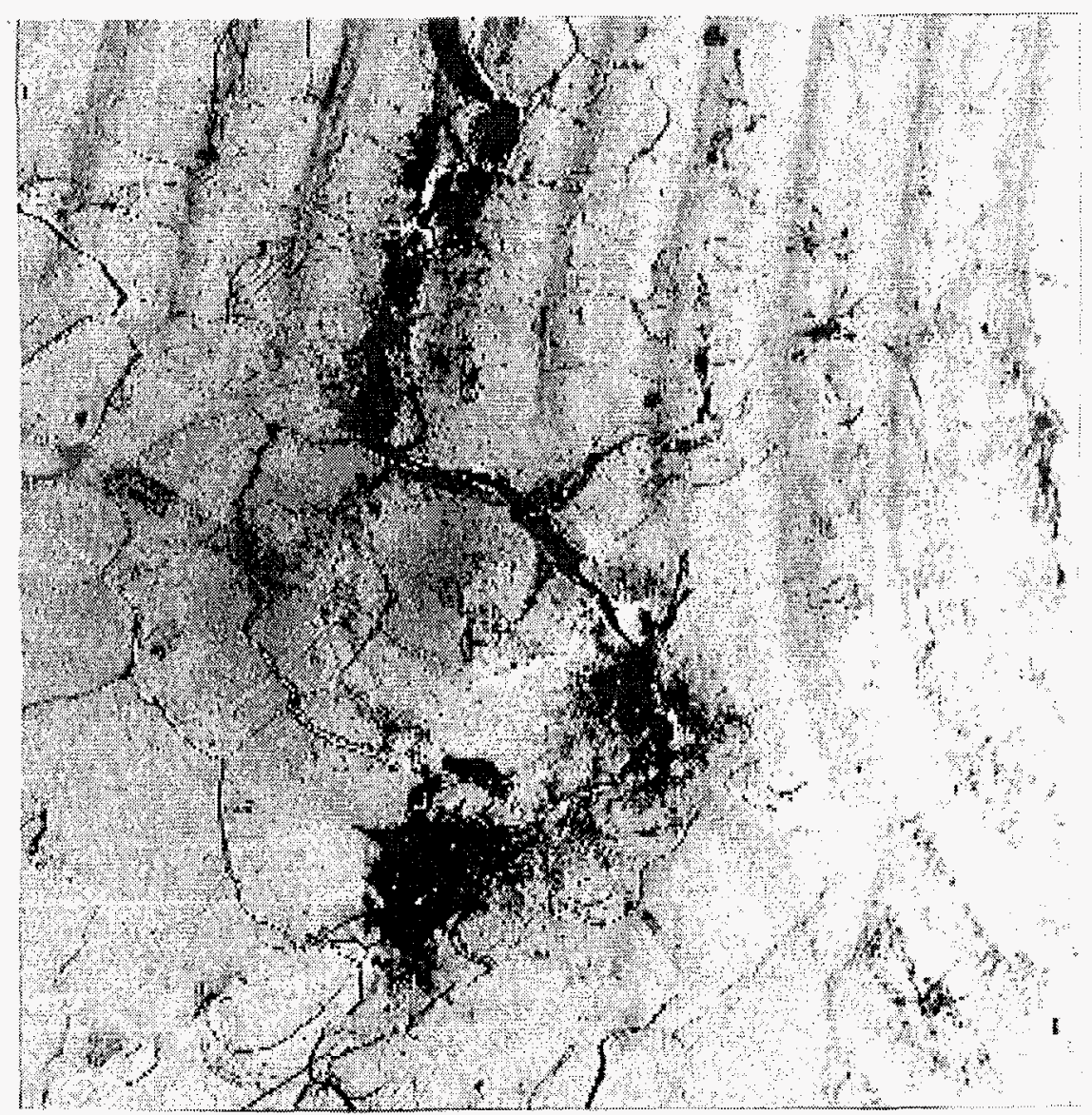

(a)

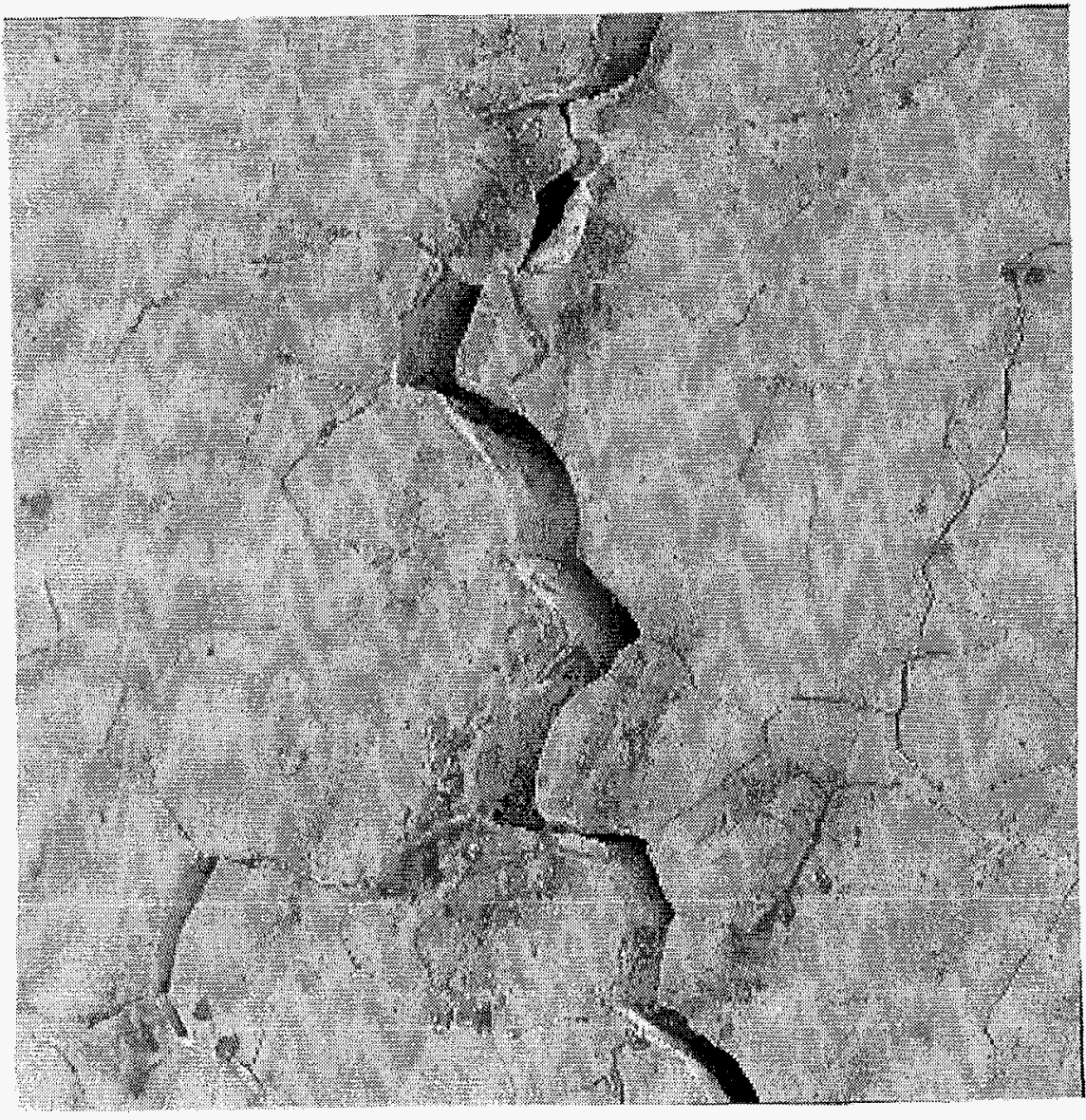

(b)

Fig. 30. Scanning electron micrographs of the failure from the outside surface of capsule 18: (a) 50× (ET05405), Outside of weld showing weld arc oscillations and cracks located along the grain boundaries. The dark regions are largely contamination around the cracks. (b) 100× (ET05407), View of one of the cracks showing its intergranular path. 


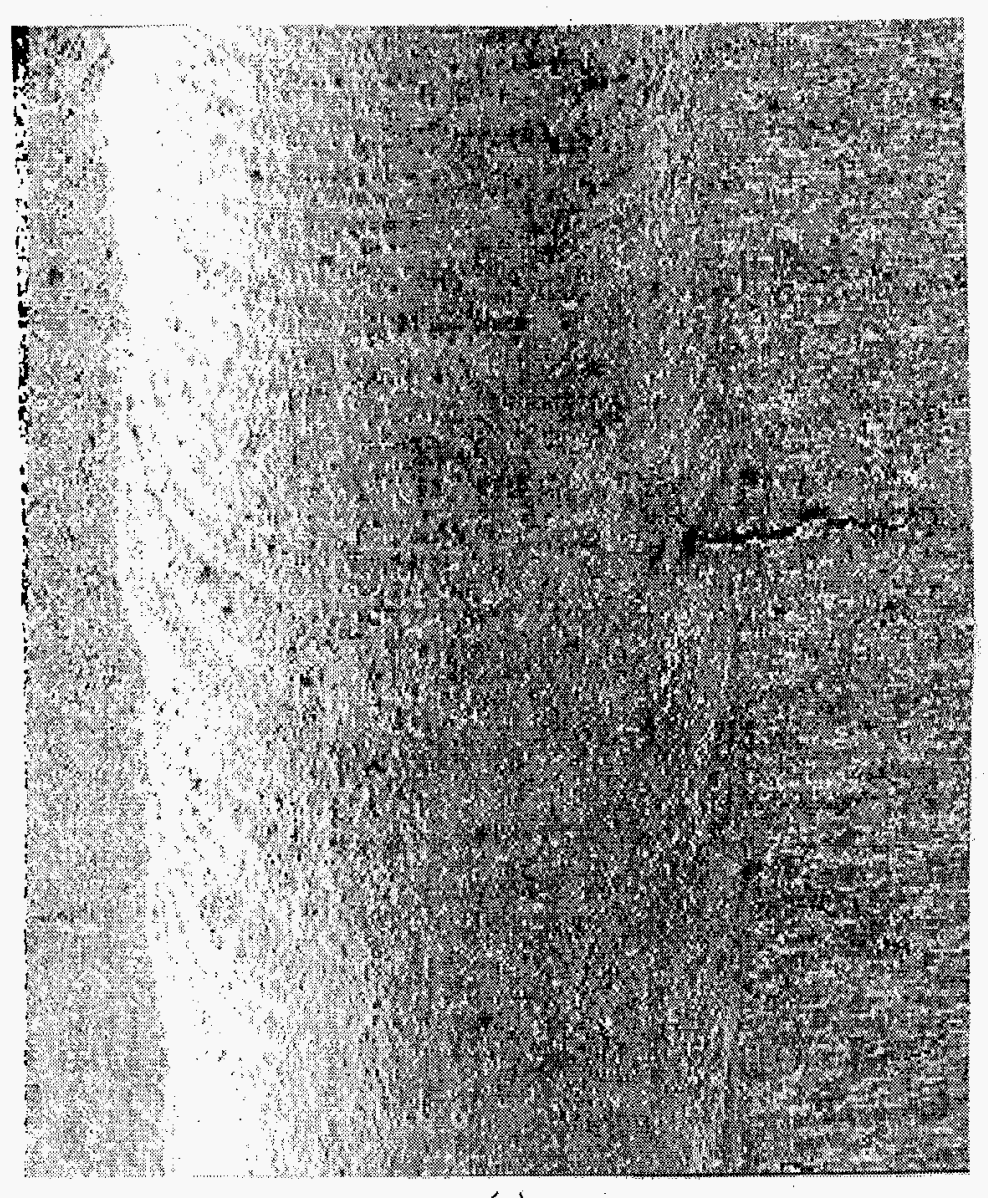

(a)

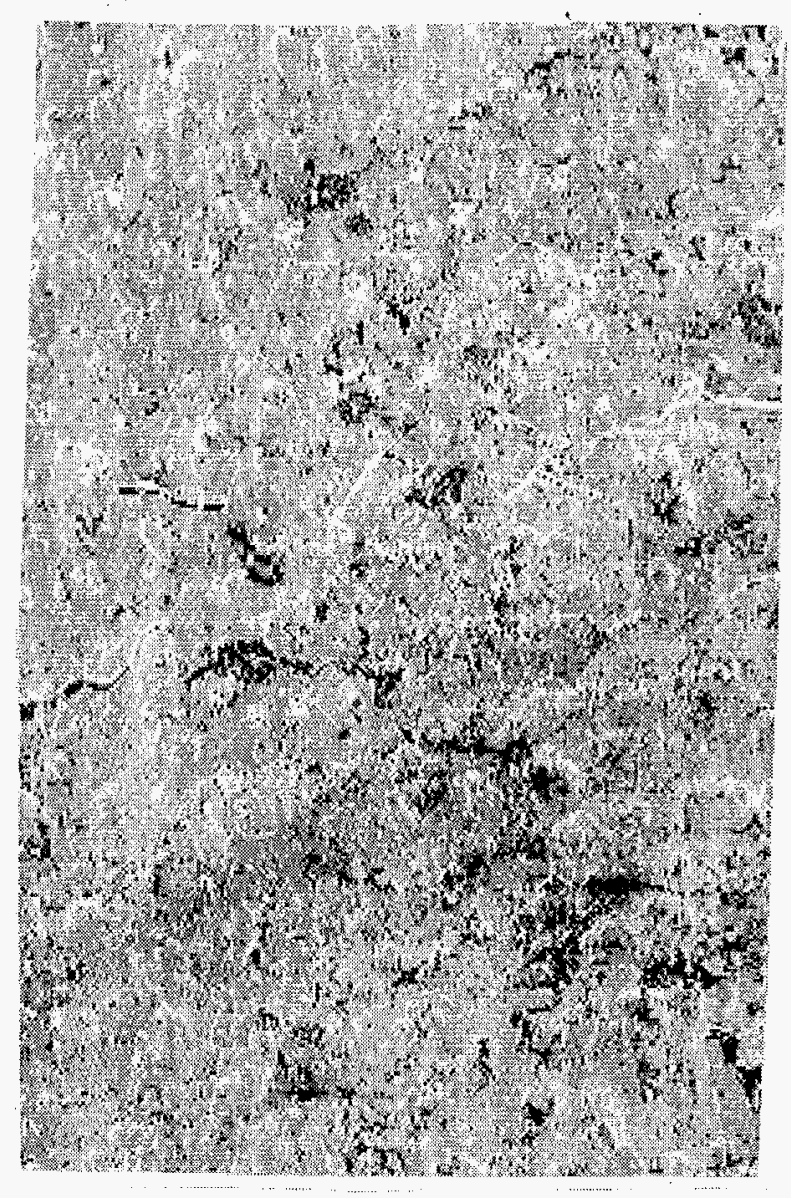

(b)

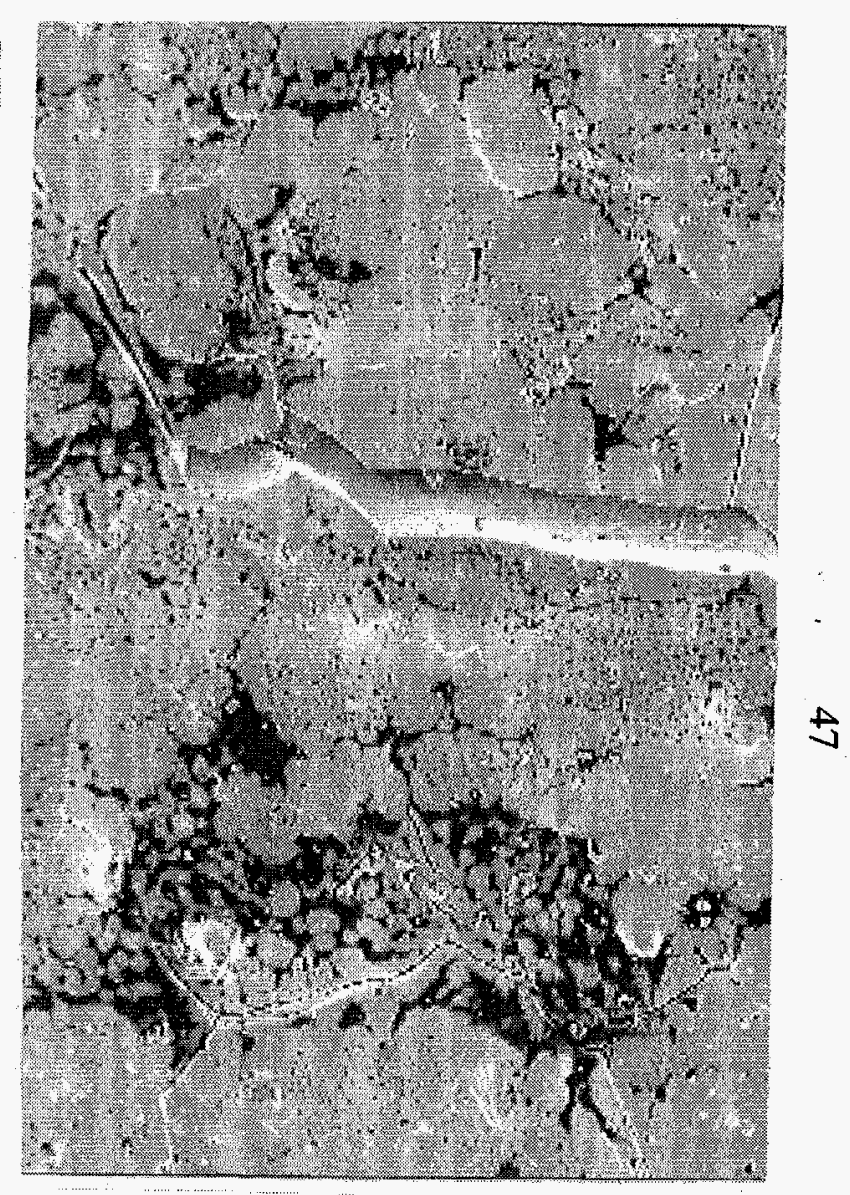

(c)

Fig. 31. Scanning electron micrographs of the failure from the inside surface of capsule 18 and opposite the failure shown in Fig. 30: (a) 20x (ET05408), Root of weld showing weld arc oscillations and cracks. (b) 100× (ET05409), View of the cracks. (c) 500× (ET05410), View of cracks and surface. 
and typical micrographs of this region are shown in Fig. 32. There is indication of a perturbation in the arc travel/power that interrupted the weld deposit pattern. There are also numerous intergranular cracks in this region.

For comparison, a region was selected for viewing along the girth weld of capsule 18 where no leaks could be detected. The outside of the girth weld in this region is shown in Fig. 33. Features that are visible include the arc oscillation marks, some surface debris, and large grains in the weld. The inside (root) surface of this region is shown in Fig. 34.

The outside surface of the failure location in capsule 15 is shown in Fig. 35. Numerous intergranular cracks extend across the weld and into the base metal. The inside surface of the weld directly opposite the outside surface in Fig. 34 is shown in Fig. 36. There is some surface debris and grain boundary grooving.

A region of capsule 15 that did not appear to be leaking that was located about $180^{\circ}$ from the leak region shown in Figs. 35 and 36 was examined. The outside surface of the weld in this region is shown in Fig. 37, and there are several intergranular cracks. The inside (root) of the weld is shown in Fig. 38, and several intergranular cracks are present as well. This capsule had a thin backup strip, and it was not fused in the region shown in Fig. 38. It is not known whether this strip is $T-111$ or another tantalum alloy.

The problem associated with failure in base metal of creep-rupture samples at laser-machined fiduciary marks was discussed previously when the creep data in Table 4 were presented. One of the fractures was examined in the scanning electron microscope, and typical micrographs are shown in Fig. 39. The laser made a hole $0.0826 \mathrm{~mm}(0.00325 \mathrm{in}$.) in diameter as it entered the T-111 and a hole $0.222 \mathrm{~mm}(0.00875 \mathrm{in}$.) in diameter as it exited. Using the average of these two diameters, the cross-sectional area was reduced about $5 \%$ by the laser hole. Our previous experience has been with a $0.0762 \mathrm{~mm}(0.003 \mathrm{in}$.) in diameter hole in a specimen twice as wide as the present specimen, which would reduce the section by $1.2 \%$. Thus failure at the present laser fiduciary marks is likely due to the specimen being narrower and the average diameter of the hole being larger than normal. The hardness impressions that were used successfully in these specimens were very shallow and did not reduce the section appreciably. 


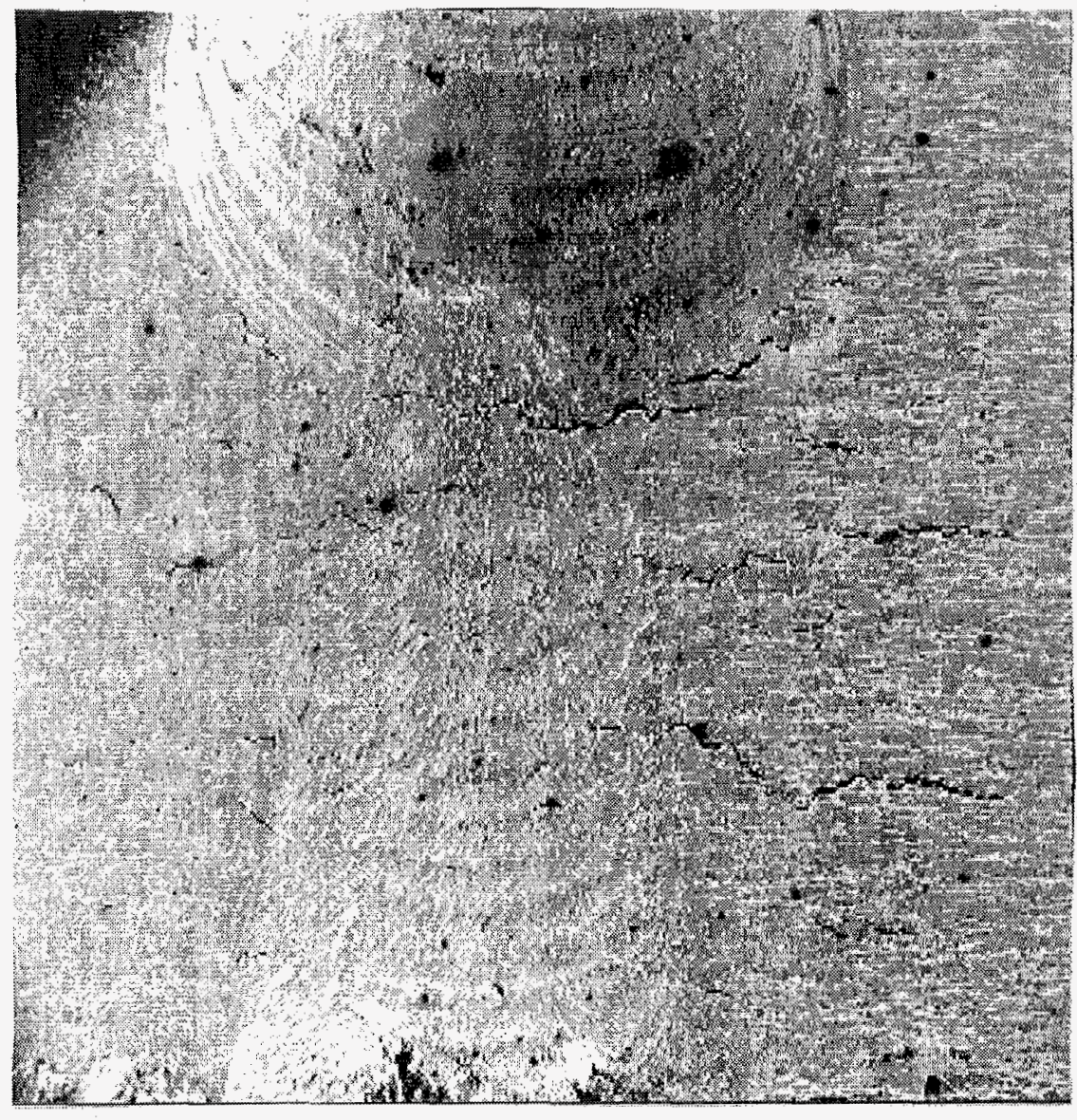

(a)

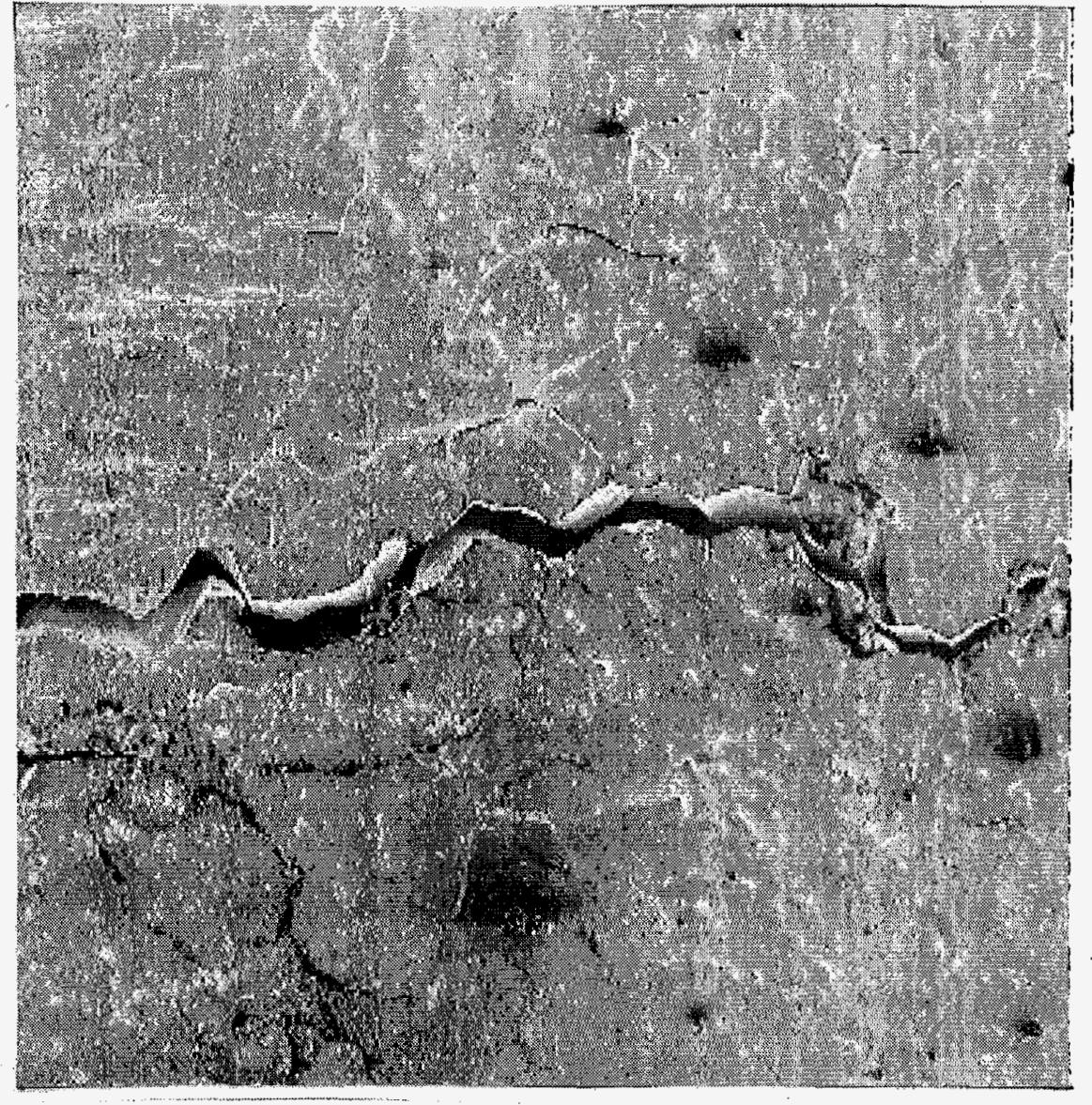

(b)

Fig. 32. Scanning electron micrographs of a cracked region on the inside surface of capsule 18 near the failure location: (a) $20 \times$ (ET05411), Root of weld showing weld arc oscillations, perturbation in weld arc travel, and cracks. (b) $100 \times$ (ET05412), View of the intergranular cracks. 


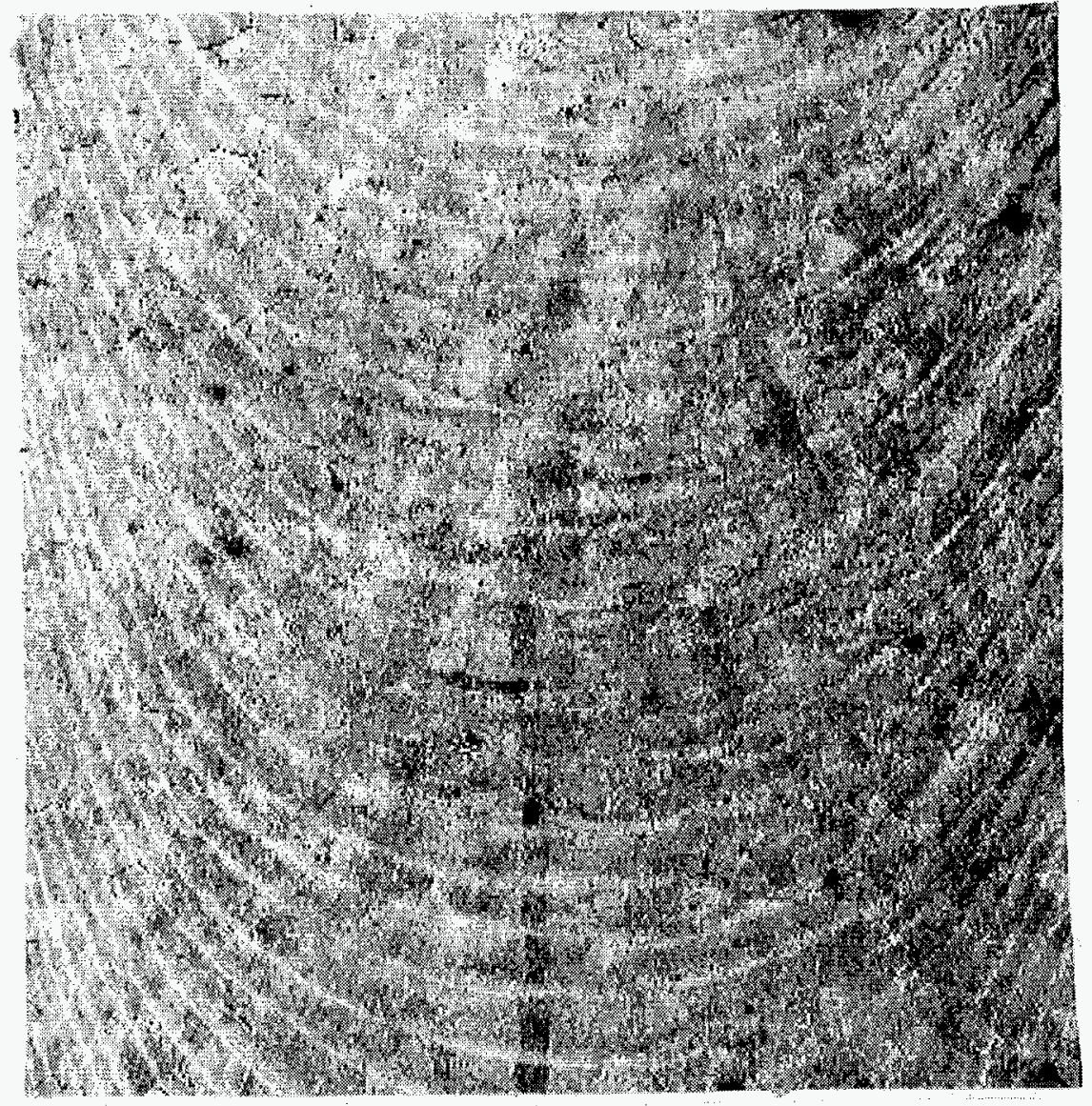

(a)

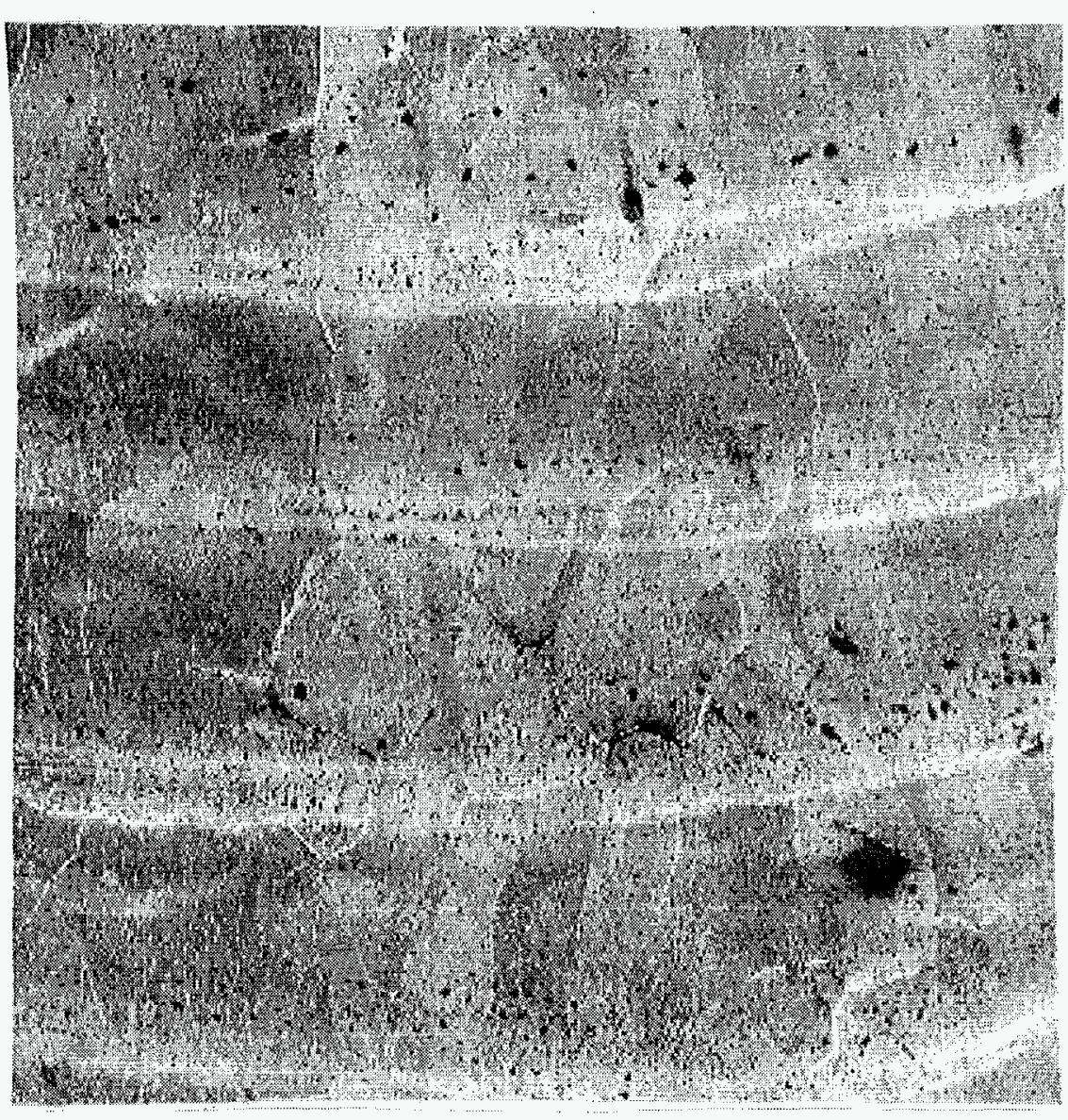

(b)

Fig. 33. Scanning electron micrographs of a sound region in the outside surface of capsule 18: (a) 20× (ET05414), Top of weld showing arc oscillations. (b) $100 \times($ ET05415), View of top of weld showing large grains and some fine surface debris. 


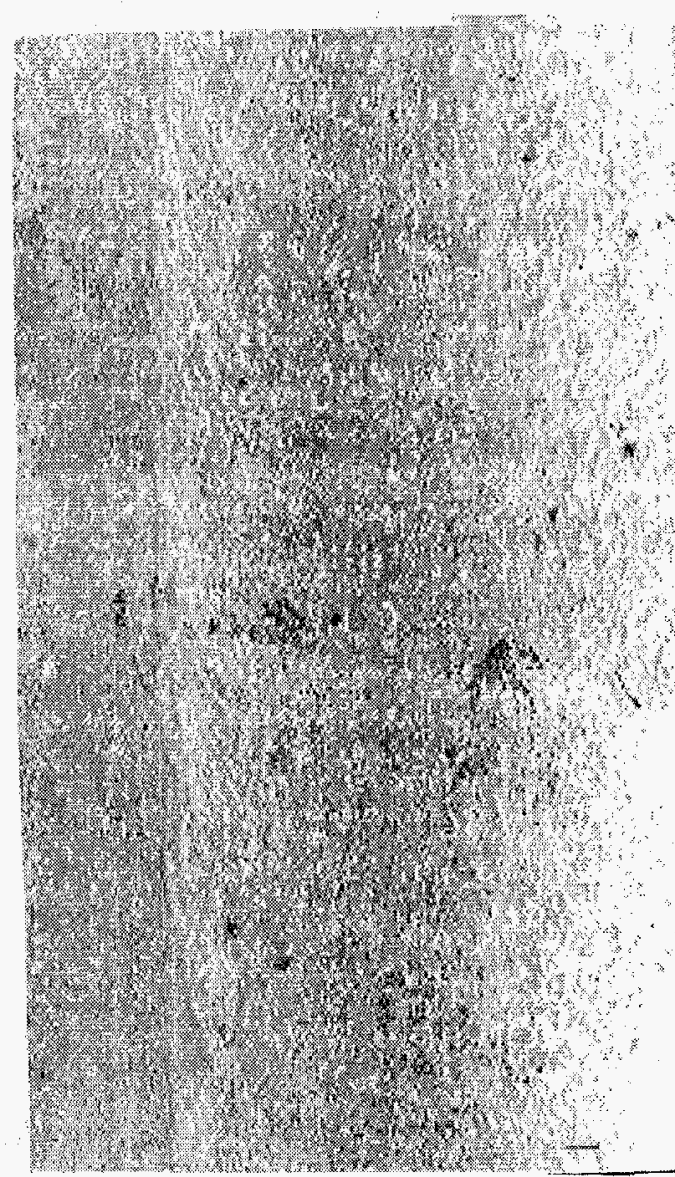

(a)
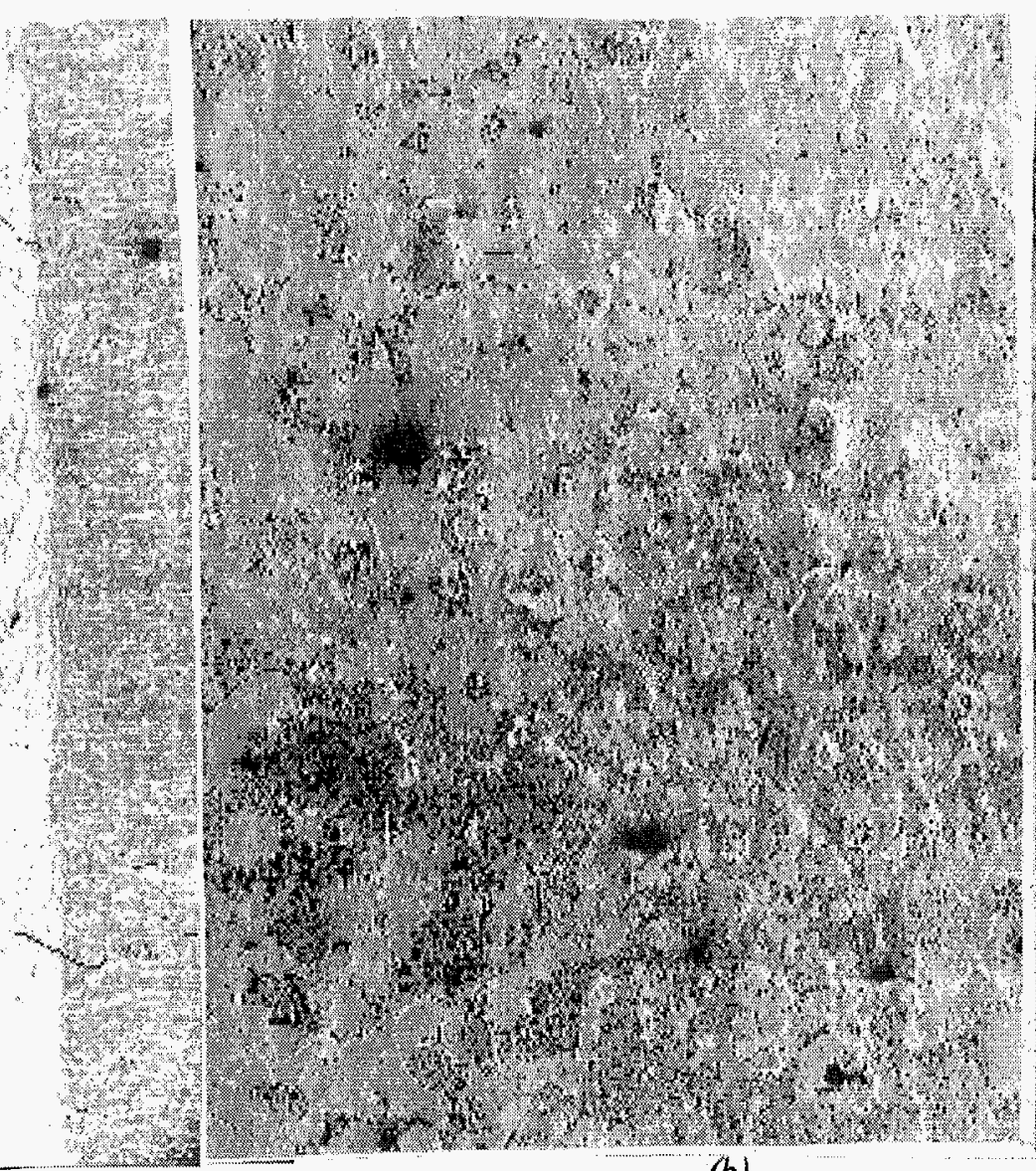

(b)

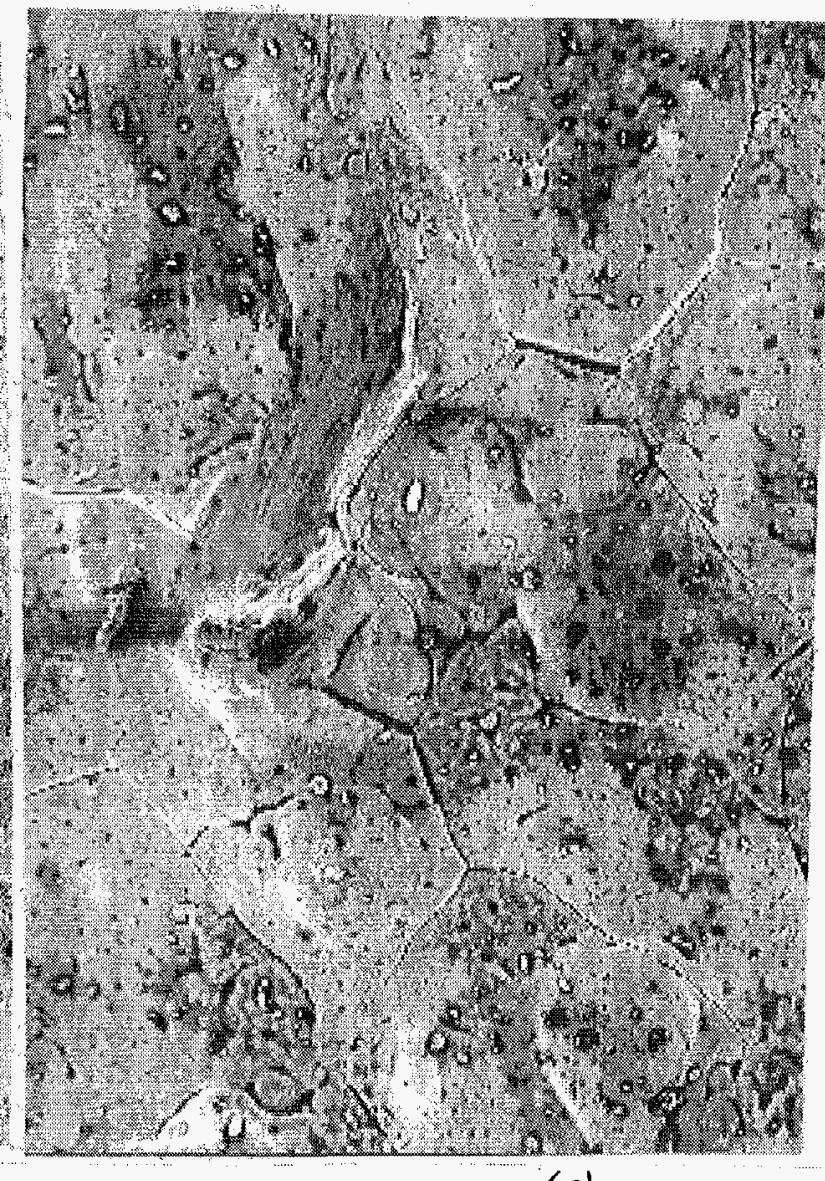

(c)

Fig. 34. Scanning electron micrographs of a sound region on the inside (root) surface of capsule 18: (a) 20× (ET05417), Bottom of weld showing arc oscillations. (b) $100 \times$ (ET05419), View of bottom of weld showing some fine surface debris. (c) $500 \times($ ET05417), View of bottom of weld showing grain boundary grooving and debris. 


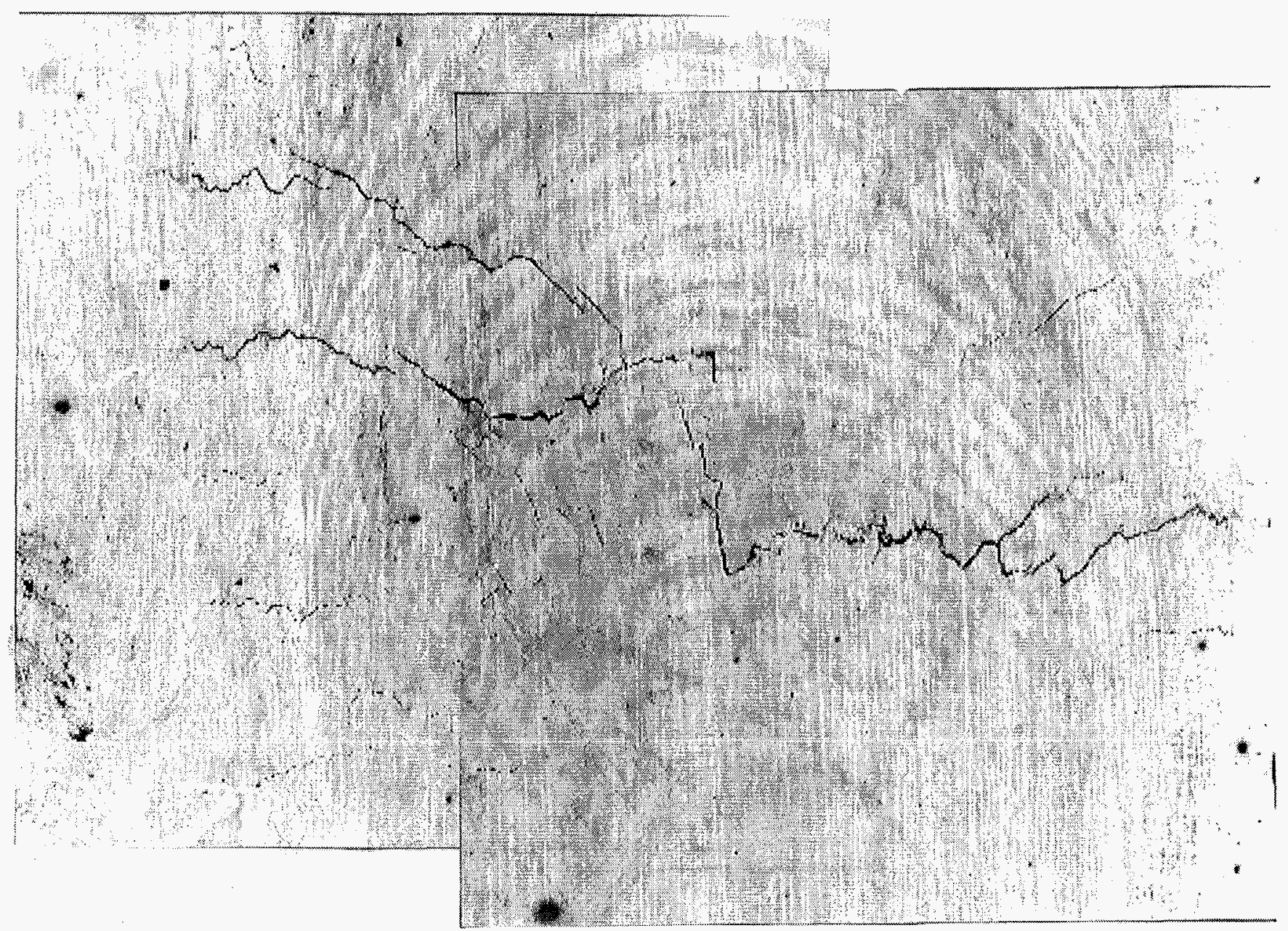

Fig. 35. Scanning electron micrographs of the top (outside) of capsule 15 showing extensive branching and intergranular nature of cracks. $20 \times($ ET05426, 7). 

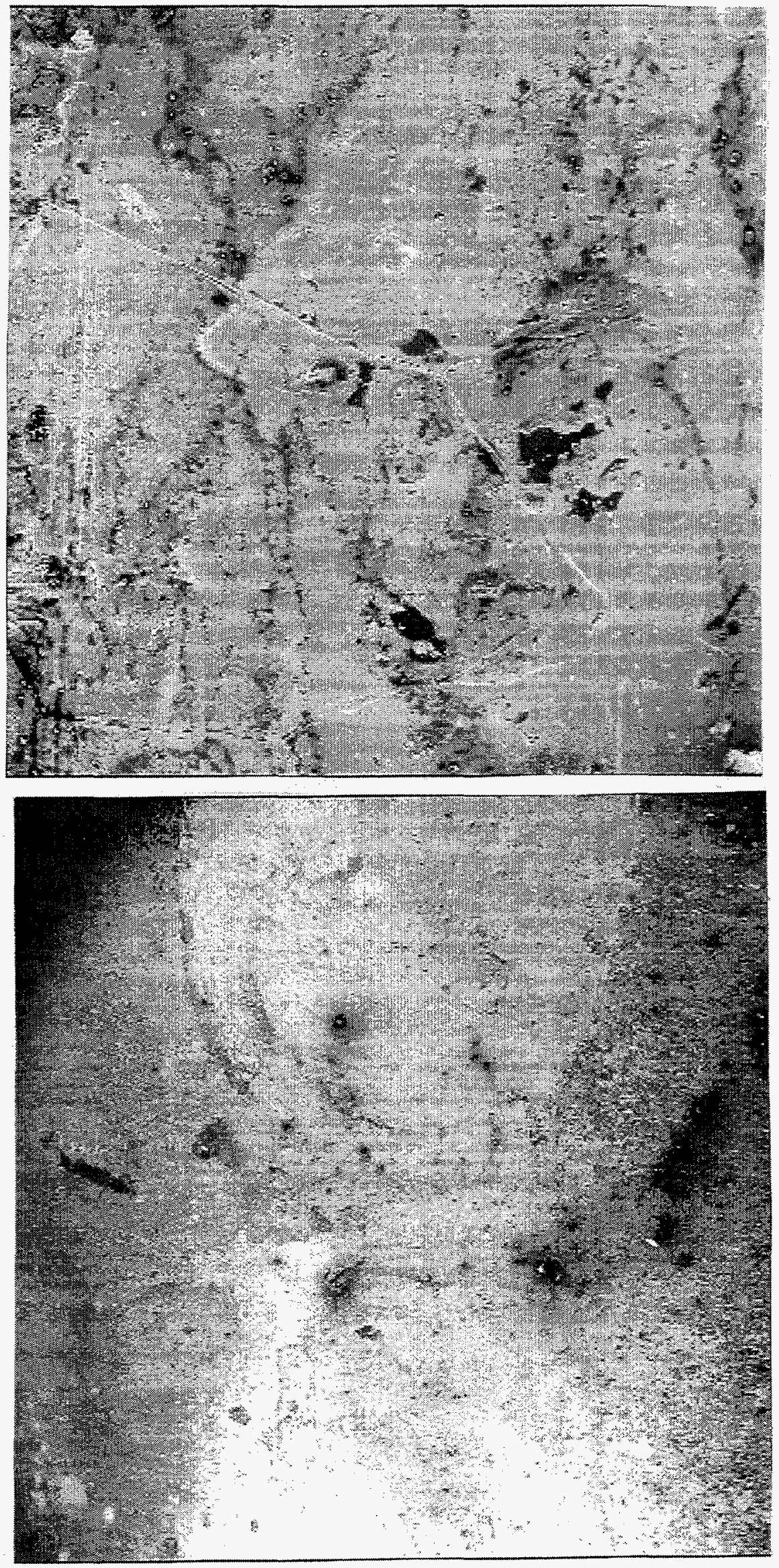


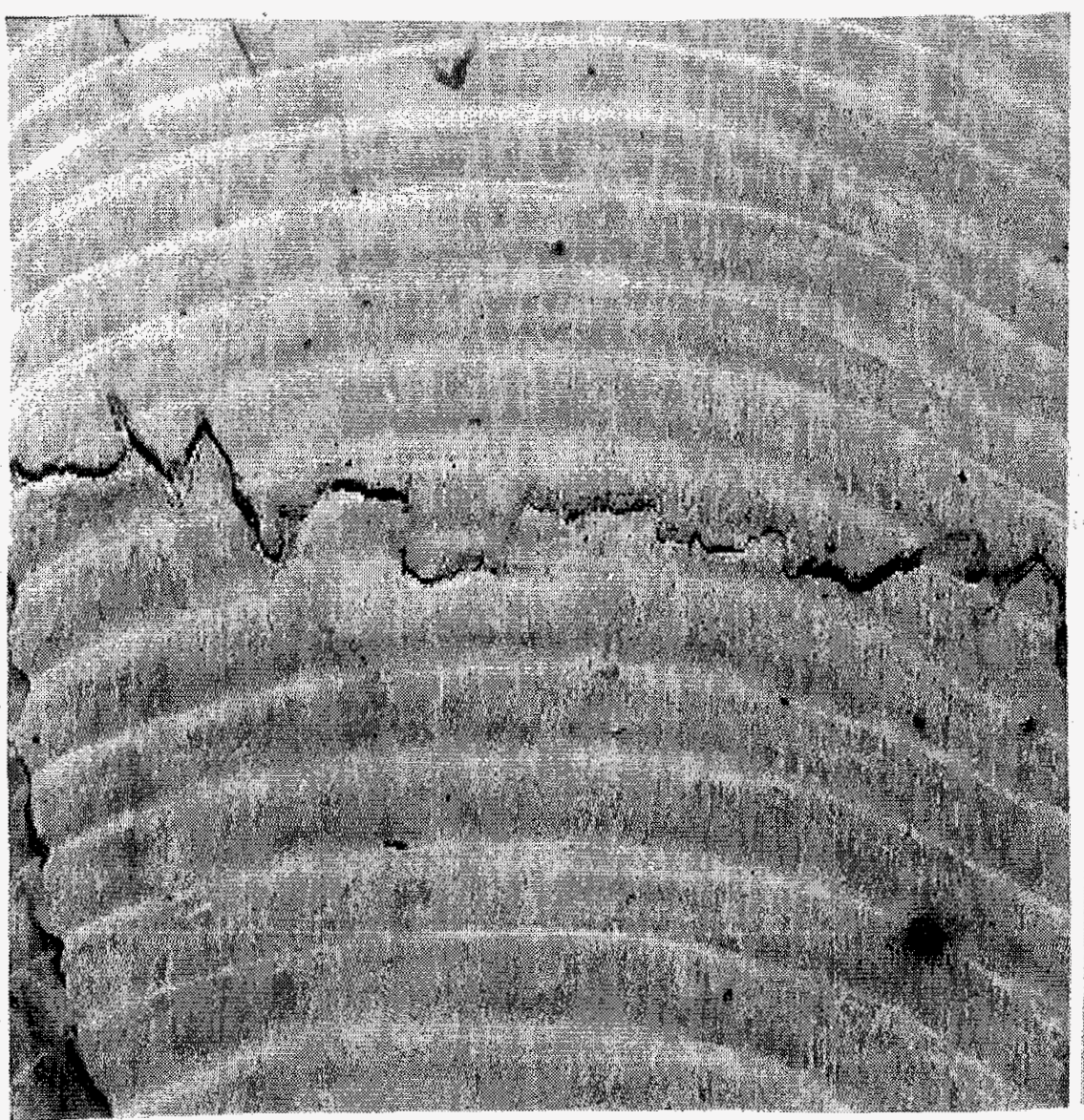

(a)

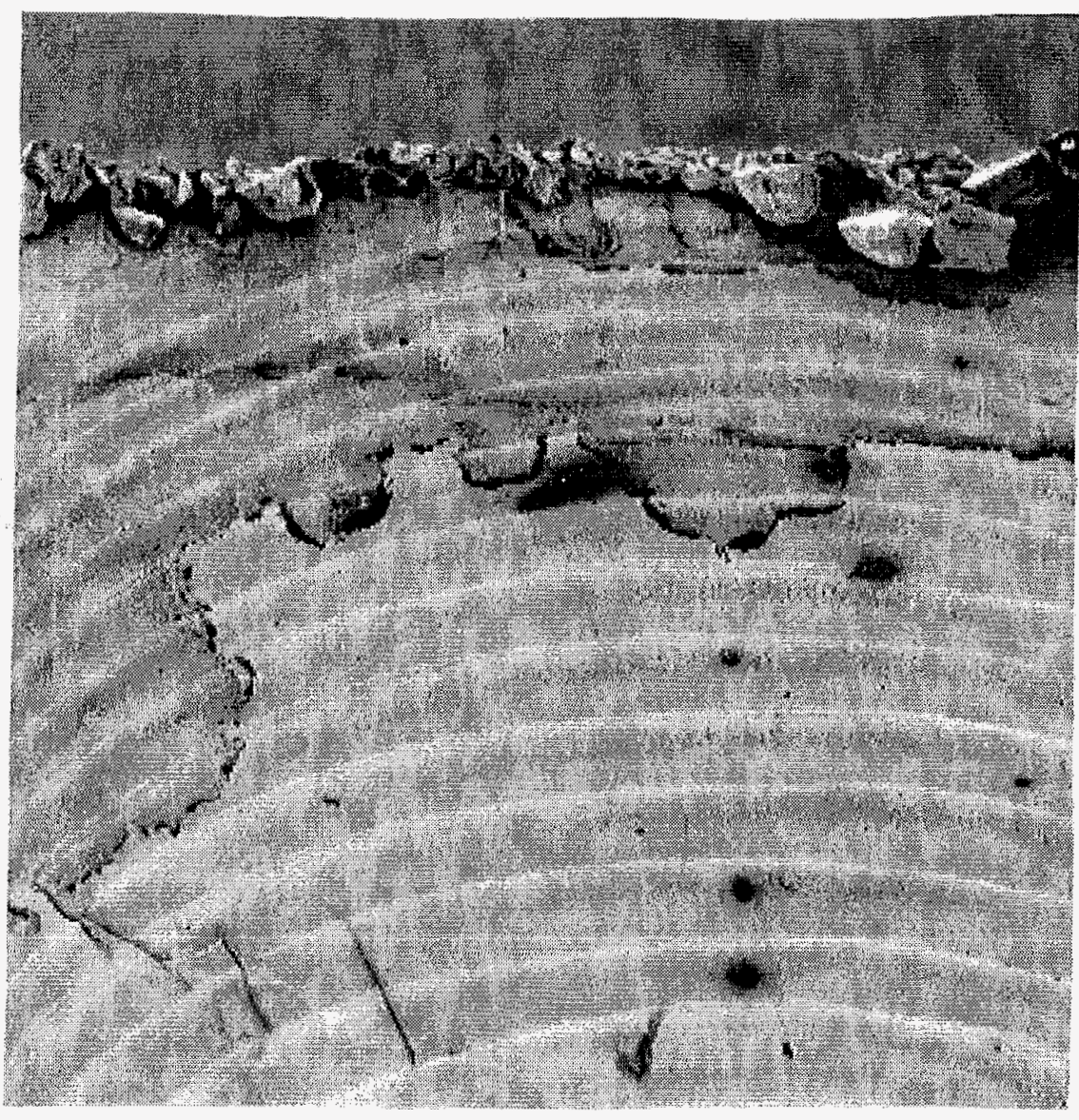

(b)

Fig. 37. Scanning electron micrographs of the top (outside) of capsule 15 approximately $180^{\circ}$ from the failure shown in Fig. 35: (a) $40 \times$ (ET05435) and (b) $40 \times($ ET05436) show arc oscillation patterns and intergranular cracks. 


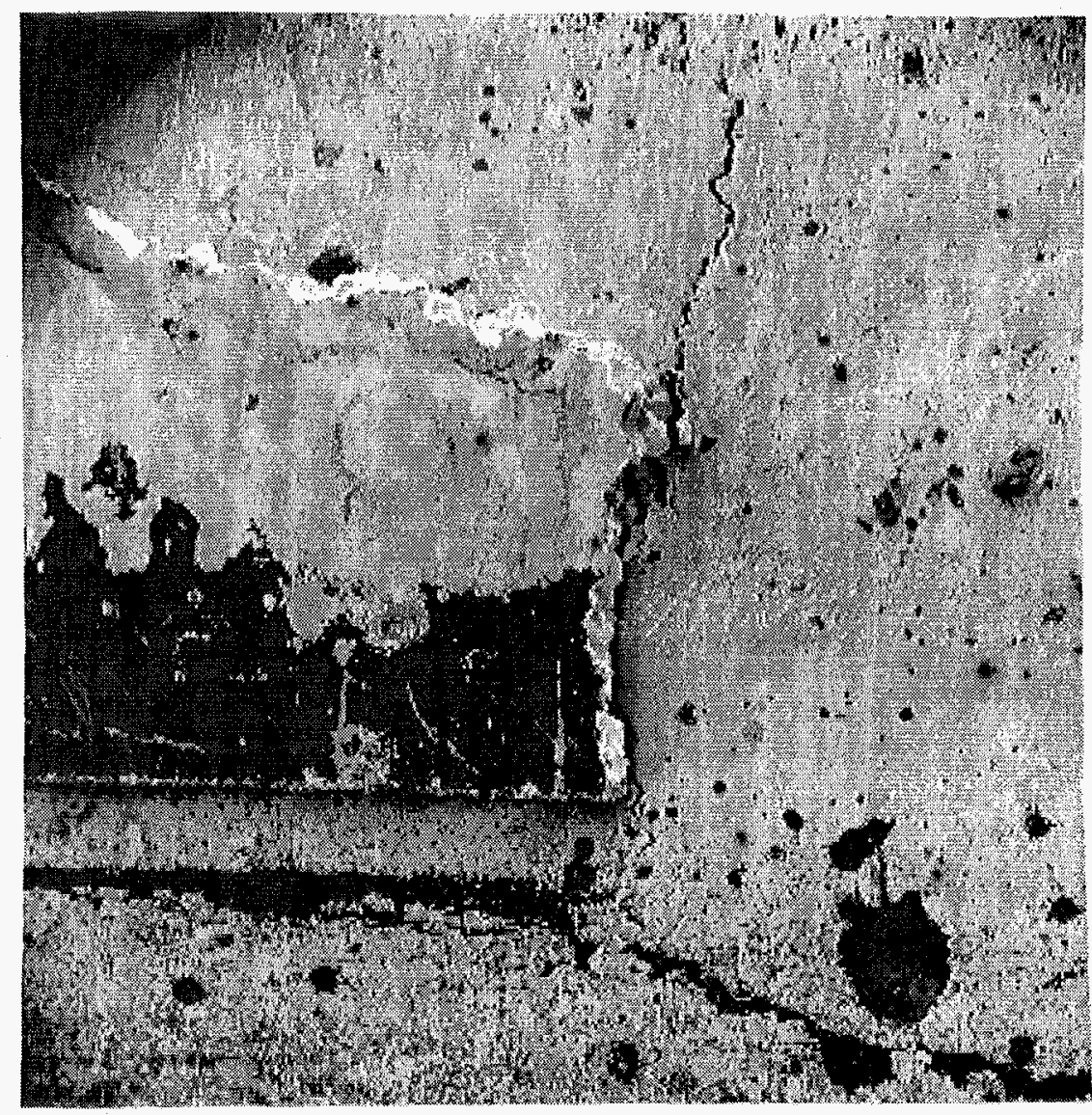

(a)

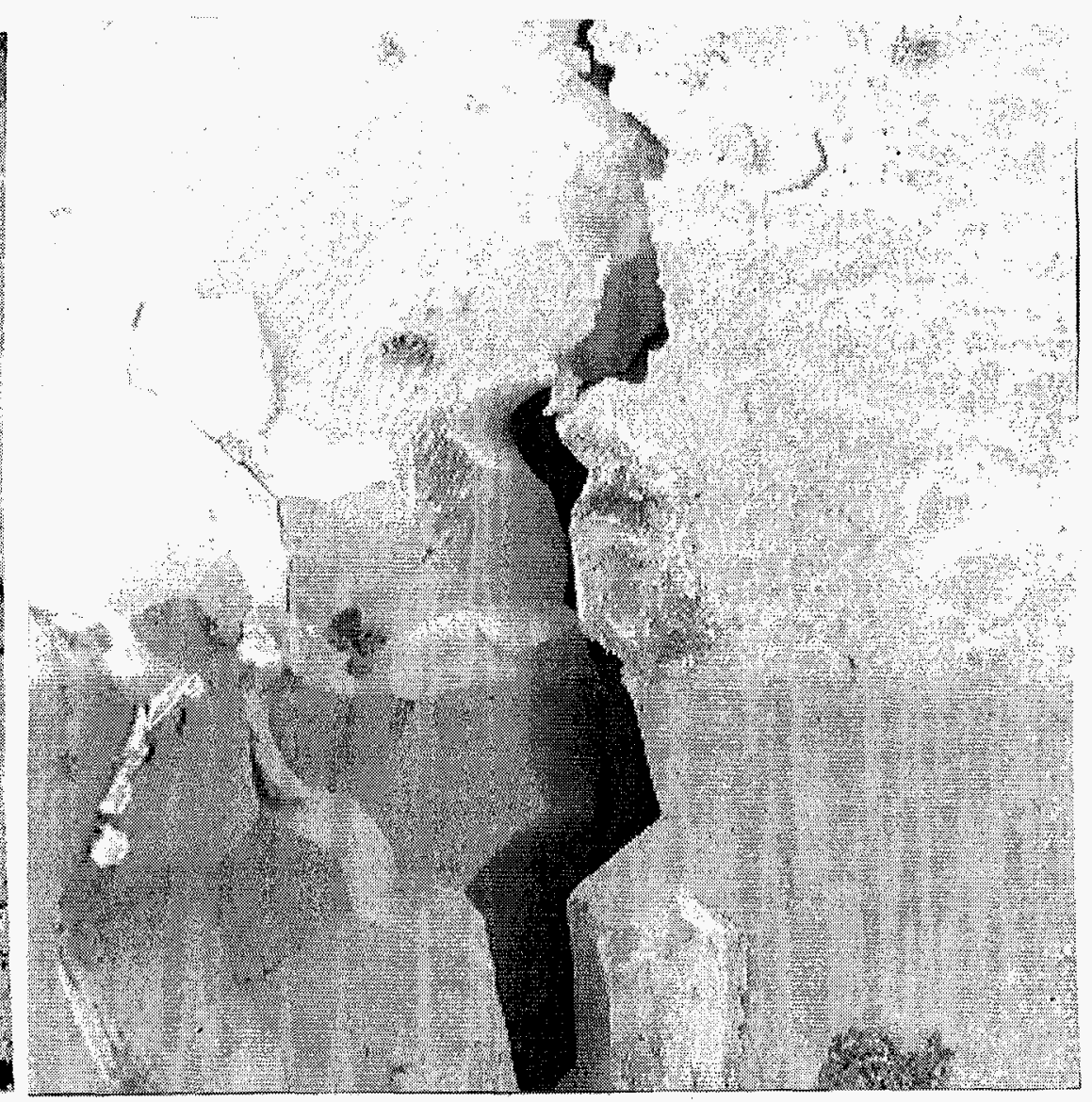

(b)

Fig. 38. Scanning electron micrographs of the root (inside) of capsule 15 under the cracks shown in Fig. 37: (a) 20× (ET05433) Shows cracks and a portion of back-up ring. (b) $200 \times$ (ET05434) Shows intergranular cracks. 


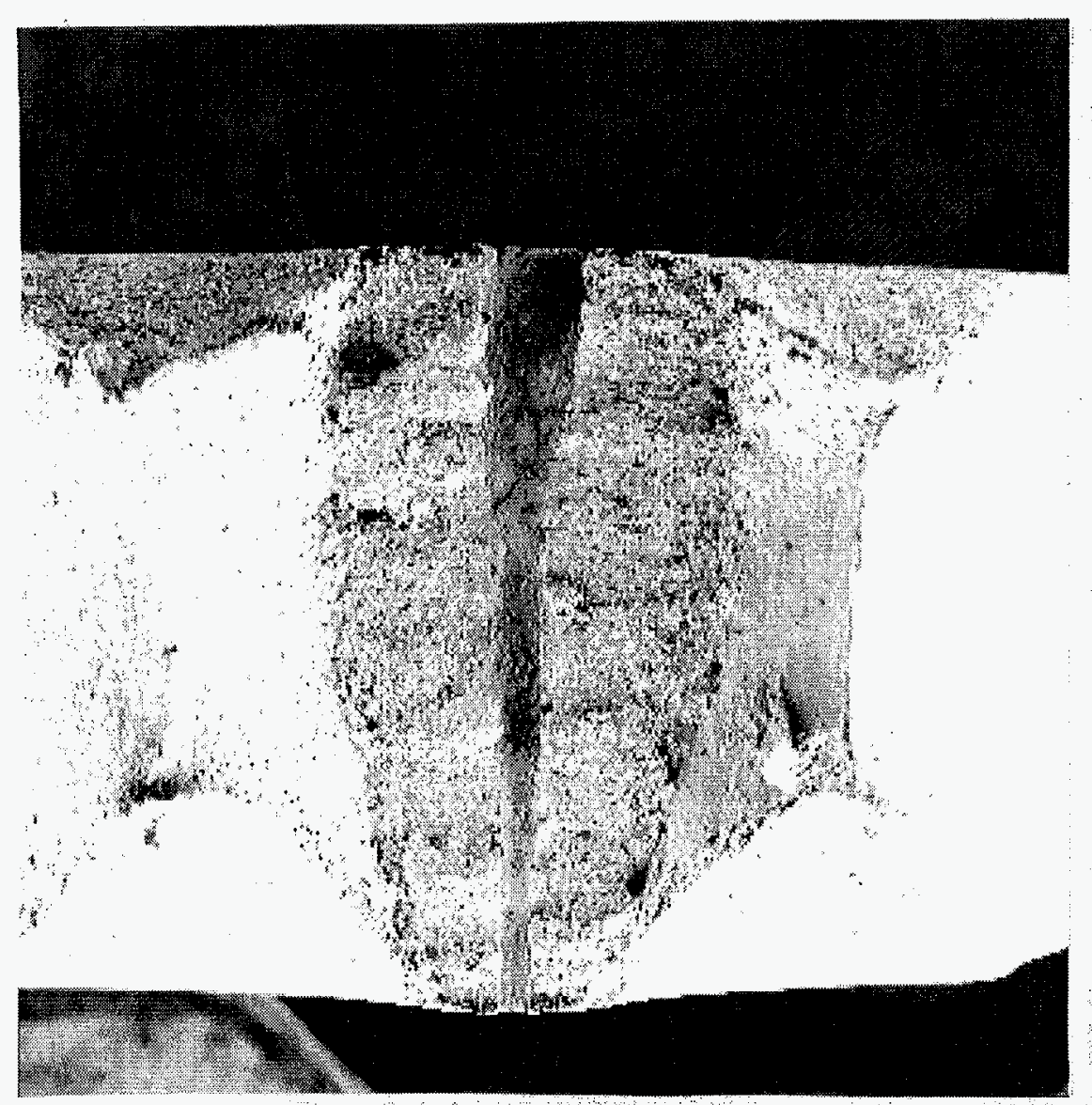

(a)

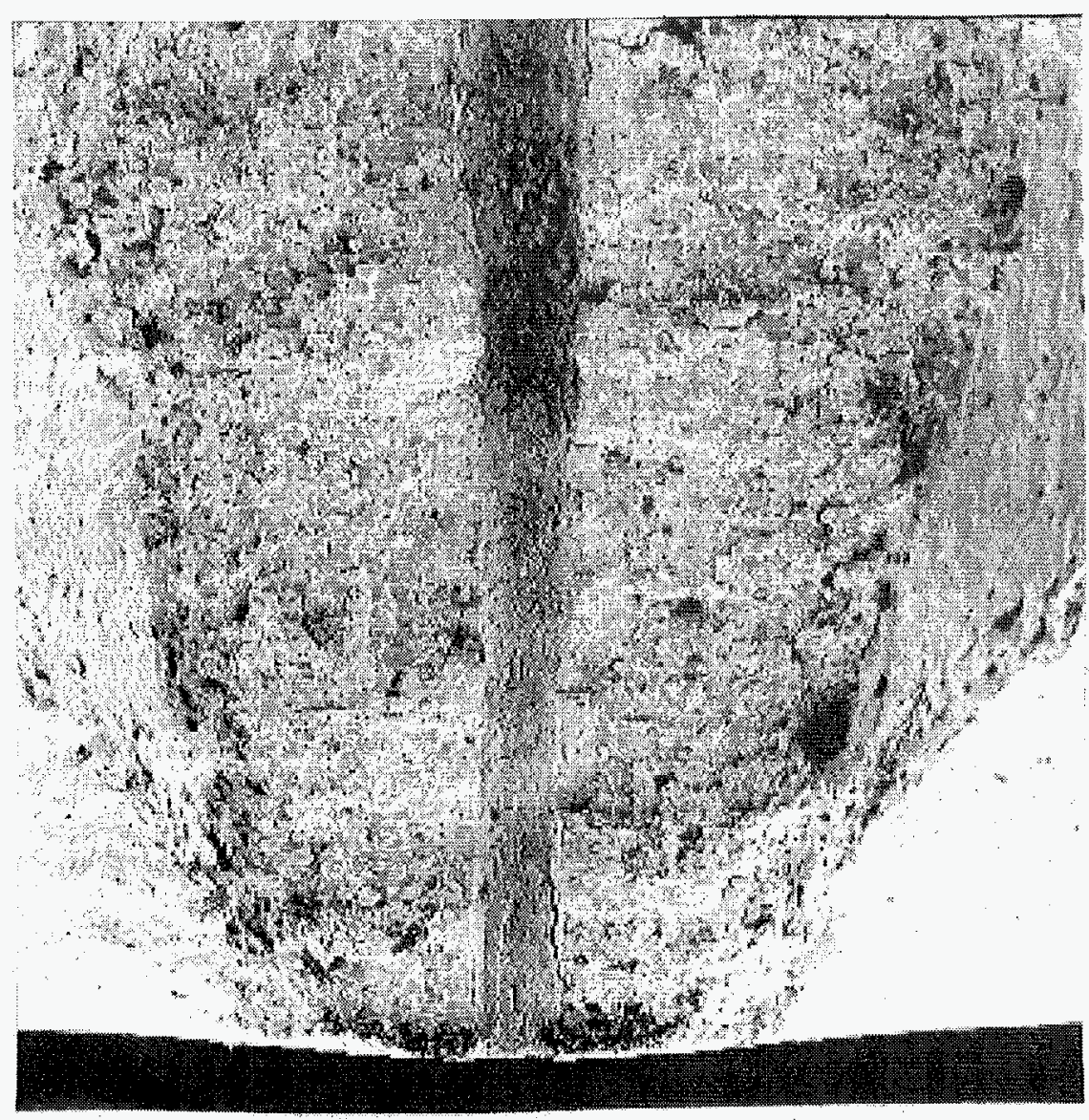

(b)

Fig. 39. Scanning electron micrographs of the fiduciary mark laser-machined into some of the base metal creep samples: (a) $40 \times(\mathrm{ET} 05421)$ and (b) $100 \times($ ET05423) 
Metallography. The sheet material used in this study was annealed at $1500^{\circ} \mathrm{C}$ prior to use and, therefore, should be in the fully recrystallized condition. Photomicrographs are shown in Fig. 40 with the material viewed in the transverse and longitudinal orientations. The grain size is about ASTM number 8 in both orientations. There appear to be more flow lines in the longitudinal than the transverse directions. Thus, the material appears rather homogenous. Photomicrographs of the bead-on-plate GTA weld used in this work were shown previously in Fig. 3.

Several welds with known welding parameters that were made by Mound in capsules of the type shown in Fig. 1 were also examined metallographically prior to developing welding parameters for the 2.3-mm (0.090-in.) sheet at ORNL. Photomicrographs of one part, designated CB-2, are shown in Figs. 41 and 42 . The weld does not fully penetrate the material. There is a crater near the root of the weld that is likely a machining defect. The photomicrographs in Fig. 42 show the three types of microstructure present in the weld: base metal with a fine grain size of ASTM number 8 , weld metal consisting of fine dendrites, and coarse grains in the HAZ having an ASTM grain size number of 3 . Based on the observed location of the fractures, the weakest part of the weld is the HAZ where the large grains are located.

A second region in CB-2 that was about $180^{\circ}$ from the one shown in Fig. 41 was examined. This second weld section, shown in Fig. 43, fully penetrates the sheet and appears sound. Weld sections were also examined in capsules designated as CB-1 and CB-3. Photomicrographs of the two sections of CB-1 are shown in Figs. 44 and 45 and one section of CB-3 in Fig. 46. These weld sections appear sound and have the same micro constituents mentioned previously.

A transverse section was taken through the failure of capsule 18. Photomicrographs are shown in Fig. 47 with the sample in the unetched condition and after etching in Fig. 48 . The weld fully penetrates the sheet, and numerous cracks are visible, particularly near the outer surface of the weld.

A longitudinal section of the failed region in capsule 18 is shown (unetched) in Fig. 49 . Some cracks were visible on the root side of the weld. The sample was etched and the photomicrographs in Fig. 50 were made. There are some small cracks on the root side of the weld, but most of the cracks were not made visible in preparation. The oscillation pattern in the weld metal is quite visible. 
(a)

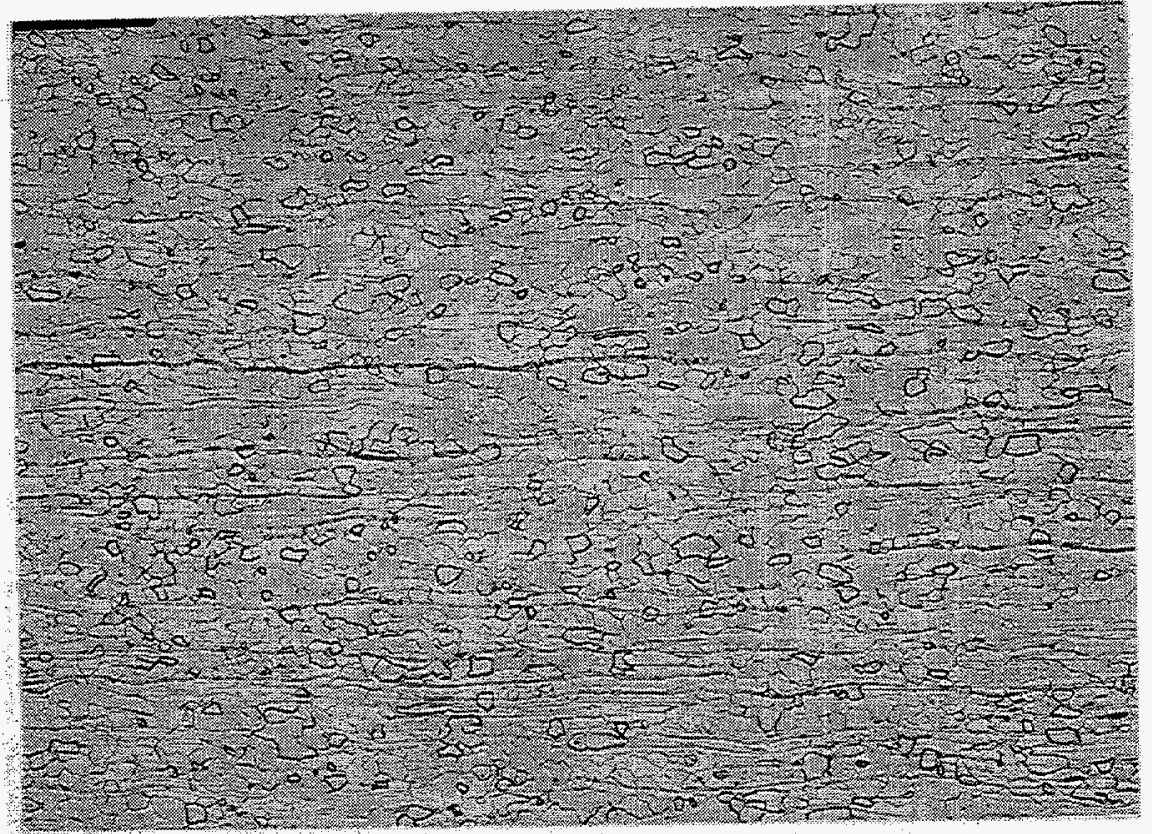

(b)

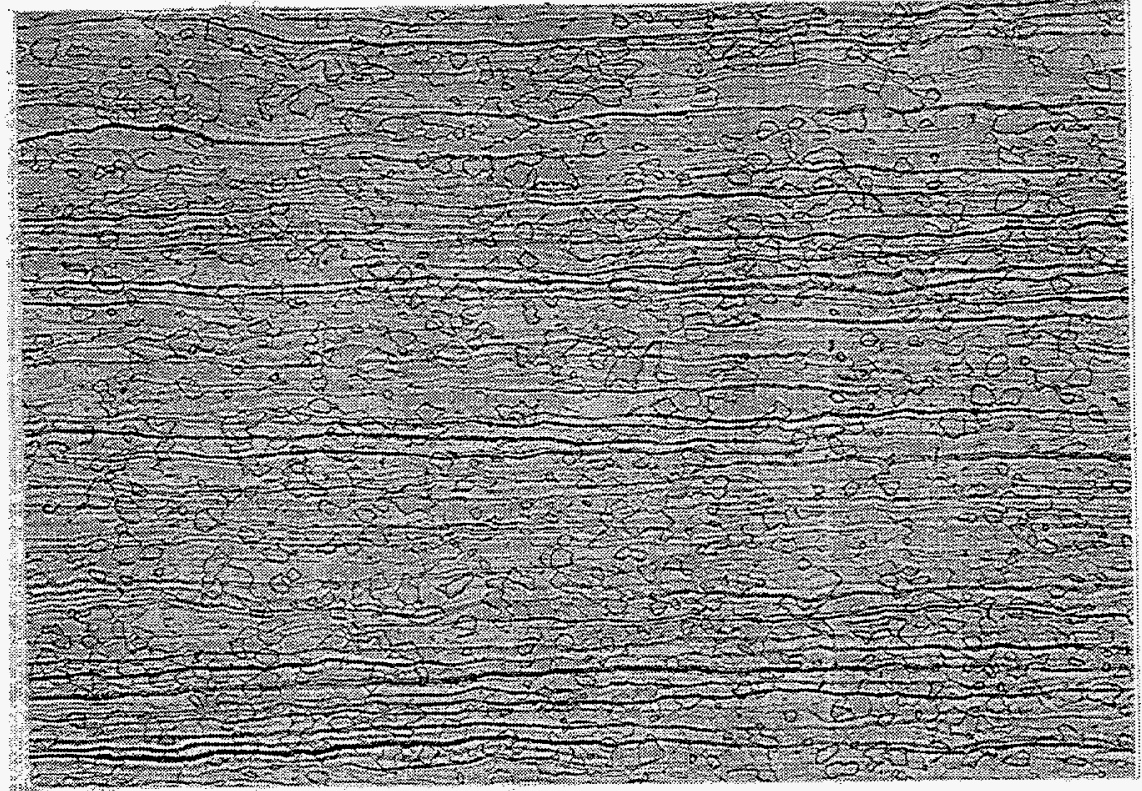

Fig. 40. Photomicrograph of the $T-111$ sheet used in this study. Etched. 100×. (a) Transverse and (b) longitudinal. 
(a)

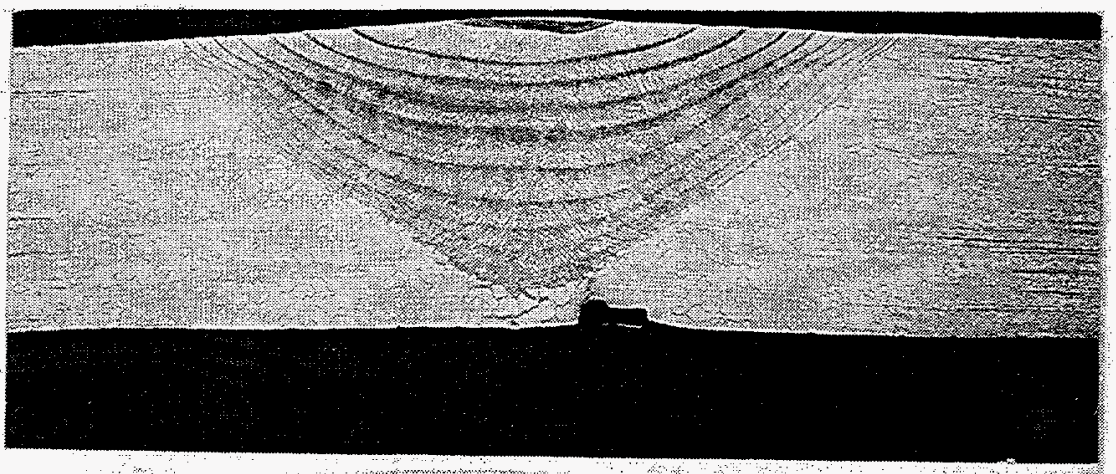

(b)

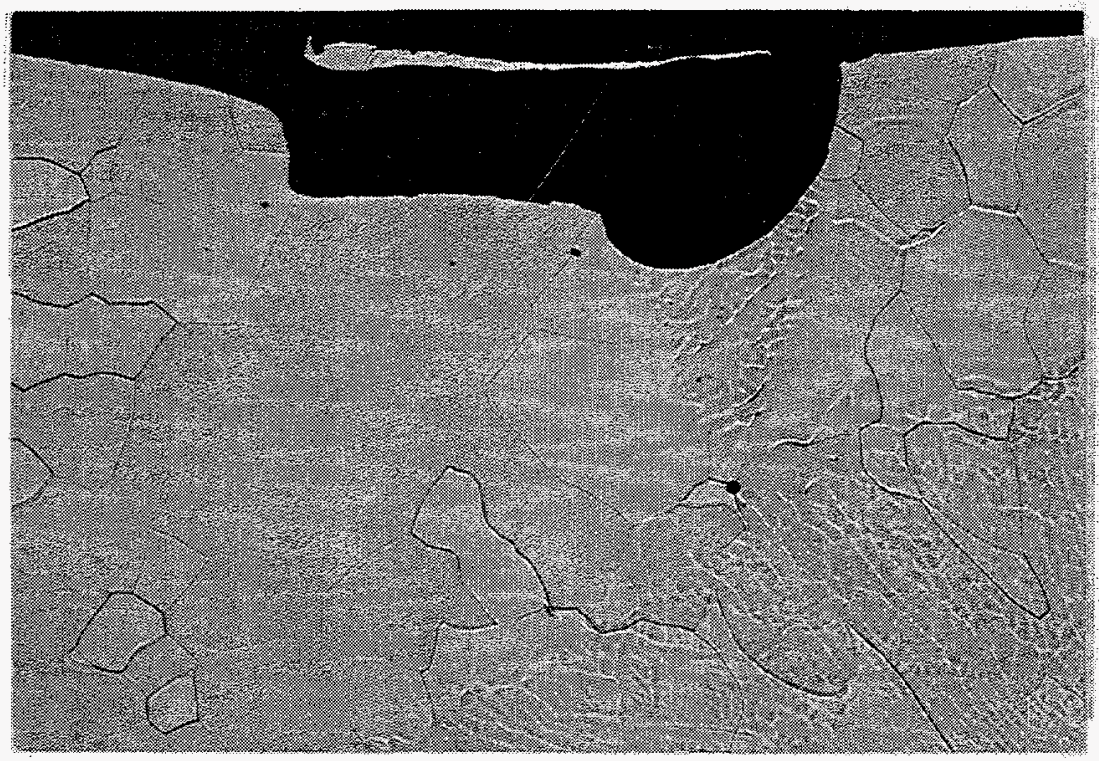

Fig. 41. Photomicrographs of the T-111 weld made by Mound and designated CB-2. Etched. (a) $12.8 \times$, Transverse section of weld and (b) 100x, defect present at the root of the weld. 
(a)

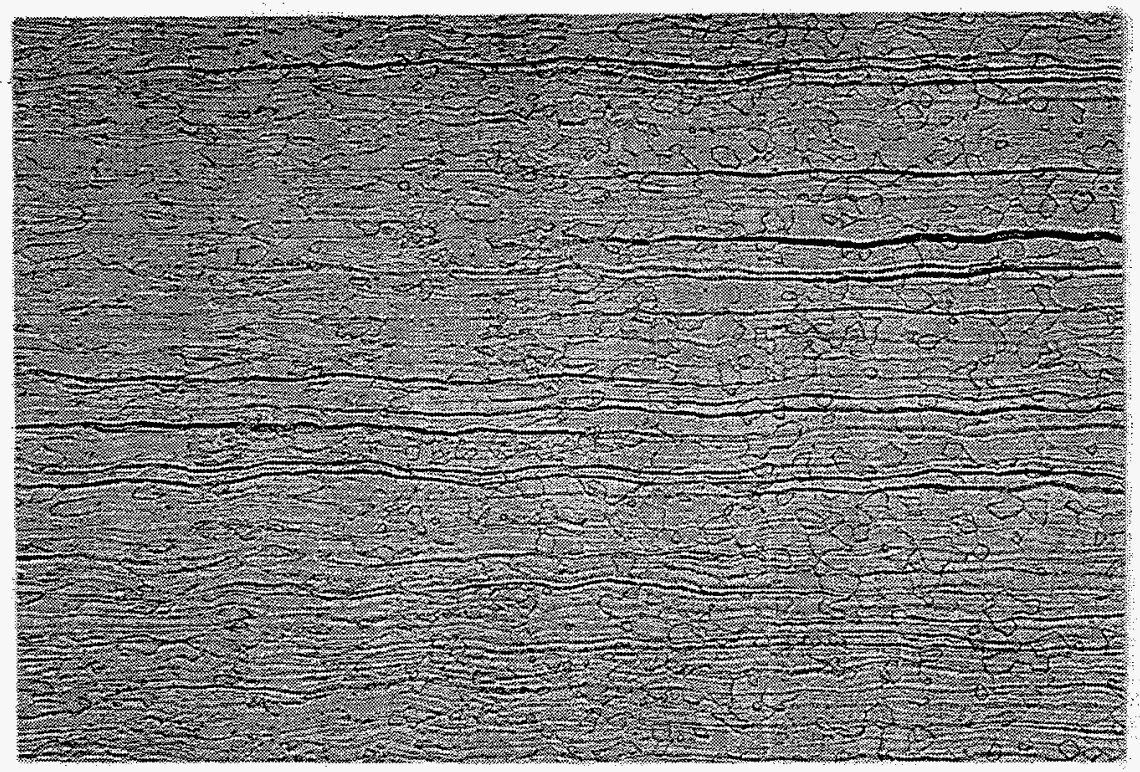

(b)

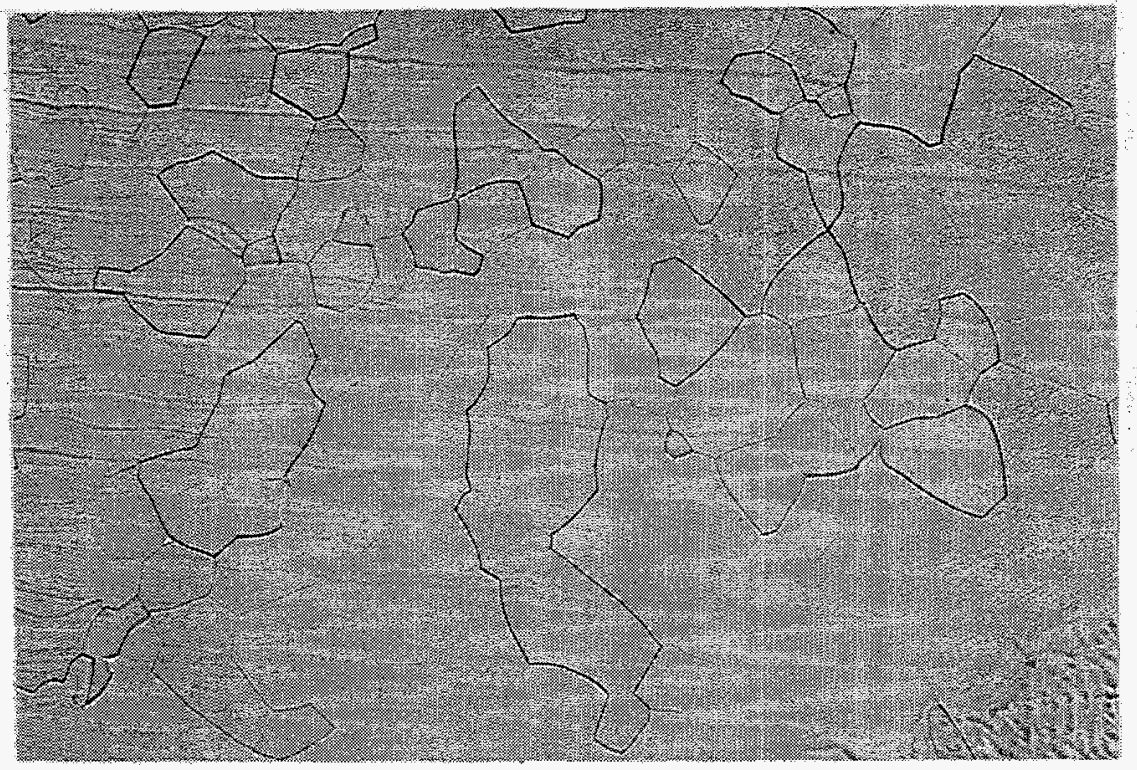

(c)

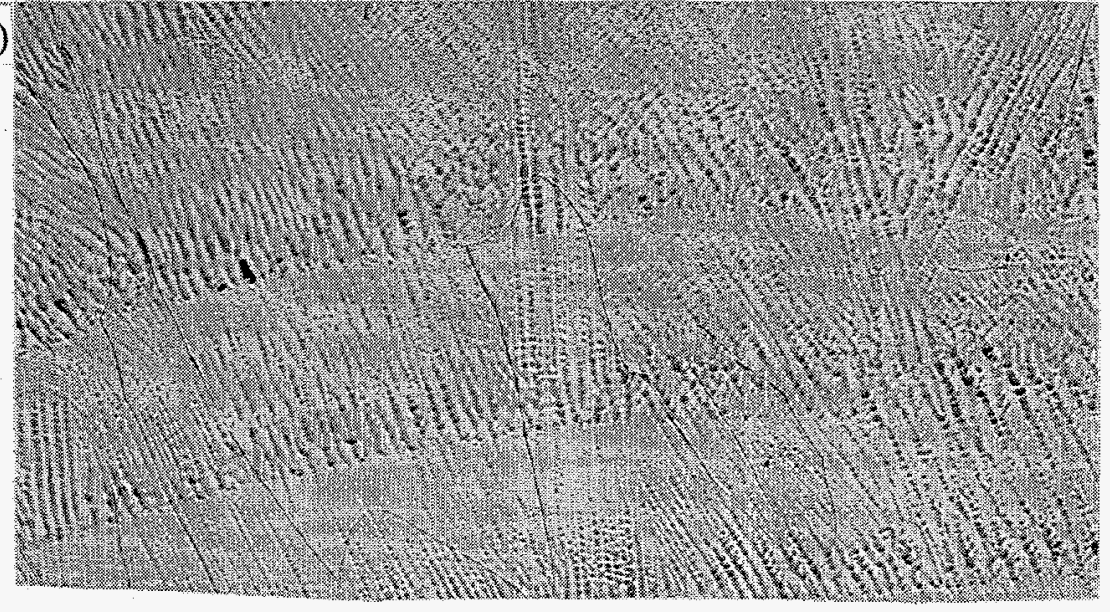

Fig. 42. Photomicrographs of the T-111 weld made by Mound and designated CB-2. Etched. 100×. (a) Base metal, (b) fusion line, (c) weld metal. 
(a)

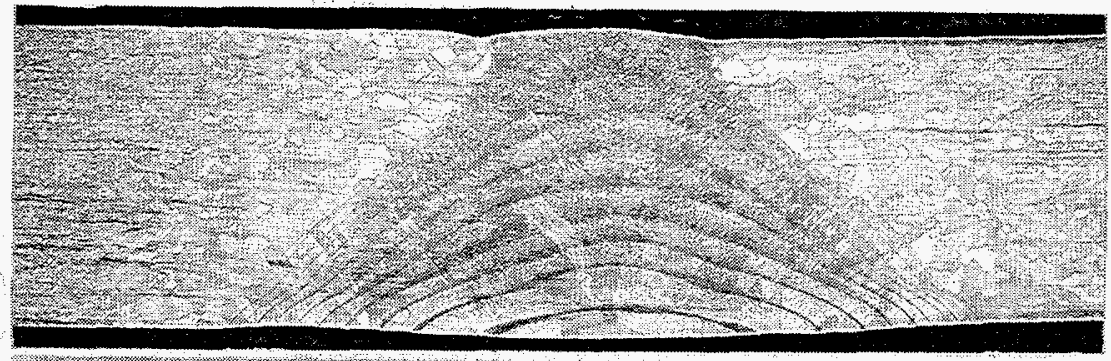

(b)

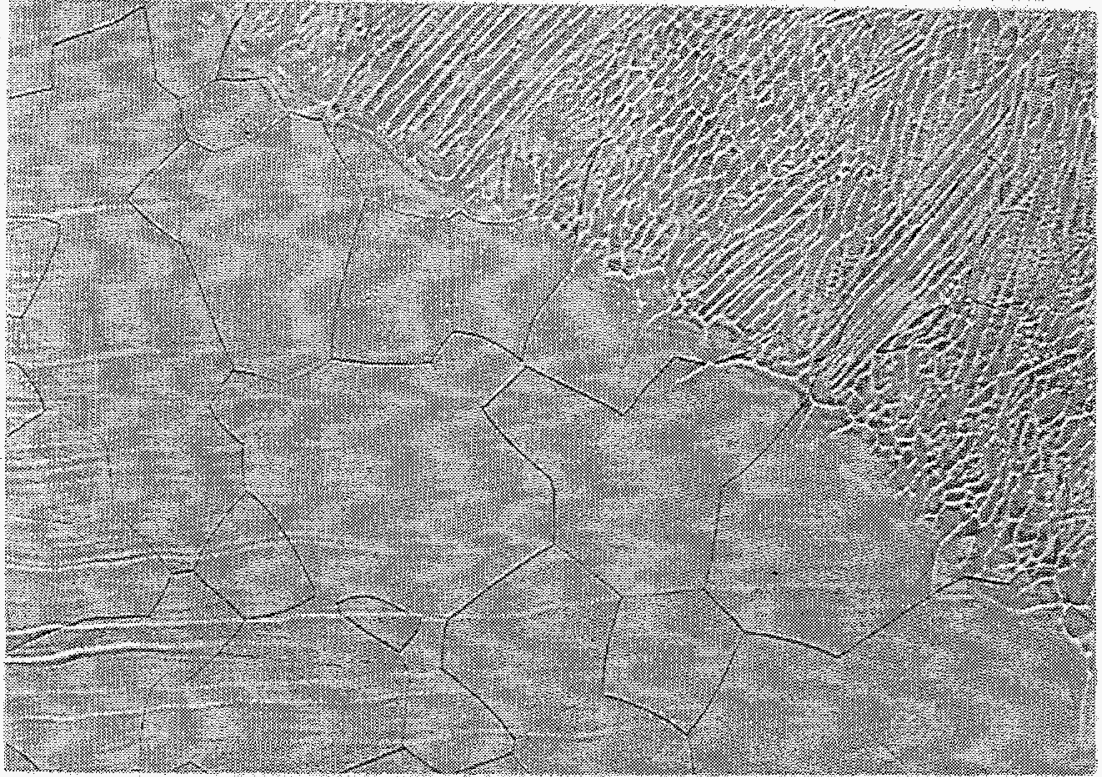

(c)

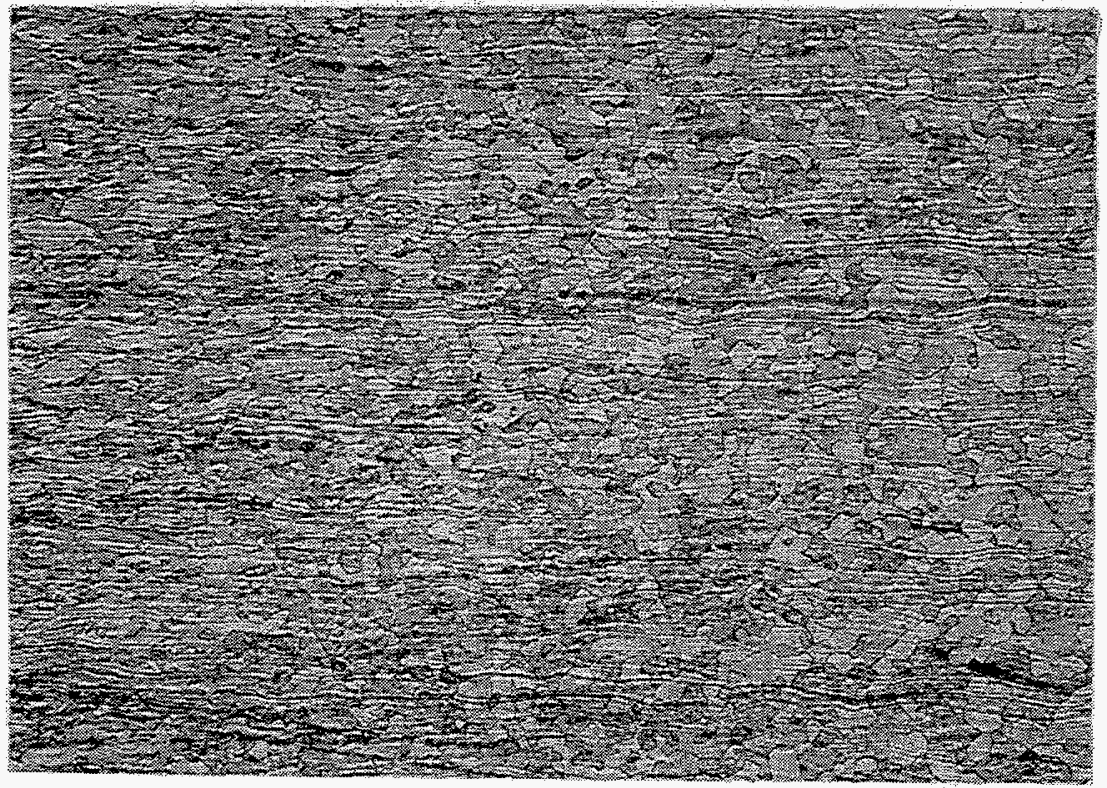

Fig. 43. Photomicrographs of the T-111 weld made by Mound and designated CB-2, oriented approximately $180^{\circ}$ from section shown in Fig. 41. Etched. (a) 12.8×, Transverse section of weld; (b) 100×, fusion line; and (c) $100 \times$, base metal. 

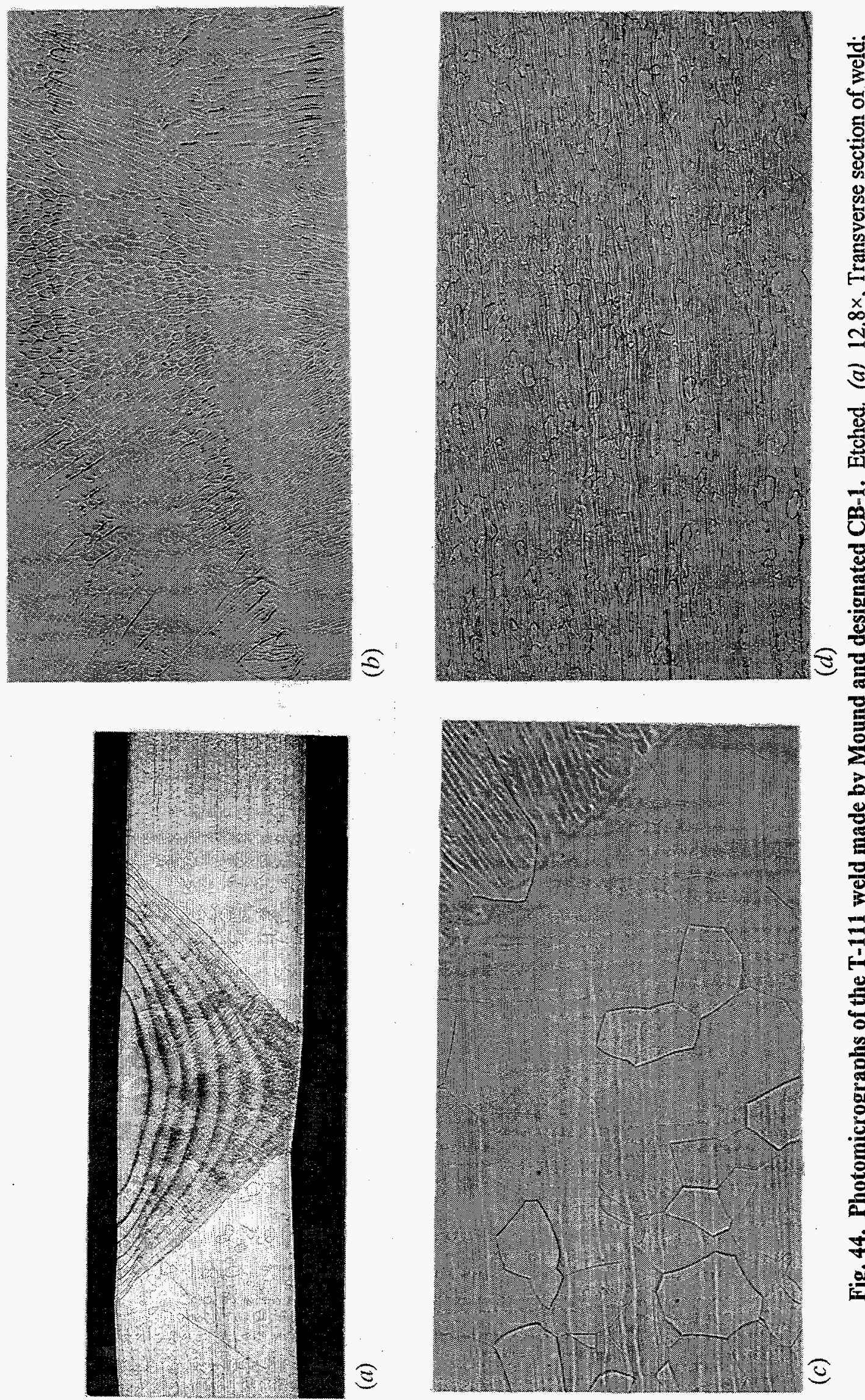

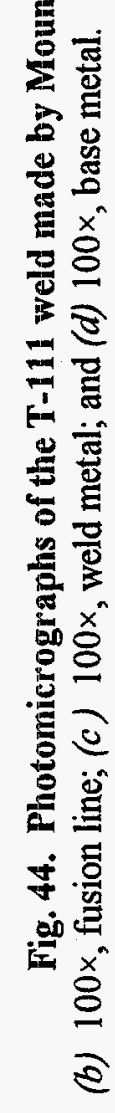




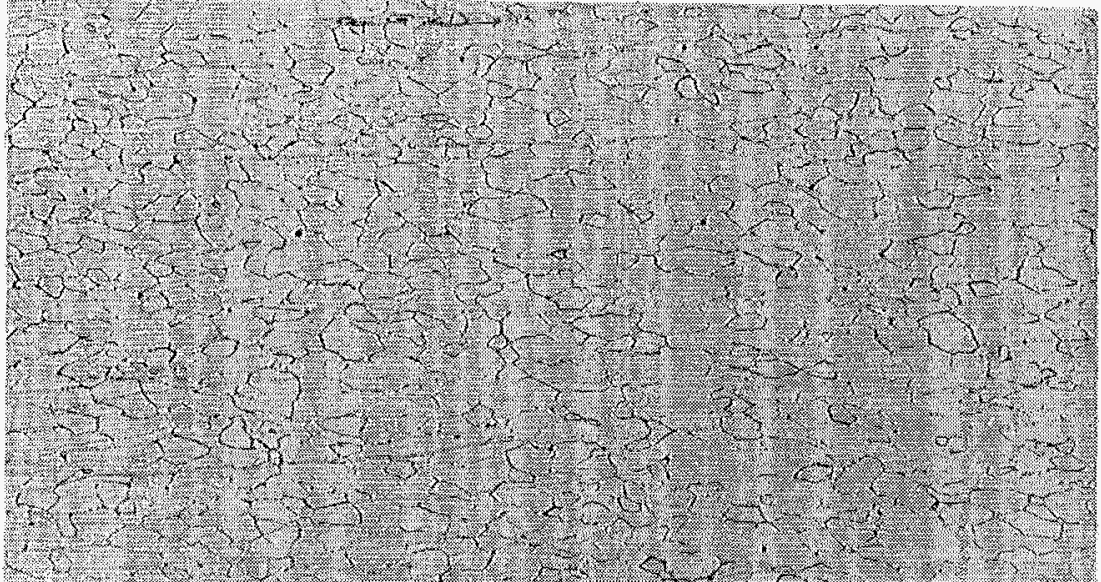

$(a)$

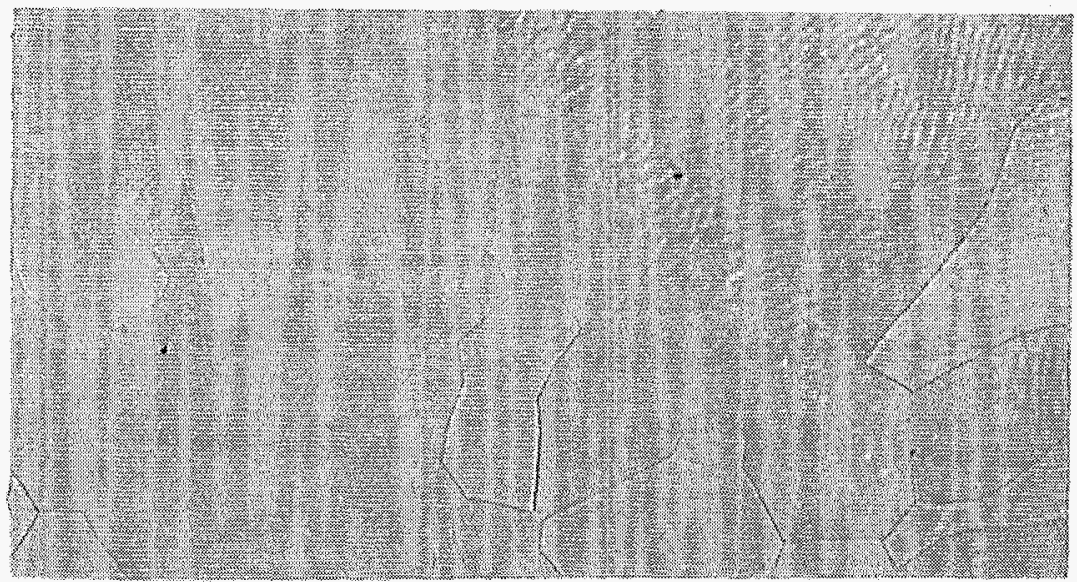

$(c)$

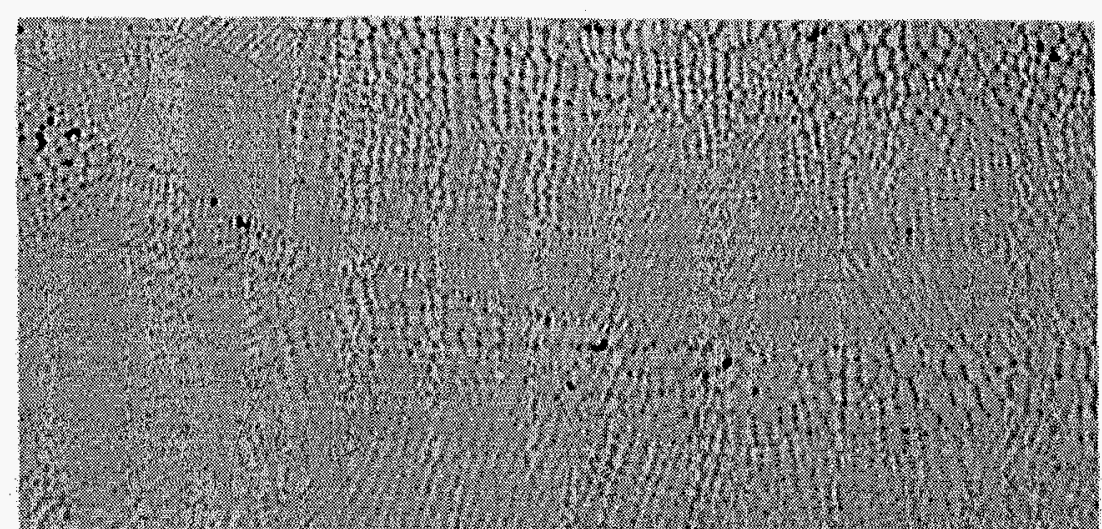

(b)

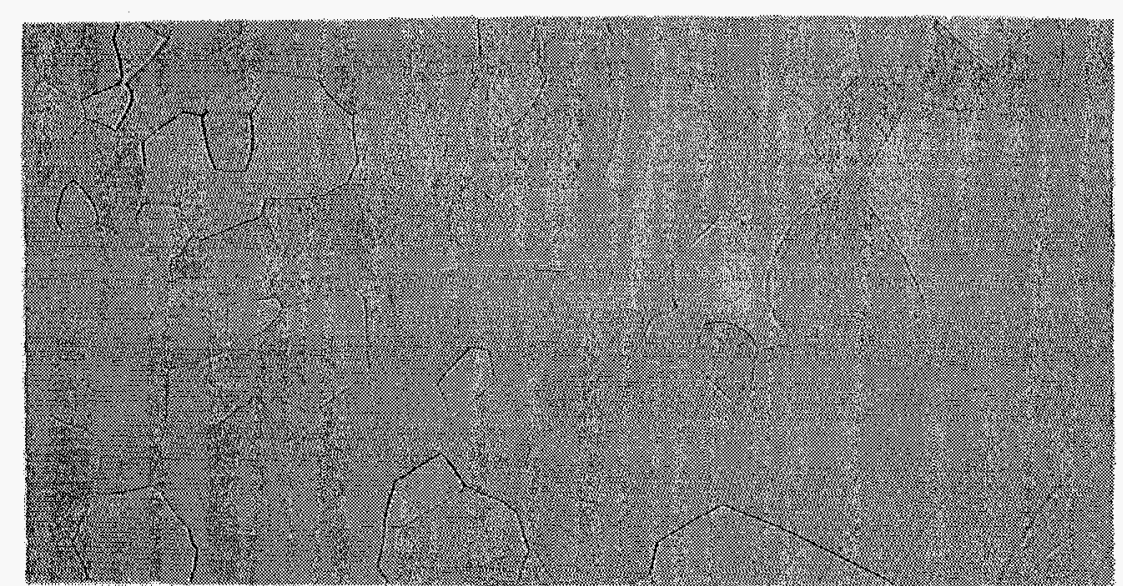

$(d)$

Fig. 45. Photomicrographs of the T-111 weld made by Mound and designated CB-1. Approximately $180^{\circ}$ from section in Fig. 44 Etched. $100 \times$ (a) Base metal, (b) fusion line, (c) weld metal, and (d) large grains in heat-affected zone. 


\section{4}
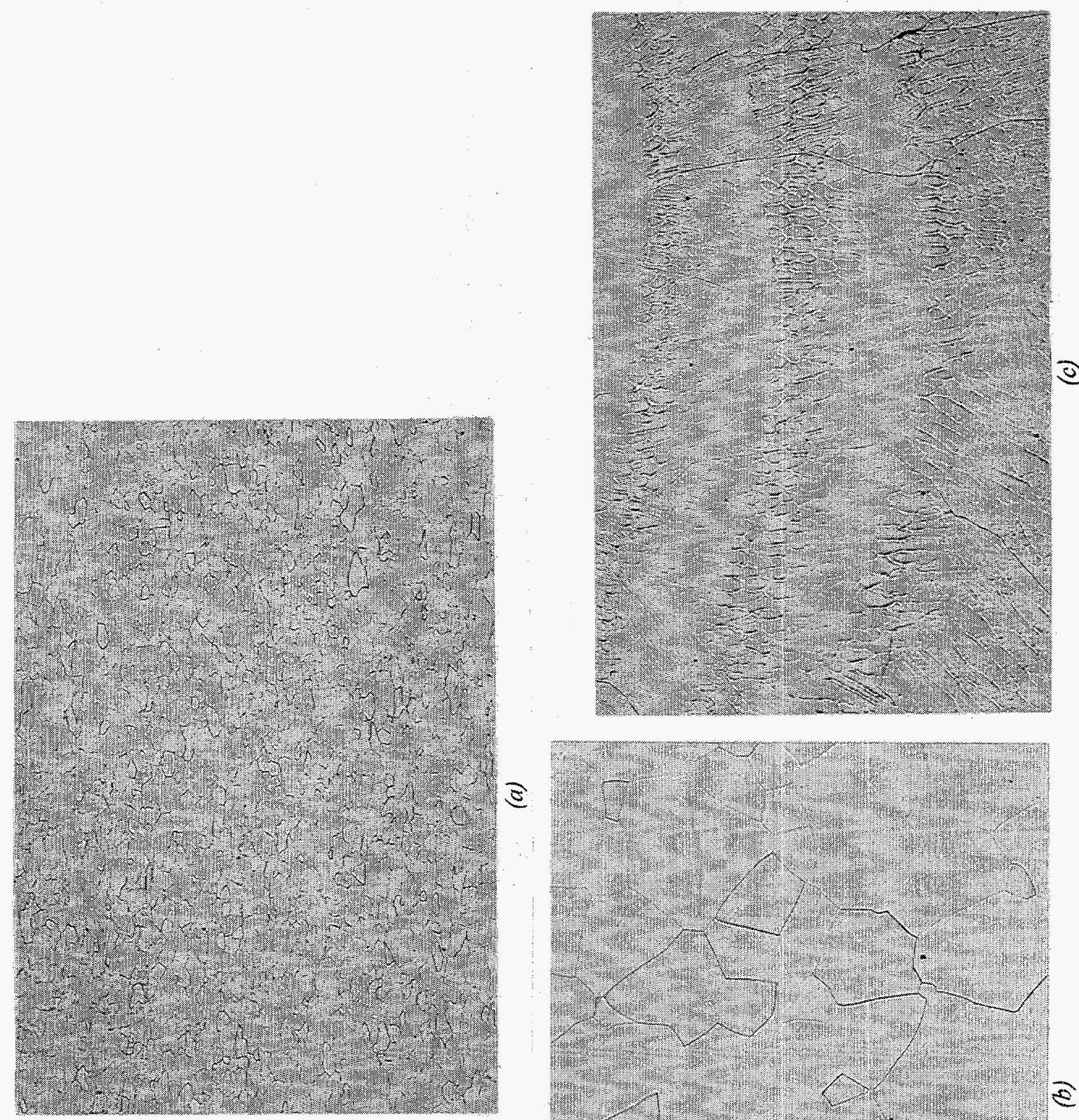

8
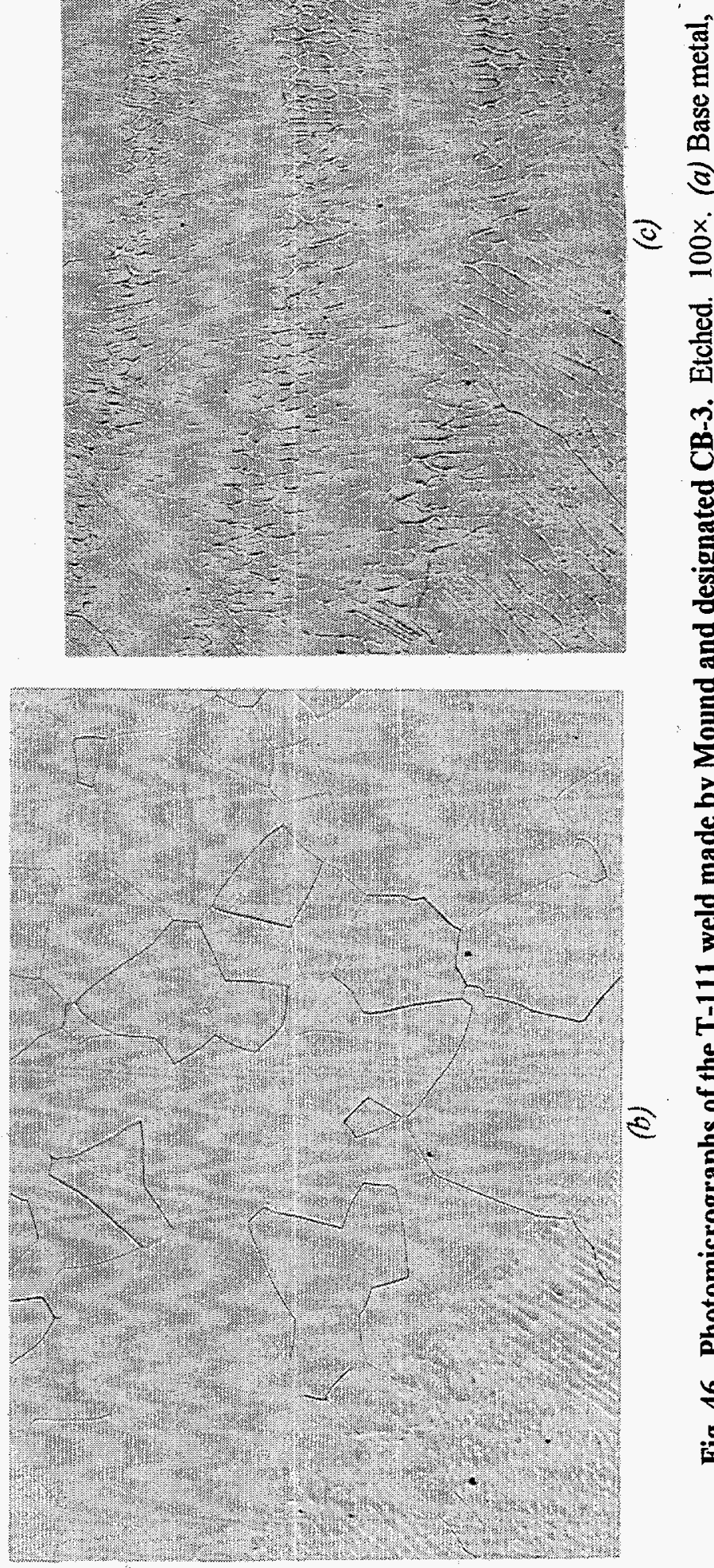

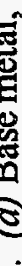
8.

马्g

1

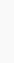

.

?

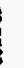

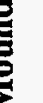

용

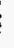

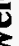

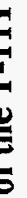

1

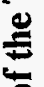

를

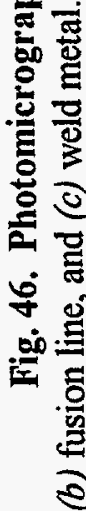




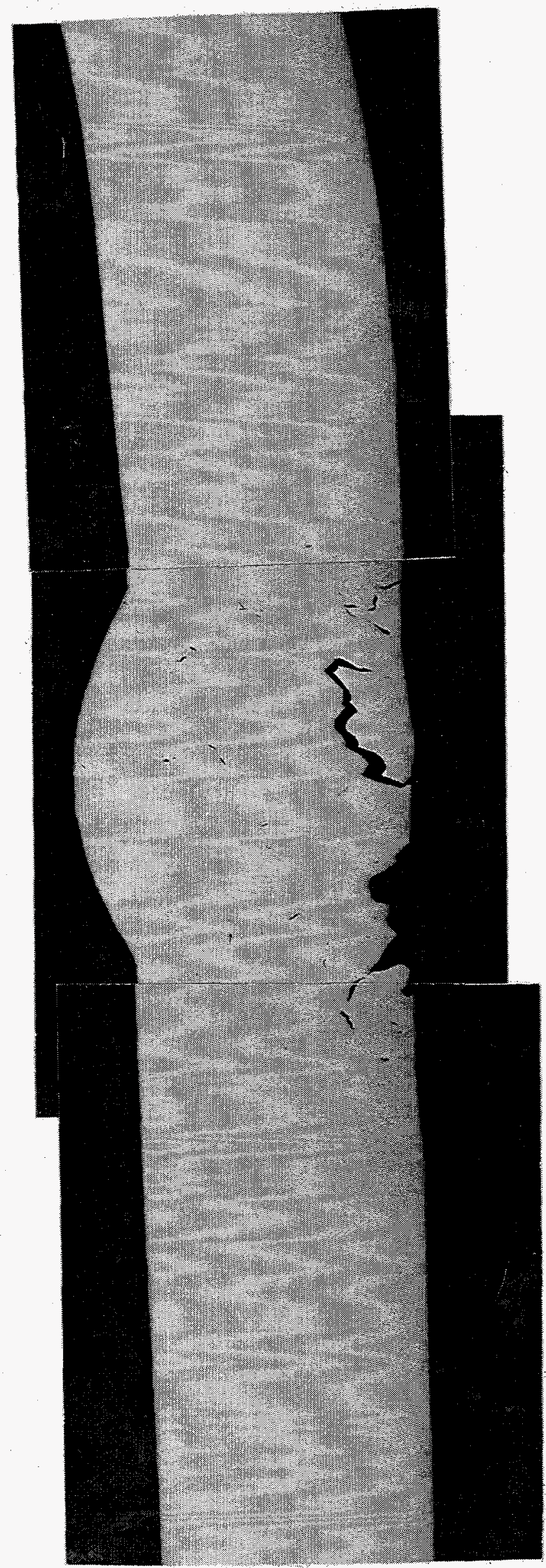

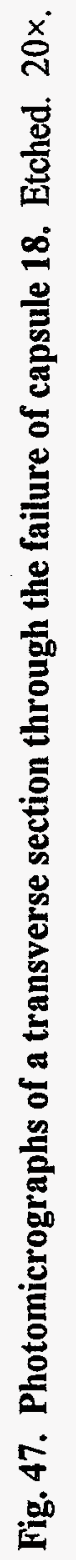




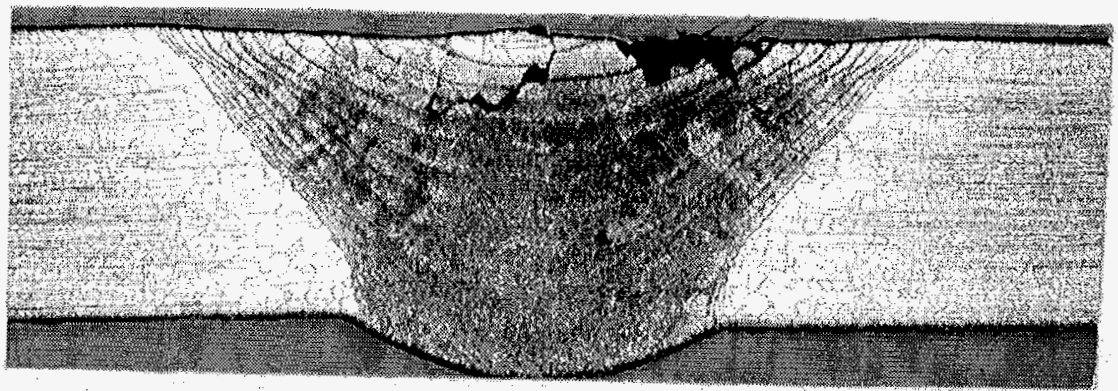

(a)

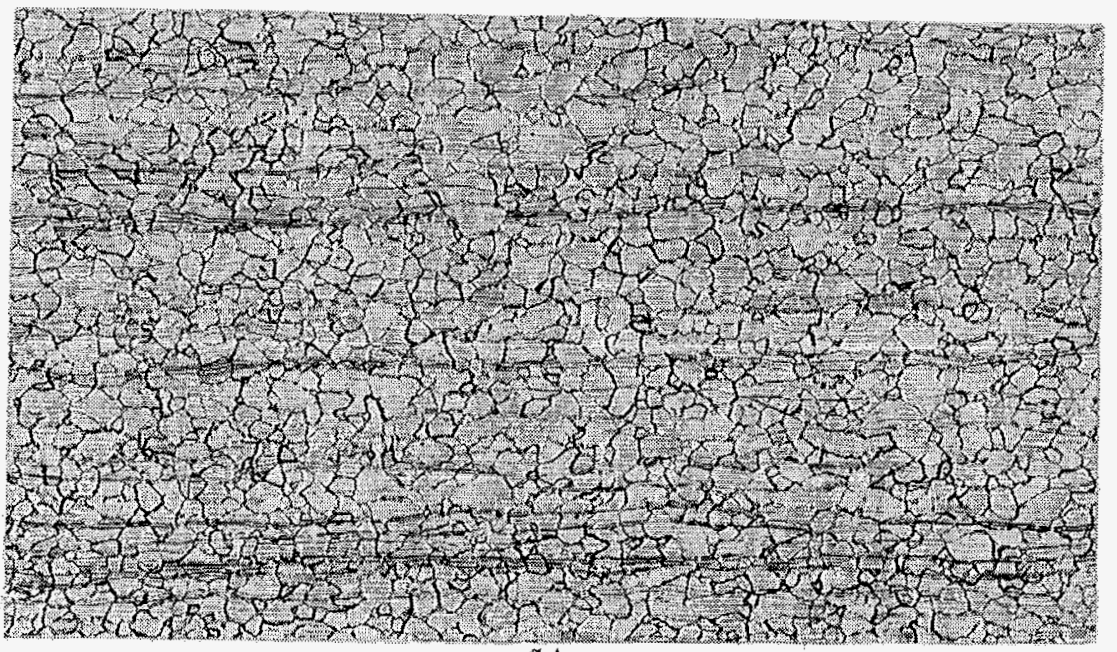

(b)

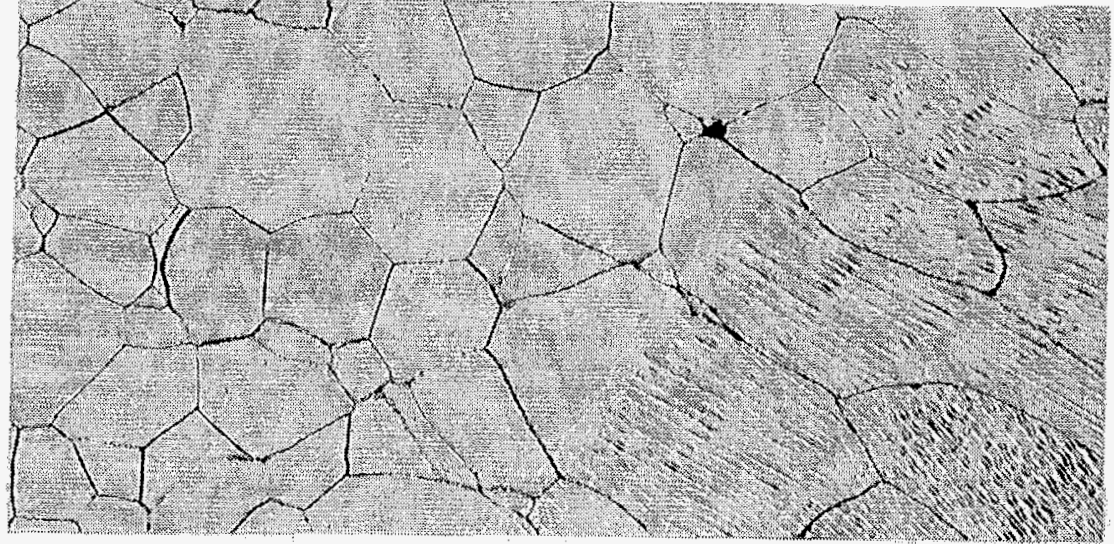

(c)

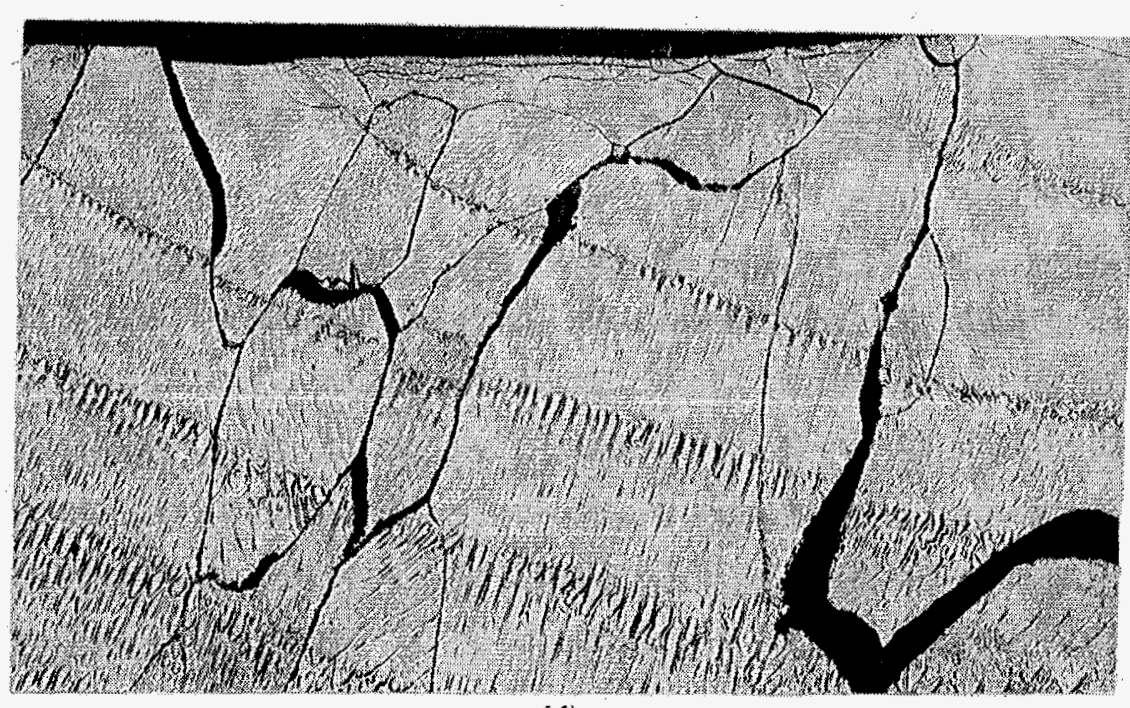

(d)

Fig. 48. Photomicrographs of a transverse section through the failure of capsule 18. Etched. (a) $12.8 \times$, Transverse section; (b) $100 \times$, base metal; (c) $100 \times$, fusion line; and (d) $100 \times$, weld metal. 


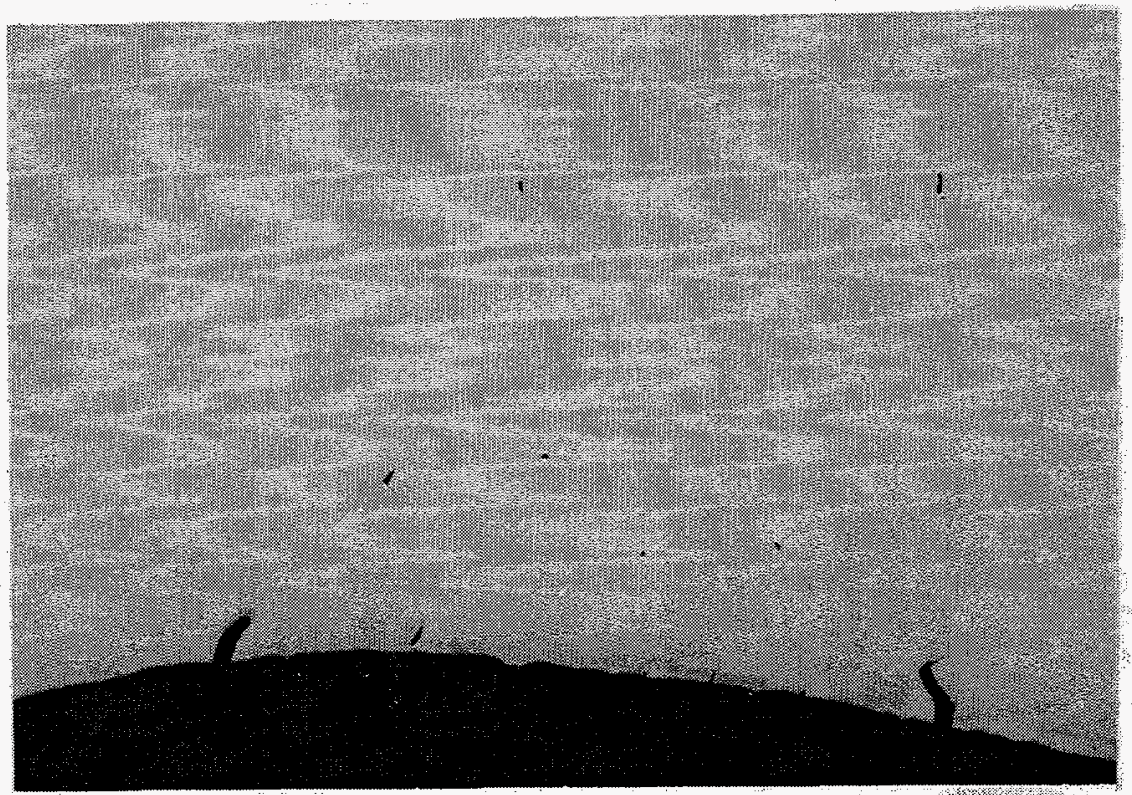

37m

Fig. 49. Photomicrograph of a longitudinal section through the failure of capsule 18. As-polished. $100 \times$. 


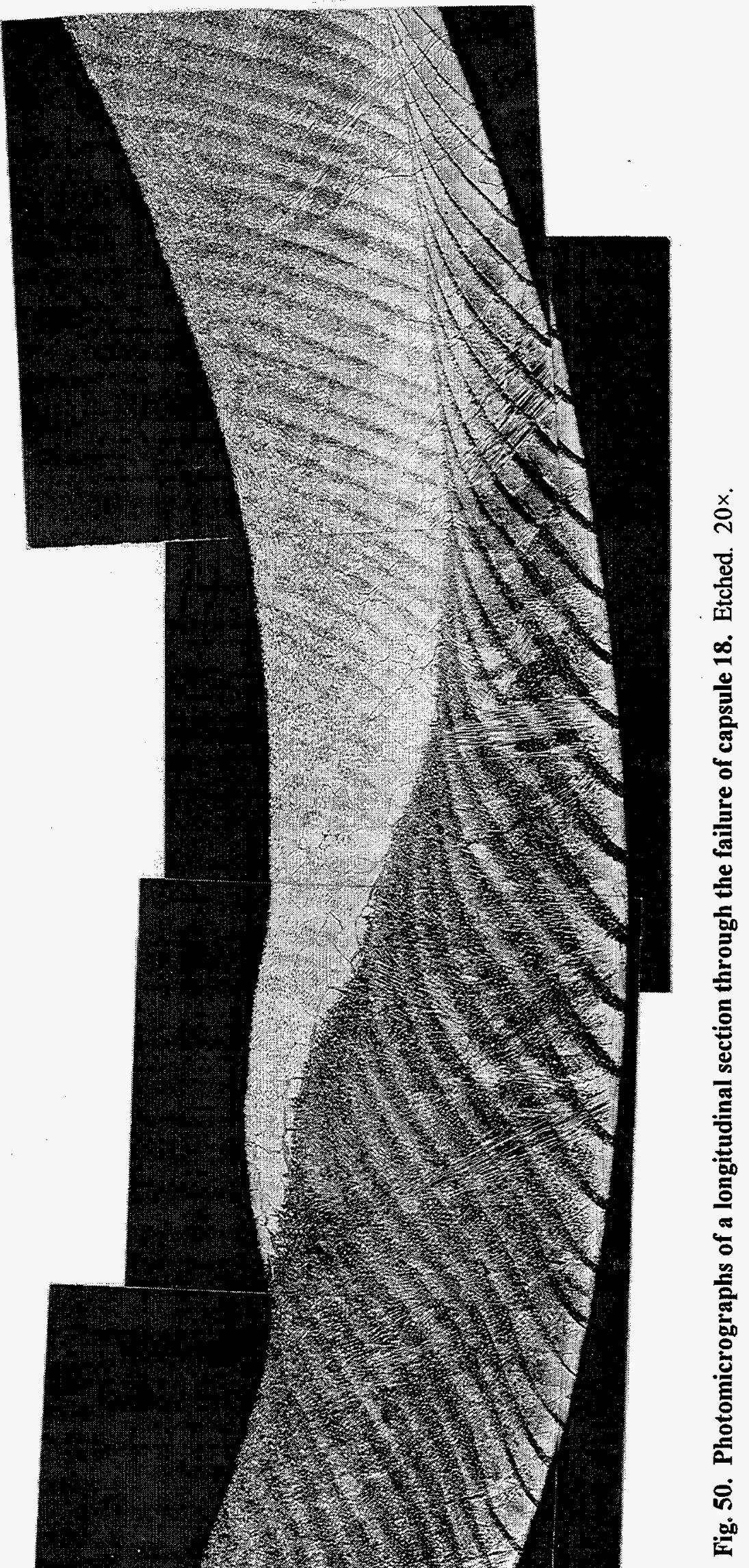


Photomicrographs of a section through the failure in capsule 15 are shown in Fig. 51 (unetched). After etching, Figs. 52 and 53 show that there are several cracks near the outer surface of the weld, but this section likely does not contain the main cracks. Examination of the root side of the transverse section revealed a surface reaction layer (see Fig. 54). This layer is quite shallow but is likely associated with the increase of oxygen and nitrogen in this sample that was previously discussed. Since the reaction layer is on the inside surface, it appears that the contaminant (likely air) was introduced through the pressurization gas.

The transverse section of the failure of capsule 15 was repolished to view a different depth. The photomicrographs shown in Fig. 55 reveal some cracks near the outer surface, but they are likely not the main ones as well.

A longitudinal section of capsule 15 had numerous cracks on both the inner and outer surfaces. The cracks are visible both in the as-polished (see Fig. 56) and etched (see Fig. 57) conditions. The backup strip is visible in Figs. 56 and 57. Photomicrographs of cracks near the inner and outer surfaces are shown in Fig. 58. Cracking is rather extensive in this view.

Microhardness across the transverse section of capsule 18 was measured, and the results are shown in Fig. 59. These results agree very well with those measured for an as-welded sample (see Fig. 5). There is very little difference in the hardness of a profile extending from base metal through weld metal to base metal. Thus the change in grain size associated with making the weld is likely more important than the small hardness change.

\section{SUMMARY}

The main thrust of this program was to determine safe design stresses for $\mathrm{T}-111$ in the temperature range of 300 to $800^{\circ} \mathrm{C}$. Tensile, creep-to-rupture, and long-term creep tests were conducted to obtain the information needed for developing a basis for determining allowable stress intensity values at these relatively low temperatures. This work determined the allowable long-term stress intensity for T-111 at temperatures up to about $850^{\circ} \mathrm{C}$ to be about $180 \mathrm{MPa}$. At higher temperatures, the allowable stress intensity must be reduced due to creep.

The service component is a small capsule that has a GTA girth weld. The tensile and creep samples were run with and without the girth weld. The weld process resulted in a deposit of melted weld metal surrounded by a region of grains that were enlarged from those of the base 
material by the heat input to the weld. This HAZ was slightly softer than the base metal and the weld metal. Most specimens having a transverse weld failed in the HAZ, but the strength was not reduced appreciably. The fracture strain was lower for samples with a transverse weld than for base metal, largely because deformation in the weld samples was generally restricted to the narrow band of large grains in the HAZ. The SEM and metallographic observations revealed that T-111 samples with a transverse GTA weld failed in the HAZ or weld.

Two capsules made by Mound using standard production procedures were tested to failure. The capsules were internally pressurized with inert gas while being heated in a vacuum system to protect the T-111 from reaction with air. Both of these capsules failed in the girth weld and had diametral strains of about $1.5 \%$. The times to failure were reasonable but were on the weak side of the larger population of strength data for T-111 base metal. After failure, leak rates of the capsules were measured at $25^{\circ} \mathrm{C}$, and the diameter of the leaking defect was calculated. The leak rates were reasonable in light of the fine cracks that were noted during destructive examination of the capsules. 

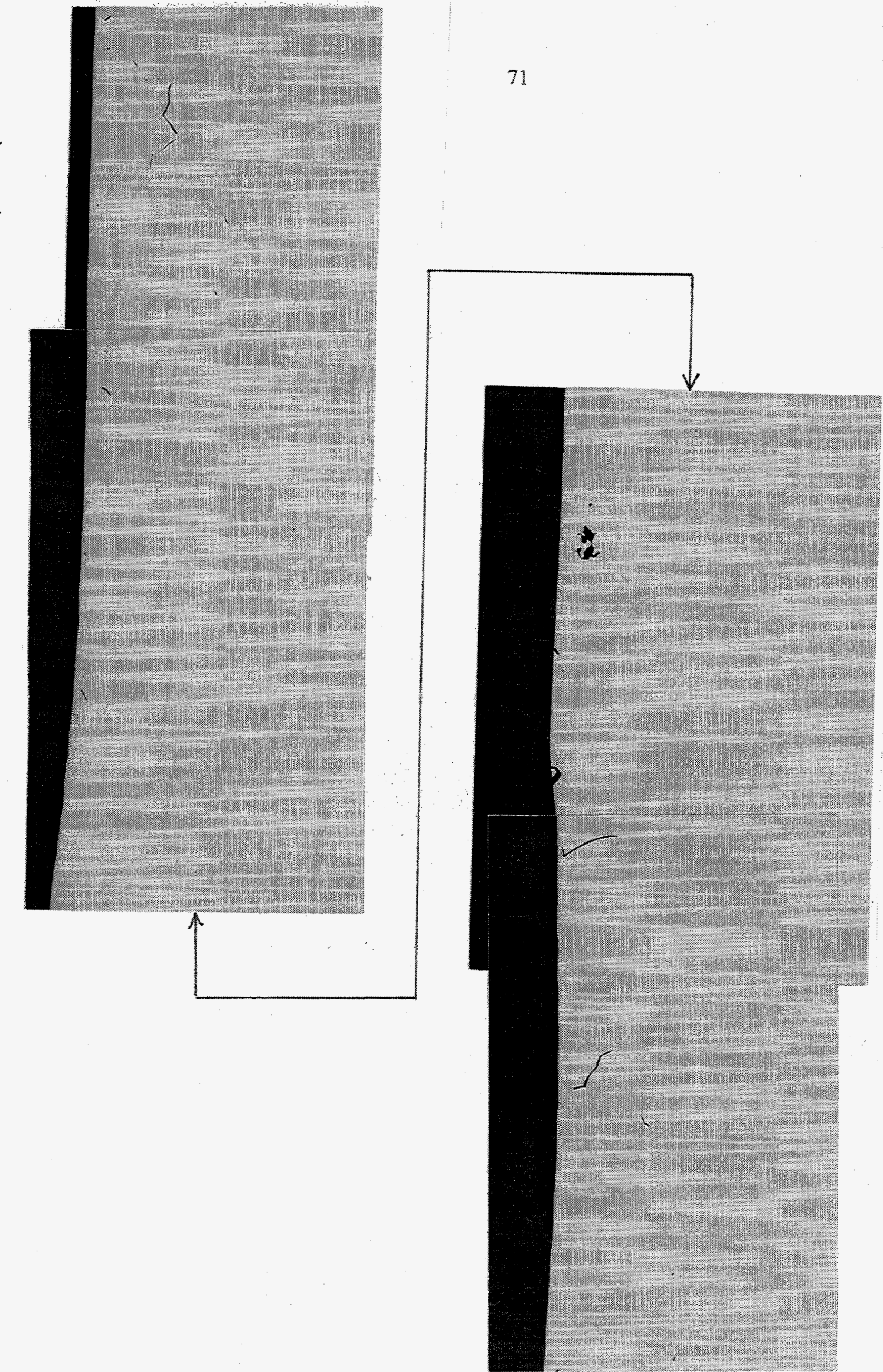
72

(a)

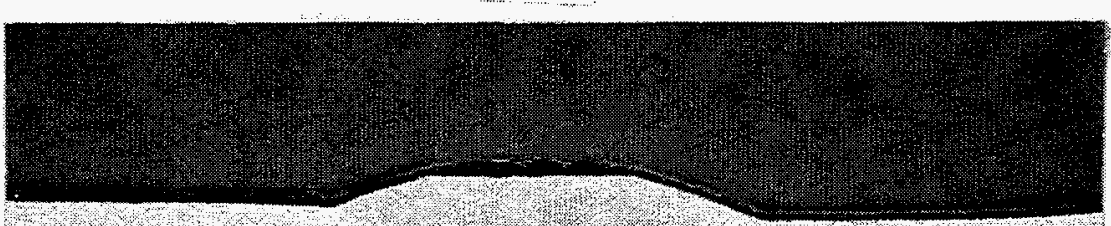

(b)

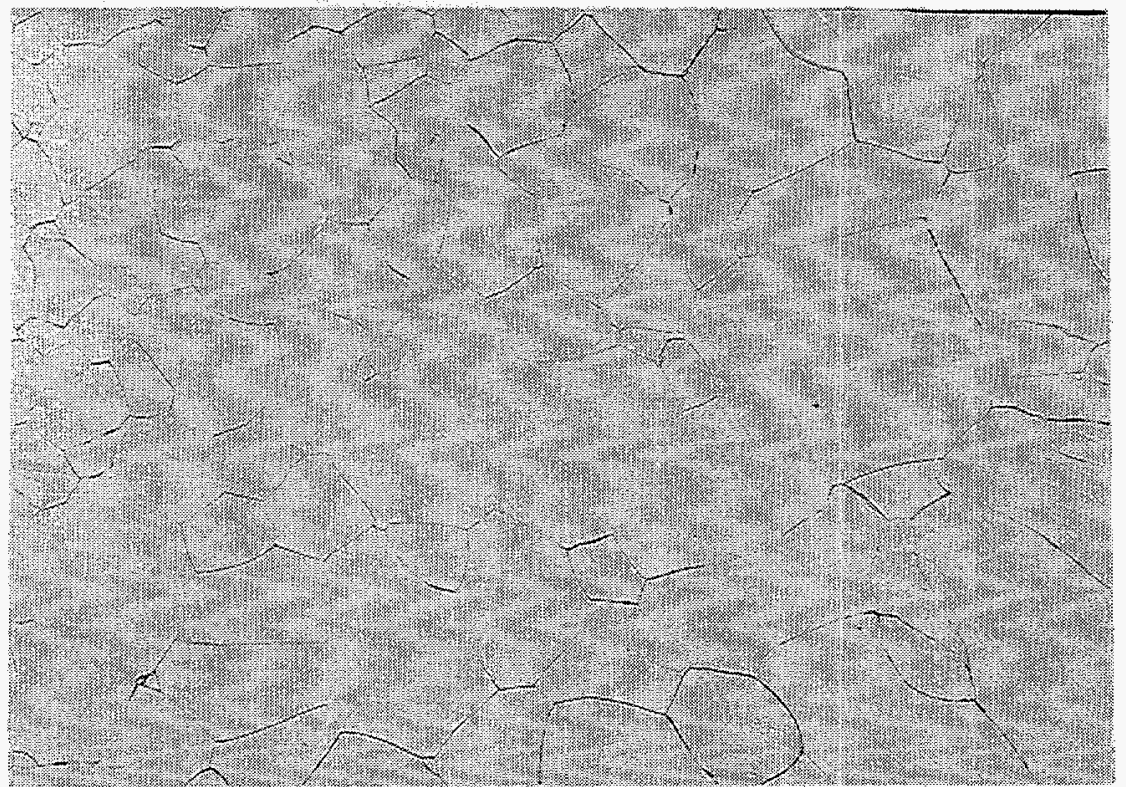

(c)

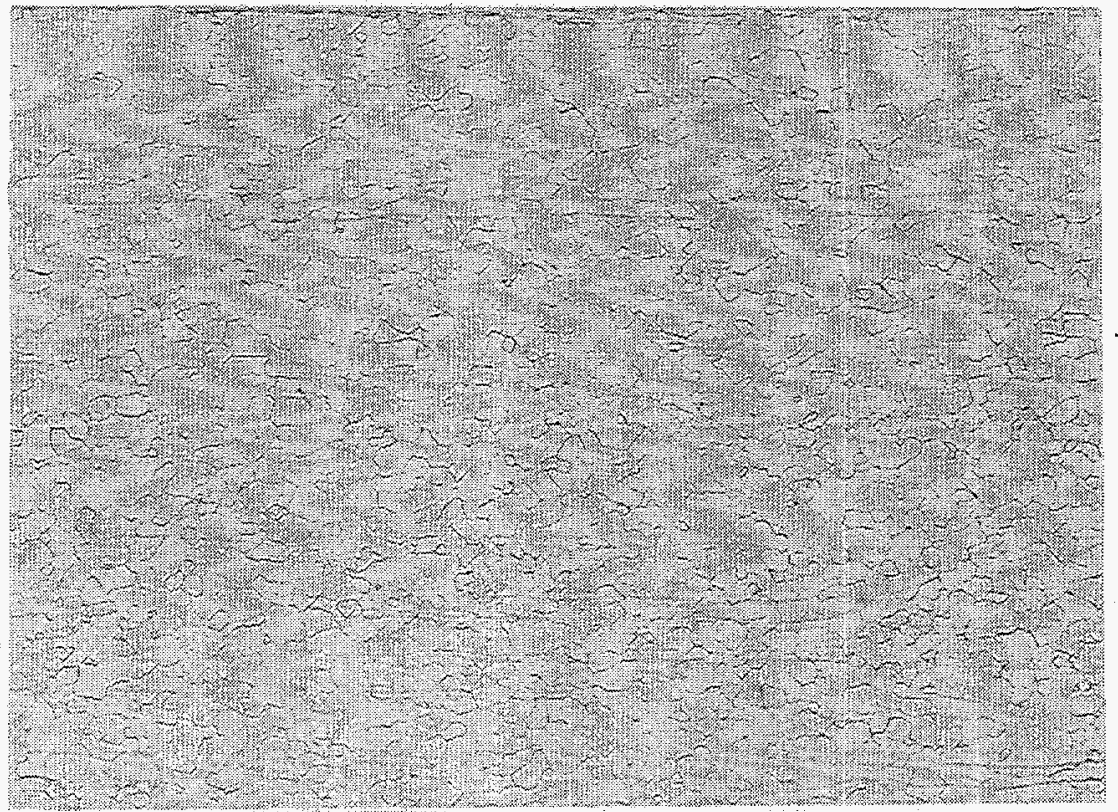

Fig. 52. Photomicrograph of a transverse section through

failure of capsule 15. (a) $12.8 \times$, Transverse section; (b) $100 \times$, large grains in the heat-affected zone, and (c) $100 \times$, base metal. 
(a)

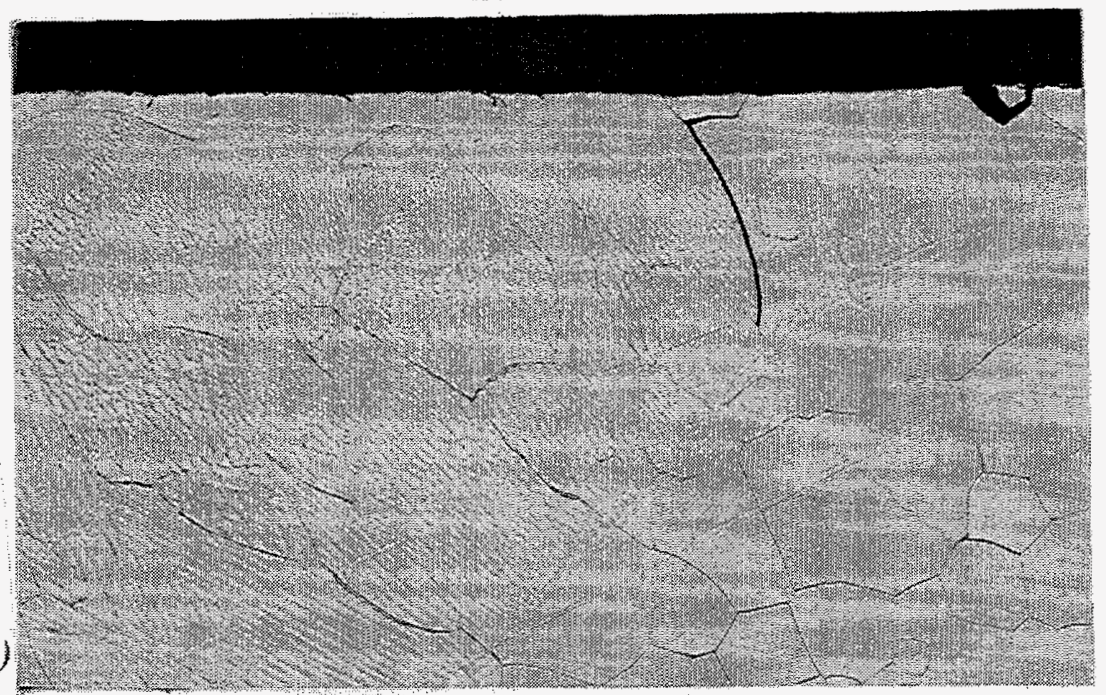

(b)

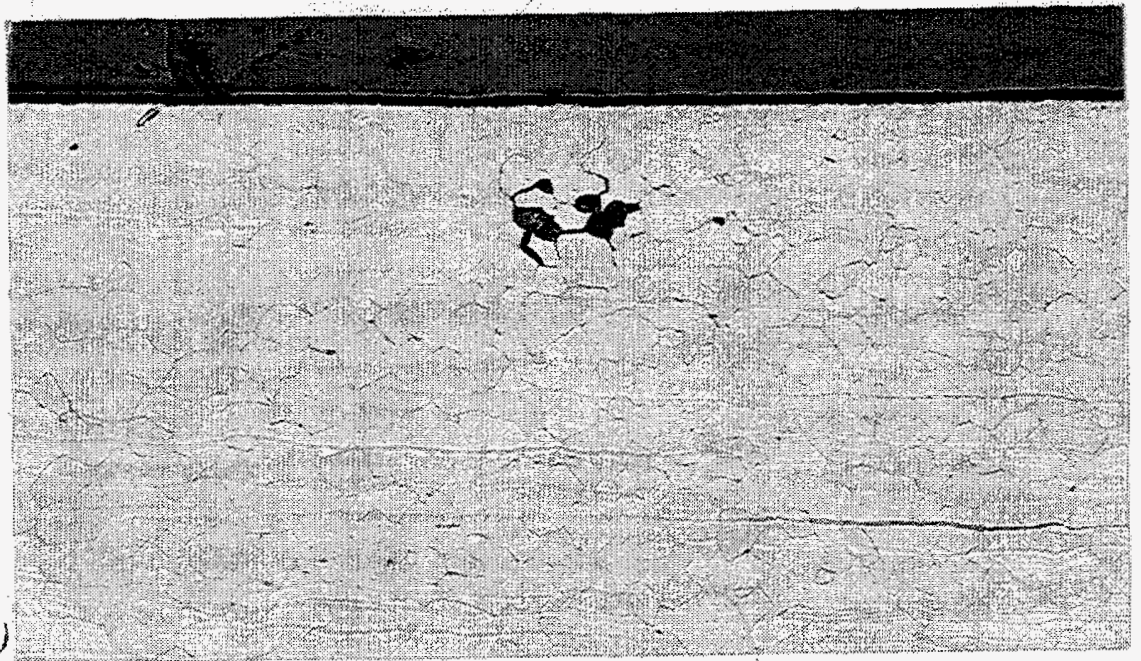

Fig. 53. Photomicrograph of a transverse section through the failure of capsule 15 showing cracks. Etched. $100 \times$

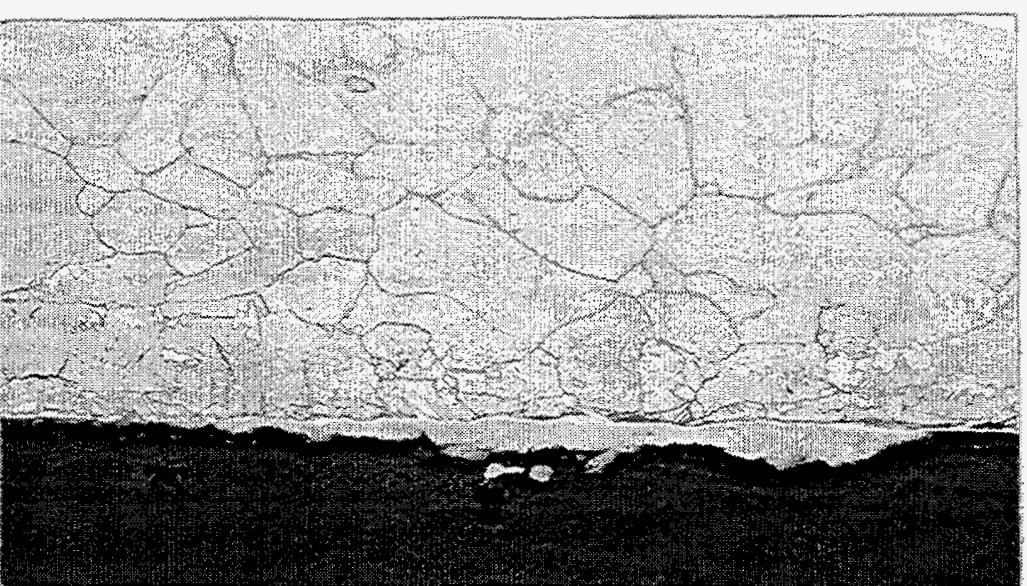

Fig. 54. Photomicrograph of the inside surface of a transverse section through the failure of capsule 15 showing surface reaction. Etched. $500 \times$. 


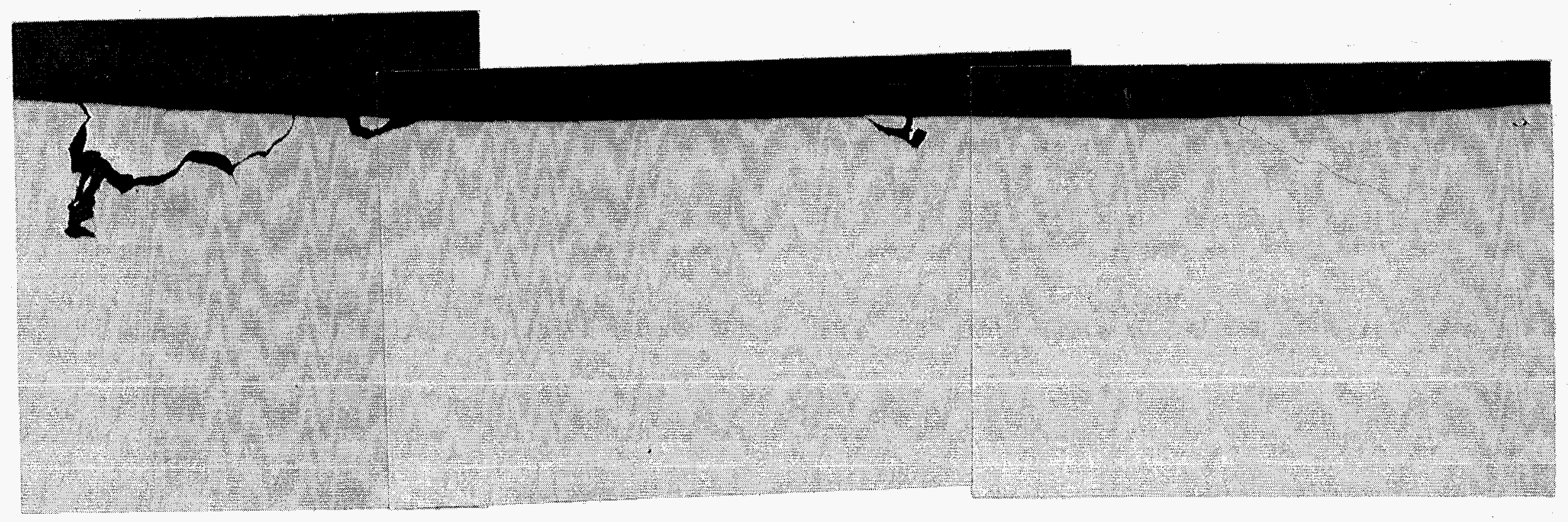

Fig. 55. Photomicrographs of a transverse section through the failure of capsule 15. Additional material was removed after the photomicrographs shown in Fig. 51 were taken. As-polished. 50x. Taken near the outside surface. 


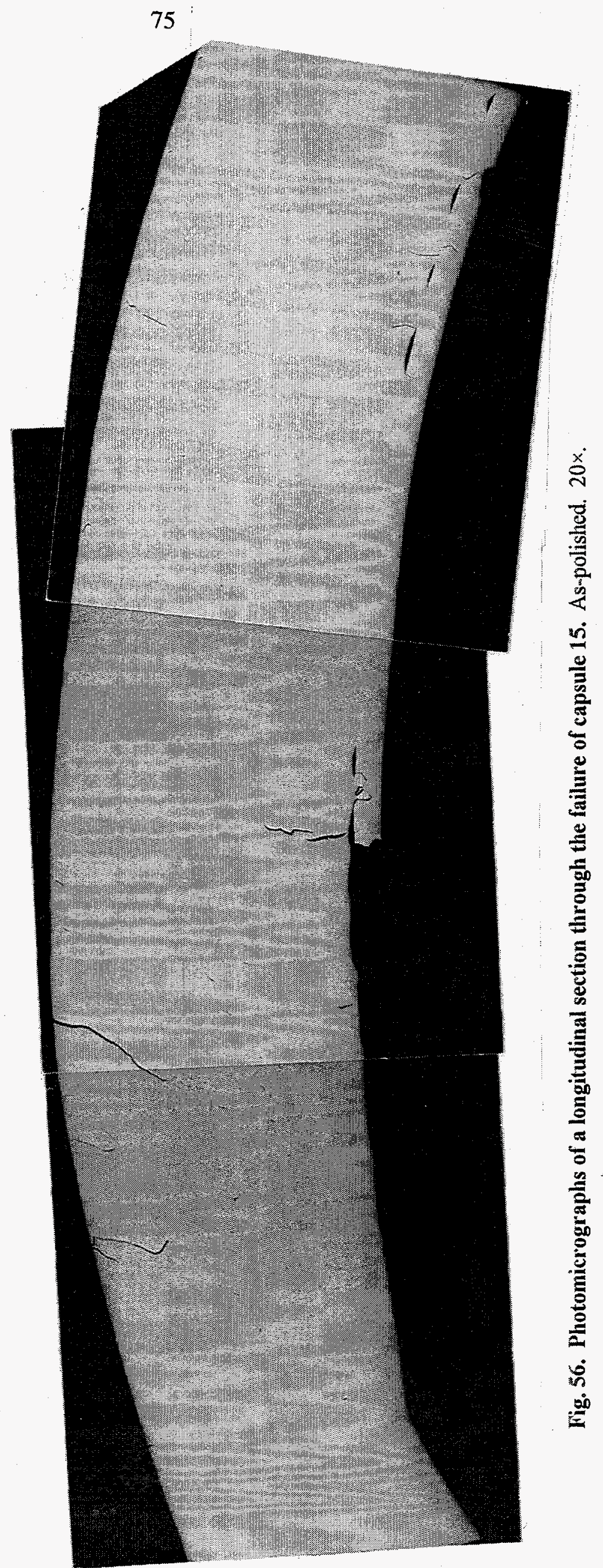




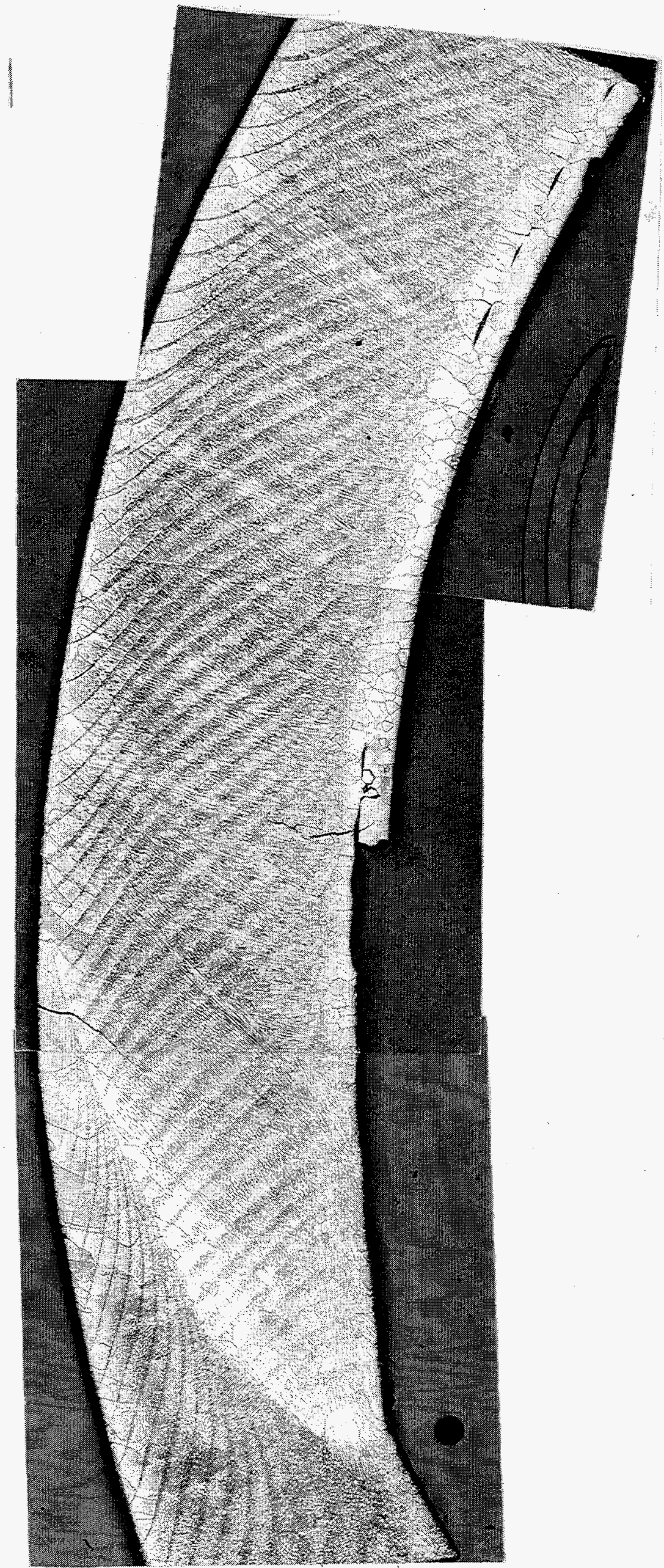

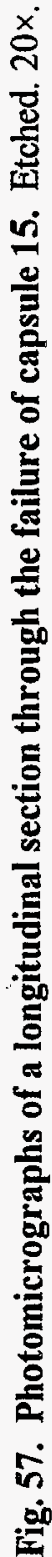




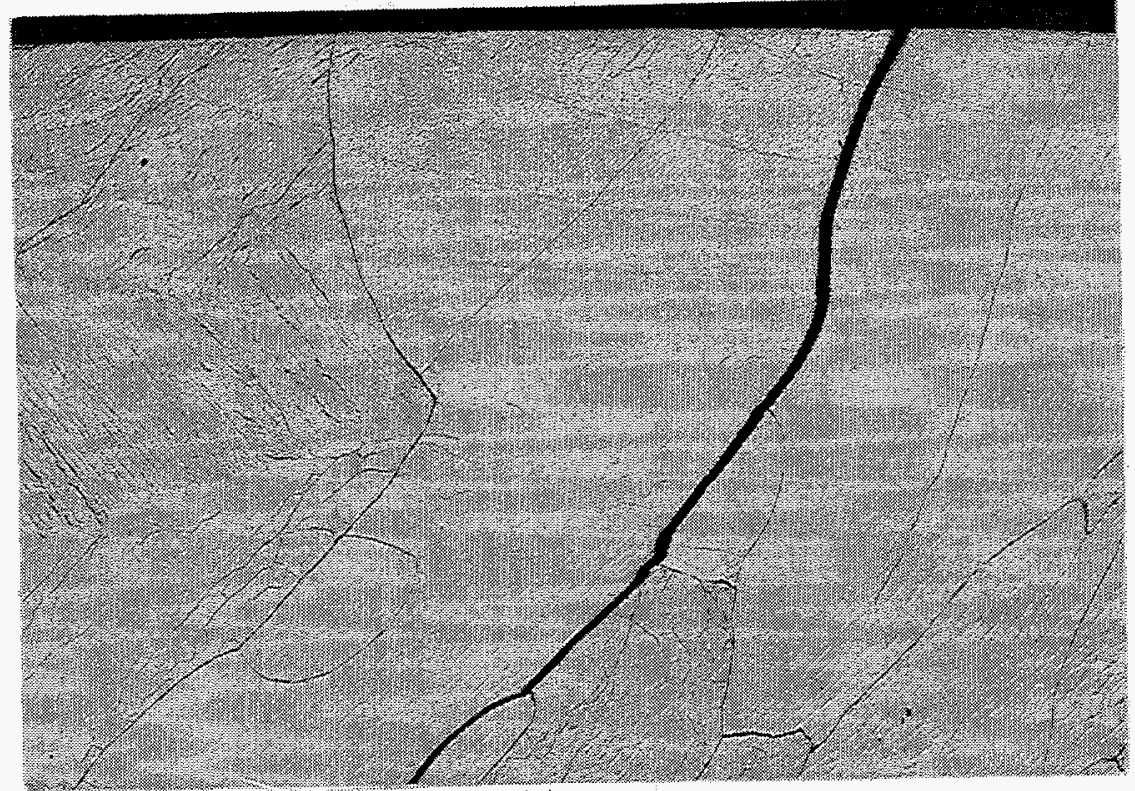

(a)

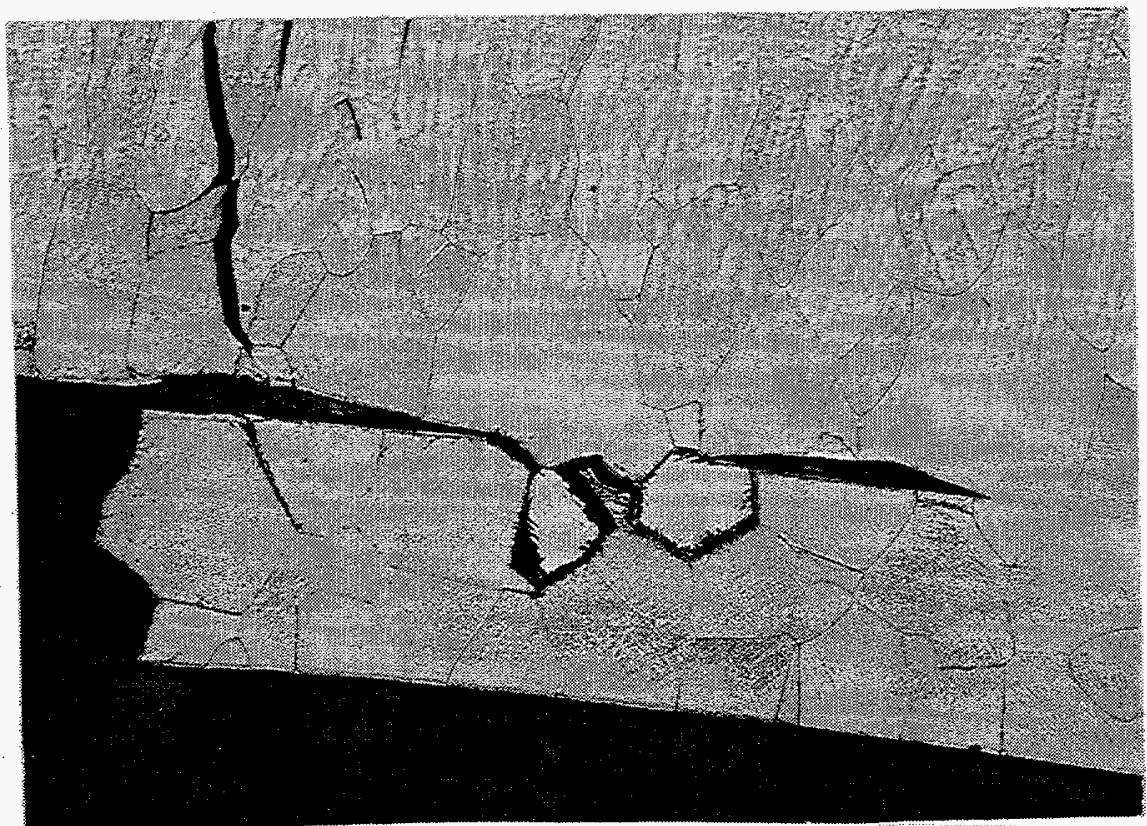

(b)

Fig. 58. Photomicrographs of a longitudinal section through the failure of capsule 15. Etched. 100×. (a) Outside edge and (b) inside edge (root). 


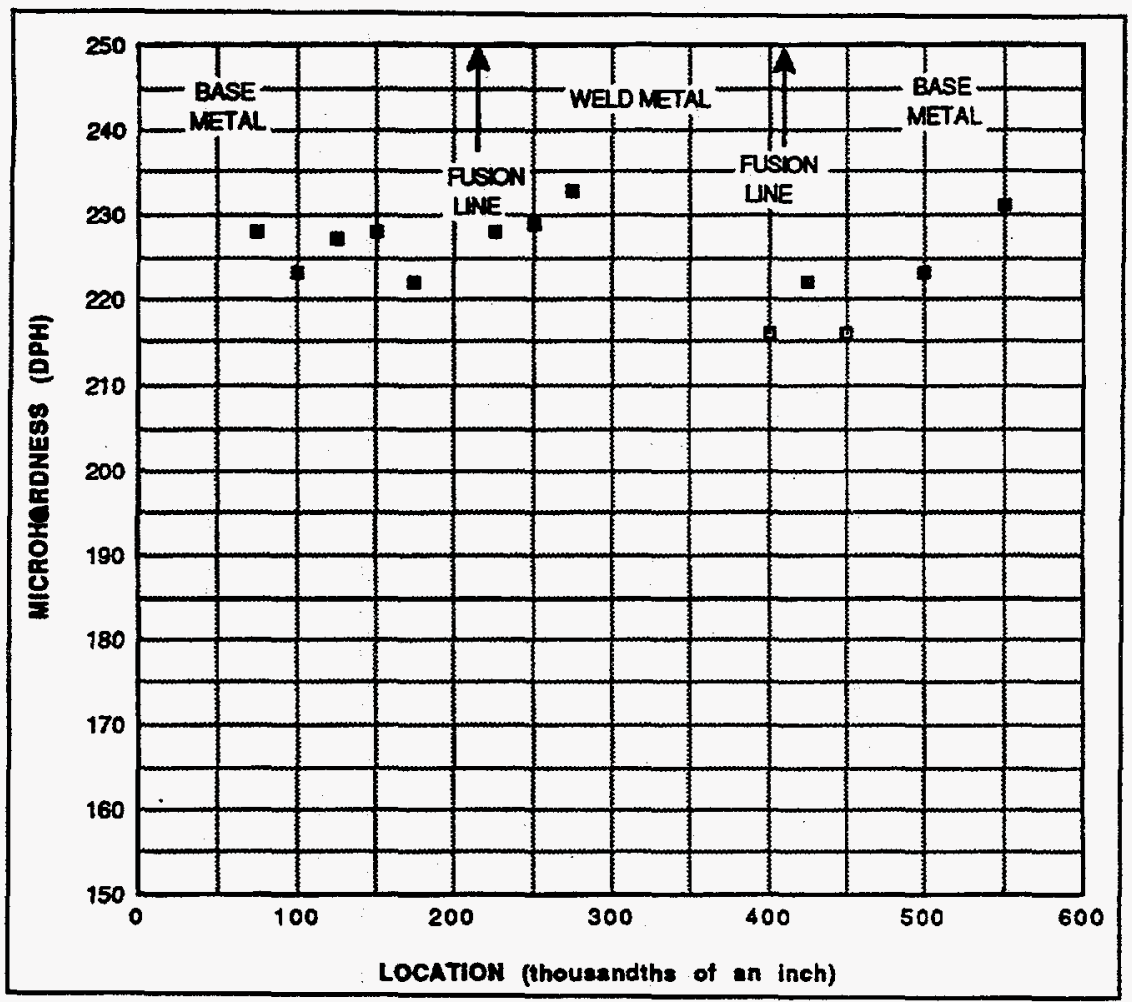

Fig. 59. Microhardness profile across transverse section of weld in capsule 18. 
The failure regions of the capsules were examined by SEM. Intergranular cracks were noted on the inner and outer surfaces. These cracks were located predominately in the weld, but often penetrated into the HAZ. Cracks were noted in some regions where leaking could not be detected by a helium leak detector. Cracks were often associated with interruptions in the welding process that resulted in craters or other steps in weld thickness. Samples of the tested capsules were examined metallographically, and cracks were noted in the failed regions of the capsules. The welds, outside the immediate failure region, appeared sound.

\section{ACKNOWLEDGMENTS}

The authors are grateful to J. P. Moore and C. R. Brinkman for programmatic and technical assistance. D. W. Coffee performed the scanning electron microscopy and H.F. Longmeir the metallography. J. F. King and R. W. Swindeman reviewed the manuscript. J. F. King was the engineer in charge of welding, and B. G. Gieseke was the engineer responsible for the tensile tests. D. A. Frederick performed the welding, and L. K. Egner, L. D. Chitwood, and C. O. Stevens were the technical support personnel who assembled the tests and operated the many pieces of test equipment. K. Spence edited the manuscript. 


\section{REFERENCES}

1. T. J. Moore, P. E. Moreland, and K. J. Bowles, Specifications for Cleaning, Fusion Welding, and Postheating Tantalum and Columbium Alloys, NASA TM X-67879, National Aeronautics and Space Administration, Washington, D.C., July 1971.

2. K. D. Sheffler and R. R. Ebert, Generation of Long Time Creep Data on Refractory Alloys at Elevated Temperatures, NAS-CR-134481, National Aeronautics and Space Administration, Washington, D.C., September 1973.

3. R. L. Stephenson and H. E. McCoy, Jr., "Comparative Mechanical Behavior of Some Tantalum-Base Alloys," J. Less-Comm. Met. 15, 415 (1968).

4. F. C. Monkman and N. J. Grant, "An Empirical Relationship Between Rupture Life and Minimum Creep Rate in Creep-Rupture Tests," Am. Soc. for Test. Mater., 14, 91, (1936).

5. Private Communication, Denton Anderson, Teledyne Brown Engineering Energy Systems, Hunt Valley, Maryland, Oct. 18, 1995.

6. J. R. McDougal, Sixty-Watt Isotopic Heat Source Safety Test Program, Summary Report, EG\&G Mound Applied Technologies, Miamisburg, Ohio, May 1995. 
APPENDICES 
A. Strain data for T-111 samples

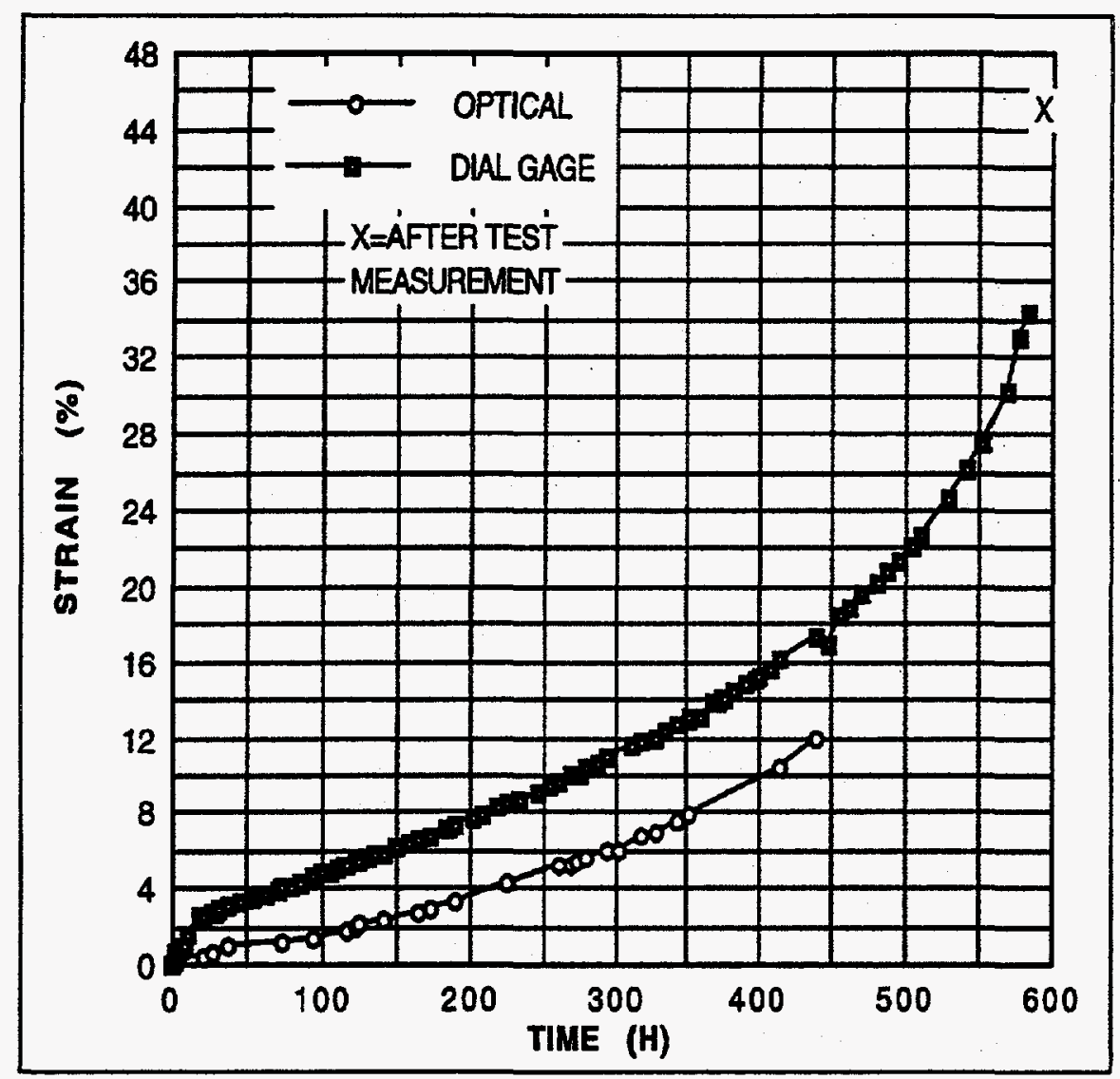




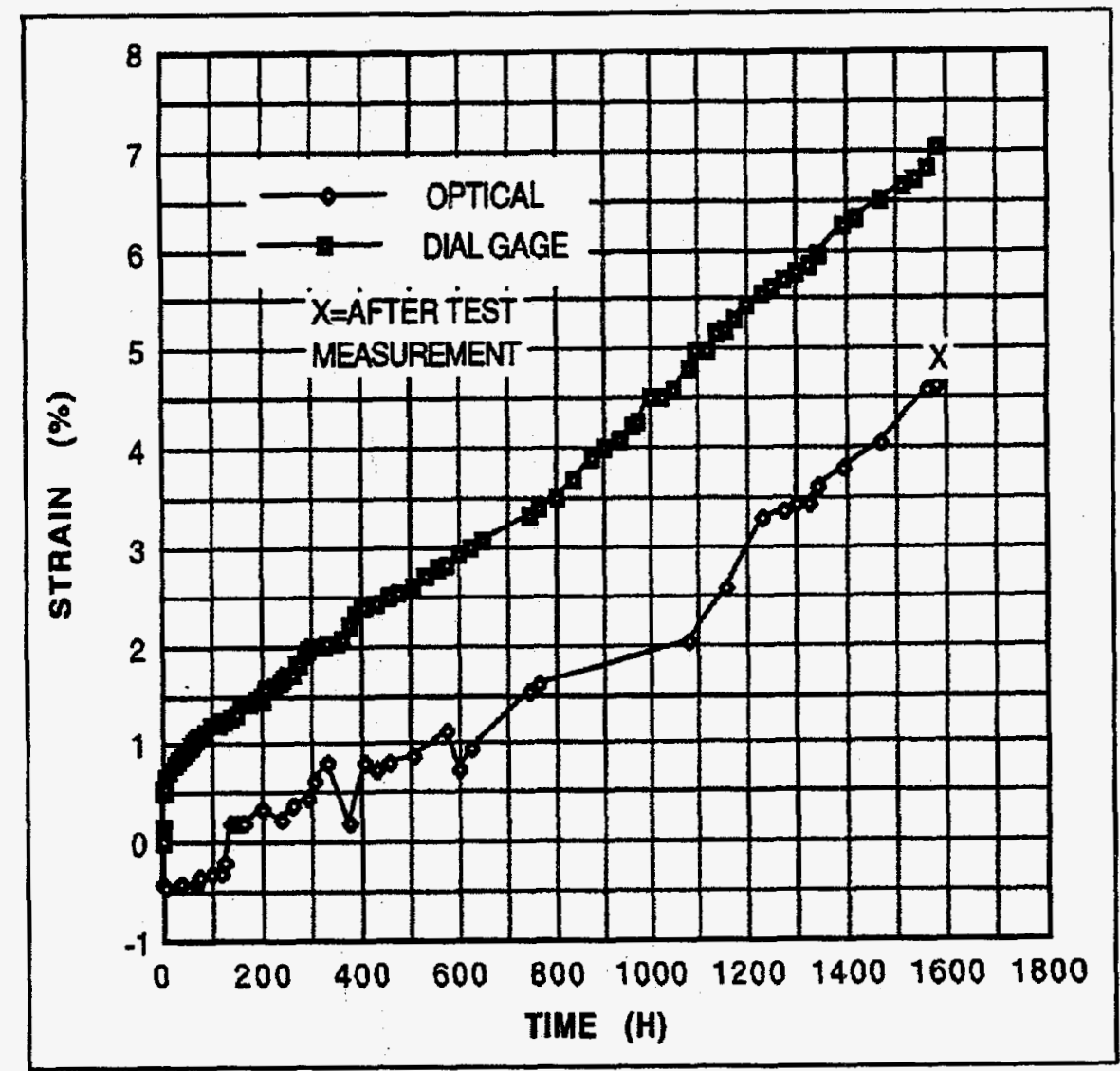




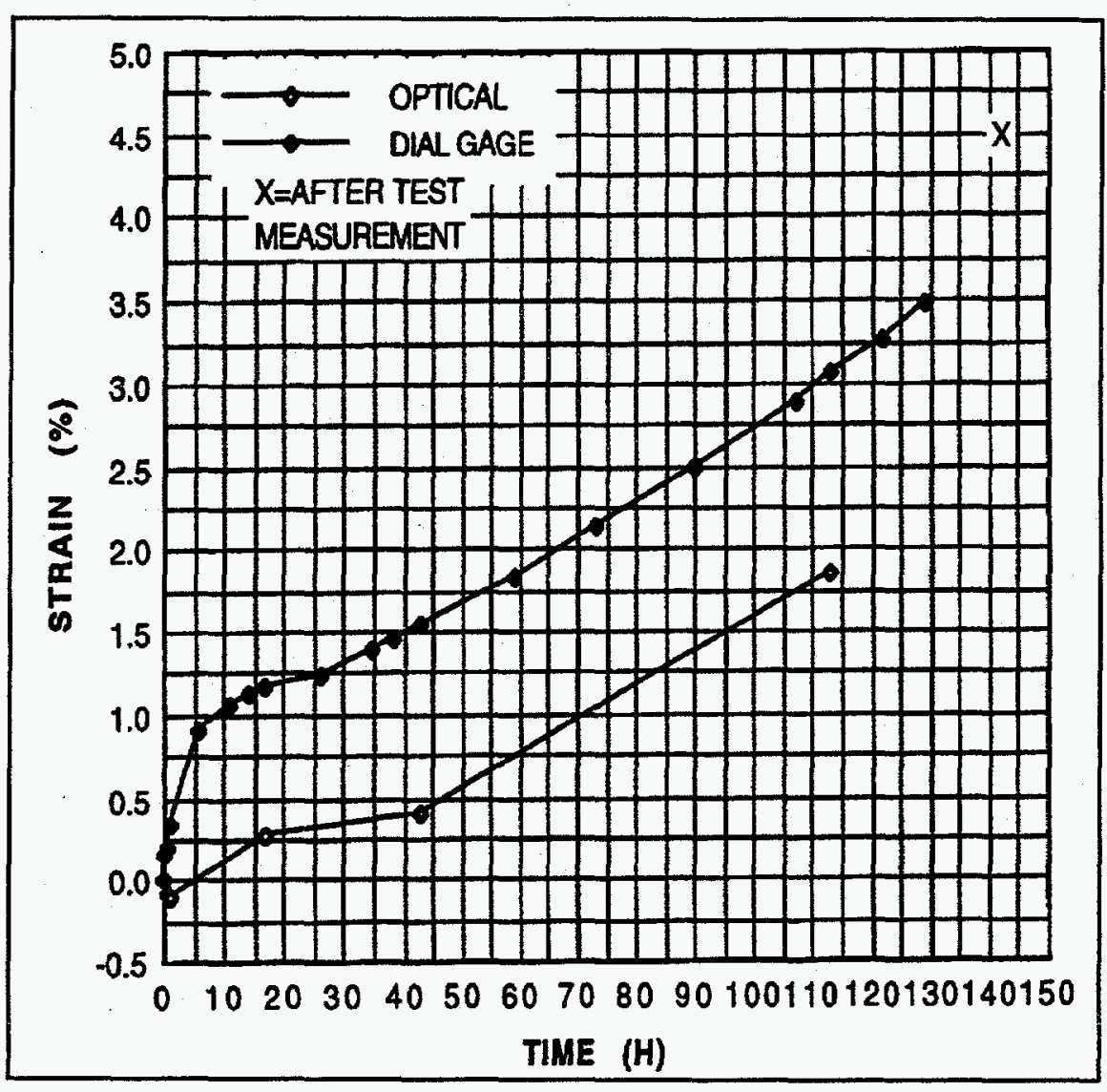




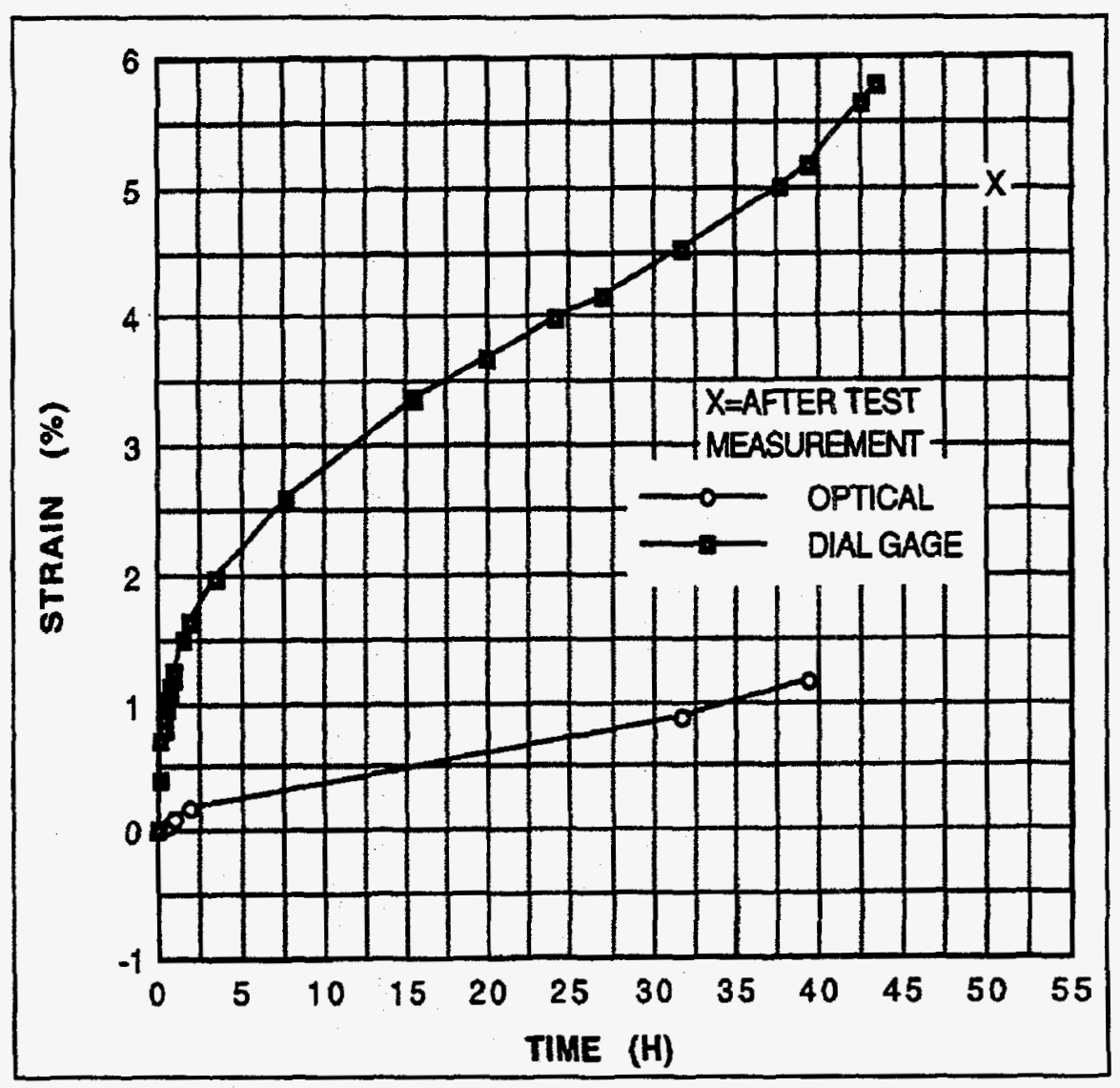




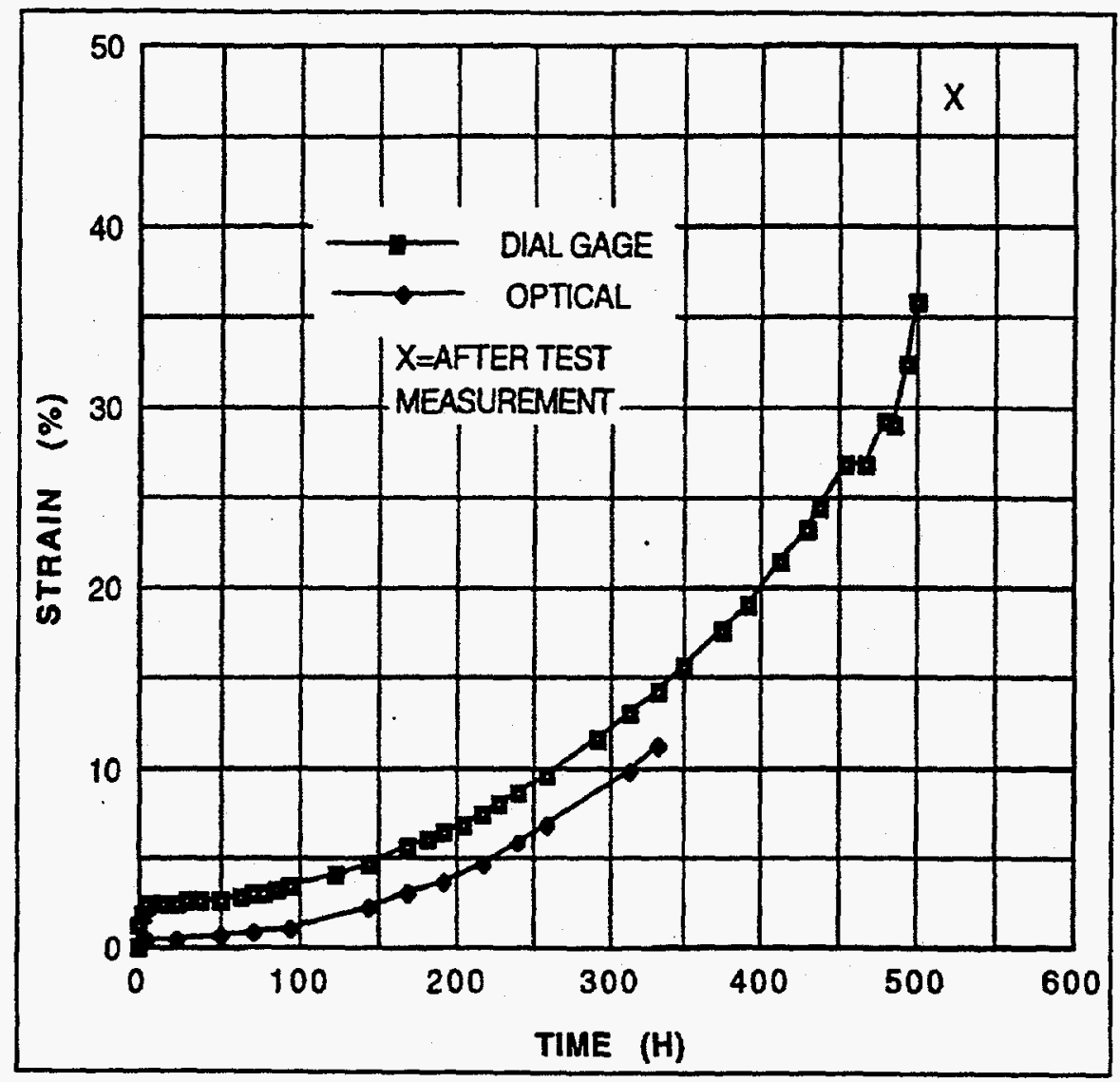




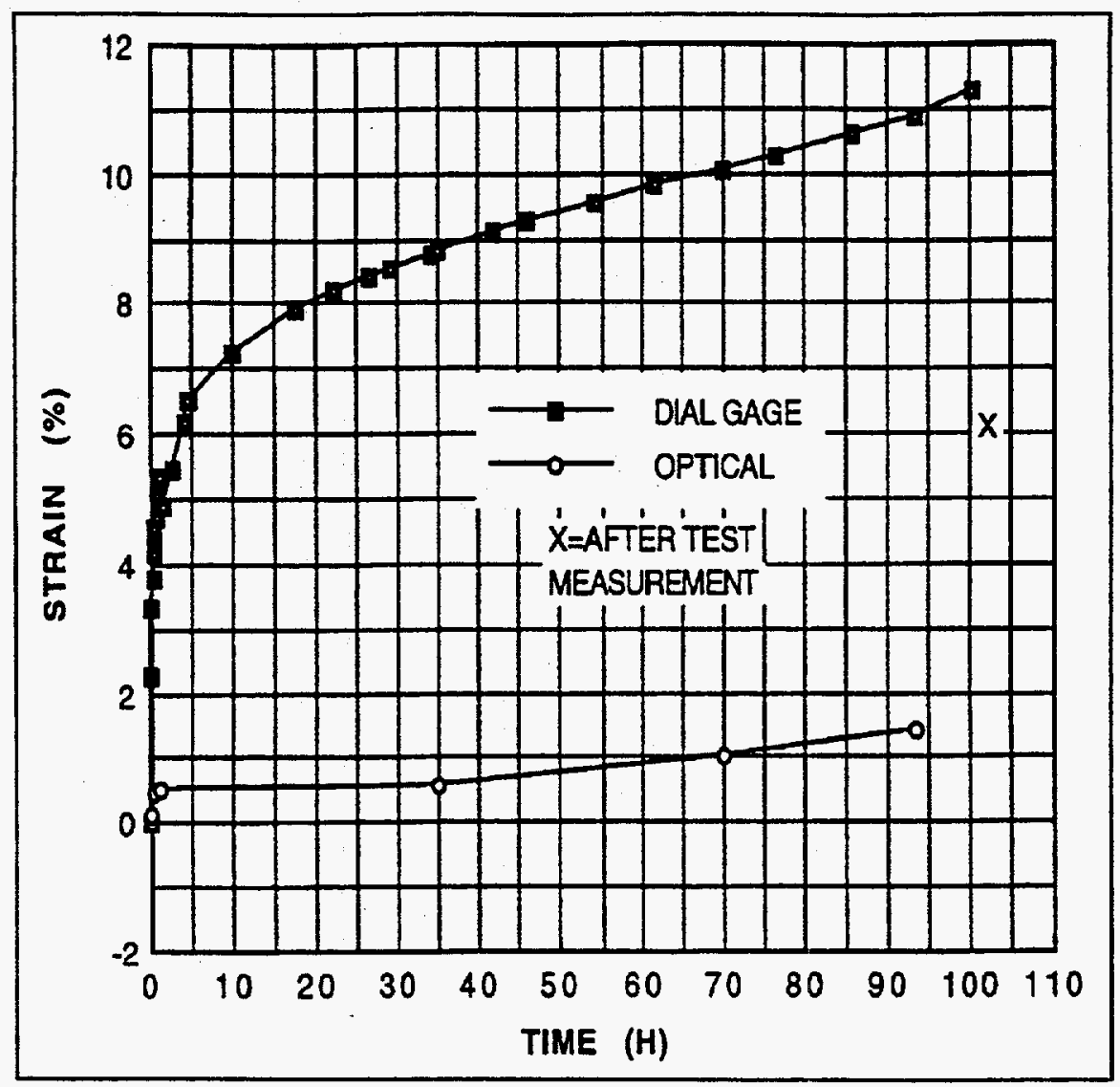




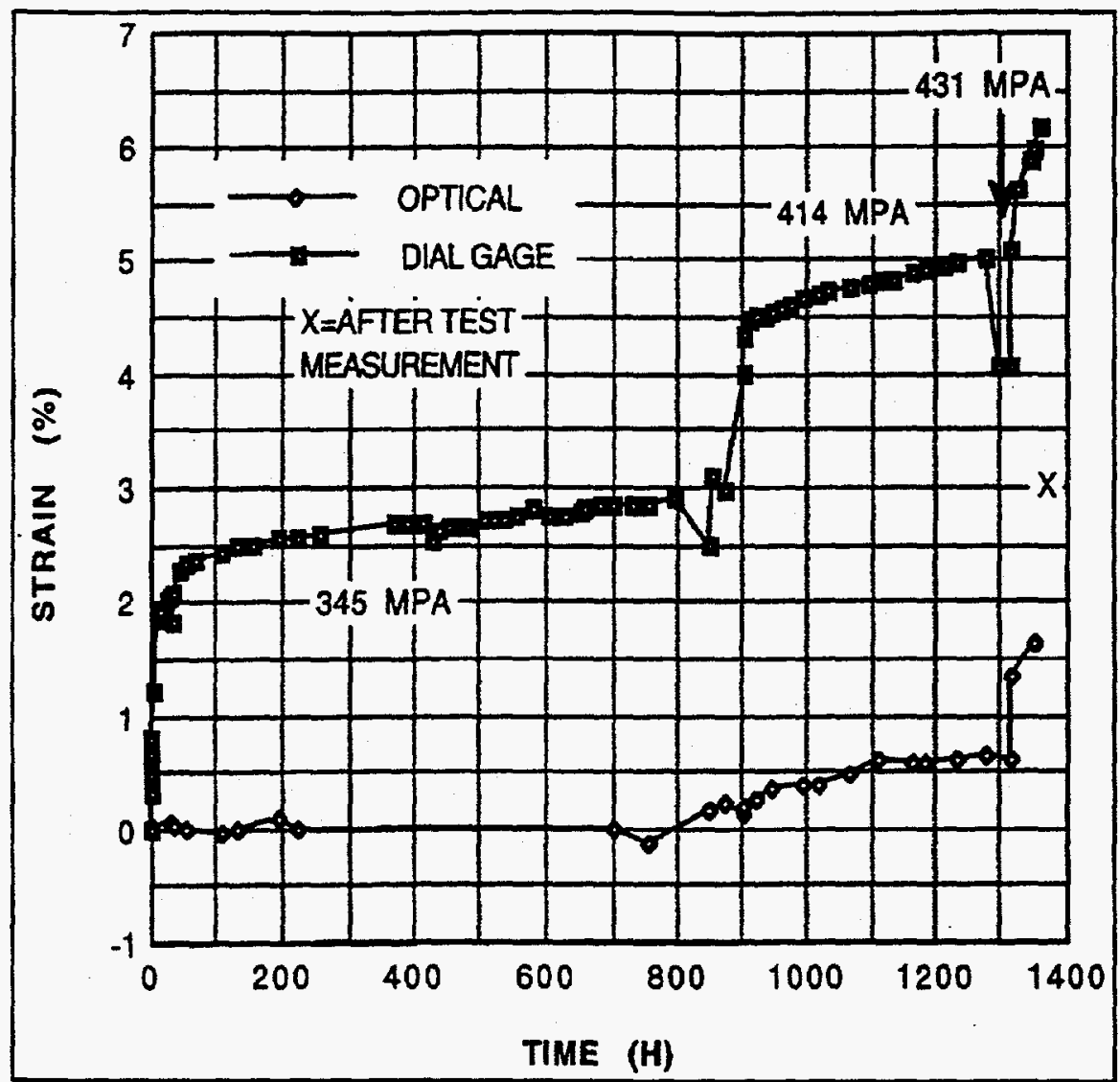




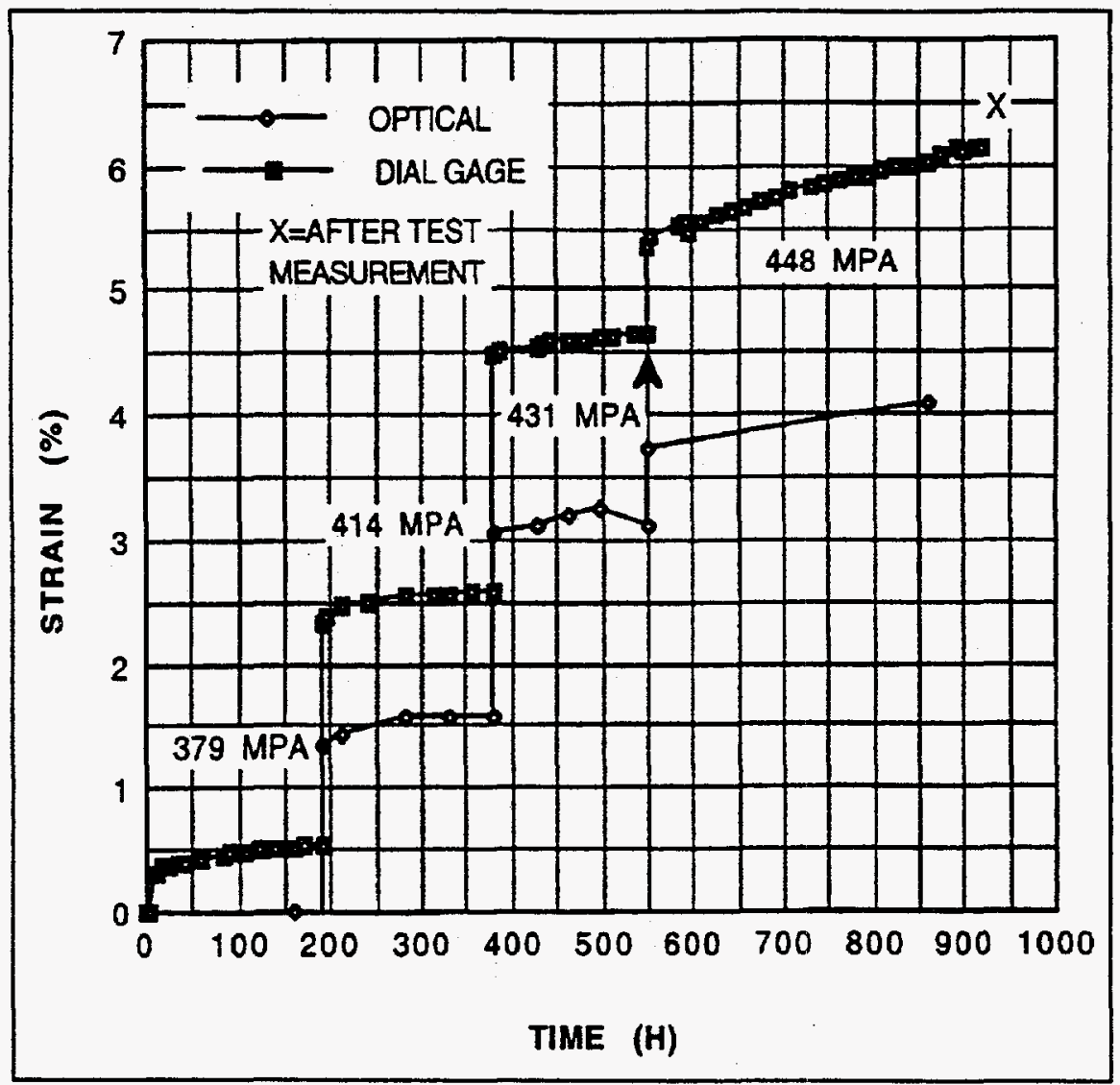




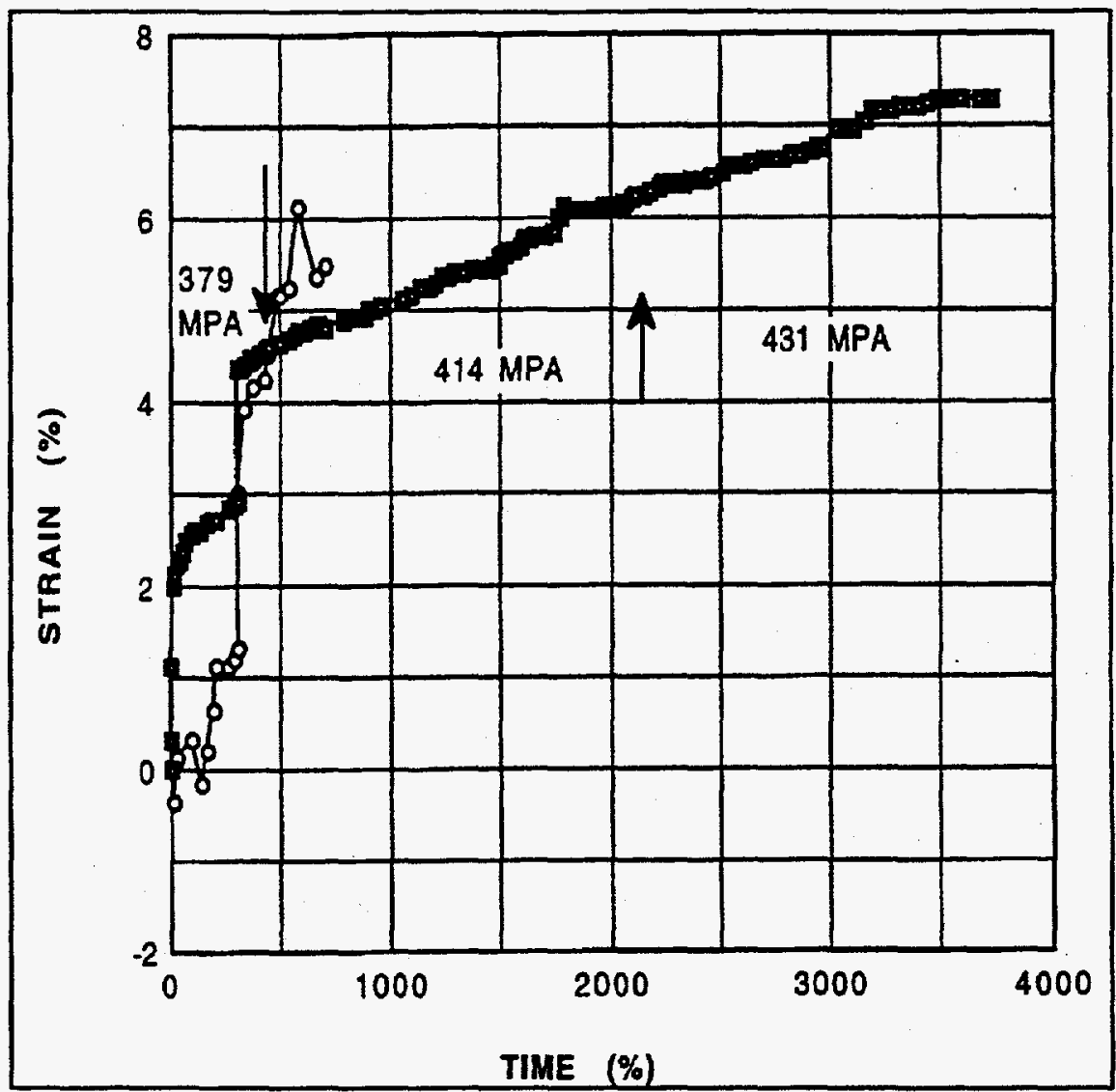


92

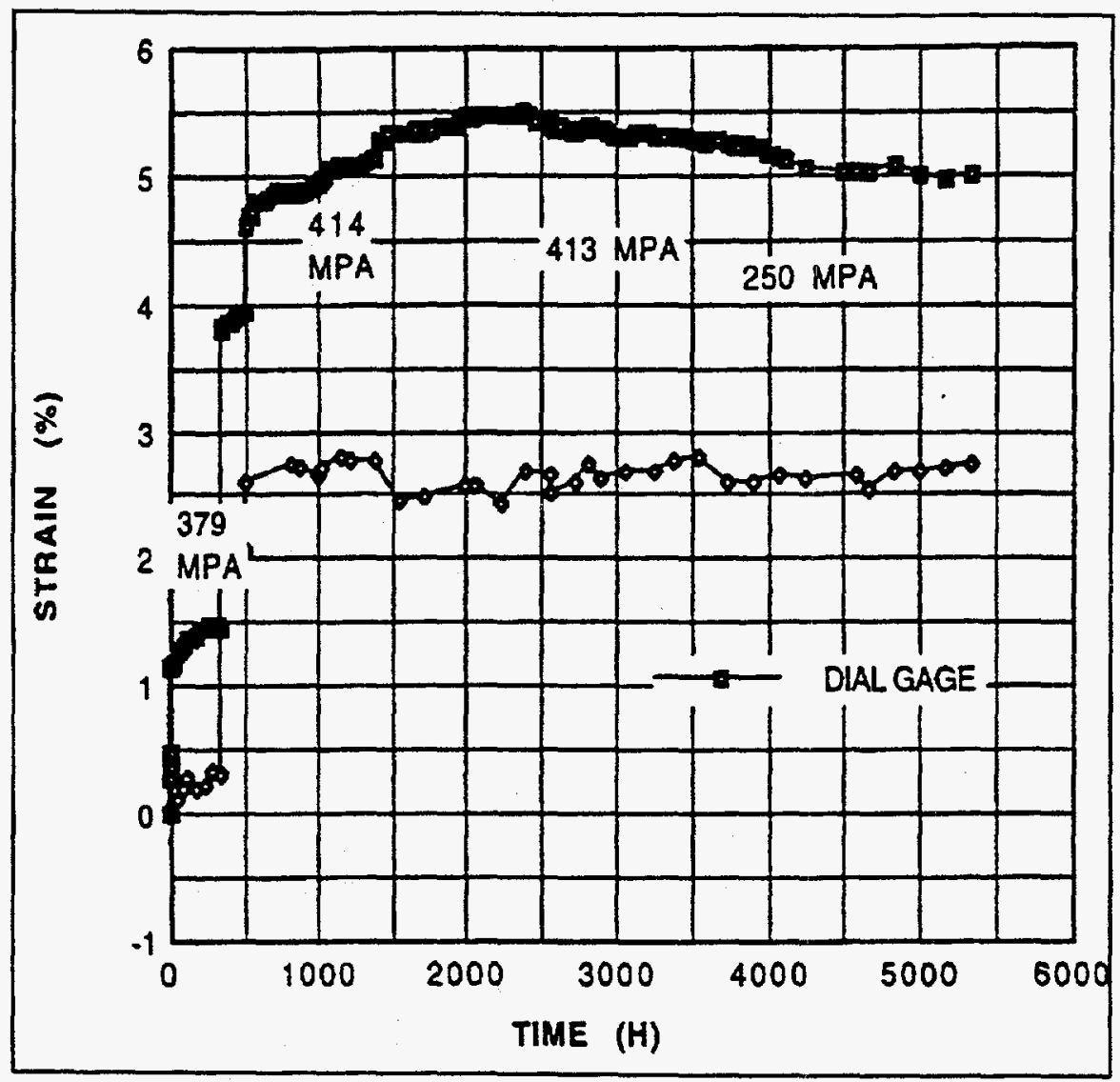




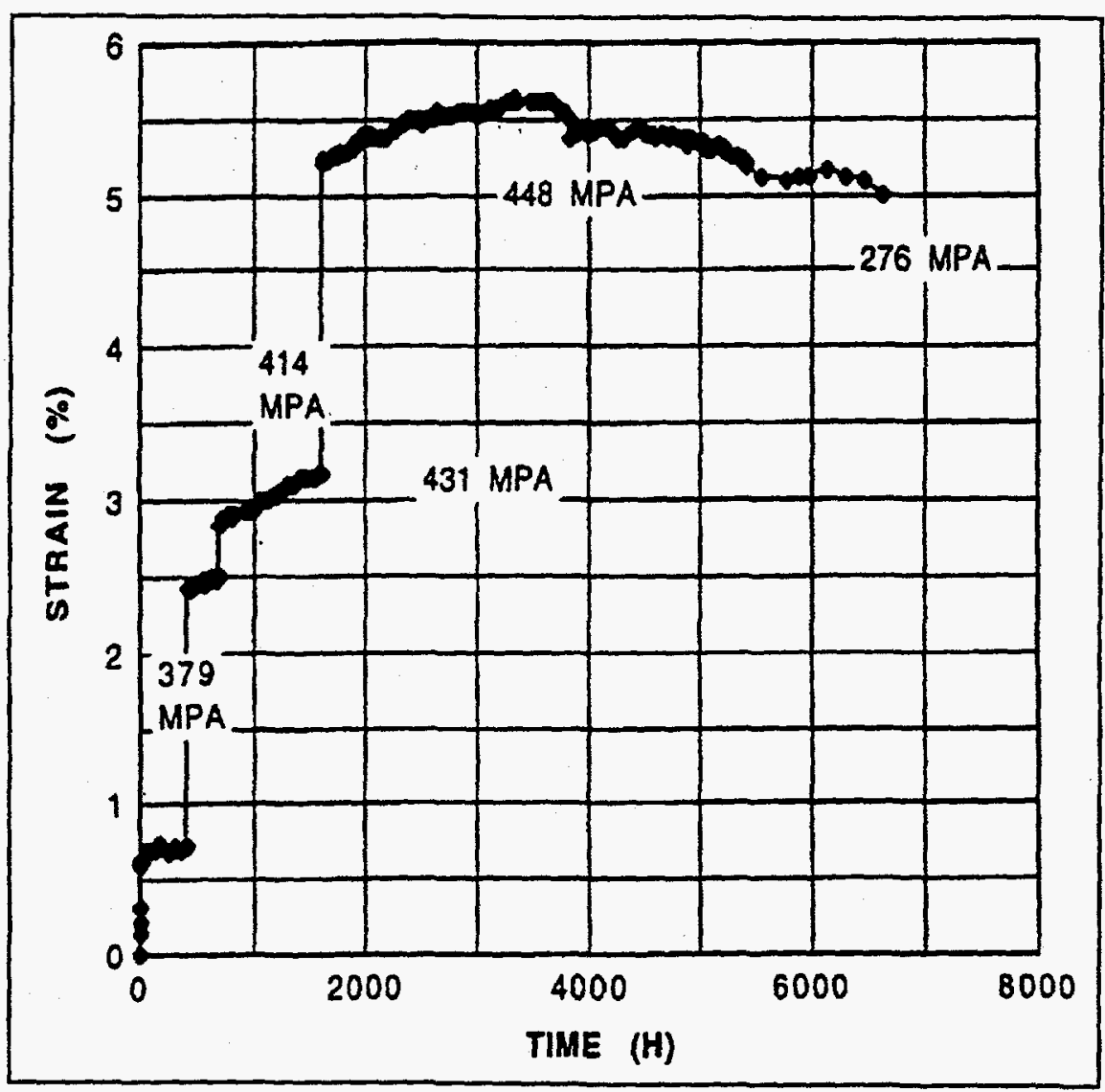




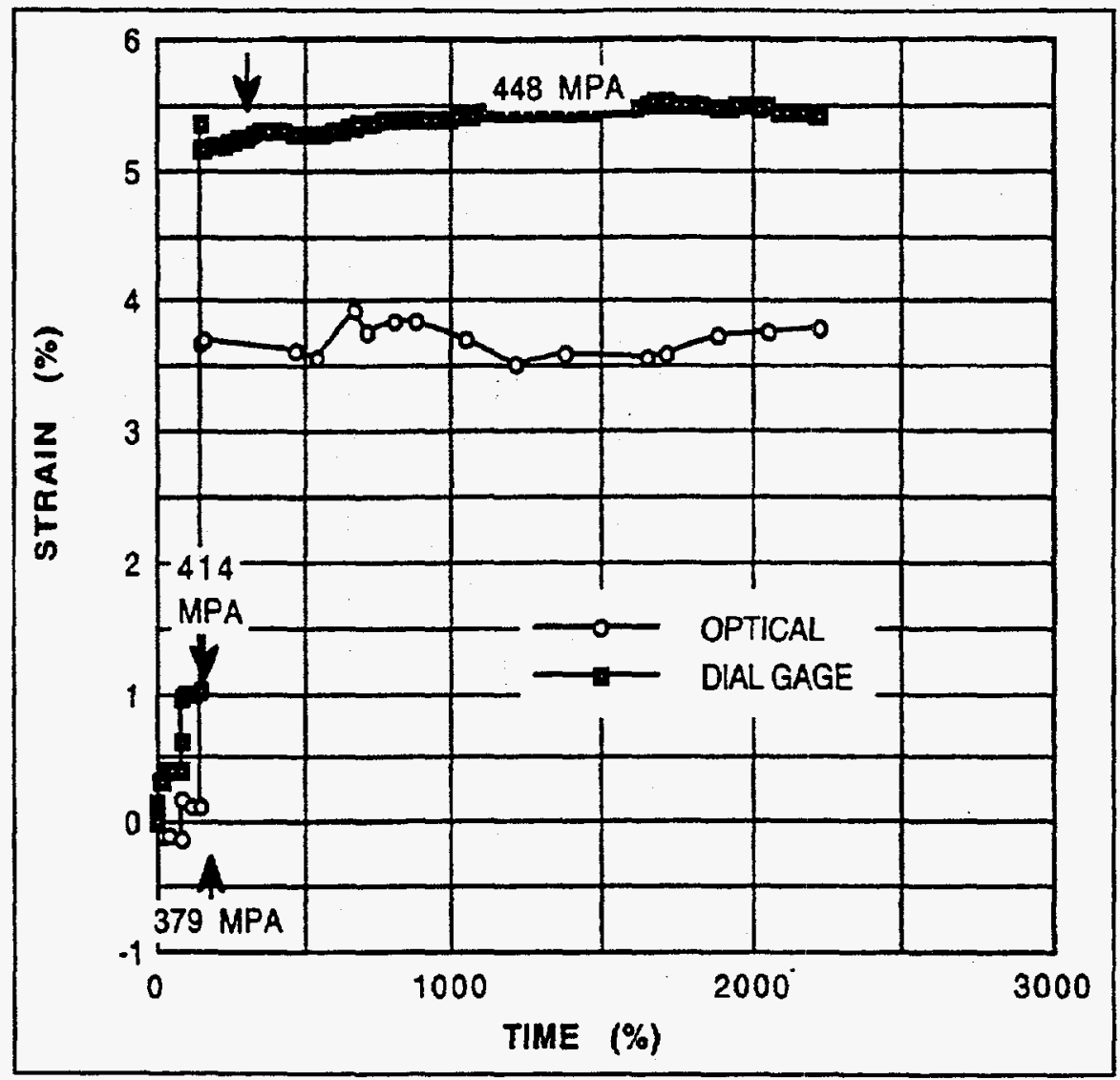




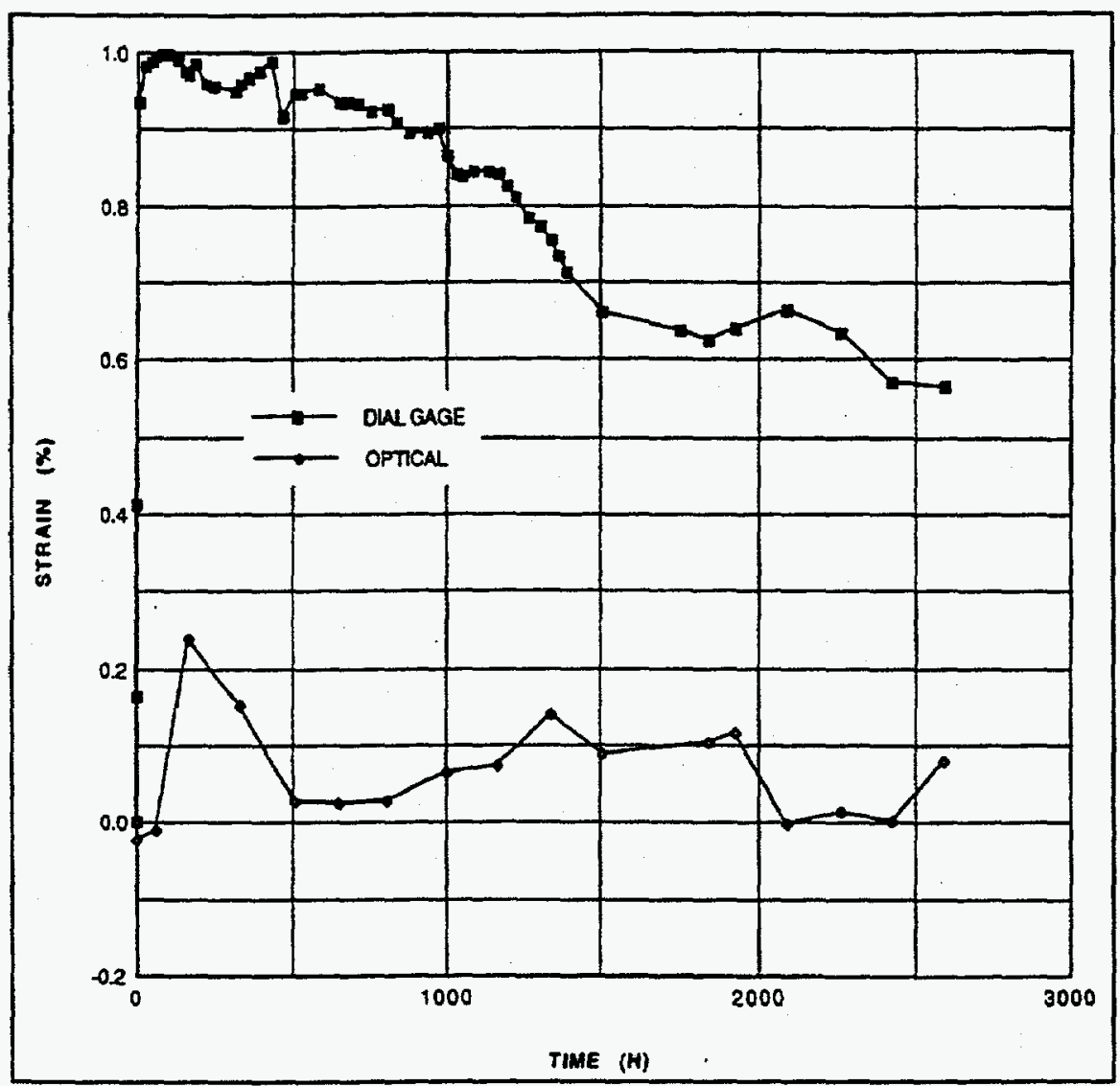




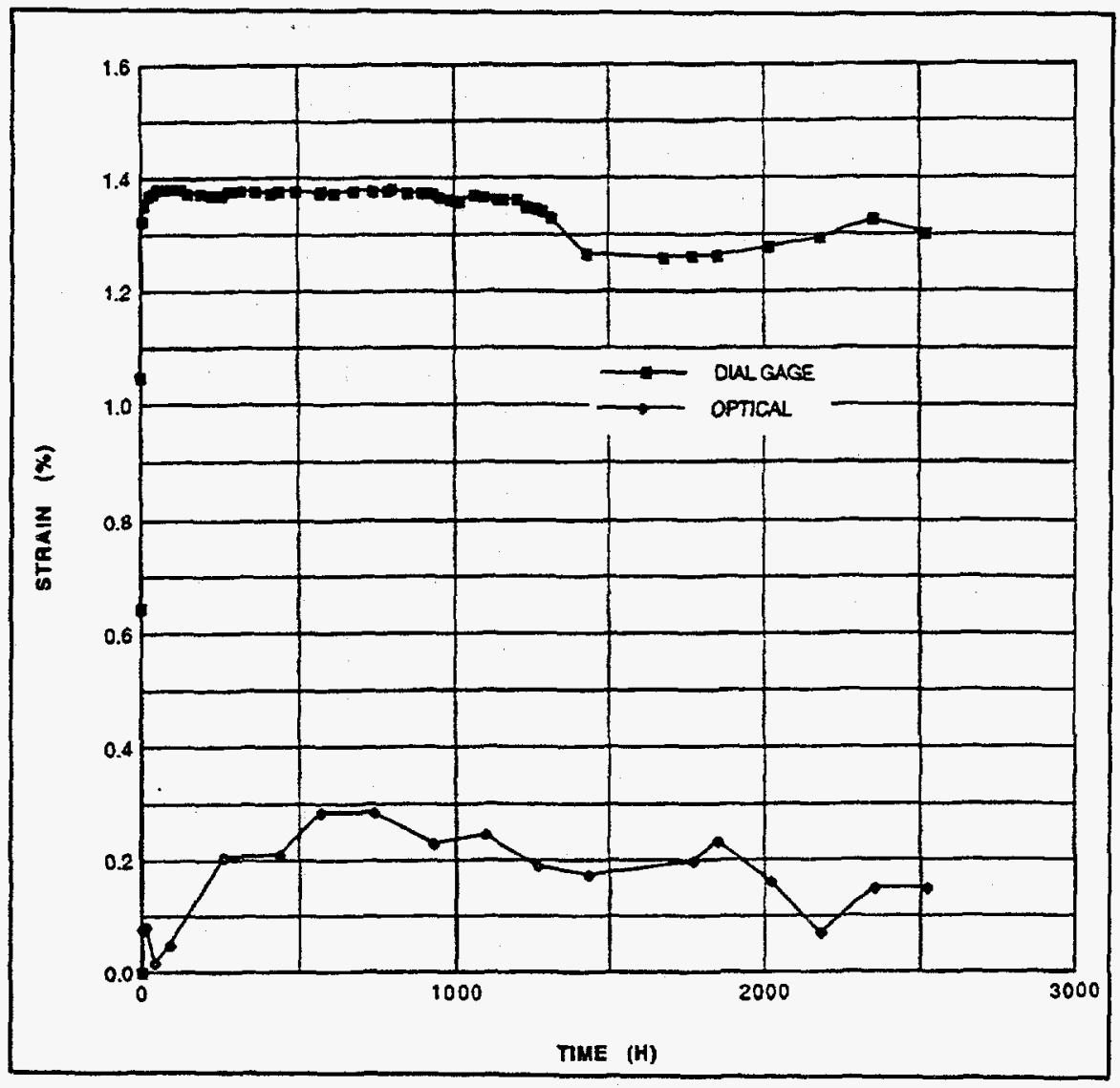




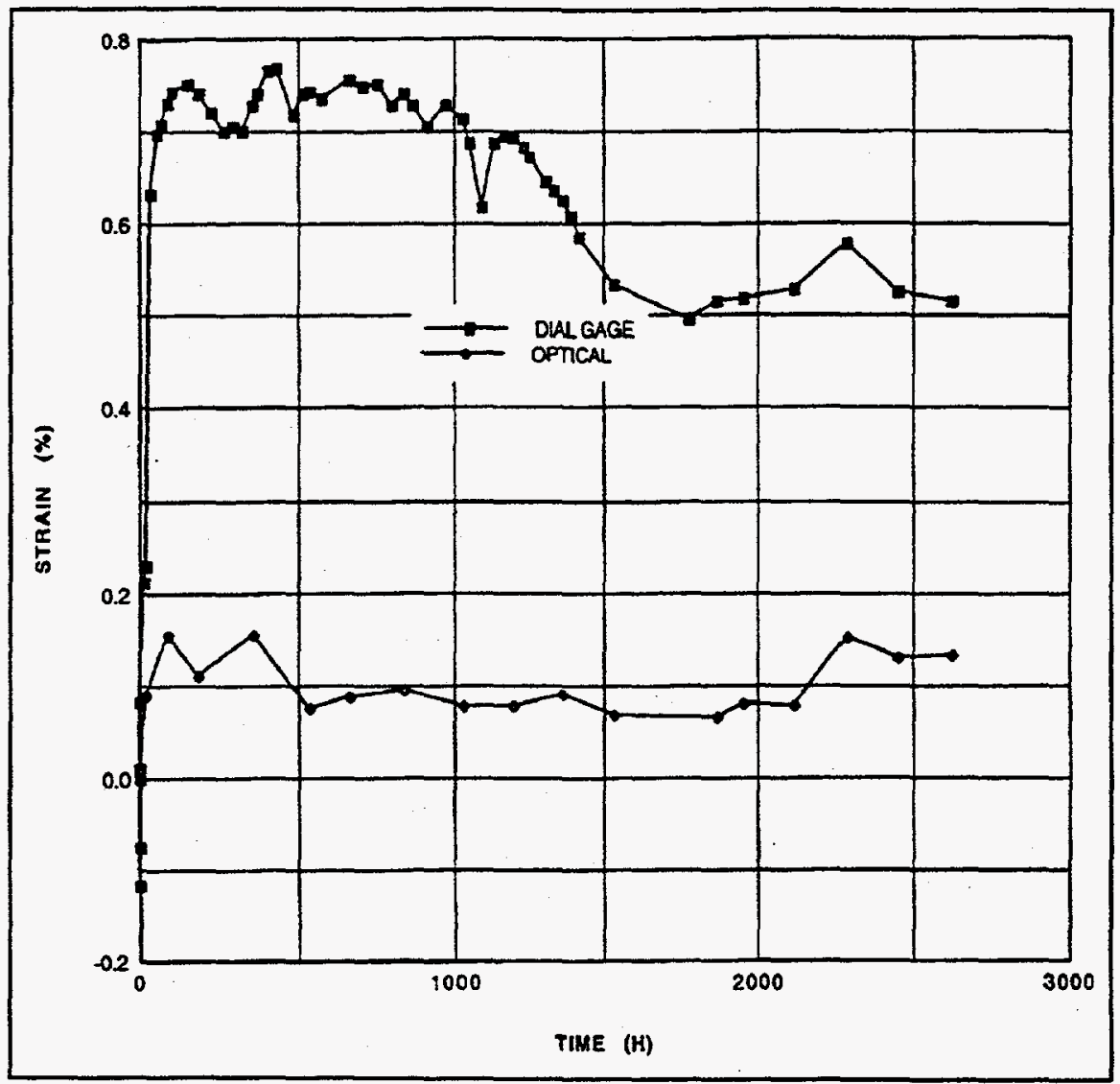



B. Measurements of the creep rate in T-111 at low stresses from 580 to $800^{\circ} \mathrm{C}$

At low to intermediate temperatures the creep-rate determinations were based on in-situ measurements of the lengths between fiduciary marks (holes) in the sides of the flat test samples. During use in the $60-\mathrm{W}$ heat source, the T-111 will spend extensive time at lower temperatures and stresses than covered above. Although expectations are that T-111 would have a vanishingly small creep rate at these temperatures, it has never been measured with the required accuracy. Therefore, an attempt was made to measure the creep rate over a temperature range of $580^{\circ} \mathrm{C}$ to $800^{\circ} \mathrm{C}$ during a relatively short time period. Because the measurements had to be made over a few months' time, the sample strain, if any, would be very low. The basic problem that had to be solved quickly was how to accurately measure strain rates on the order of $10^{-7} / \mathrm{h}$ with available equipment.

A new approach was taken to improve the measurement accuracy. This consisted of more accurately measuring the distances between fiduciary marks (diamond hardness impressions) and then installing the samples in the high-vacuum creep furnaces. The individual samples were heated to the desired temperature and then placed under the predetermined stress. At various time intervals the samples were cooled to room temperature, removed from the creep furnaces, and the gage lengths between fiduciary marks were remeasured. Towards the end of the effort, a positioning fixture was implemented that enhanced the reproducibility of gage measurements. Samples were then returned to the furnaces for further exposure to temperature and stress. Samples used in this study and results from the creep-rate measurements are described below.

Table B-1 provides information about (1) test number, (2) sample number, (3) sample type, (4) test temperature, and (5) stress. The first two samples were new tests of base metal. The last three all contained transverse welds near mid-plane, and they were continuations of tests already being conducted. As noted previously, the transverse welds were quite similar to girth welds on the T-111 strengthening capsules. The weld samples were previously exposed to the same test conditions of temperature and stress. The samples with transverse welds contained four fiduciary marks on the side opposite the holes used to make the in-situ measurements so that strain could be measured in the base metal both above and below the weld and across the weld per se. The gage lengths were measured for all three individual sections and for the total. 
Measurements of sample gage length were made using a Nikon Measurescope and a Boeckler Instruments Microcode II digital readout. With this system, gage-length measurements $\mathrm{cab}$ be determined to the nearest $0.00005 \mathrm{in}$. Ten measurements were made each time and the highest and lowest readings were discarded. The mean value and standard deviation of each set of measurements were recorded.

Table B-1 contains results of creep-rate measurements. After 1200 to $1500 \mathrm{~h}$, the two base metal samples at test temperatures of $580^{\circ} \mathrm{C}$ and $800^{\circ} \mathrm{C}$ showed no sign of creeping within the measurement precision. Strain measurements with time of these two samples tend to scatter about constant values. Therefore, for each sample, the standard deviation of the data above the average was determined. A maximum creep rate that could be inferred from the data was obtained by dividing twice the standard deviation by the total run time. This approach indicates that the creep rates of BM 32 and BM 33 are $<0.2 \times 10^{-6} / \mathrm{h}$ and $<0.3 \times 10^{-6} / \mathrm{h}$, respectively.

Table B-1. Results from "high accuracy" creep rate measurements and from previous longer term data using the optical instrument for in-situ measurements

\begin{tabular}{||c|c|c|c|c|c||}
\hline $\begin{array}{c}\text { Sample } \\
\#\end{array}$ & $\begin{array}{c}\text { Sample } \\
\text { Type }\end{array}$ & $\begin{array}{c}\mathrm{T} \\
\left({ }^{\circ} \mathrm{C}\right)\end{array}$ & $\begin{array}{c}\text { Stress } \\
\text { KSI }\end{array}$ & $\begin{array}{c}\text { From Recent } \\
\text { Exposures } \\
\text { CR } \\
\times 10^{-6} / \mathrm{h}\end{array}$ & $\begin{array}{c}\text { Optical } \\
\text { Strain Data } \\
\text { CR } \\
\times 10^{-6}\end{array}$ \\
\hline BM 32 & Base metal & 580 & 40.0 & $<0.2^{a}$ & ${\mathrm{~N} / \mathrm{A}^{b}}^{\mathrm{N}}$ \\
\hline BM 33 & Base metal & 800 & 32.8 & $<0.3^{a}$ & $\mathrm{~N}^{b}$ \\
\hline TW 17 & Transverse Weld & 680 & 36.3 & $<0.5$ & $<0.27^{a}$ \\
\hline TW 16 & Transverse Weld & 580 & 40.0 & $<4$ & $<0.34^{a}$ \\
\hline TW 18 & Transverse Weld & 800 & 32.8 & $<0.6$ & $<0.32^{a}$ \\
\hline
\end{tabular}

${ }^{a}$ Best value for the upper limit of creep rate based on data currently available.

${ }^{b}$ Not previously tested.

It should be noted that the standard deviations for both base metal samples were greater than expected based on the measurement instrument readability. This was caused by a combination of several effects including thermal, sample alignment, fiduciary mark clarity, etc.

Strain measurements on the samples with transverse welds behaved differently when they 
were restarted. Instead of scattering about a constant value, they exhibited an effect similar to primary creep. If successive measurements from one of these samples were used to calculate the creep rate, the value obtained was less than the calculated value from the previous interval. Table B-1 shows the value calculated for each sample for the last 200-300 h of the test. It is felt that the actual creep rate expected from long-term testing of these samples would be substantially lower than the tabulated values. This approach for determining the creep rate would have to be extended for a few thousand more hours to obtain meaningful results for secondary creep. Therefore, it was decided to follow another tack towards assessing the creep rate.

Each of the samples with transverse welds had previously been tested under the same conditions listed in Table B-1. During these previous exposures for times approaching $3000 \mathrm{~h}$, in-situ strains were measured with the same optical instrument used for creep measurements at higher temperature. An assessment of the results from the optical measurements afforded a more realistic idea of the limit for the creep rate of these samples with transverse welds. The optical data for each sample were treated as described below.

Examination of the optical strain data for a given sample with a transverse weld indicates that results are scattered about an average value so that the only inference that can be drawn from the data is that the creep rate is zero. However, there is a limit to the assurance of this statement. This limit was estimated by calculating the standard deviation of the optical strain measurements about the average value. It was assumed that the maximum creep would be less than twice the standard deviation divided by the time duration of the test. Table B-2 provides some information about the results of this analysis for the three samples with transverse welds.

Table B-2. Results of optical strain measurements on samples with transverse welds

\begin{tabular}{|c|c|c|c|c|}
\hline Sample \# & $\begin{array}{c}\text { Previous } \\
\text { Exposure Time } \\
\text { (h) }\end{array}$ & $\begin{array}{c}\text { Number of } \\
\text { Optical } \\
\text { Measurements }\end{array}$ & $\begin{array}{c}\text { Standard } \\
\text { Deviation }\end{array}$ & $\begin{array}{c}\text { Estimated } \\
\text { Maximum Creep } \\
\text { Rate } \\
\left(\mathrm{h}^{-1}\right)\end{array}$ \\
\hline TW 16 & 2930 & 13 & $4.8 \times 10^{-4}$ & $0.34 \times 10^{-6}$ \\
\hline TW 17 & 2619 & 19 & $3.6 \times 10^{-4}$ & $0.27 \times 10^{-6}$ \\
\hline TW 18 & 2858 & 13 & $3.8 \times 10^{-4}$ & $0.32 \times 10^{-6}$ \\
\hline
\end{tabular}

${ }^{a}$ Twice the standard deviation divided by the exposure time.

The three creep-rate values in the last column are entered in Table B-1 as representing the 
upper limit for the creep rate until the samples can be exposed to stress and temperature for a longer time to compensate for the unavoidable limits in the accuracy of the strain measurement. 
ORNL/TM-13265

\section{INTERNAL DISTRIBUTION}

1. Central Research Library

2. Document Reference Section

3. ORNL Patent Section

3-4. Laboratory Records

5. Laboratory Records - RC

6-7. M\&C Records Office
7. C. R. Brinkman

8. R. H. Cooper, Jr.

9-13. J. R. Distefano

14. S. R. Martin, Jr.

15. J. P. Moore

\section{EXTERNAL DISTRIBUTION}

16-19. TELEDYNE BROWN ENERGY SYSTEMS, $110 \mathrm{~W}$. Timonium Road, Timonium, MD 21093

D. Anderson

W. M. Brittain

C. Christenbury

M. F. McKittrick

20-21. EG\&G MOUND APPLIED TECHNOLOGIES, INC, P.O. Box 3000, Miamisburg, OH $45342-3000$

D. M. Gabriel

J. R. McDougal

22-23. ORBITAL SCIENCES CORP., 20301 Century Blvd., Germantown, MD 20874

R. T. Carpenter

E. A. Skrabek

24-26. US DOE, SPACE AND NATIONAL SECURITY PROGRAMS, Office of Engineering and Technology Development NE-53, Germantown Bldg., 19901 Germantown Road, Germantown, MD 20874-1290

B. A. Cook

A. S. Mehner

L. L. Rutgers

27. DOE-Miamisburg Office, P.O. Box 66, Miamisburg, OH 45343-0066

T. A. Frazier 
28. DOE, OAK RIDGE OPERATIONS OFFICE, P.O. Box 2001, Oak Ridge TN 37831-6269

Office of Assistant Manager for Energy Research and Development

29. DOE, OFFICE OF SCIENTIFIC AND TECHNICAL INFORMATION, P.O. Box 62, Oak Ridge, TN 37831-0062 